\title{
MASTER IN ARCHITECTURE
}

Sustainability in prefabricated architecture

\begin{abstract}
A comparative life cycle analysis of container architecture for residential structures
\end{abstract}

By Alejo Andrés Palma Olivares

Supervisor: Dr. Robert Vale

A thesis submitted to the Victoria University of Wellington in fulfilment of the requirements for the Degree of Master in Architecture.

Wellington, New Zealand, July 2010 



\begin{abstract}
The aim of this research is to establish whether container architecture in the residential sector of New Zealand is energy efficient in contrast with traditional houses built by different building materials.

This study is part of a discussion on sustainability in prefabricated architecture. The term "container architecture" has not been assessed in depth yet. On the other hand, the concept of prefabrication in architecture is well documented. Despite the large amount of empirical knowledge, little is known about container architecture in the residential sector. A comparative life cycle analysis has been undertaken by emphasising three different approaches: Energy consumption, $\mathrm{CO}_{2}$ emissions and the thermal performance of three conventional building materials (steel, concrete and timber-based structures) in the residential sector of New Zealand. Results from international studies of the Life Cycle Analysis (LCA) method in houses have been mixed. A number of studies suggest the importance of this methodology in order to achieve benefits in the reduction of energy consumption and $\mathrm{CO}_{2}$ emissions. Most of these studies agree that operational energy is the highest driver of both the energy consumed and $\mathrm{CO}_{2}$ emitted. However, some studies disagree with this approach due to the assumption made in the underestimation of the energy used in the transport of raw materials in the construction process of a building. Establishing a comparative life cycle analysis between a container-house, a concrete dwelling and a timber residence may provide further insight in the understanding of the patterns related to the energy consumption and $\mathrm{CO}_{2}$ emissions in the residential sector when container houses are used. Such understanding may be useful in developing more efficient houses. The household data for each project has been calculated and this information has been used to explore the drivers of the energy consumption and $\mathrm{CO}_{2}$ emissions through the lifespan of every example.
\end{abstract}

Three case studies have been selected for this comparative life cycle analysis. Selection criteria are based upon relationships between container-architecture's main features that match with some ideals of the Modern Movement in Architecture: the construction of prefabricated and mass produced elements, modularity and formal simplicity. Emphasis is put on numerical relationships related to shipping steel-boxes, size and form, scale, material properties, density, site location and climatic conditions. The three case studies are: for steel, the Stevens House, which is the first container house constructed in Wellington, for concrete, a single dwelling unit of the Jellicoe Towers, a post-WWII model of Modern Architecture in New Zealand built in the late 1960s and for timber, the Firth House, a wooden-based house designed by Cedric Firth which was inspired by the works of Walter Gropius and Konrad Wachsmann, German figures of the Modern Movement in Architecture. 
The life cycle energy consumption is given by using two different software packages. The first is known as Gabi, which has a European database. It is useful to calculate the total amount of energy used and the amount of $\mathrm{CO}_{2}$ released into the atmosphere by the different projects through their lifespan. The second program is New Zealand software known as ALF 3 (Annual Loss Factor 3), developed under BRANZ (Building Research Association of New Zealand) which is useful to calculate space heating energy.

The outcome of the research shows that the usage of shipping containers in buildings leads to a major consumption of energy (per square metre) and release of $\mathrm{CO}_{2}$ into the atmosphere (per square metre) in comparison with traditional concrete and timber buildings. 


\section{ACKNOWLEDGEMENT}

This research is dedicated to the lovely memory of my Grandfather Alberto and my best friend Charlie.

The author would like to thank to the Primary Supervisor, Mr. Robert Vale and his wife Ms. Brenda Vail for their dedication, support and guidance on this project.

First, I am very grateful to Alejandra and Lukas for believing in me. Without their support would be impossible fulfill this investigation.

Also, I would like to express my more deeply gratitude to all those people who shared with me in Wellington: Jonathan, Mila and their daughter Oriana, Jessie, Moe, Susan Smith, Amardeep Dugar, Jenny Browne, Fran Gleisner, Javiera Santibañez, Jessica Kinsey, Remy Leblanc, David Estrada, Rodrigo Cartagena, Angel and Alejandra Muñoz.

Finally, I would like to acknowledge to my Family: my parents, David and Veronica, Alejo Abel, to my brothers and sister, Francisco, Cristobal and Andrea and finally to my lovely Barbara. 
TABLE OF CONTENTS

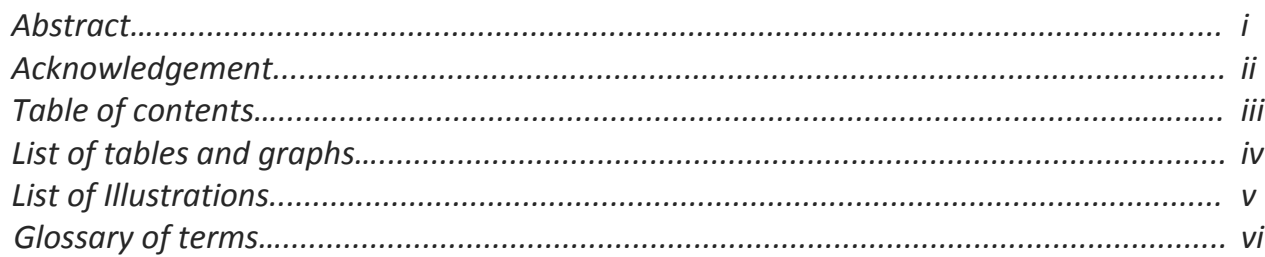

Introductory Chapter

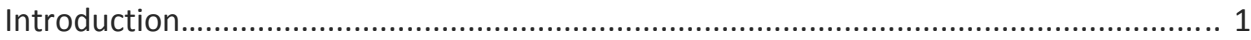

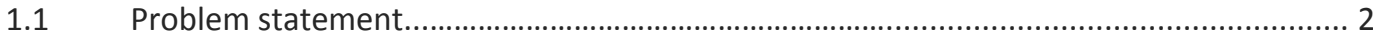

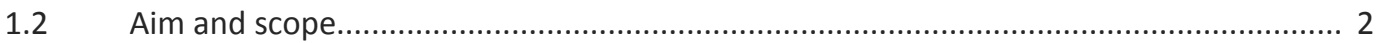

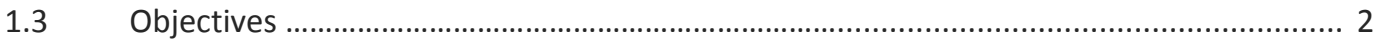

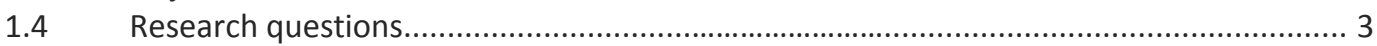

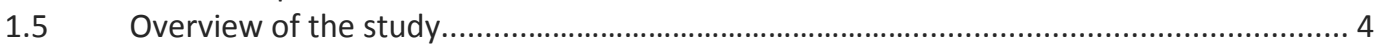

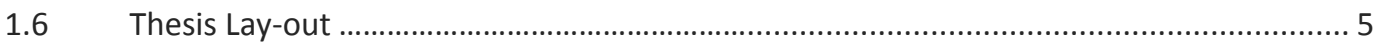

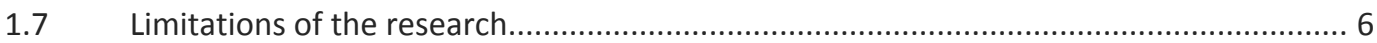

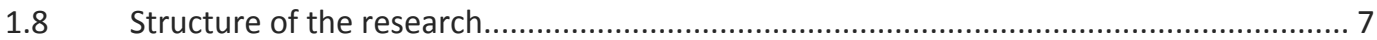

Chapter I-Container architecture

1.1 Background

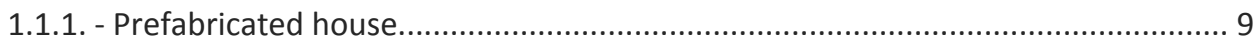

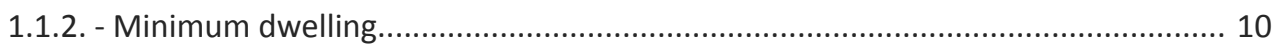

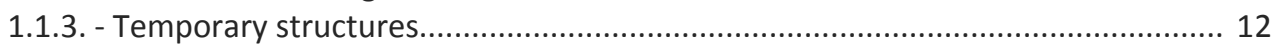

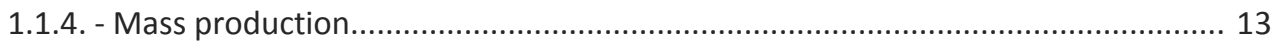

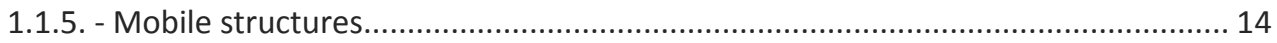

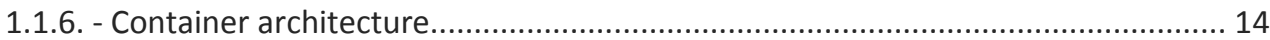

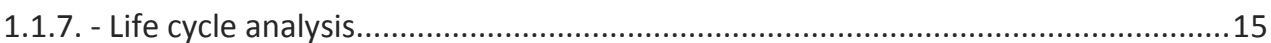

1.1.8. - Comparative life cycle analysis for construction materials.................................... 15

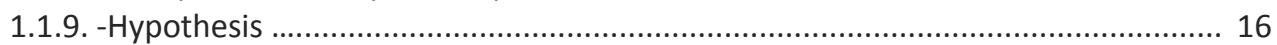

1.2 Definition of container architecture......................................................................... 17

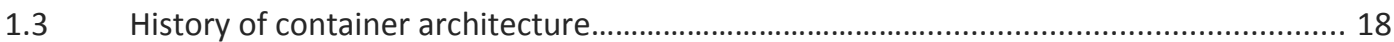

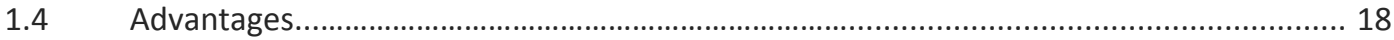

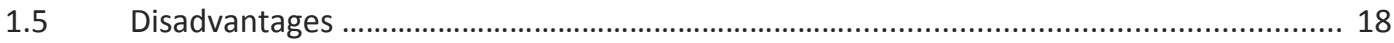

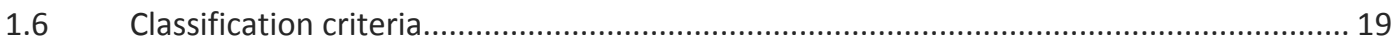

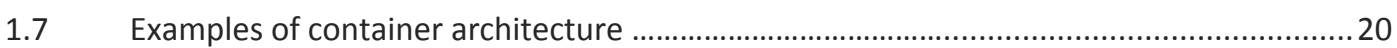

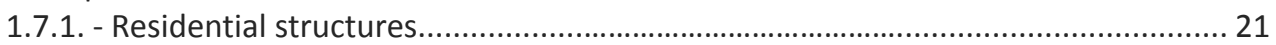

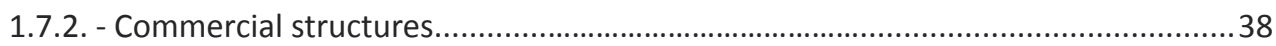

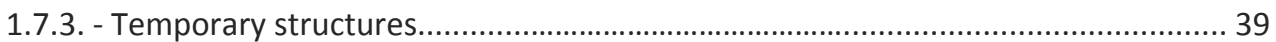

1.7.4. - Mobile structures.............................................................................................. 40

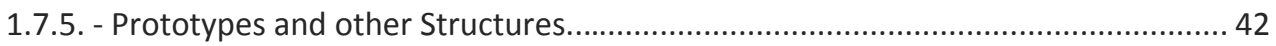

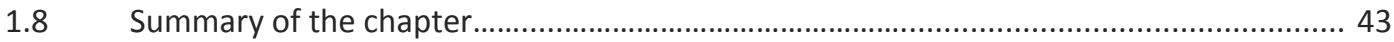

Chapter II-General background

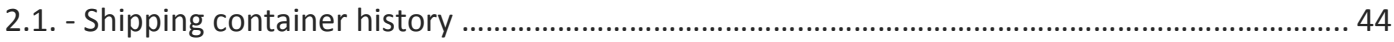

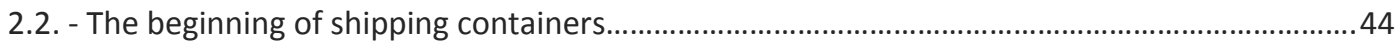

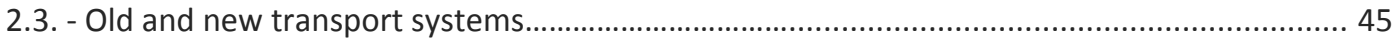

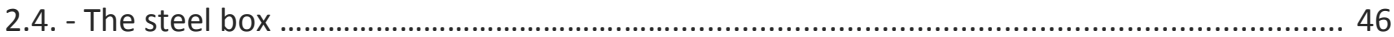

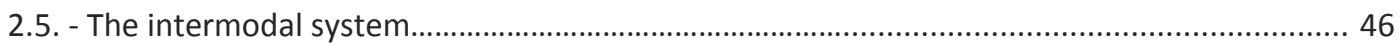

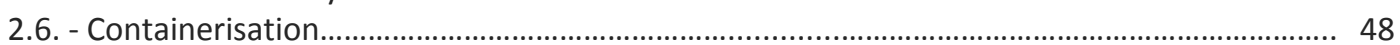

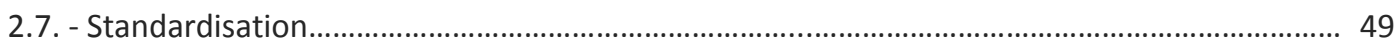

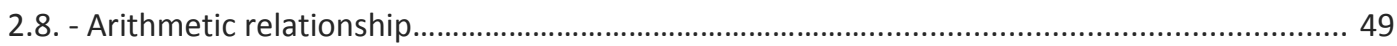

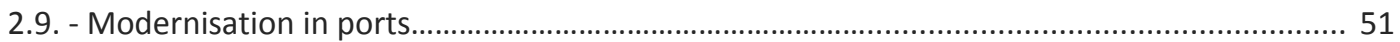

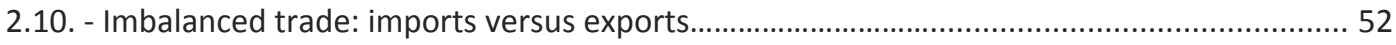

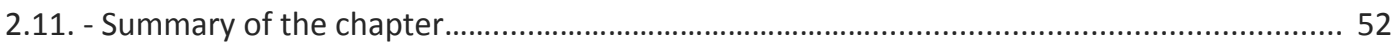


Chapter III - Physical characteristics of ISO containers

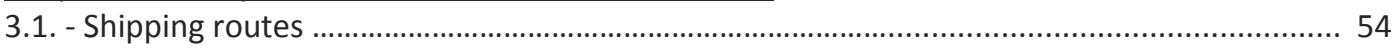

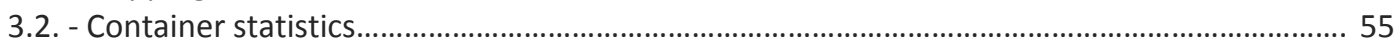

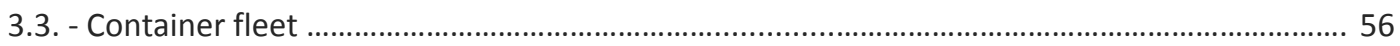

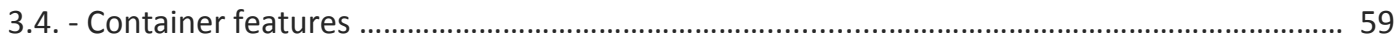

3.5. - Shipping container (steel manufacturing) .......................................................................... 59

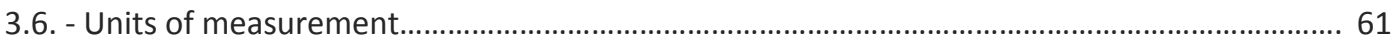

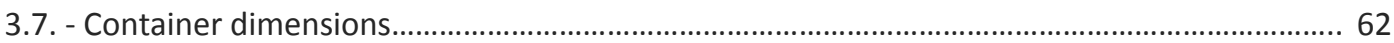

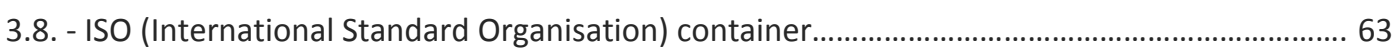

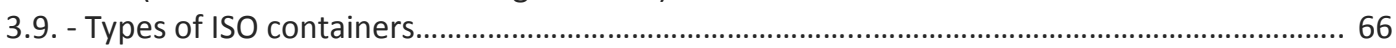

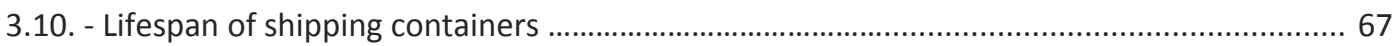

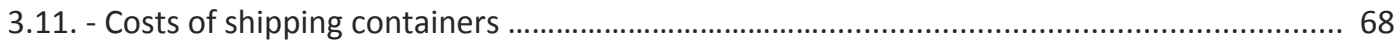

3.12. - Problems and disadvantages of shipping containers................................................ 72

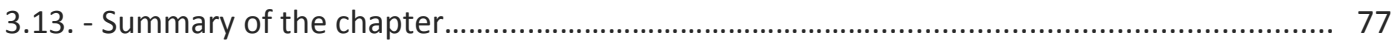

Chapter IV - Energy Generation, energy consumption and environmental issues in the construction sector

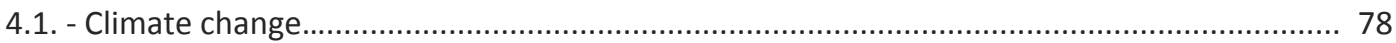

4.2. - Total primary energy supply and fossil fuels .............................................................. 78

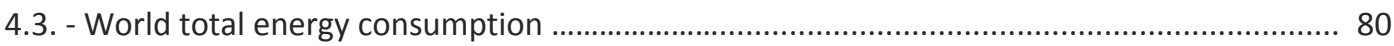

4.4. - Environmental effects of energy use......................................................................... 82

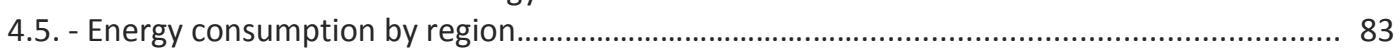

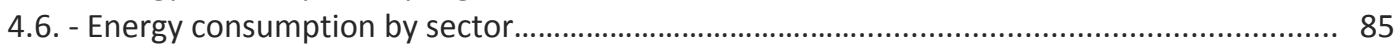

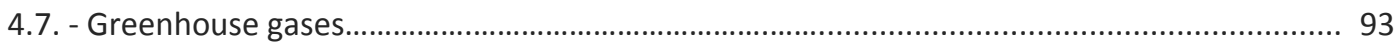

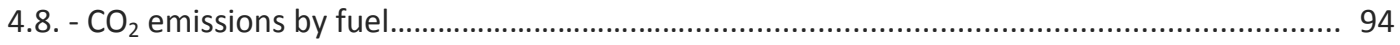

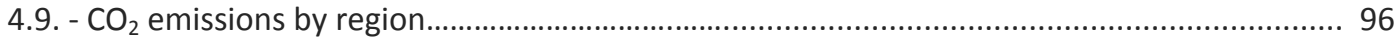

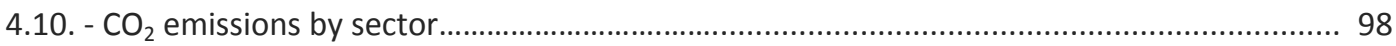

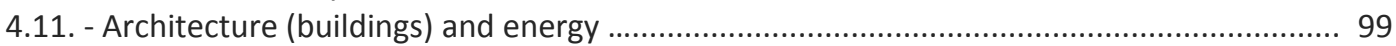

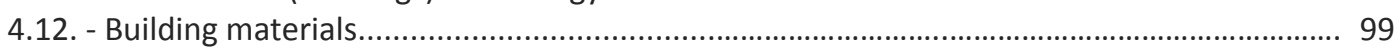

4.13. - Summary of the chapter............................................................................................. 100

Chapter V-Energy use in residential buildings

5.1. - Urban development and residential constructions (background) .................................. 101

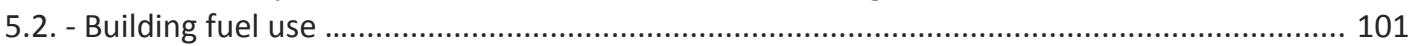

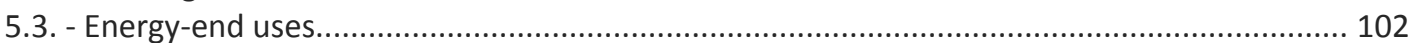

5.4. - Energy-end uses in residential buildings ............................................................................ 103

5.5. - Comparison between residential and commercial buildings............................................. 105

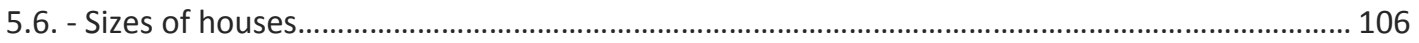

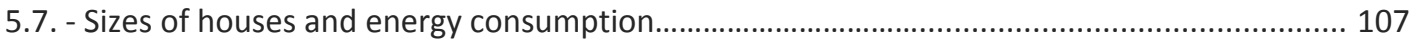

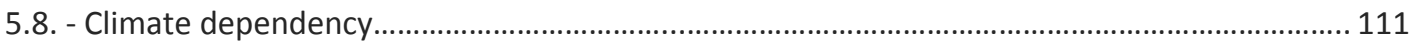

5.9. - Exterior envelope and thermal mass.............................................................................. 111

5.10. - Thermal insulation of exterior envelope................................................................................ 112

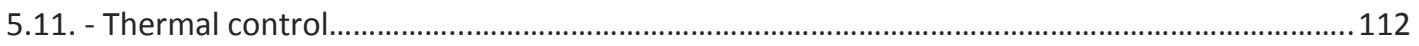

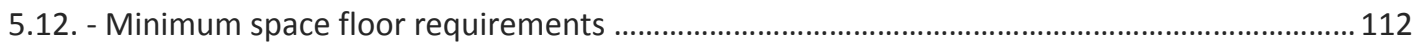

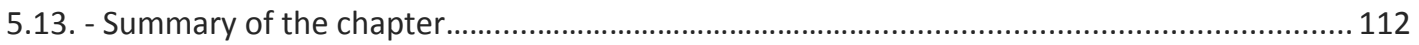


Chapter VI-Life cycle assessment

6.1. - Life cycle analysis methodology....................................................................................... 114

6.2. - Life cycle analysis of residential structure....................................................................... 115

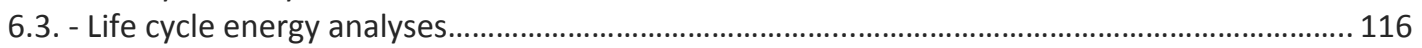

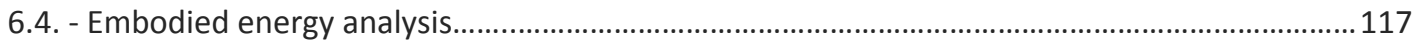

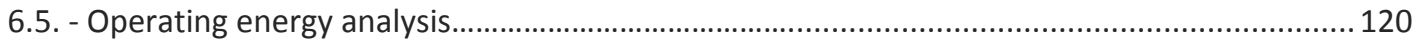

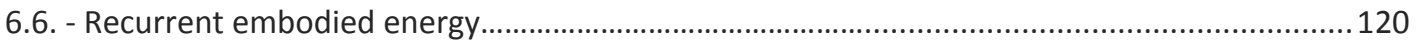

6.7. - Embodied energy for steel structures.............................................................................. 121

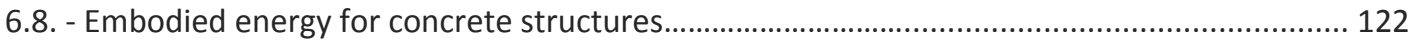

6.9. - Embodied energy for wooden structures............................................................................ 123

6.10. - Comparison of steel, concrete and wood-based structures............................................ 124

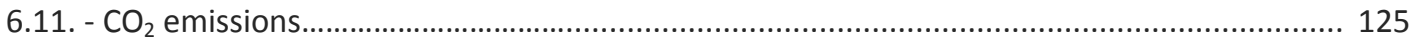

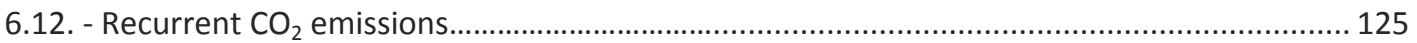

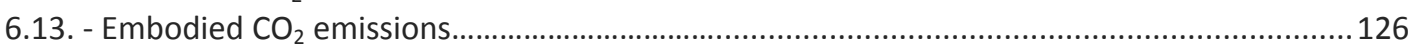

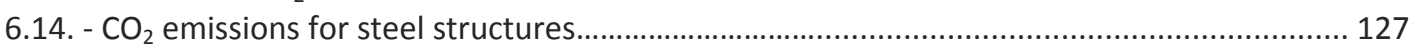

6.15. $-\mathrm{CO}_{2}$ emissions for concrete structures ................................................................. 127

6.16. - $\mathrm{CO}_{2}$ emissions for wooden structures ....................................................................... 127

6.17. - Comparison of steel, concrete and wooden $\mathrm{CO}_{2}$ emissions................................................. 128

6.18. - Summary of the chapter........................................................................................... 129

Chapter VII - Life cycle energy for houses in New Zealand

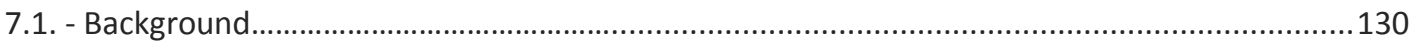

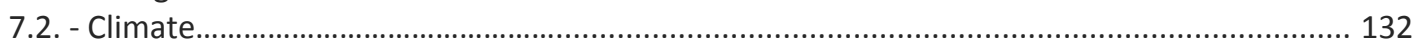

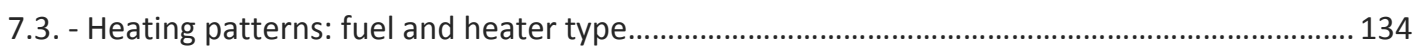

7.4. - Energy use in residential buildings in New Zealand................................................................. 138

7.5. - Life cycle analysis for houses in New Zealand........................................................................ 140

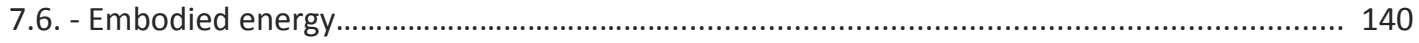

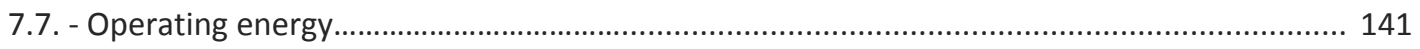

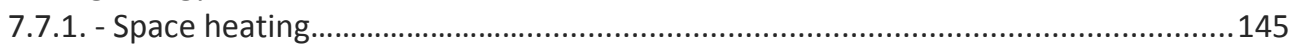

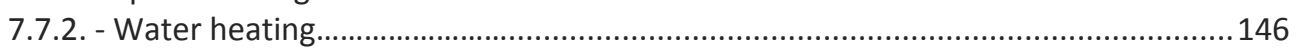

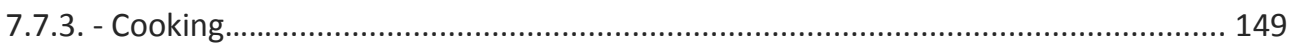

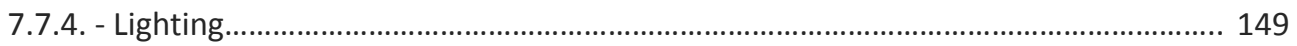

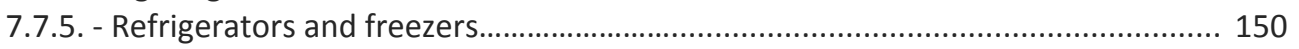

7.7.6. - Domestic appliances and equipment.......................................................... 150

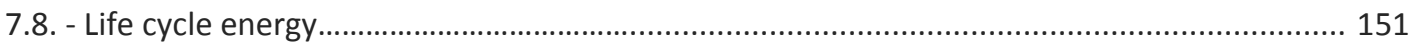

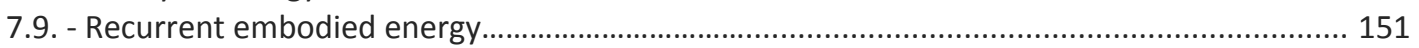

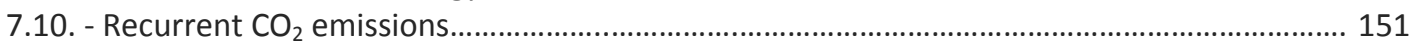

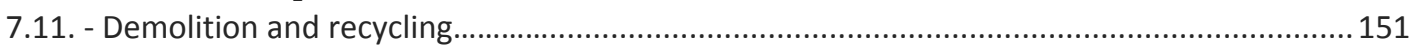

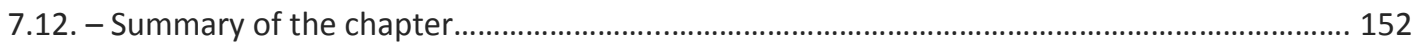

Chapter VIII-Environmental control of ISO containers

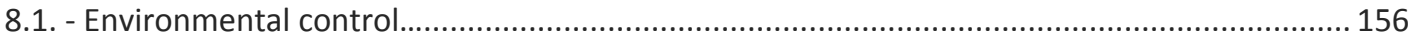

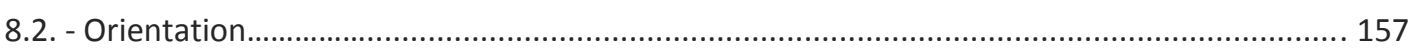

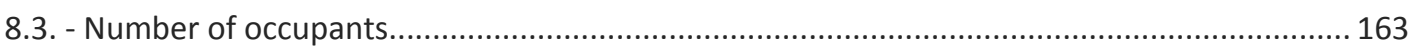

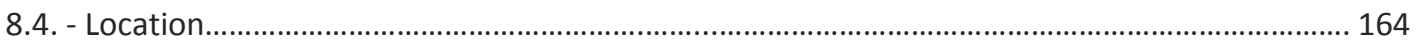

8.5. - Different building materials .............................................................................................. 166

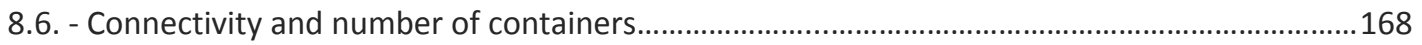

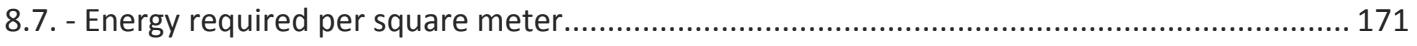

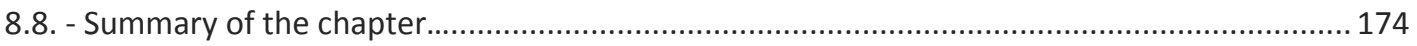


Chapter IX-Case studies

9.1. - Site and structure.

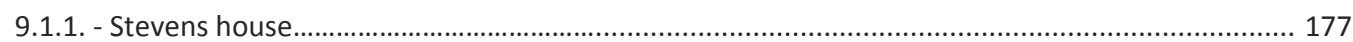

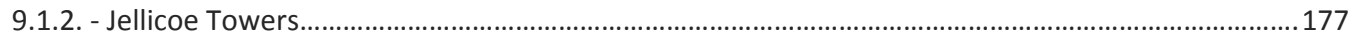

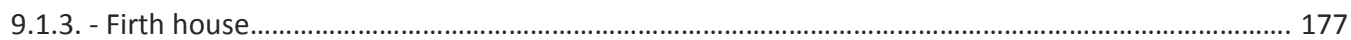

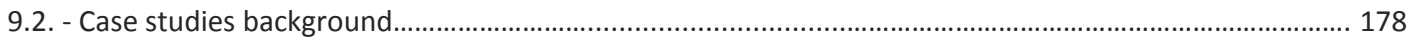

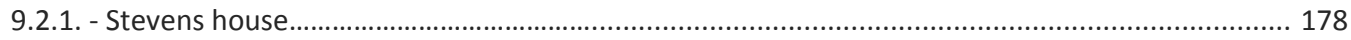

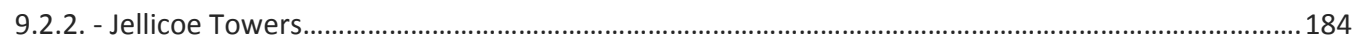

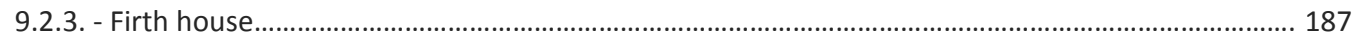

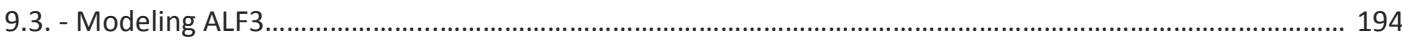

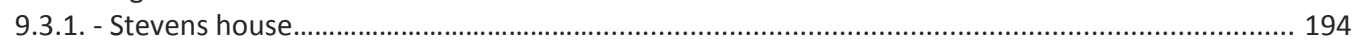

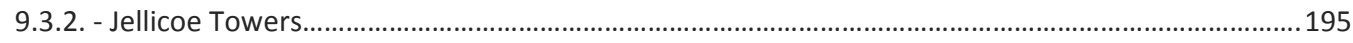

9.3.3. - Firth house

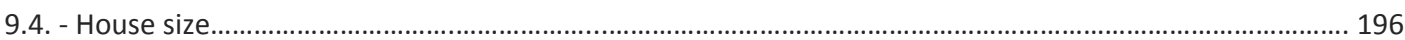

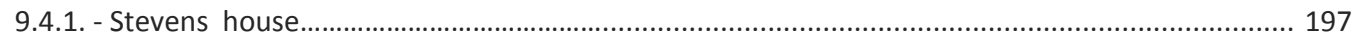

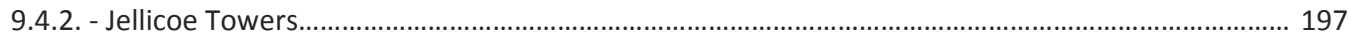

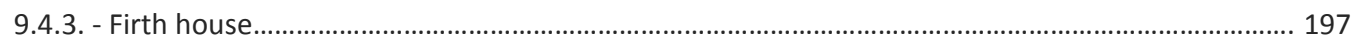

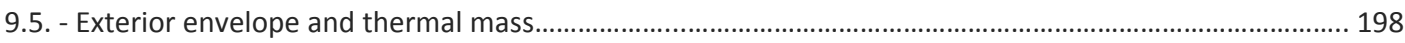

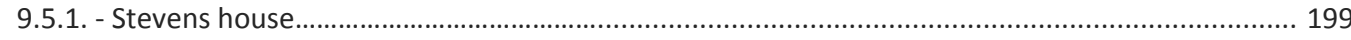

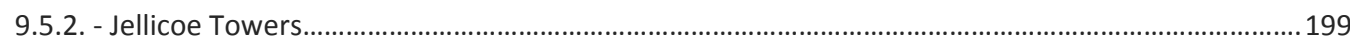

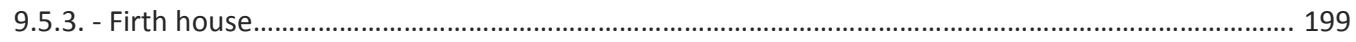

9.6. - Thermal insulation of the envelope

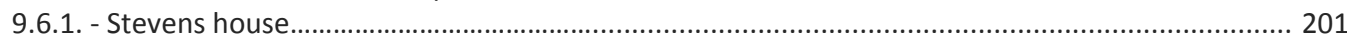

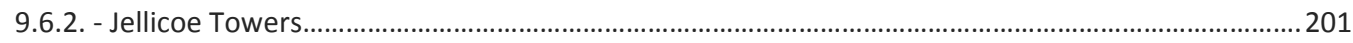

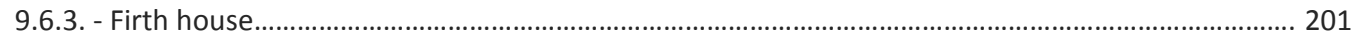

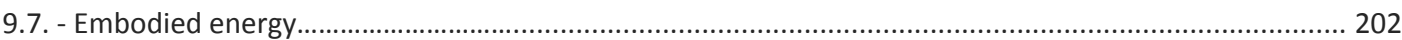

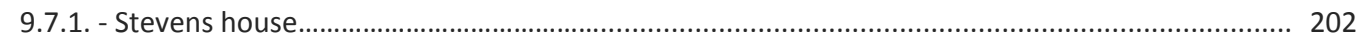

9.7.2. - Jellicoe Towers............................................................................................................................. 202

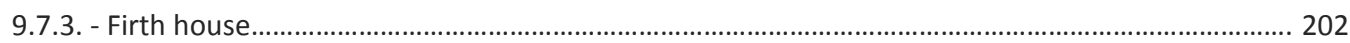

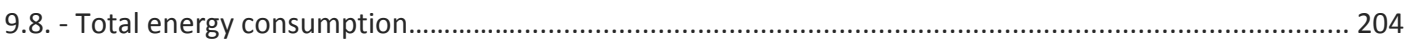

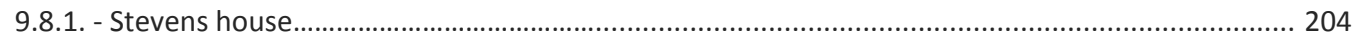

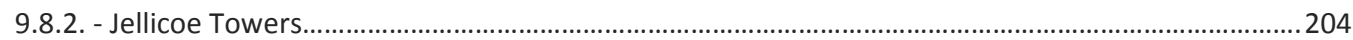

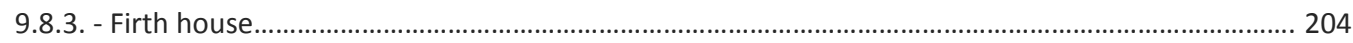

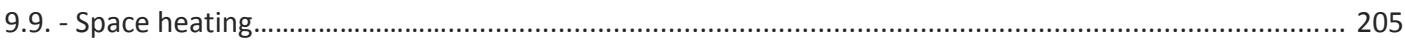

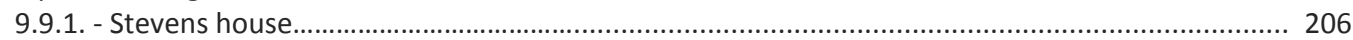

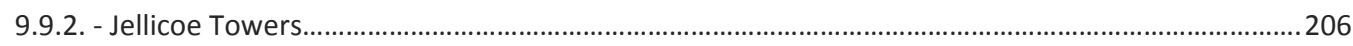

9.9.3. - Firth house

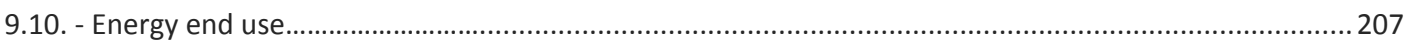

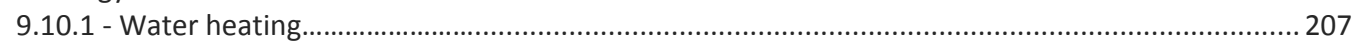

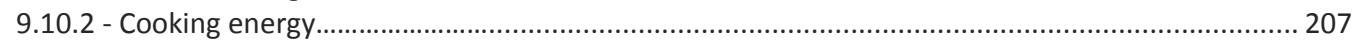

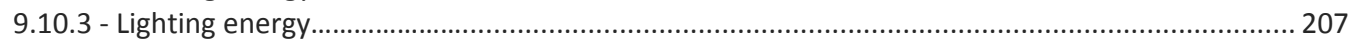

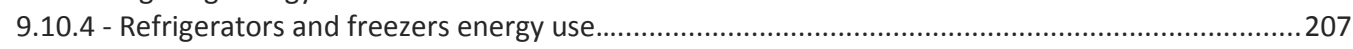

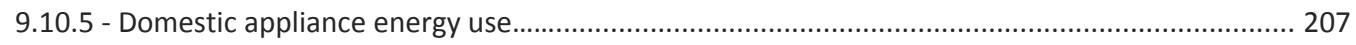

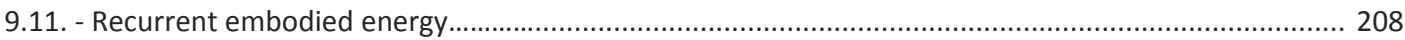

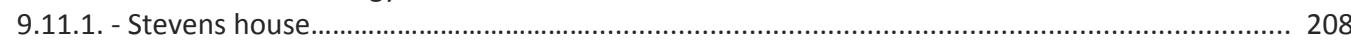

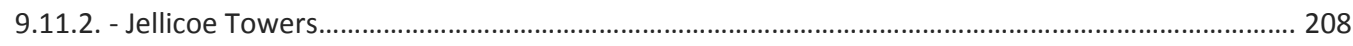

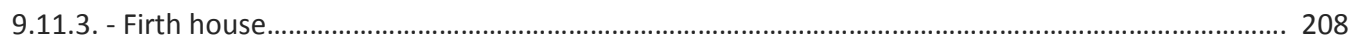

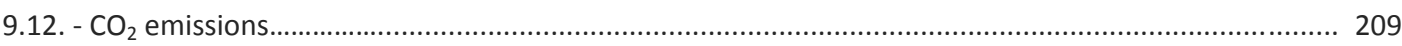

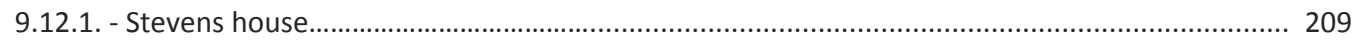

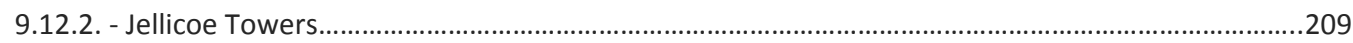

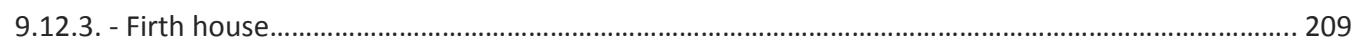

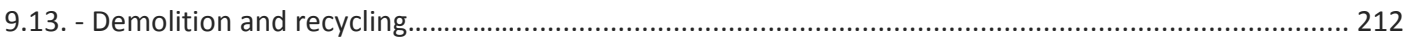

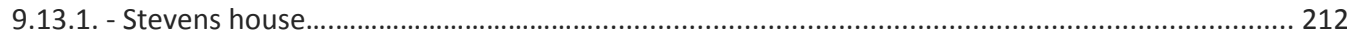

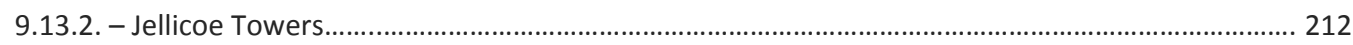

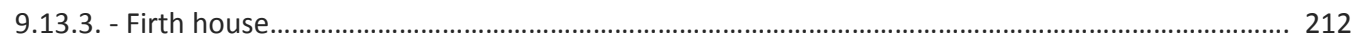

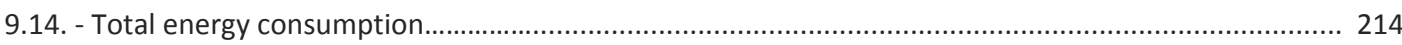

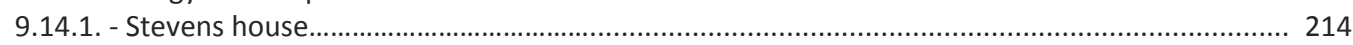

9.14.2. - Jellicoe Towers...................................................................................................................... 214

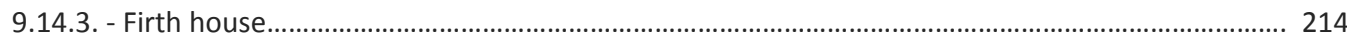

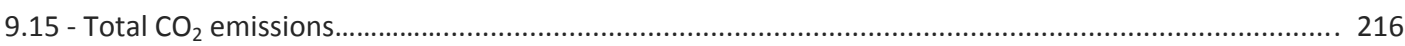

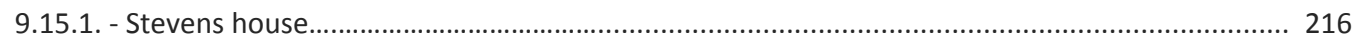

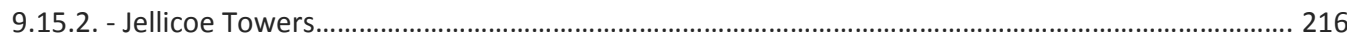

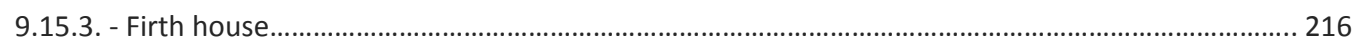




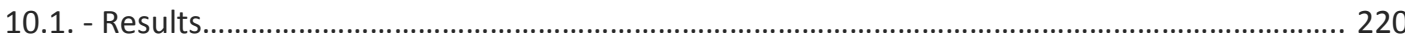

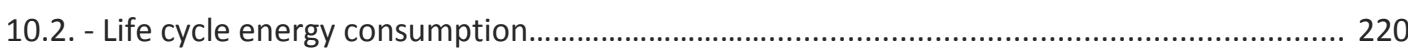

10.3. - Life cycle operating energy consumption ................................................................ 221

10.4. - Life cycle energy consumption for steel structures...................................................... 221

10.5. - $\mathrm{CO}_{2}$ emissions for steel structures......................................................................................... 222

10.6. - $\mathrm{CO}_{2}$ emissions for concrete structures ........................................................................... 222

10.7. - $\mathrm{CO}_{2}$ emissions for timber structures ............................................................................. 222

Discussion

10.8. - Life cycle energy consumption..................................................................................... 222

10.9. - Life cycle operating energy consumption .................................................................. 223

10.10. - Life cycle energy consumption for steel structures....................................................... 224

10.11. - Life cycle energy consumption for concrete structures .................................................. 224

10.12. - Life cycle energy consumption for wooden structures ............................................... 224

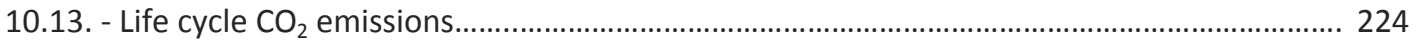

10.14. - $\mathrm{CO}_{2}$ emissions for steel structures................................................................................... 225

10.15. - $\mathrm{CO}_{2}$ emissions for concrete structures........................................................................ 225

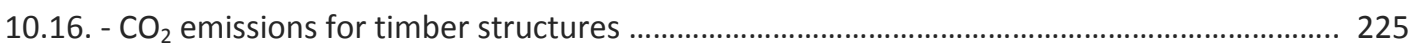

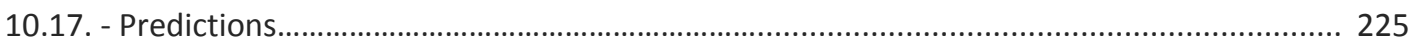

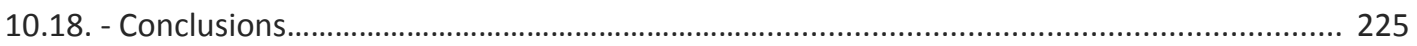

\section{List of tables}

\section{Chapter I Container Architecture}

Table $\mathrm{N}^{\circ} 1$ Shipping container buildings

Chapter III Physical characteristics of ISO containers

Table $\mathrm{N}^{\circ} 1$ Energy use of various forms of freight transport .................................................... 53

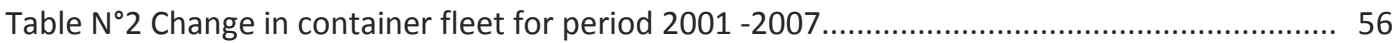

Table $\mathrm{N}^{\circ} 3$ Amount of ISO shipping containers in the world by years.................................... 58

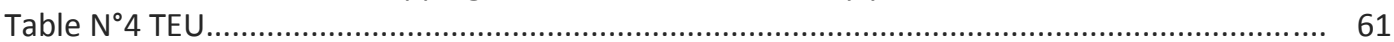

Table $\mathrm{N}^{\circ} 5$ 20-foot ISO Shipping container of steel for general purpose (Dry Container)............. 62

Table $N^{\circ} 620$-foot ISO Shipping container of steel for general purpose (Dry Container)............... 66

Table $N^{\circ} 740$-foot ISO Shipping container of steel for general purpose (Dry Container)............. 67

Table $\mathrm{N}^{\circ} 8$ 20-foot shipping container prices.................................................................... 69

Table $\mathrm{N}^{\circ} 9$ 40-foot used shipping container prices........................................................... 70

Table $\mathrm{N}^{\circ} 10$ 40-foot high cube shipping container prices.................................................... 71

Chapter IV Energy Generation, energy consumption and environmental issues in the construction sector

Table N¹ Evolution from 1971 to 2007 of world total primary energy supply by fuel (M toe)...... 79 Table $N^{\circ} 2$ Evolution from 1971 to 2007 of world total primary energy consumption by fuel....... 81 Table $\mathrm{N}^{\circ} 3$ Combustion of fossil fuels...................................................................................... 82

Table $N^{\circ} 4$ Evolution from 1971 to 2007 of world total energy consumption by region.................. 84

Table N5 Evolution from 1971 to 2007 of world total coal consumption by sector....................... 86

Table $N^{\circ} 6$ Evolution from 1971 to 2007 of world total oil consumption by sector...................... 88

Table $\mathrm{N}^{\circ} 7$ Evolution from 1971 to 2007 of world total gas consumption by sector...........................90

Table $N^{\circ} 8$ Evolution from 1971 to 2007 of world total electricity consumption by sector.............. 92

Table $\mathrm{N}^{\circ} 9$ Evolution from 1971 to 2007 of world total $\mathrm{CO}_{2}$ emissions by fuel.................................. 95

Table $\mathrm{N}^{\circ} 10$ Evolution from 1971 to 2007 of world total $\mathrm{CO}_{2}$ emissions by region......................... 97

Table $\mathrm{N}^{\circ} 11$ Embodied Energy and $\mathrm{CO}_{2}$ emissions per building material....................................... 99

Chapter $\mathrm{V}$ Energy use in residential buildings

Table $\mathrm{N}^{\circ} 1$ Sizes of houses and energy consumption

Table $\mathrm{N}^{\circ} 2$ Household energy consumption per square metre per year........................................ 110 


\section{Chapter VI Life cycle assessment}

Table $\mathrm{N}^{\circ} 1$ Literature on energy use in the production phase of residential building................... 117

Table $\mathrm{N}^{\circ} 2$ Embodied energy of concrete building materials................................................. 122

Table $\mathrm{N}^{\circ} 3$ List of materials and primary energy used per kilograms and cubic meter................ 123

Table $\mathrm{N}^{\circ} 4$ List of materials and primary energy used per kilograms and cubic meter............... 124

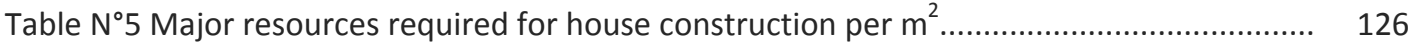

\section{Chapter VII Life cycle energy for houses in New Zealand}

Table $N^{\circ} 1$ Winter living room evening temperatures and heating energy by heater type............ 135

Table $\mathrm{N}^{\circ} 2$ Heating time in different North Island cities............................................................... 142

Table $\mathrm{N}^{\circ} 3$ Average winter evening temperature....................................................................... 143

Table $\mathrm{N}^{\circ} 4$ Energy end use in New Zealand houses in 2003.................................................. 144

Table $\mathrm{N}^{\circ} 5$ Average winter evening temperatures for living and bedrooms.................................. 145

Table $\mathrm{N}^{\circ} 6$ Domestic hot water fuel comparison......................................................................... 147

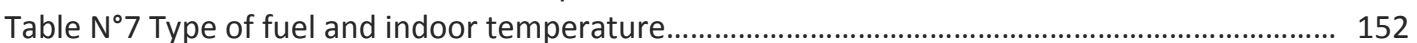

\section{Chapter VIII Environmental control of ISO containers}

Table $\mathrm{N}^{\circ} 1$ Space heating by orientation for a 20 foot shipping container with insulation............ 157

Table $\mathrm{N}^{\circ} 2$ Space heating by orientation for a 20 foot shipping container without insulation....... 157

Table $\mathrm{N}^{\circ} 3$ Space heating by orientation for a 40 foot shipping container with insulation............ 158

Table $\mathrm{N}^{\circ} 4$ Space heating by orientation for a 40 foot shipping container without insulation..... 158

Table $N^{\circ} 5$ Energy use per square meter in 20 and 40-foot shipping containers............................ 171

Table $N^{\circ} 6$ Two 40-foot shipping containers 1 and 2 levels with insulation 1 occupant

located in Wellington and windows in both sides.

\section{Chapter IX Case studies}

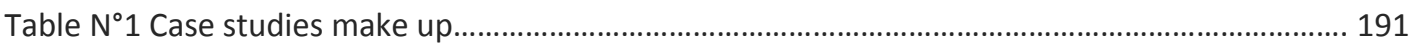

Table $N^{\circ} 2$ Total and interior useful areas per project............................................................. 196

Table $\mathrm{N}^{\circ} 3$ Walls and glazing areas per project...................................................................... 199

Table $\mathrm{N}^{\circ} 4$ Construction materials used in different case studies.............................................. 202

Table $N^{\circ} 5$ Total energy consumption .......................................................................................... 204

Table $N^{\circ} 6$ Case studies space heating energy required per square meter.................................... 206

Table $N^{\circ} 7$ Energy end use in New Zealand houses in 2003.................................................... 207

Table $N^{\circ} 8$ Maintenance stage of case studies................................................................................ 208

Table $\mathrm{N}^{\circ} 9$ Life cycle analysis broken down in the operation stage.......................................... 209

Table $\mathrm{N}^{\circ} 10$ Life cycle analysis broken down in the construction stage $\mathrm{CO}_{2}$ emissions................ 210

Table $\mathrm{N}^{\circ} 11$ Life cycle analyses broken down in the maintenance stage................................. 211

Table N¹2 Demolition and waste treatment............................................................................... 212

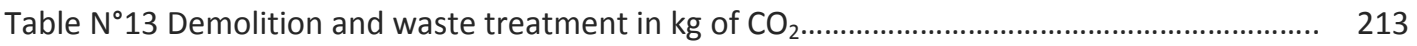

Table $\mathrm{N}^{\circ} 14$ Total energy consumption............................................................................................. 213

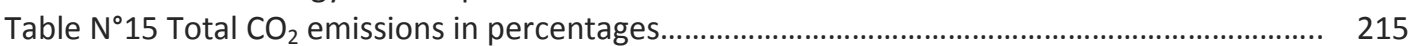

Table $\mathrm{N}^{\circ} 16$ Total $\mathrm{CO}_{2}$ emissions in absolute values..................................................................... 215

Table $\mathrm{N}^{\circ} 17$ Total $\mathrm{CO}_{2}$ emissions per square meters.................................................................. 218 


\section{List of graphs}

\section{Chapter III Physical characteristics of ISO containers}

Graph $N^{\circ} 1$ Freight cargo using shipping containers.............................................................. 55

Graph $N^{\circ} 2$ World fleet by principal vessel types, selected years............................................... 57

Graph N³20 foot ISO Shipping container make up for general purpose (Dry Container).......... 66

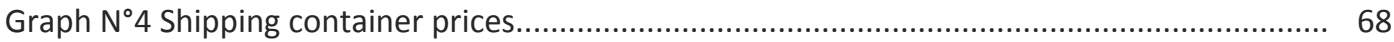

Chapter IV Energy Generation, energy consumption and environmental issues in the construction sector

Graph N¹ Evolution from 1971 to 2007 of world total primary energy supply by fuel .............. 78 Graph N² Evolution from 1971 to 2007 of world total primary energy consumption by fuel...... 80 Graph N³ Evolution from 1971 to 2007 of world total energy consumption by region........... 83 Graph N 4 Evolution from 1971 to 2007 of world total coal consumption by sector.................. 85 Graph N5 Evolution from 1971 to 2007 of world total oil consumption by sector..................... 87 Graph N6 Evolution from 1971 to 2007 of world total gas consumption by sector.................... 89 Graph $N^{\circ} 7$ Evolution from 1971 to 2007 of world total electricity consumption by sector........ 91 Graph N 8 GHGs make up............................................................................................................ 93 Graph $N^{\circ} 9$ Evolution from 1971 to 2007 of world total $\mathrm{CO}_{2}$ emissions by fuel.......................... 94 Graph N¹0 Evolution from 1971 to 2007 of world total $\mathrm{CO}_{2}$ emissions by region................... 96

\section{Chapter V Energy use in residential buildings}

Pie Chart $\mathrm{N}^{\circ} 1$ The energy consumption per sector in the United Kingdom...... 102

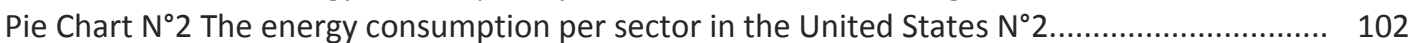

Pie Chart $\mathrm{N}^{\circ} 3$ The energy consumption per sector in the United States................................... 104

Pie Chart $\mathrm{N}^{\circ} 4$ The energy consumption per sector in China................................................... 104

Pie Chart $\mathrm{N}^{\circ} 5$ The energy consumption per sector in the United States.................................. 105

Graph $N^{\circ} 1$ Household energy consumption per square meter per year.................................... 110

\section{Chapter VII Life cycle energy for houses in New Zealand}

Pie charts $\mathrm{N}^{\circ} 1$ and $\mathrm{N}^{\circ} 2$ preliminary results of HEEP based on types of fuels and energy end-use. 138 Pie chart $\mathrm{N}^{\circ} 3$ Energy end use per household in New Zealand in 2002 ......................................... 141 Pie chart $\mathrm{N}^{\circ} 4$ Energy end use in New Zealand houses in 2003................................................. 144 Pie charts $N^{\circ} 5,6$ and 7 Energy end uses over the years in New Zealand....................................... 149

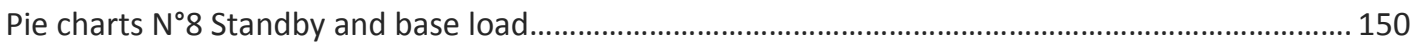

\section{Chapter VIII Environmental control of ISO containers}

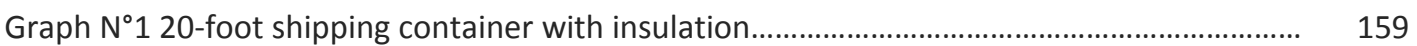

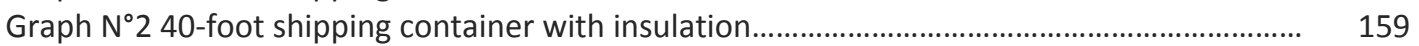

Graph N³ 20-foot shipping container without insulation................................................... 160

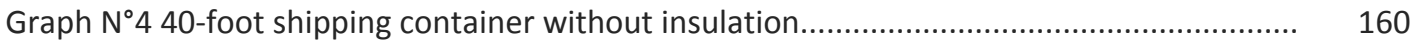

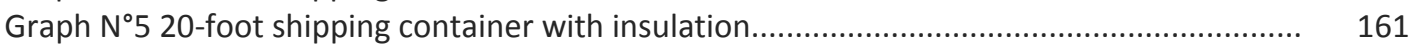

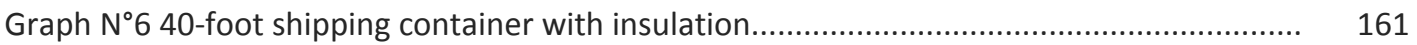

Graph N`7 20-foot shipping container without insulation.................................................. 162

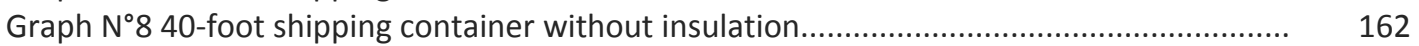

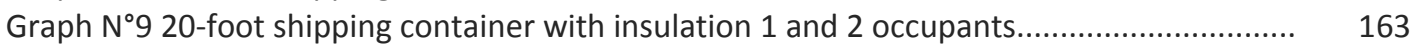

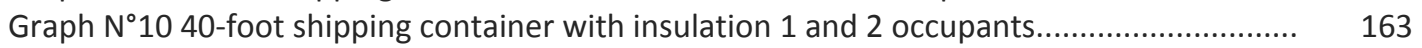

Graph N¹1 20-foot container with insulation 1 occupant located in Auckland and Wellington... 164

Graph N¹2 40-foot container with insulation 1 occupant located in Auckland and Wellington... 165

Graph N¹3 20-foot shipping container with insulation 1 occupant located in Wellington........ 166

Graph $N^{\circ} 14$ 40-foot shipping container with insulation 1 occupant located in Wellington......... 167

Graph N¹5 Two 40-foot container 1 level with insulation 1 occupant located in Wellington.... 169 Graph N¹6 Two 40-foot container 2 levels with insulation 1 occupant located in Wellington... 169 
Graph N¹7 Two 40-foot shipping containers 1 level with insulation 1 occupant located in Wellington and windows in both sides.....

Graph N 18 Two 40-foot shipping containers 2 levels with insulation 1 occupant located in Wellington and windows in both sides......................................................................... 170

Graph N ${ }^{\circ} 19$ Energy use per square meter in 20 and 40-foot shipping containers......................... 172

Graph N²0 Two 40-foot shipping containers 1 and 2 levels with insulation 1 occupant located

in Wellington and windows in both sides.

\section{Chapter IX Case studies}

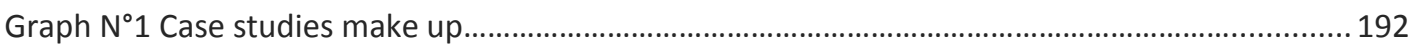

Graph $\mathrm{N}^{\circ} 2$ Total and interior useful areas per project............................................................. 197

Graph N³ Percentage of walls and glazing areas............................................................................... 198

Graph $\mathrm{N}^{\circ} 4$ Walls and glazing areas per project in square metres.............................................. 200

Graph $\mathrm{N}^{\circ} 5$ Case studies space heating energy required in kWh/year............................................ 205

Graph $\mathrm{N}^{\circ} 6$ Case studies space heating energy required per square metre..................................... 206

Pie chart $\mathrm{N}^{\circ} 1$ Energy end use in New Zealand houses in 2003................................................. 207

Graph $\mathrm{N}^{\circ} 7$ Case studies: $\mathrm{CO}_{2}$ produced in operation and other stages........................................... 209

Graph $\mathrm{N}^{\circ} 8$ Life cycle analysis broken down in the maintenance stage.......................................... 211

Graph $N^{\circ} 9$ Energy net calorific value (MJ) per square metres ..........................................................214

Graph $\mathrm{N}^{\circ} 10$ Total $\mathrm{CO}_{2}$ emissions in percentages.......................................................................... 216

Graph $\mathrm{N}^{\circ} 11$ Total $\mathrm{CO}_{2}$ emissions in absolute values................................................................... 217

Graph $\mathrm{N}^{\circ} 12$ Total $\mathrm{CO}_{2}$ emissions in absolute values in all stages................................................ 218

Graph $\mathrm{N}^{\circ} 13$ Total $\mathrm{CO}_{2}$ emissions per square meter.............................................................. 219

\section{List of Illustrations}

\section{Introduction Chapter}

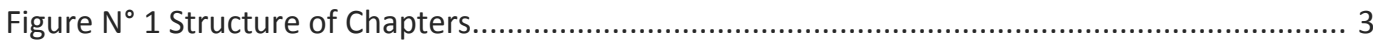

\section{Chapter 1 Container Architecture}

Figure $\mathrm{N}^{\circ} 1$ Approaches of the research............................................................................... 8

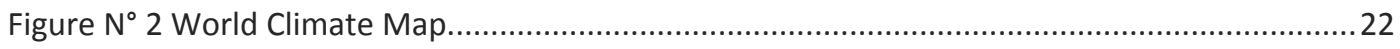

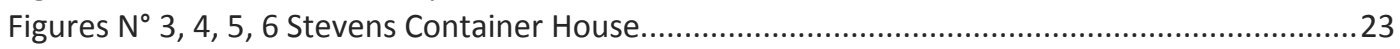

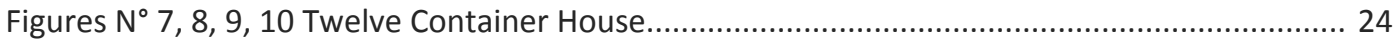

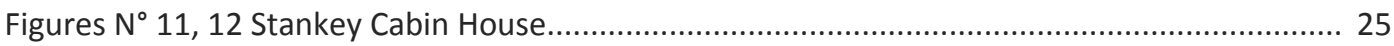

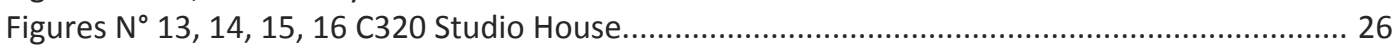

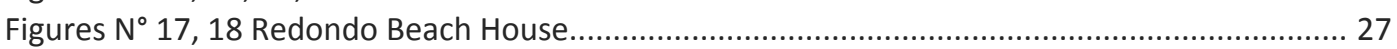

Figures $\mathrm{N}^{\circ} 19,20$ Redondo Beach House................................................................................ 28

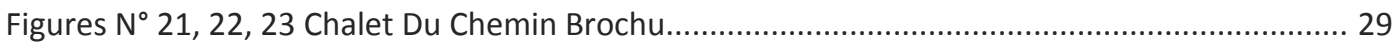

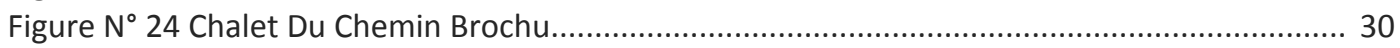

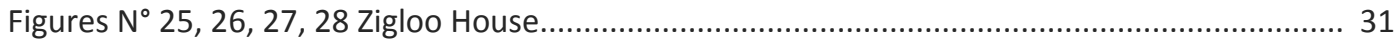

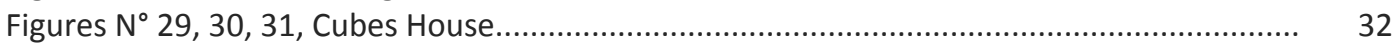

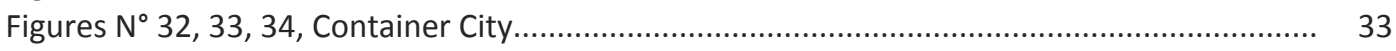

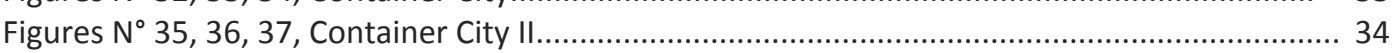

Figures $\mathrm{N}^{\circ} 38,39,40,41$ the Riverside Building.................................................................. 35

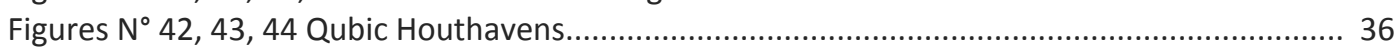

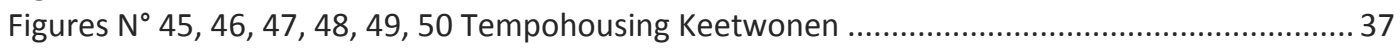

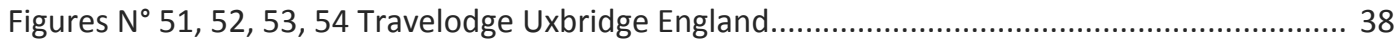

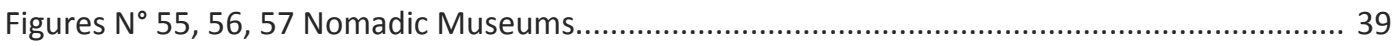

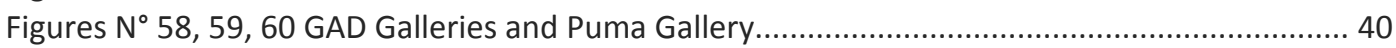

Figures $\mathrm{N}^{\circ} 61,62,63,64,65$ Tree-house temporary school........................................................ 41

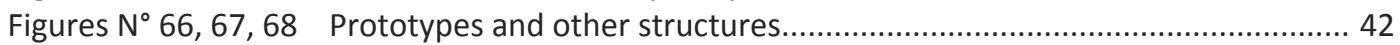


Figure $\mathrm{N}^{\circ} 1$ Process of modernisation in the Transport Industry.....

Chapter 3 Physical characteristics of ISO containers

Figure $\mathrm{N}^{\circ} 1$ Map of the boom in shipping trade........................................................... 54

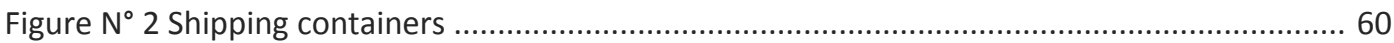

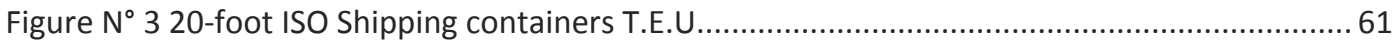

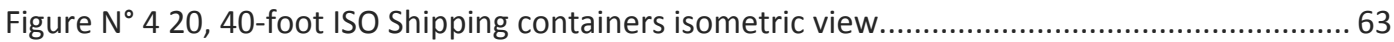

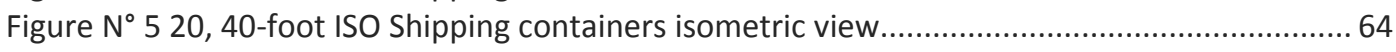

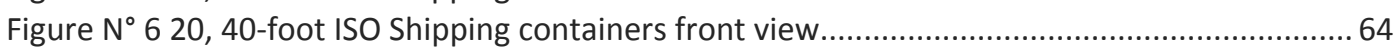

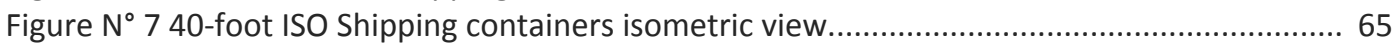

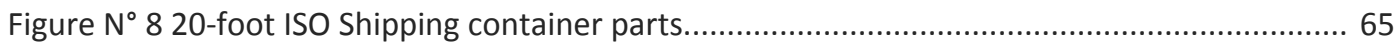

Figure $\mathrm{N}^{\circ} 920$-foot ISO Shipping container vertical weight requirement .................................... 65

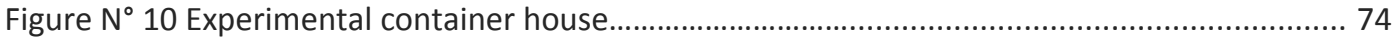

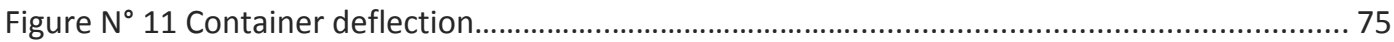

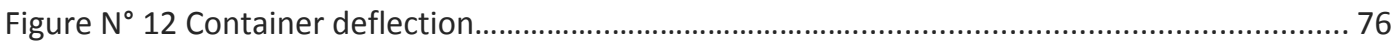

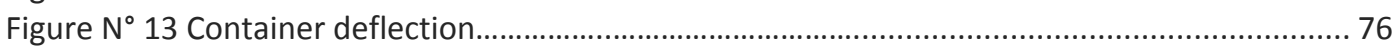

Chapter 5 Energy use in residential buildings

Figure $\mathrm{N}^{\circ} 1$ Average sizes of houses internationally............................................................. 106

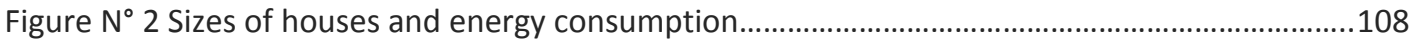

\section{Chapter 6 Life cycle assessment}

Figure $\mathrm{N}^{\circ} 1$ Embodied and operating energy over a building life cycle...................................... 118

Figure $\mathrm{N}^{\circ} 2$ Operational and embodied energy as a function of building life................................ 119

Figure $\mathrm{N}^{\circ} 3$ Embodied energy of wall construction systems per element area........................... 121

Figure $\mathrm{N}^{\circ} 4 \mathrm{CO}_{2}$ emissions possible scenarios........................................................................... 125

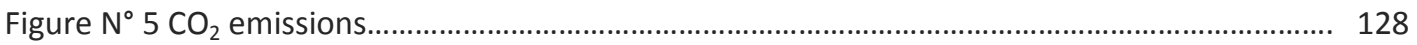

\section{Chapter 7 Life cycle energy for houses in New Zealand}

Figure $\mathrm{N}^{\circ}$ 1: Climate zones for New Zealand......................................................................... 133

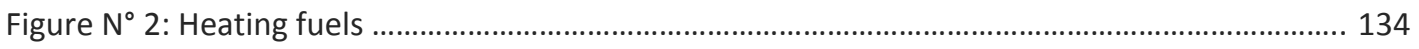

\section{Chapter 8 Environmental control of ISO containers}

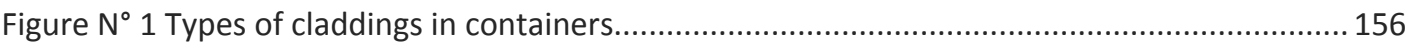

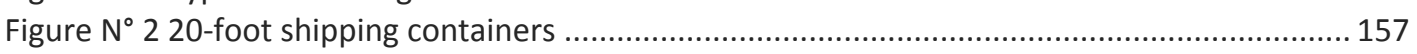

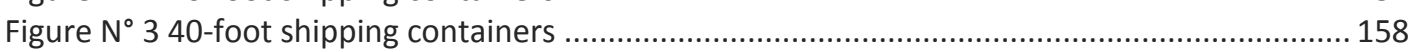

Figure $\mathrm{N}^{\circ} 4$ 40-foot shipping containers horizontal connectivity.............................................. 168

Figure $\mathrm{N}^{\circ} 5$ 40-foot shipping containers vertical connectivity............................................... 168

\section{Chapter 9 Case studies}

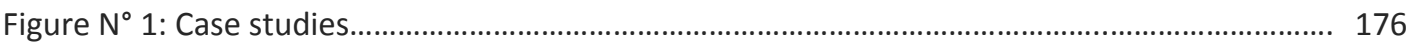

Figure $\mathrm{N}^{\circ}$ 2: Stevens House, the Jellicoe Towers single unit and the Firth House.......................... 177

Figure $\mathrm{N}^{\circ}$ 3: Basement and first floor Stevens House..................................................................178

Figure $N^{\circ} 4$ : Second floor Stevens House.......................................................................................... 179

Figure $\mathrm{N}^{\circ}$ 5: Stevens House west elevation.............................................................................. 180

Figure $\mathrm{N}^{\circ}$ 6: Stevens House east elevation................................................................................... 181

Figure $\mathrm{N}^{\circ}$ 7: Stevens House north and south elevation.............................................................. 182

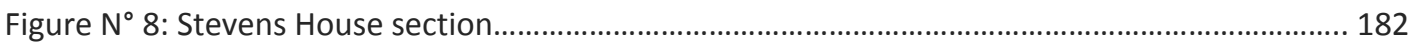

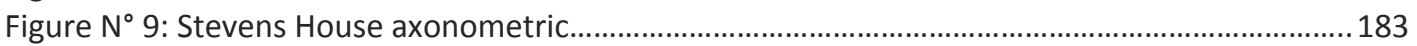


Figure $\mathrm{N}^{\circ}$ 10: Jellicoe Towers.

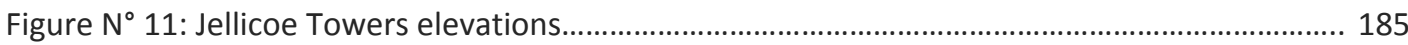

Figure $\mathrm{N}^{\circ} 12$ : Jellicoe Towers axonometric.................................................................................. 187

Figure $\mathrm{N}^{\circ} 13$ : Basement Firth House ...................................................................................... 187

Figure $\mathrm{N}^{\circ} 14$ : First floor Firth House .................................................................................... 187

Figure $\mathrm{N}^{\circ} 15$ : Second floor Firth House...................................................................................... 188

Figure $\mathrm{N}^{\circ} 16$ : Facades Firth House........................................................................................ 189

Figure $\mathrm{N}^{\circ}$ 17: Facades Firth House axonometric............................................................................. 190

Figure $N^{\circ} 18$ : Facades Firth House axonometric............................................................................. 191

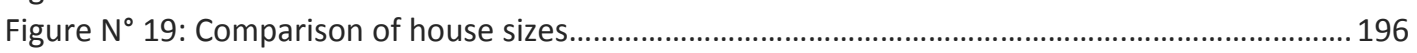

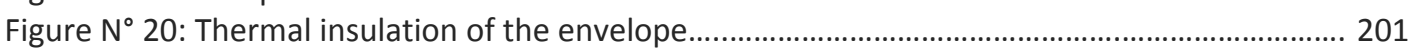

\subsection{1. - Glossary of terms}

Before carrying out a literature survey related to freight transport and containerisation, it is advisable to provide a glossary of some of the specialised terms used in the freight transport industry.

Break Bulk Cargo: is a system of loading goods individually. Before the introduction of shipping containers this method was the most used in ports, handling of cargo by longshoremen around the world for centuries.

Cell: for this research, the word, "cell" is related to the idea of shipping container or the basic module of a building, for example: a studio of an apartment.

Containerisation: (or containerization) is a system of intermodal freight transport using standard intermodal containers that are standardized by the International Organization for Standardisation (ISO). These can be loaded and sealed intact onto container ships, railroad cars, planes, and trucks. ${ }^{1}$

Industrialisation: is the process of social and economic change whereby a human group is transformed from a pre-industrial society into an industrial one. It is a part of a wider modernisation process, where social change and economic development are closely related with technological innovation, particularly with the development of large-scale energy and metallurgy production. It is the extensive organisation of an economy for the purpose of manufacturing. Industrialization also introduces a form of philosophical change, where people obtain a different attitude towards their perception of nature. ${ }^{2}$

Intermodal system: Specialized transportation facilities, assets, and handling procedures designed to create a seamless transportation system by combining multimodal operations and facilities during the shipment of cargo. ${ }^{3}$

\footnotetext{
${ }^{1}$ Burg, G.V. (1975, p. 68)

2 (The free dictionary), Retrieved 19 August 2009 from http://www.thefreedictionary.com/containerisation

${ }^{3}$ (The free dictionary), Retrieved 19 August 2009 from http://www.thefreedictionary.com/intermodal+systems
} 
I.S.O.: International Organization for Standardisation.

Longshoreman: a person employed on the wharves of a port, as in loading and unloading vessels. ${ }^{4}$

Marad committee: United States Maritime Administration.

MH-5: Materials Handling Sectional Committee 5 was a special committee created in 1958 in the middle of the process of standardisation. It was made up by subcommittees that represented the United State Government, engineers and experts that represented the interest of Maritime Companies. ${ }^{5}$

Prefabrication: in architectural construction, a technique whereby large units of a building are produced in factories to be assembled, ready-made, on the building site. The technique permits the speedy erection of very large structures. It has been applied to urban housing for more than a century. Major architects, including Walter Gropius, Konrad Wachsmann, and Buckminster Fuller, have been involved significantly in the development of prefabrication.

Shipping containers: in transportation industry are steel boxes, a container with strength suitable to withstand shipment, storage, and handling. Shipping containers range from large reusable steel boxes used for intermodal shipments to ubiquitous corrugated boxes. ${ }^{6}$

Standardisation: Standardization or standardisation is the process of developing and agreeing upon technical standards. A standard is a document that establishes uniform engineering or technical specifications, criteria, methods, processes, or practices. Some standards are mandatory while others are voluntary. Voluntary standards are available if one chooses to use them. Some are de facto standards, meaning a norm or requirement which has an informal but dominant status. Some standards are de jure, meaning formal legal requirements. Formal standards organizations, such as the International Organization for Standardization (ISO) or the American National Standards Institute, are independent of the manufacturers of the goods for which they publish standards. ${ }^{7}$

\footnotetext{
${ }^{4}$ (Dictionary), Retrieved 19 August 2009 from http://dictionary.reference.com/browse/longshoreman

${ }^{5}$ (Levinson, 2006, pp. 131-132)

${ }^{6}$ Burg, G.V. $(1975$, pp. 62-70)

${ }^{7}$ Burg, G.V. (1975, p. 71)
} 


\section{Introduction}

This thesis introduces the study of container architecture for the residential sector in New Zealand. It analyses, compares and discusses its performance in contrast with traditional building systems both as design and in terms of energy consumption, $\mathrm{CO}_{2}$ emissions and the effect of thermal mass on house energy-end use using the life cycle analysis as the methodology of corroboration of the hypothesis. This research focuses on sustainability in prefabricated architecture.

But first, can containers be called architecture?

..."When you cut holes ... (the containers) are no longer an instrument of trade," said David Cross... "They turn into an instrument of construction"... Grant A. (2008, p. 1)

The history of the transport industry can be divided in two parts: before and after the historic introduction and subsequent rise of the intermodal container. In 1956 an

entrepreneur from Maxton, North Carolina, often called "the father of containerisation" 1 had the idea that a metal-made trailer truck frame could be lifted by a crane and put into a vessel to be delivered to its final destination. The new scheme potentially would require less time and would save shipping costs. On $26^{\text {th }}$ of April of 1956 the ideal- $X$, a vessel filled with fifty eight 35-foot shipping containers, sailed from the port of Newark, New Jersey to Houston. $^{2}$ The idea had a positive impact in the transport industry, achieving the optimisation of the whole haulage process. This marked the birth of the cargo container; the core of an intermodal freight transport system which replaced the traditional and old break bulk cargo, where every item was loaded and unloaded individually.

Since then these steel boxes have made the world smaller and the world economy bigger. But shipping containers have changed over time and they now have evolved into the familiar ISO cargo-containers of 20,30 and 40-foot length. Little is known about who crossed the line first in turning freight containers into architecture. But now these metal boxes have become an alternative in the construction sector. They provide a practical, prefabricated, mass produced, modular, stackable, available, strong and affordable element in which the human scale potentially can fit.

\footnotetext{
${ }^{1}$ Levinson (2006)

${ }^{2}$ Ibid
} 
Where the concept of container-architecture was first coined remains uncertain. Worldwide there are a few examples of projects made of shipping containers and some of them have become icons such is the case of Container City I and II or Keetwonen Student accommodation in Amsterdam, The Netherlands, which is unique in its kind. ${ }^{3}$

\section{1. - Problem statement}

Prefabrication in architecture is a familiar concept; it has both succeeded and failed. ${ }^{4}$ Thus prefabricated houses represent a small proportion in comparison with the total amount of traditional residences. At the same time, shipping container dwellings represent a small proportion of prefabricated houses. Shipping container architecture has been named as a category of prefabricated buildings. In addition, the production of new container-houses is growing. Despite the large accumulation of empirical information related to prefabrication in architecture and prefabricated houses, (where the term "container architecture" was first coined) plus the lack of technical data of the energy and resource-use, $\mathrm{CO}_{2}$ emissions and thermal performance of container-homes, in comparison with conventional houses continues to be unclear. This represents a gap between empirical knowledge and future applications of this type of buildings. Is it possible to enhance energy efficiency in the residential sector by using them?

\section{2. - Aim and scope}

The aim of this research is to establish whether container architecture in the residential sector of New Zealand is energy efficient in contrast with traditional houses built with conventional building materials.

\section{3. - Objectives}

General

- To determine the sustainability of container architecture in terms of energy consumption and in terms of $\mathrm{CO}_{2}$ emissions through the lifespan of the buildings.

Specifics

- To compare and contrast the building energy-use performance of container architecture against traditional edifices constructed by conventional building materials.

- To determine the justification of container architecture as a low-energy house.

\footnotetext{
${ }^{3}$ Kotnik, J. (2008)
}

${ }^{4}$ Davies, C. (2005) 


\section{4. - Research questions}

The following research will be about the development of container architecture as a new response in architecture, with advantages and disadvantages, assuming that this represents only a small part of a new way of making sustainable architecture and -at the same time- aims to present the next investigation in an original perspective of what has been called green architecture.

First, there are some questions that will be answered in the development of the thesis such as:

How is the relationship between Container Architecture and sustainable design?

How does the election of a building material affect the energy consumption and the emissions of $\mathrm{CO}_{2}$ through the lifespan of a building?

Can shipping container houses be more energy efficient in contrast with houses built by using concrete and timber structures?

Can container houses be named low-energy houses in the residential sector of New Zealand?

How should C.A. ${ }^{5}$ be manipulated by architects?

Why is it, if there are potentially more advantages than disadvantages of using containers, that container architecture is not more popular among architects and house designers?

Can shipping containers houses become a source of low income houses?

In summary, could Container Architecture be called the new environmental living box?

${ }^{5}$ C.A.: container architecture 


\section{5. - Overview of the study}

Therefore, to achieve the above aim the research moves towards two different but complementary directions: shipping container-architecture theoretical background and residential energy end-use. This thesis can be broken down into three different sections: The first part made up by chapters 1, 2 and 3 explores the concept of shipping container architecture through the study of a series of worldwide examples of buildings which use containers as main components. In addition, the background of shipping containers and the shipping industry is shown in detail encompassing a comprehensive development of the steel-box itself, its later evolution and the consequences in its use through the last sixty years, including historical, architectural and economical approaches. Lastly, this section discusses the evolution of the elements that make up shipping container industry statistics at the present day.

The second part of this thesis is made up by chapters $4,5,6,7$ and 8 related explicitly to energy supply/consumption and energy use in residential buildings. These five chapters aim to introduce, explain and discuss specific data linked to the energy delivered into residential buildings from the most general to the most specific background. This starts discussing the elements of world energy supply and world energy consumption, establishing relationships between them and the way energy is consumed lately in the residential sector. Comparisons are made among different OECD $^{6}$ countries with New Zealand in order to understand energy consumption patterns.

The third and final section is made up by the case studies and the conclusions which are fed by the previous parts.

In parallel, eight different approaches are established associated with the amalgam between "shipping container's" main features when they become inhabitable. These points become crucial to identify theoretical issues and enclose this thesis in a holistic frame. The hierarchy has been defined by the most general to the most specific approach.

- 1.5.1. - Prefabrication and the prefabricated house: represents the realm of this study, is the most general subject, and sets up where container-architecture belongs and points out the advantages and disadvantages of using prefabricated systems despite traditional constructions.

- 1.5.2. - Minimum dwelling: as a consequence in the usage of shipping containers when they turn into buildings. This approach investigates minimum environmental comfort, modern health requirements and economic affordability. But more

\footnotetext{
${ }^{6}$ OECD, mostly: Australia, Canada, Japan, UK, USA and China.
} 
important, it shows the problems and argues the need of deep environmental assessment when space becomes minimum.

- 1.5.3. - Temporary structures: discusses a group of emergency housing projects developed in the past 60 years.

- 1.5.4. - Mass production: examines the introduction of the concept of fordism into architecture and links a series of hypothetical ideals of Modern Architects concerning the Living Machine presented by Le Corbusier. Lately, it demonstrates the importance of the theoretical model of mass production and its real applications in architecture.

- 1.5.5. - Mobile structures, this approach starts out from a series of projects that owned this particular feature, showing the advantages and disadvantages of this construction system in comparison with traditional buildings.

- 1.5.6. - Container architecture: fed by the other issues, this stage argues the need of a sustainable approach in order to develop this concept into architectural forms. Thus, this point sets up the relationships between the main features of shipping containers and how these features become turned into architecture in the form of dwellings. Unfortunately, there is a lack of theoretical evidence connected to the proper term of shipping container architecture.

- 1.5.7. - Life cycle analysis: introduces the methodology in which case studies will be carried out. In addition, it discusses the research method where the model can be developed and tested in New Zealand residential buildings.

- 1.5.8. - Comparative life cycle analysis for construction materials, the last point compares the difference in embodied-energy and thermal performance of three traditional construction materials: Steel, concrete and timber.

\section{6. - Thesis Lay-out}

Chapter one discusses the term of container architecture and explores the advantages and disadvantages of using containers in residential buildings around the world. These are shown according to, location, climate conditions and scale.

Chapter two analyses the contribution of shipping containers to the world as part of the intermodal system of transport and the subsequent processes involved, such as automation, containerisation, standardisation, mechanisation and final modernisation that occurred in many ports and cities around the world since its introduction in 1956 . But more important this chapter links the concept of shipping container architecture to its historical context. 
Chapter three enables the reader to understand the connections between the evolved shipping container and its main physical features and demonstrates its importance as fundamental part of an integrated system of cargo transport.

Chapter four unequivocally marks a pause. Its function is to provide information from the open and general to more specific data of world energy supply versus world energy consumption. In addition, this chapter sets up the bond between other elements, such as the diverse types of fuels, how much is produced, where they are produced, who consumes energy and how it is consumed. But, more important this chapter shows the evolution of energy generation and consumption patterns over time, setting new parameters according to the present day.

Chapter five feeds off chapter four; this chapter establishes relationships with energy enduse and residential buildings. Its function is to select a suitable study area for the future case studies.

Chapter six creates the boundaries of the study in terms of sustainability and architecture. Its main function is to set up the methodology and selection criteria in which case studies will be assessed.

Chapter seven shows the energy end-use patterns of residential buildings in New Zealand selecting a suitable study area in Wellington.

Chapter eight feeds off past chapters and highlights possible and theoretical improvements of how container-architecture should be modified in order to increase energy efficiency in a practical way.

The model is evaluated in Chapter nine and conclusions are drawn in Chapter ten.

\section{7. - Limitations of the research}

Although, this research does not aim to focus particularly on historical facts, it is important to understand the history of architecture in order to recognise the wide spectrum of variables, its holistic vision, which finally determine every period in the time line of mankind.

Moreover, this study is not centred in the History of the Modern Movement in Architecture itself. But it has a background, a model of interpretation in which some actions could be inspired by past facts and be solved in different ways, such is the case of prefabrication in architecture. In addition, this is not intended to be a compilation of prefabricated houses. 
1.8. - Structure of the research

Figure $N^{\circ} 1$ Structure of Chapters

\section{Introductory Chapter}

Chapter I: Container Architecture

Chapter II: General Background

Chapter III: Physical Characteristics of ISO Containers

Chapter IV: Energy generation, energy consumption and environmental issues in construction sector

Chapter V: Energy use in residential buildings

Chapter VI: Life cycle assessment

Chapter VII: Life cycle energy for houses in New Zealand

Chapter VIII: Environmental control of ISO containers

Chapter IX: Case studies

Conclusions 


\section{Chapter I-Container architecture}

The scope of this investigation encompasses the concept of sustainability in prefabricated architecture, putting emphasis on three specific aspects:

- Energy consumption

- $\mathrm{CO}_{2}$ emissions

- Thermal performance for three conventional building materials: steel (containers), concrete and timber-based structures.

This chapter aims to introduce the concept of shipping container architecture. In addition, eight different theoretical subjects are set up due to the physical features of the containers when they are converted into architectural forms. These approaches can be divided into two directions: historical and physical. The first group is defined by qualitative facts and the second group defined by quantitative facts.

1. Prefabrication and the Prefabricated house

2. Minimum dwelling

3. Temporary structures

4. Mass production

5. Mobile structures

6. Container architecture

7. Life cycle analysis

8. Comparative life cycle analysis for construction materials

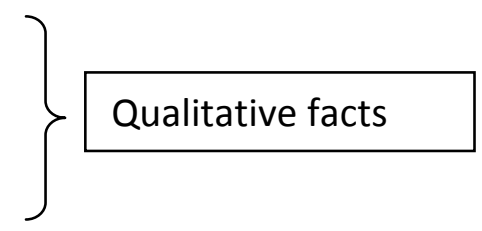

The first five approaches are related explicitly to the main features of the utilitarian box when containers are turned into architectural forms. On the other hand, the last two points are based on physical facts. Container architecture is the bond between these two realms.

Figure $\mathrm{N}^{\circ} 1$ Approaches of the research

Container Architecture

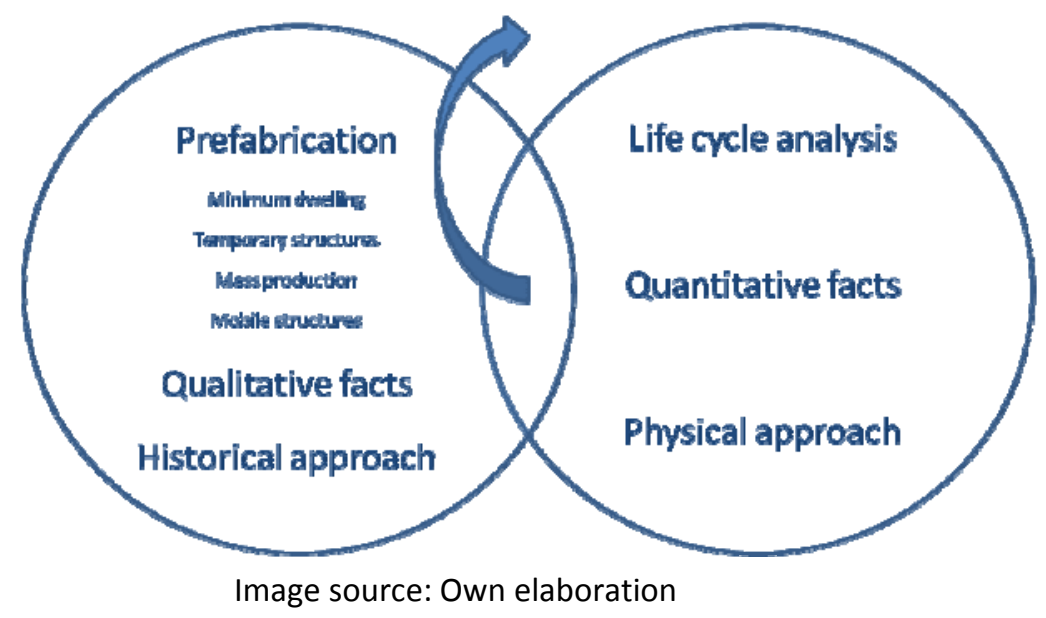




\subsection{Background}

\subsection{1. - Prefabrication}

One of the first problems that this investigation had to face was the fact that the usage of containers in buildings is something relatively new in architecture. There is a lack of empirical information and where the concept of Container Architecture was first coined remains uncertain. In addition, one of the preliminary assumptions was that Container Architecture would belong to the realm of prefabrication because these buildings use mainly prefabricated steel boxes.

Prefabrication in architecture is a familiar concept and has both succeeded and failed. Davies, C. (2005) presents a complete and a comprehensive study of the history, through the analysis of a series of worldwide examples of prefabricated houses showing the most important achievements and the most disappointing failures of prefabrication in architecture. The study found out that prefabrication can be divided in two main streams. The first one, an architectural history which is full of big failures and the second, -the non architectural history- its successful counterpart. However, the author describes the factors and the actors from historical, architectural, economical and political approaches in both cases.

According to Davies, C. (2005, pp. 7-8)

..." why should the prefabricated house be the key to the reform of modern architecture? Because, although we think of architecture being in some sense in charge of the activity of building, for 150 years or more the prefabricated house has managed perfectly well without architecture's guidance...the strength of the prefabricated house lies in its popularity, its cheapness and the industrial base from which it operates."

On the other hand Davies, C. (2005, pp. 8-9) states, the relationship between architecture and prefabrication has always been problematic.

The Prefabricated House

In addition, Davies, C. (2005, p. 9) suggests

..."the early Modernists put the prefabricated house at the centre of their programme of reform. Architectural history may pretend otherwise, but the fact is that their prefabricated house projects all failed. Some architects interpreted this failure of the prefabricated house per se, a proof that buildings do not lend themselves to factory production. But this is not true. Millions of successful prefabricated houses have been built all over the world, but architectural history ignores them because they are beyond the pale of the architecture field." 
Finally Davies, C. $(2005$, p. 11) states

..."the prefabricated house is an important theme, perhaps the most important, in the conventional, canonical history of twentieth-century architecture."

\subsection{2. - Minimum dwelling}

Gropius, W. (1956, pp. 117-118) suggests that

..."the dwellings must be provided in buildings which satisfy modern health requirements, particularly in regard to adequate illumination and ventilation. These requirements are best satisfied by small house construction in the wider sense of the word. The aim should be one-family dwellings with gardens. If local conditions require large apartment houses, the height of such buildings is to be limited to a maximum of three residential stories in medium-size towns and a maximum of four residential stories in larger cities."

In his book ("the minimum dwelling") Karol Teige sets up a comprehensive and holistic analysis behind the concept of the minimum dwelling. His study emphasises that the main concern of this concept is to provide the minimal requirements for healthy living. ${ }^{1}$

In addition other factors are explained, such as social behaviours and economic issues, in this same context, according to Teige, K. (2002, p. 234)

..."the geneses of the catch-phrase "minimum dwelling" as the most pressing architectural problem can be traced to a number of causes; among the most important are the changes in the social structure of the population that have taken place during the last few decades".

The second most important reason which underlies the concept of minimum dwelling is the economic and real estate speculations. Teige, K. (2002, p. 234) sets up that the housing market tried to adapt, recognising that the biggest demand was for small and inexpensive houses.

In addition Teige, K. (2002, p. 234) affirms that

..."the private construction sector built more houses with small apartments, which had become an attractive speculative proposition. This confirms the well known fact that the most profits can be made on the worst and smallest apartments, because their construction costs can be kept to a minimum and because they provide a primitive level of comfort compared with larger apartments."

\footnotetext{
${ }^{1}$ Teige, K. (2002, p. 234)
} 
All of these economic issues brought a series of negative consequences. For example: buildings lacking all comfort, with just enough light and ventilation provided to satisfy minimal code requirements. For environmental comfort and energy efficiency Teige, $\mathrm{K}$. (2002, p. 248) states that

..."the specifications of the dwelling minimum must not be reduced below biologically acceptable limits" ..."inhabitants must be provided with sufficient sun, light, and air, as well as adequate space to work, rest, sleep, eat, and bathe."

In the same line of discussion the New Zealand Building Code, in its Clause G4 related to Ventilation states that its main objective is to safeguard people from illness or loss of amenity due to lack of fresh air. ${ }^{2}$ In order to achieve these goals for functional requirements spaces within buildings shall be provided with adequate ventilation consistent with their maximum occupancy and their intended use. ${ }^{3}$ However, these topics will be discussed deeply in chapter five.

Schneider, T. (2007, p. 15) identifies three key directions that influenced the development of minimum dwelling or flexible housing:

- The first, in the early 1920 s arose out of the need for European social housing programmes to provide mass housing.

- The second direction, starting in the 1930 s and 1940 s and continuing to the present day, came out of a belief that prefabrication and emerging technologies could and should provide solutions to mass housing provision.

- The third direction, move towards participation and users' involvement in the 1960s and 1970s, led to a renewed interest in flexible housing as a means of providing user choice.

Existenzminimum (minimum subsistence level)

The second CIAM congress of international architects held in Frankfurt in 1929, entitled Die Wohnung für das Existenzminimum (translated as The Subsistence Dwelling) was a forum for debate as to the best solutions for the new reduced space standards. One response was to introduce the notion of flexibility. If there was to be less space, then that space needed to be used in as efficient and flexible a manner possible. ${ }^{4}$ The consequences of the debate around the minimum dwelling supposed a wide diversity of approaches depending on each country and each architect- planner and even social elements were included and strongly studied. Family make up played an important role in the appraisal of the different activities of a single unit (dwelling).

\footnotetext{
${ }^{2}$ Department of Building and Housing $(2008$, p. 3)

${ }^{3}$ Ibid

${ }^{4}$ Schneider, T. (2007, p. 16)
} 


\subsection{3. - Temporary structures}

Most of the books related to temporary structures in architecture show projects linked with the world of the arts and other performances such as stands for public expositions and industrial design. In addition, finding a building and a study which fit with temporary structures in the residential sector may be difficult.

Despite this issue there are some wide-ranging studies:

- Vale, B. (1995) Prefabs: a History of the UK Temporary Housing Programme

- Stevenson, G. (2003) Palaces for the people: Prefabs in Post-war Britain

- Davies, C. (2005) The prefabricated house

There are some good examples of those constructions especially in Great Britain and the United States such is the case of:

- $\quad$ AIROH Houses (Aircraft Industries Research Organisation of Housing).

- Arcon Mark V Bungalow

- The Tennessee Valley Authority (T V A houses for dam workers)

Probably the most significant case of temporary houses is the Temporary Housing Programme an ambitious plan of temporary homes or Bungalows for people who returned from the war and they were commissioned for the British Government. The fact that this project was a great success raises the question about temporary structures in architecture, many of these houses lasted over 5 times the lifespan estimated in their preliminary design. ${ }^{5}$

According to Davies, C. (2005, p. 61)

..."Britain's post -First World War prefabricated housing was the most advanced in the world. In Britain, however, it was seen only a temporary solution. After the Second World War similar situations prevailed, but in a big scale. It came in October 1944 when the government spent $£ 150$ million for the provision of temporary houses."

Why temporary?

Vale, B. (1995, pp. 106-110) suggests three reasons:

..."first to persuade the public to accept small, two bedroom houses built by unconventional means, second, to placate the building unions and reassure traditional building workers that their skills were being reserved for a permanent housing programme; and third, because the houses were going to be paid for by a central government that had no wish to trespass on the territory of local authority housing providers in the long term."

${ }^{5}$ Stevenson, G. (2003) 
The success of the Post-war British Prefab housing program can be explained by a series of factors:

- In 194486,000 Arcon temporary houses were produced ${ }^{6}$ and the number of the total bungalows delivered by the programme reached over 156,000

- Simplicity of purpose.

- Vale, B. (1995, p. 37) states that ..."the fact remained that the average bungalow was not designed by those in the visual arts but by those closest to the desire of the users."

- Vale, B. (1995, pp. 37-38) suggests that ..."by 1948 almost 125,000 "prefabs" had been built. Residents' satisfaction with them was very high, perhaps because they combined the two essential qualities of the universally desired country-cottage type, namely compact inside and large garden. Many people were sorry to leave their prefabs."

\subsection{4. - Mass production}

Le Corbusier tried to introduce the concept of fordism into the architecture. The ideal of the factory produced house was one of his main concerns.

According to Le Corbusier (1927)

..."If houses were constructed by industrial mass-production, like chassis, unexpected but sane and defensible forms would soon appear and a new aesthetic would be formulated with astonishing precision."

- Post-war British prefab

According to Davies, C. (2005, p. 61)

..."The AIROH House was designed to make use of spare capacity in the aircraft industry. Made in five factories scattered around the country, it was that rare thing in the history of the prefabricated house: a truly mass produced product."

On the other hand, Davies, C. (2005, p. 143) states that

..."it is economically out of the question (to emulate car production) unless identical buildings are to be produced in thousands...the necessity for constant adaptation to different site conditions and different use requirement means that, in the end, it is usually cheaper to build in bricks and mortar."

\footnotetext{
${ }^{6}$ Vale, B. $(1995$, p. 6)
} 


\subsection{5. - Mobile structures}

- The Tennessee Valley Authority TV A houses for dam workers

Towne $(1942$, p. 55)

...."The idea of moving houses from one construction site to another has always been a favourite topic of discussion in TVA. In 1938 the discussions bore fruit. Seventy-two houses originally built and used at Pickwick Landing Dam were moved from their foundations to barges, floated 200 miles downstream to the mouth of the Tennessee River to the construction village being built to house workers on the Kentucky Dam."

Towne \& Purnel (1946, p. 57)

..."The basic scheme adopted for making a house mobile was very simple; it was built in large sections, each of which was a load of width, length and height that would permit its safe transportation over a highway. Section lines bore no particular relationship to the floor plan of the house except to avoid door and window openings."

Gray $(1945$, p. 61)

..."Between 1942 and 1944 some 1,627,290 family houses were constructed of which approximately 40 percent were temporary and further 4 percent demountable."

\subsection{6. - Container architecture}

Lot-Ek, Mobile Dwelling Unit is perhaps the first graphic record of shipping containers used in architectural projects. Scoates, Tolla, \& Lignano (2003) describe the concept of M.D.U. or Mobile Dwelling Unit, the transformation of an existing forty foot shipping container into a portable living space, equipped with a series of expandable and retractable sub-volumes.

Kotnik, J. (2008) describes different types of projects linked with the usage of shipping containers. The book is divided into three different categories, these are: Public space, Residential and finally a compilation of Theoretical projects. 


\subsection{7. - Life cycle analysis}

Adalberth, K. (1996, p. 317) defines

..."Life Cycle Analysis of a building applies to all temporal phases or stages, from the point where the construction materials are produced until the building is to be demolished."

Williamson, T. (2002, p. 98) suggests that there are two main methods of analysis related to the environmental impact of a building, one technique called E.I.A. or Environmental Impact Assessment, which is focused on a given site and a given context. On the other hand, the L.C.A. or Life Cycle Analysis, which is centred and formulated for assessing the non-site-specific potential environmental impacts of a product regardless of where, when or who uses it. ${ }^{7}$

Mithraratne, Vale, \& Vale (2007, p. 23) define L.C.A. as ..." a quantitative assessment of resource uses (raw materials and energy) and waste discharges for every step of the life of the products, services, activities and technologies, and thereby provides a way to evaluate and quantify the environmental impacts of a wide range of products and activities. The L.C.A. embraces the entire life, including extraction and processing of row materials, supply of energy, manufacturing, transportation and distribution, use / re-use / maintenance, recycling and final disposal of the product". Depending on the system boundary selected, life cycle analysis is of two kinds:

1. Cradle to grave analysis - analysis of the entire life of a material or product up to the point of disposal.

2. Cradle to cradle analysis - analysis of a material or product the life of which does not end with disposal but which becomes the source of a new product through a recycling process.

\subsection{8. - Comparative life cycle analysis for construction materials}

Eaton \& Amato (1998) reported on two typical modern commercial buildings using life cycle analysis (LCA) methodology to compare the environmental impacts of different steel, composite, reinforced and precast concrete options for the main structure. The study focussed on energy consumption and $\mathrm{CO}_{2}$ emissions as the key environmental parameters.

The study found that there is no significant difference among various types of construction with regard to:

- The initial embodied energy and embodied $\mathrm{CO}_{2}$ emission values.

- The operational embodied energy and operational $\mathrm{CO}_{2}$ emission values.

- The total life cycle energy and $\mathrm{CO}_{2}$ emission values.

\footnotetext{
${ }^{7}$ Williamson, T. (2002, p. 98)
} 
Davies, C. (2005, p. 67) suggests that

..."the big advantage of timber over steel or concrete for prefabrication is that it does not require a large investment in factory plant. One of the most successful British timber-frame systems of the 1970s was Frameform promoted by Riley and Partners."

\subsection{9. - Hypothesis}

According to Davies, C. (2005, p. 9)

..."Prefabrication is nothing new. Parts of buildings have been made in factories for at least 200 years. Machine made bricks, ceramic tiles, sawn timber, sheet glass; sash windows, cast-iron columns and beams all were familiar factory-made products in nineteenth century Europe and America. Whole buildings- houses, hospitasl, churches, factories, barracks- were made in kit form and shipped to colonies and war zones all over the world. Twentieth century examples include the mobile home, the post-war British prefab and container cabins for offshore oil workers."

If prefabrication in architecture has been available for many years:

Why should container architecture contribute to the relationship between prefabrication and architecture?

Could it be possible that container architecture has a positive impact in terms of sustainability?

Could container architecture be more energy efficient than traditional buildings while including two different factors: Urban Quality and Environmental Sustainability at the same time?

Is it possible to enhance energy efficiency in the residential sector of New Zealand by using shipping containers as main components in buildings? 


\subsection{Definition}

Can containers be called architecture?

..."When you cut holes ... (the containers) are no longer an instrument of trade," said David Cross... "They turn into an instrument of construction"... Grant, A. (2008, p. 1)

Container architecture might be preliminarily defined as all of those projects of architecture that use shipping containers as an instrument of construction. This can be done in many ways: partial, total or mixed structures.

Why were containers designed and what is their primary purpose? Steel boxes are instruments of trade designed to carry goods from point A to point B, to be lifted, stacked and loaded in ships, railway wagons and trucks and the shipping container's success is the outcome of form, geometry, dimensions, size and the proper use of materials. Containers are designed to protect merchandise from inclement weather conditions, to prevent the exposure to the elements of the internal content.

Considering the design intent and purpose of containers, are they suitable for architectural use and can they satisfy the whole spectrum of customer demands to the same quality as "standard" constructions?

This research will discuss the Life Cycle Analysis of projects linked with shipping containers. In addition, they will be compared with traditional residential structures made up of timber and concrete to determine the advantages and disadvantages of the new system.

Key environmental parameters will be the energy consumption and $\mathrm{CO}_{2}$ emission through the lifespan of a building. Embodied energy of the components and operational energy will also be assessed. 


\subsection{History}

Today container architecture might represent a new option in structural design, an avantgarde approach for some professionals or the architectural development of new building technologies and new materials in order to improve the performance of the minimum dwelling. However, it is a simple predilection for others. Unfortunately container buildings are something completely new and its history goes back only to recent years.

\subsection{Advantages}

- Strength and durability: containers are largely made of steel, aluminium, FRP Fiberglass Reinforced Plastic or reinforced wood. ${ }^{8}$

- Modular: ISO Containers possess an arithmetic relationship.

- Transportable: they are the core of the intermodal system of transport.

- Availability: containers are practically everywhere. On the other hand, imbalance of trade could contribute to the shortage or surplus of them depending on country to country and city to city.

- Cost: due to their mass production new and used shipping containers are relatively cheap.

\subsection{Disadvantages}

- Temperature: low insulation: Containers in their standard form are prone to condensation.

- Labour: cutting steel requires specialised workers and sometimes residential contractors are not used to using special machinery such as cranes.

- Construction site: steel boxes are generally better suited to be in flat than sloping sites.

- Building permits: most of the time buildings that use cargo containers are evaluated as non-standard structures which mean more paperwork.

- Treatment of timber floors: the floor is treated against insects and smells nasty.

- Cargo spillages: many of them carry toxic substances.

- Solvents: some solvents and sealant are used that can be harmful for human health.

\footnotetext{
${ }^{8}$ Burg., G. V. (1975, pp. 64-65)
} 


\subsection{Classification criteria.}

The scope of this research aims to explore the implication of container architecture in the residential sector. In order to achieve this and organise all the documents in the best possible way, three different classifications are given.

This first organisation in accordance with the architectural program proposed by Kotnik, J. (2008) in his book "Container Architecture". Here, the projects are classified in three main displays.

1. Non residential or Public buildings: temporary structures, travelling expositions, schools, restaurants

2. Residential sector: Houses / small workshops, student accommodation

3. Prototypes, portable units, mobile dwellings, emergency housing

However, regardless of the differences in the architectural program, all projects are shown randomly, making it hard to trace them in many ways. For instance, there is a lack of appropriate criteria in the categorisation and subsequent presentation of all samples of buildings.

This led to the creation of four proposed categorisations:

- Classification according to the type of structure

1. Steel or "standard" structures

2. Hybrid structures

- Classification according to the scale

1. Small projects

2. Large projects

- Classification according to locations.

- Classification according to weather conditions or climate zones. 


\subsection{Examples of container architecture}

This chapter presents a total of 21 different projects that use steel boxes. Most of them are linked with the residential sector.

Table $\mathrm{N}^{\circ} 1$ (next page) shows the thirteen residential projects located in different places around the world.

The table is divided into seven columns: the first makes reference to the name of each project followed by location. The third column is the weather code for each case study followed by the explanation of the climate zones. The fifth column shows the number of shipping containers used, this is important because it illustrates the wide variety of boxes employed from 2- minimum- to 1,056 -the maximum. Finally, the last two columns present the architectural program and year of completion.

The first project corresponds to the Stevens Container House, located in New Zealand. The rest of the examples are organised by country. Samples 2-3-4-5 are located in the U.S. Meanwhile, samples 6-7 are in Canada. Cases 8-9-10-11-12 and 13 are sited in Europe. The second criterion is linked with weather conditions, from the coldest place to the warmer place. Finally criterion is the year of construction.

Image $\mathrm{N}^{\circ} 1$ shows the climate world map. According to (www.boqueteweather.com) World climate patterns are typically classified with the Köppen Climate Classification Scheme using average annual temperature and precipitation data. 


\subsection{1. - Residential structures}

\begin{tabular}{|c|c|c|c|c|c|c|c|}
\hline & Project's Name & Place & climate & Climate Zone & $\mathrm{N}^{\circ}$ of shipping & Program & Year \\
\hline & & & code & & containers & & \\
\hline \multirow[t]{3}{*}{1} & Stevens Container House & Wellington & Cfb & Humid temperate climate & 3 & Residence & 2006 \\
\hline & & New Zealand & & No dry season & 40-foot & & \\
\hline & & & & Cool Summer & & & \\
\hline \multirow[t]{3}{*}{2} & 12 Container House & Brooklyn & Dfb & Humid cold climate & 12 & $\begin{array}{c}\text { Temporary } \\
\text { house }\end{array}$ & 2002 \\
\hline & & Maine & & No dry season & 20-foot & & \\
\hline & & U.S.A. & & Cool Summer & & & \\
\hline \multirow[t]{3}{*}{3} & Stankey Cabin & Holyoke & Dfb & Humid cold climate & 2 & $\begin{array}{c}\text { Temporary } \\
\text { house }\end{array}$ & 2006 \\
\hline & & Minnesota & & No dry season & 20-foot & & \\
\hline & & U.S.A. & & Cool Summer & & & \\
\hline \multirow[t]{3}{*}{4} & C 320 Studio & Seattle & Cfb & Humid temperate climate & 2 & $\begin{array}{c}\text { Temporary } \\
\text { house }\end{array}$ & 2004 \\
\hline & & U.S.A. & & No dry season & 20-foot & & \\
\hline & & & & Cool Summer & & & \\
\hline \multirow[t]{4}{*}{5} & Redondo Beach House & Redondo Beach & Bsh & Dry climate & 9 & Residence & 2007 \\
\hline & & California & & Semiarid & (4) 20 -foot & & \\
\hline & & U.S.A. & & Hot & (2) 30 -foot & & \\
\hline & & & & & (3) 40 -foot & & \\
\hline \multirow[t]{3}{*}{6} & Chalet Du Chemin Brochu & Quebec & Dfb & Humid cold climate & 3 & Residence & 2006 \\
\hline & & Canada & & No dry season & 40-foot & & \\
\hline & & & & Cool Summer & & & \\
\hline \multirow[t]{3}{*}{7} & Zigloo & Victoria $\mathrm{BC}$ & Cfb & Humid temperate climate & 8 & Residence & 2006 \\
\hline & & Canada & & No dry season & 20-foot & & \\
\hline & & & & Cool Summer & & & \\
\hline \multirow[t]{3}{*}{8} & Cubes & Peaton Hill & Cfb & Humid temperate climate & 6 & $\begin{array}{c}\text { Temporary } \\
\text { house }\end{array}$ & 2002 \\
\hline & & Scotland & & No dry season & 20-foot & artists & \\
\hline & & & & Cool Summer & & & \\
\hline \multirow[t]{3}{*}{9} & Container City I & London & Cfb & Humid temperate climate & 20 & Residence & 2001 \\
\hline & & U.K. & & No dry season & 40-foot & artists & \\
\hline & & & & Cool Summer & & & \\
\hline \multirow[t]{3}{*}{10} & Container City II & London & Cfb & Humid temperate climate & 30 & Residence & 2002 \\
\hline & & U.K. & & No dry season & 40-foot & artists & \\
\hline & & & & Cool Summer & & & \\
\hline \multirow[t]{3}{*}{11} & The Riverside Building & London & Cfb & Humid temperate climate & 73 & Residence & 2005 \\
\hline & & U.K. & & No dry season & 40-foot & Offices & \\
\hline & & & & Cool Summer & & & \\
\hline \multirow[t]{3}{*}{12} & Qubic Houthavens & Amsterdam & Cfb & Humid temperate climate & 1,005 & Student & 2005 \\
\hline & & The Netherlands & & No dry season & 40-foot & accommodation & \\
\hline & & & & Cool Summer & & & \\
\hline \multirow[t]{3}{*}{13} & Tempohousing Keetwonen & Amsterdam & Cfb & Humid temperate climate & 1,056 & Student & 2005 \\
\hline & & The Netherlands & & No dry season & 40-foot & accommodation & \\
\hline & & & & Cool Summer & & & \\
\hline
\end{tabular}


Figure $\mathrm{N}^{\circ} 2$ World Climate Map

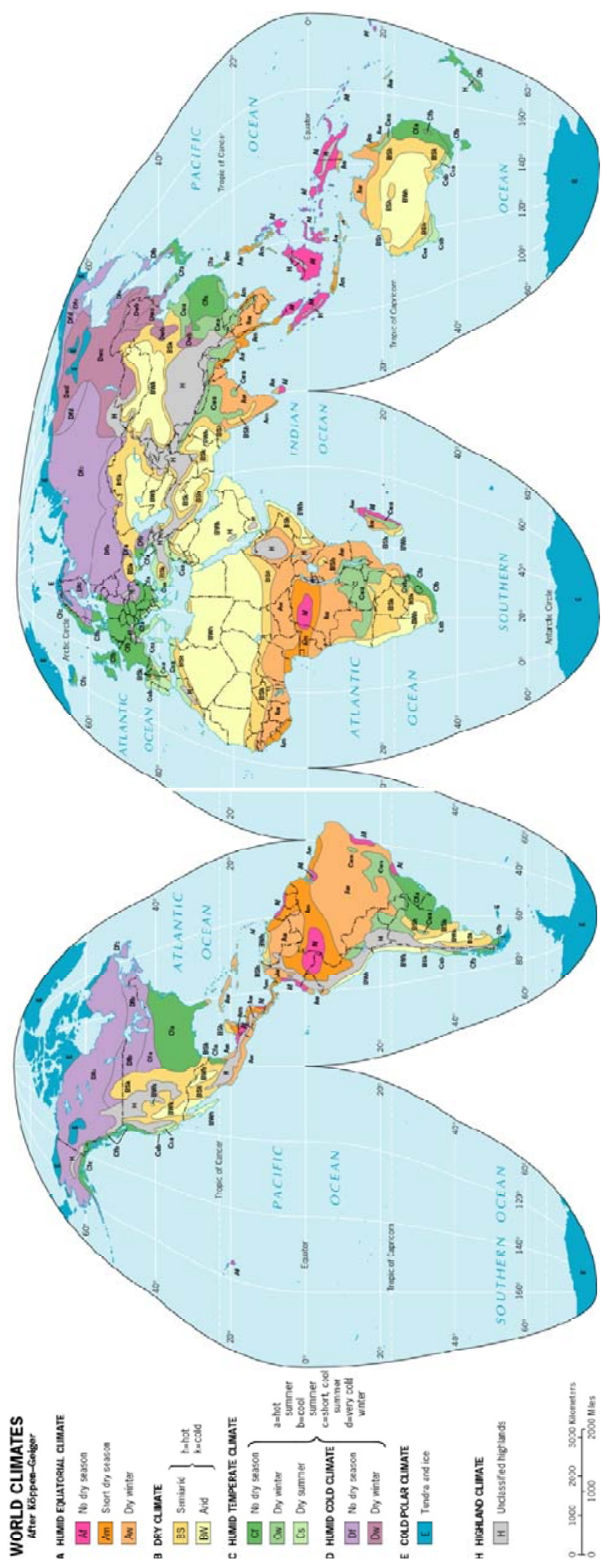

Image source: $\underline{w w w}$.boqueteweather.com/climate article.htm 
Stevens Container House

A purist and simple building, the Stevens container house is perhaps the most relevant and important example of shipping container dwellings in Wellington and New Zealand of the current time.

Located in Happy Valley Road, Wellington -near to the rubbish dump- the residence takes advantage of a geographic accident of the hill and the house is encompassed by a big rock which acts like a natural limit.

Made up by three refrigerated 40-foot shipping containers the program is divided into four levels, the first one being the basement -garage at street level-a steel structure and a concrete slab which supports the rest of the building.

The first level contains the public spaces, living, kitchen a small toilet and an intermediate space between the container and the rock. Vertical circulation is placed in an external corridor. The second level includes two bedrooms and an inner spiral stair which connects the second with the third levels from the interior. The final deck holds two more bedrooms.

From an engineering point of view the building is highly sensitive because it utilises the existing structure of the containers by positioning the volumes to transmit loads directly into their intended connection points.

This building will be one of the three case studies and will be assessed thoroughly in a future chapter nine.

There are some issues linked with energy consumption, which will also be discussed in chapter nine.

Image source: Figures N³-4-5-6 Retrieved on 31 $1^{\text {st }}$ March 2010 from

http://www.flickr.com/photos/petraalsbach/sets/721575945723 87467/show/with/413364835
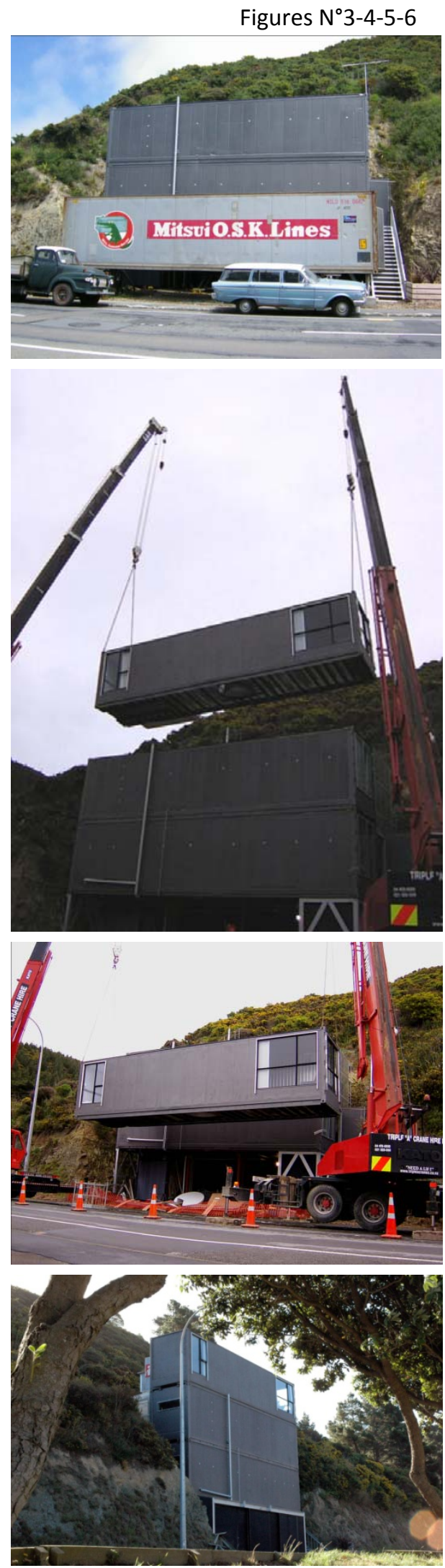


\section{Container house}

Kalkin is an architect experienced in the world of shipping container construction.

Nine different projects are shown on his website www.architectureandhygiene.com. He has self published a number of books.

Built in 2003, this summer home is located in Brooklyn Maine, United States, for this particular structure twelve 20-foot freight containers were used.

Made of concrete floor, with symmetric " $\mathrm{T}$ " shape organisation, the residence is divided into five main parts. A hierarchical space is composed using eight containers minored across a central living space. Two containers form an L-shape two containers high in each side of the dwelling.

The public area is placed on the first level and this space is defined by the modularity of the container itself, giving 20-foot width between the boxes and 48 foot length. Moreover, this section is enclosed by transversal steel roof structure beam and may be covered with a corrugated steel cladding.

Local weather conditions consist of a humid cold climate with no dry season and cool summer.

Despite the fact that this project has been published in a wide diversity of media, there is no technical information of the building that can help to the reader to understand the construction process and the life cycle assessment of this example.

Image source: http://designcrave.com/2009-06-22/10brilliant-boxy-and-sustainable-shipping-container-homes/

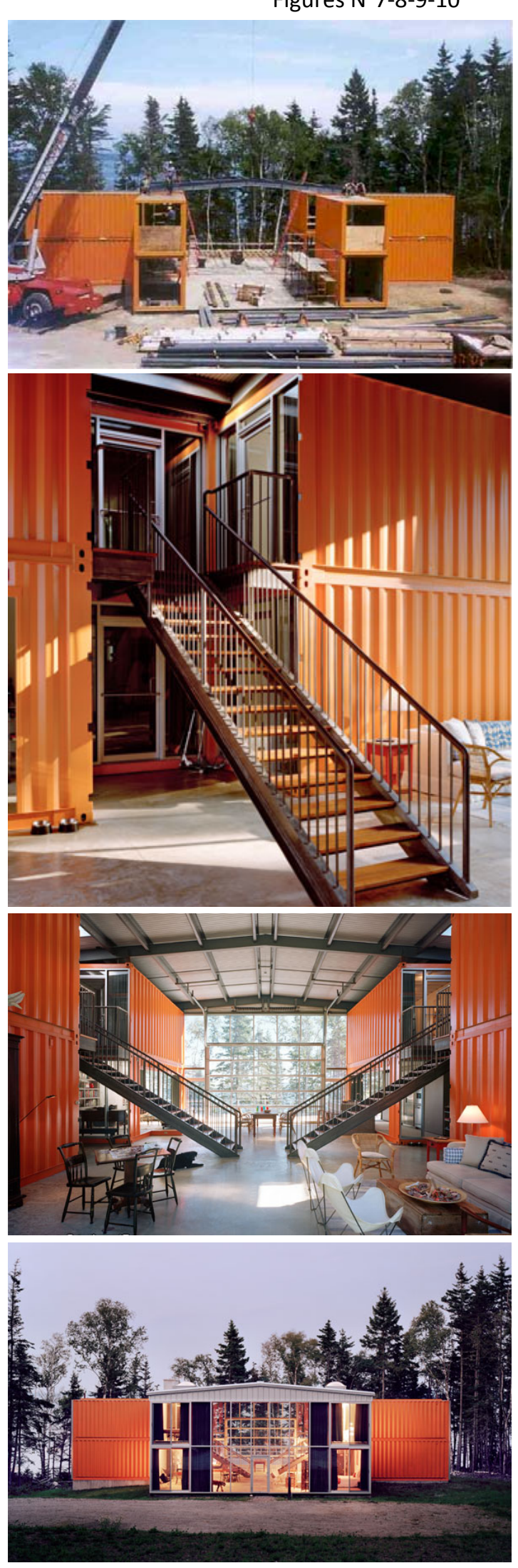


Stankey Cabin

Stankey Cabin is a temporary house located in Holyoke Minnesota United States and built in 2006. The cabin consists of two 20-foot used containers spaced out and connected by a two level glazed space. ${ }^{9}$

Many of the projects shown in this research are related in several ways to port cities or most of them are located in areas close to the Ocean. In this scenario: How much energy would be needed in order to transport a used shipping container from main ports?

Holyoke Minnesota is a small town located up north of the United States, close to Canada, $1,562 \mathrm{~km}$. from Atlanta, 1,606 km from New York and 2,581km from Los Angeles, ${ }^{10}$ cities which have the most important supply of freight containers among the U.S. ${ }^{11}$

On the other hand, a quotation provides one of the owner's opinion: "The cabin is partially powered by solar power arrays and connected to a rainwater cistern making this building an ecologically sustainable vacation home."12

Image source: Container Architecture (Kotnik, 2008, pp. 136,138)

\footnotetext{
${ }^{9}$ Kotnik, J. (2008, p. 137)

${ }^{10}$ (www.geobytes.com)

${ }^{11}$ Levinson, M. (2006)

${ }^{12}$ (www.openarchitecturenetwork.org)
}

Figures $\mathrm{N}^{\circ} 11-12$

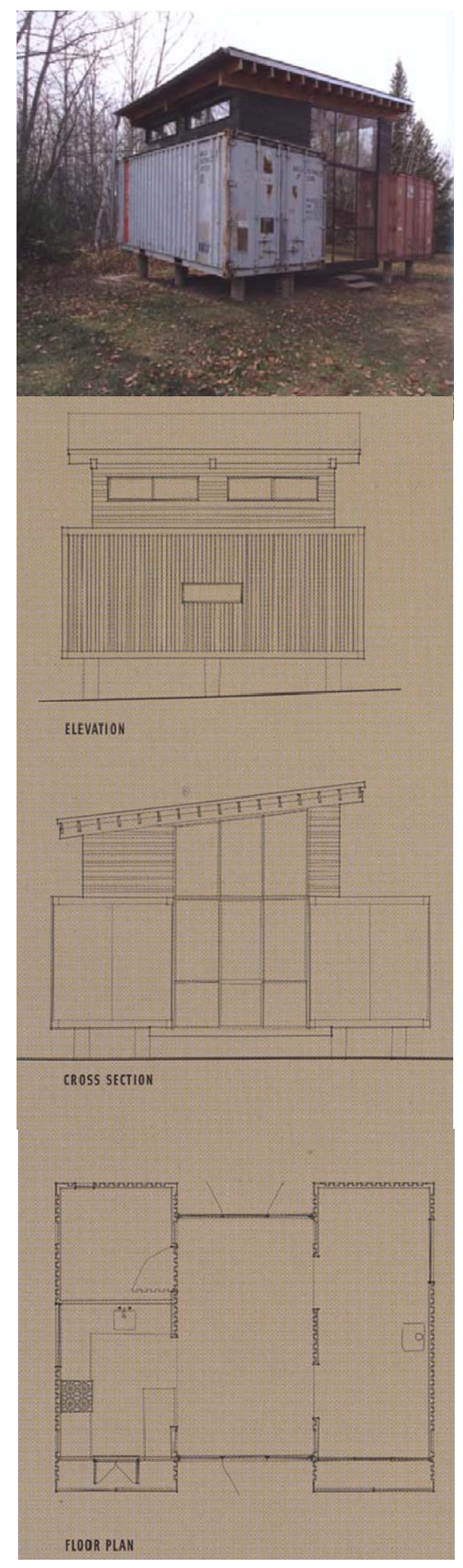


C320 Studio

Figures $\mathrm{N}^{\circ} 13-14-15-16$

C320 Studio is located in Seattle, U.S. and its weather presents similar conditions to Wellington, a humid temperate climate with no dry season and a cold summer.

The building is organised using a horizontal distribution, allowing the opportunity to displace the volume which determines the areas of hygiene, cooking and sleeping.

From an engineering point of view, horizontal lay-outs permit certain degrees of liberty in the formal design of the space, because no vertical loads are present from above.

According to the AIA (American Institute of Architects) Seattle the building had an estimated cost of $\$ 24,000$ USD estimated and excluding the price of the land.

The container itself had a cost of $\$ 1,800$ USD and it took forty five days to fabricate the studiodwelling. The foundations were built of pre-cast concrete footings. The installation took less than one day. ${ }^{13}$
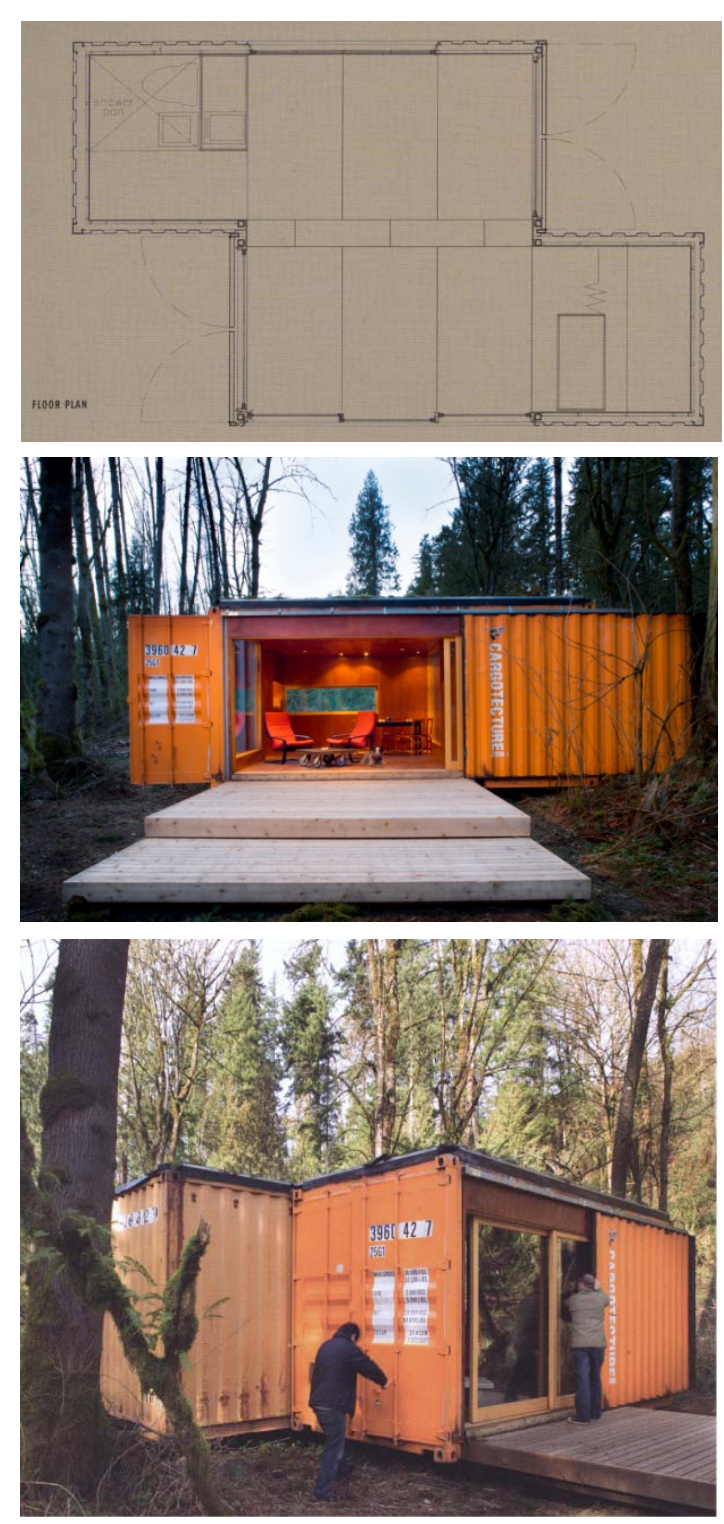

Image source: Container Architecture Kotnik, J. (2008, pp. 130-133).

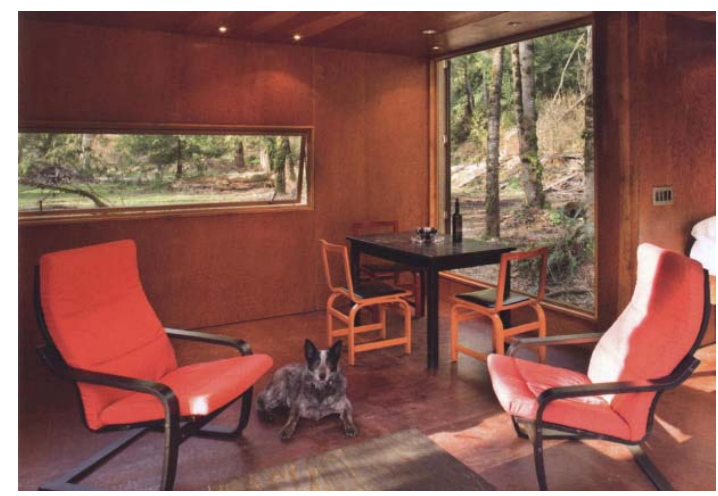

${ }^{13}$ (www.openarchitecturenetwork.org) 
Redondo Beach House

Figures $\mathrm{N}^{\circ} 17-18$

U.S. national's massive trade deficit with China and other countries produces hundreds of thousands of shipping containers that have to be piled up and kept in storage all over the country. ${ }^{14}$

This economic imbalance may have motivated a chain reaction in where customers, designers, architects and engineers of the United States search new uses for this surplus of materials because of the potential low priced of used empty shipping containers in the construction sector.

Redondo Beach House represents one of the first houses that use shipping containers, a hybrid between concrete and steel. Using 9 cargo-containers in total and 3 different types, four of them are 20foot, other two 30-foot and finally three of 40-foot.

Among the rest of the buildings situated in the United States, Redondo Beach House is located in the warmest place, California.

There are some considerations that need to be counted. The house is located near to the San Andreas Fault, and weather condition corresponds to a dry climate, semiarid and hot summer season.

Image source: Container Architecture Kotnik, J. (2008, p. 162) Figure $\mathrm{N}^{\circ} 18$.
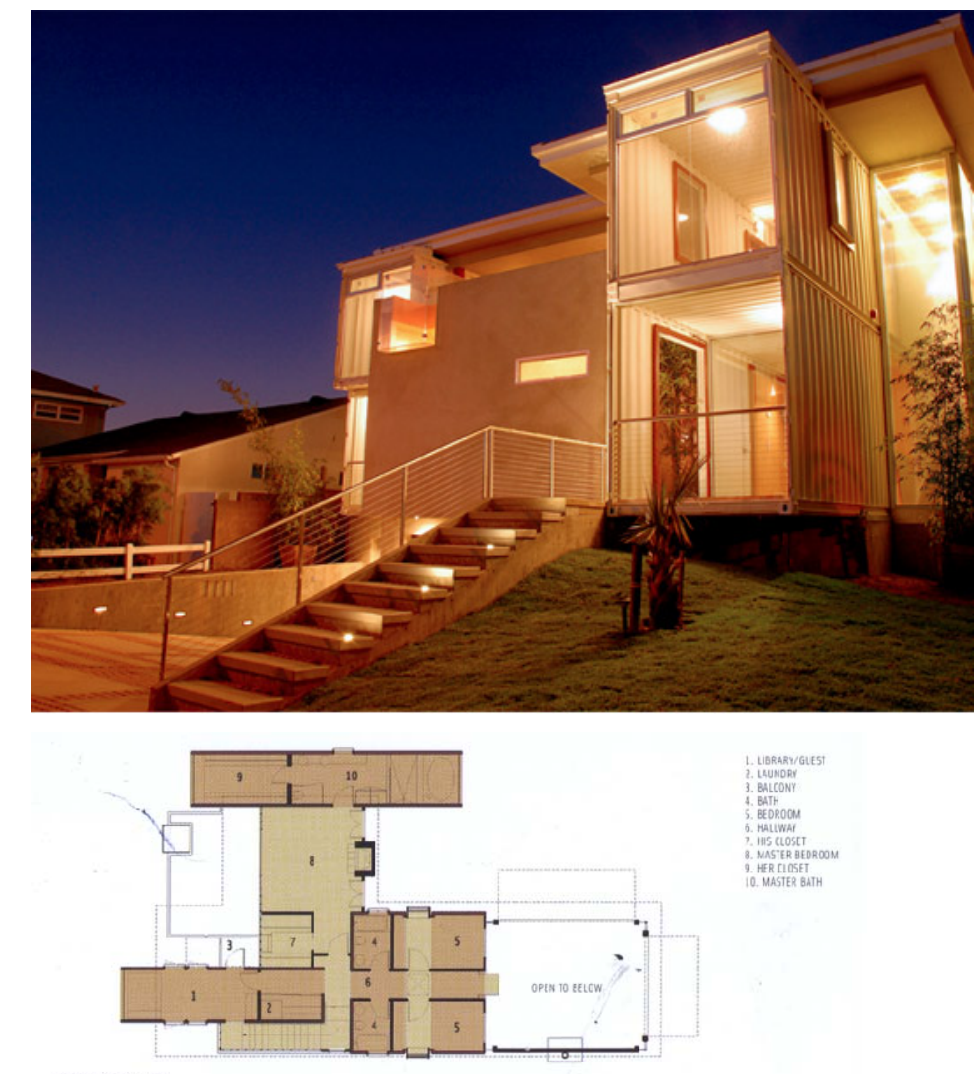

FIRST ILOOR PLAY
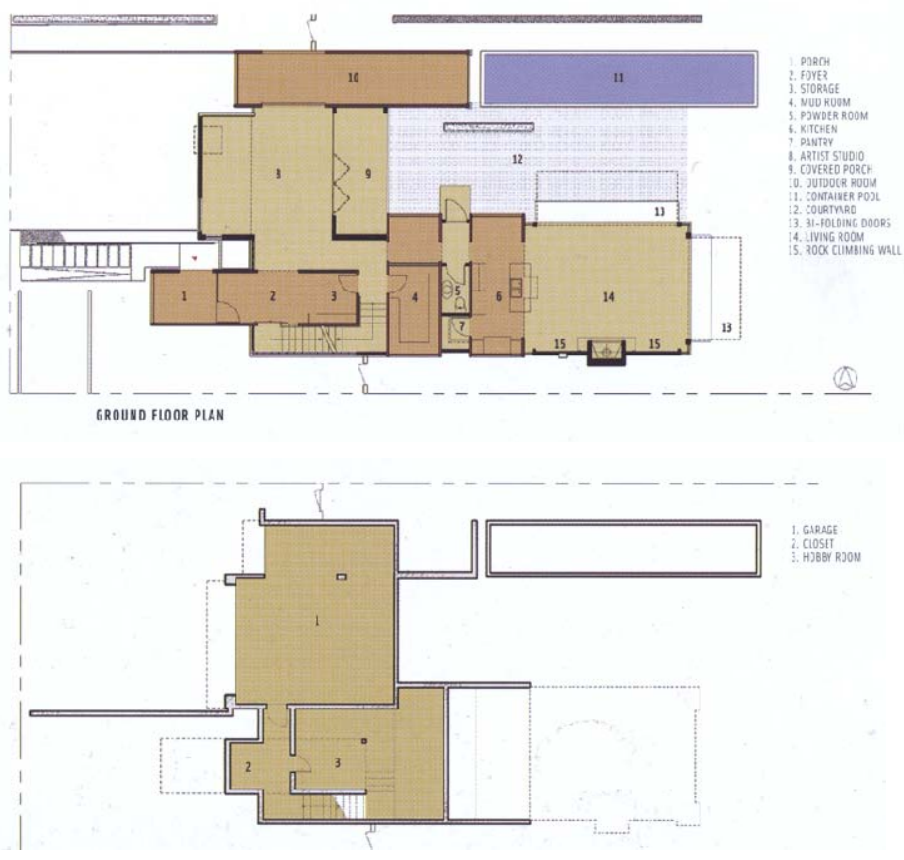

14(www.youtube.com) 
Redondo Beach House

Figures $N^{\circ} 19-20$

\section{Formal style}

The complexity of this particular case resides in the interpretation that can be done. Standard or non standard, this is the question. The house may be a duality. Flat and corrugated walls, concrete and steel, large glassed areas, wooden window frames.

Based on the photographs, most of the projects shown in this paper have the same language, the same constructive elements. But the example shown in this page is different; it looks like the containers were added into the façade randomly.

Image source: Container Architecture (Kotnik, 2008, p. 163) Figure $N^{\circ} 20$.
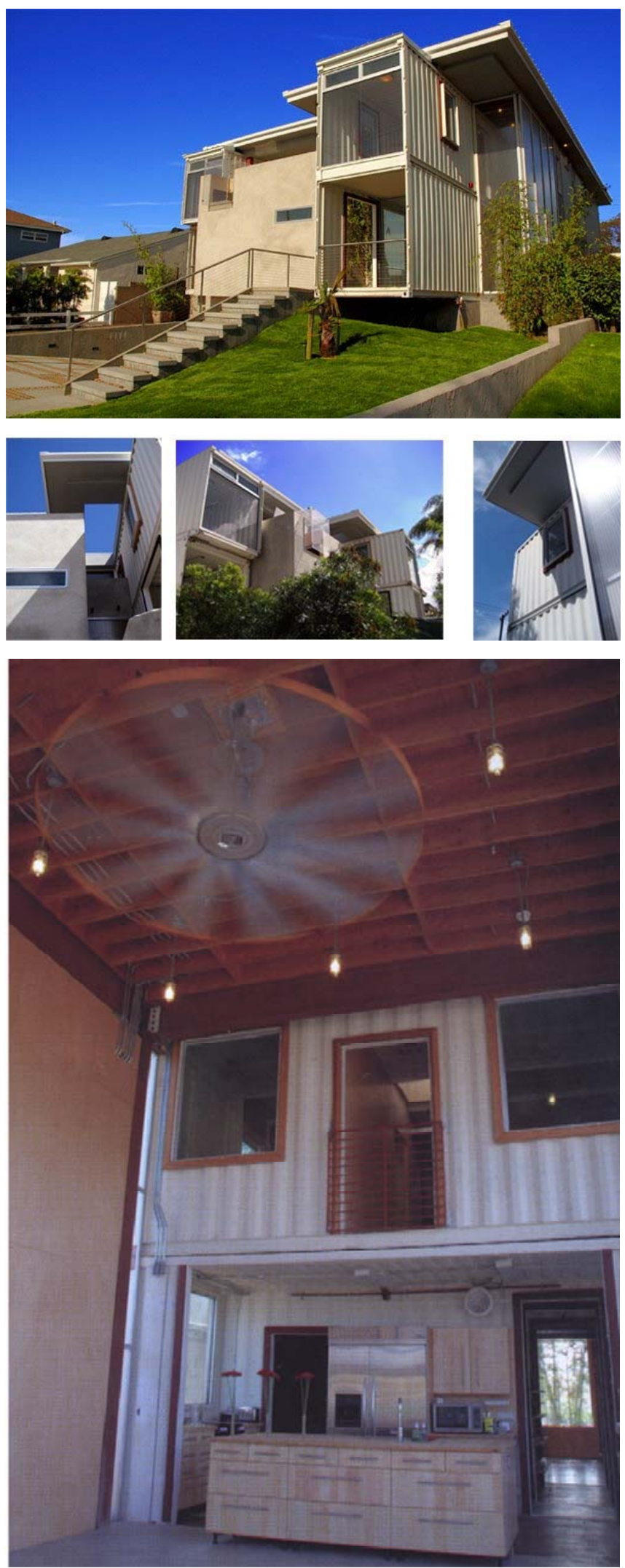
Chalet Du Chemin Brochu, Québec Canada.

Figures $N^{\circ} 21-22-23$

Another example of hybrid construction, in this case, a timber layer enfolds the container structure hiding it from the outside view. This operation may have two or more interpretations. On the one hand, thermal insulation is needed due to the characteristics of the weather in that area and, on the other hand an aesthetic solution is designed in order to avoid the exposure of the corrugated walls. The house is made up using three recycled shipping containers painted black.

\section{Enclosure}

The bungalow has three different layers; the exterior is covered with timber panels, underneath are the black steel containers, while the inner space has another wooden coating. The structure is supported by a basement made of concrete. ${ }^{15}$

The ground floor of the dwelling is made up by two 40foot steel boxes and they are separated by a central corridor, an inner circulation route made of wood which connects them. Functions are placed on the ground floor: The kitchen, dining room and living room. ${ }^{16}$

Image source: Container Architecture Kotnik, J. (2008, pp. 154-155156-157) Figures $\mathrm{N}^{\circ} 21-22-23$.

\footnotetext{
${ }^{15}$ Kotnik, J. (2008, p. 155)

${ }^{16}$ Ibid
}
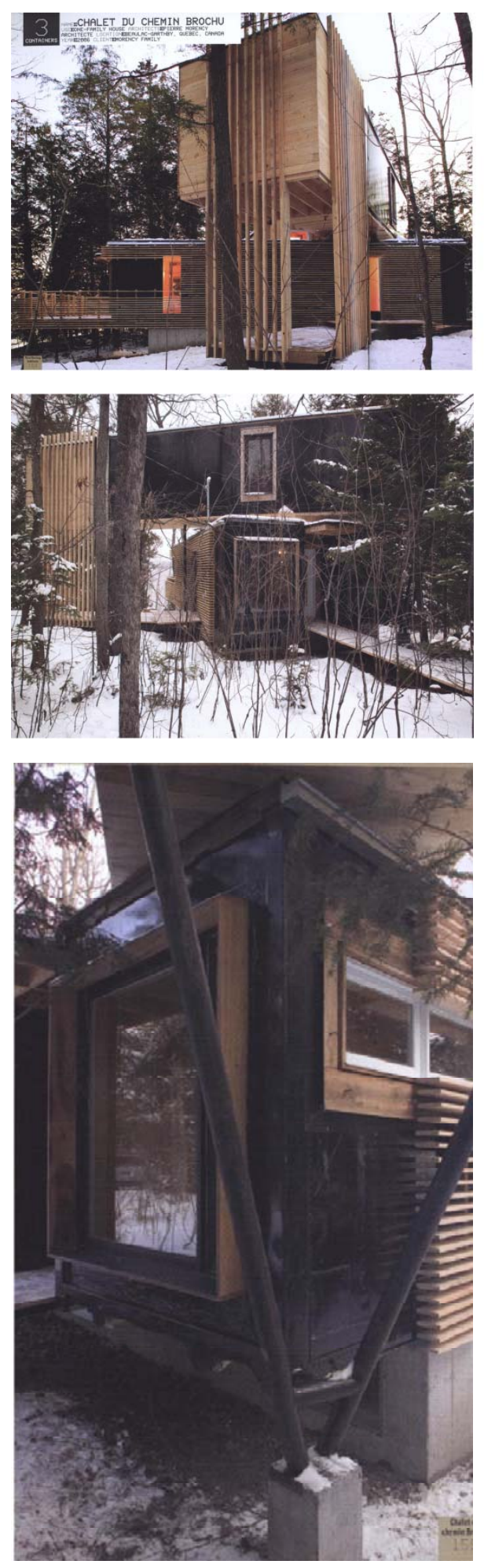
Figure $N^{\circ} 24$

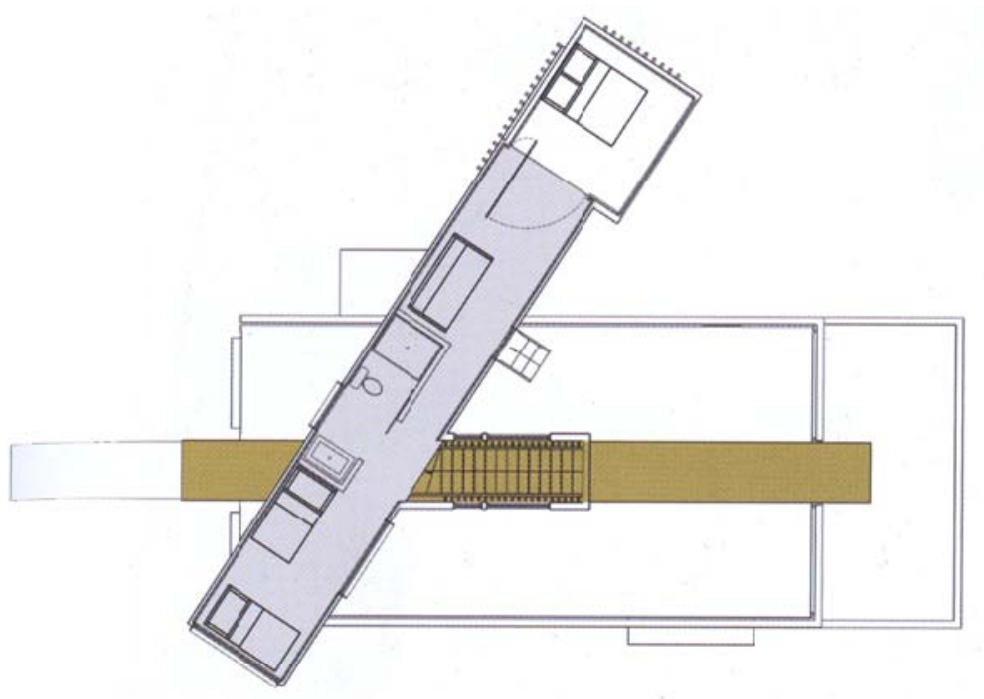

FIRST FLOOR
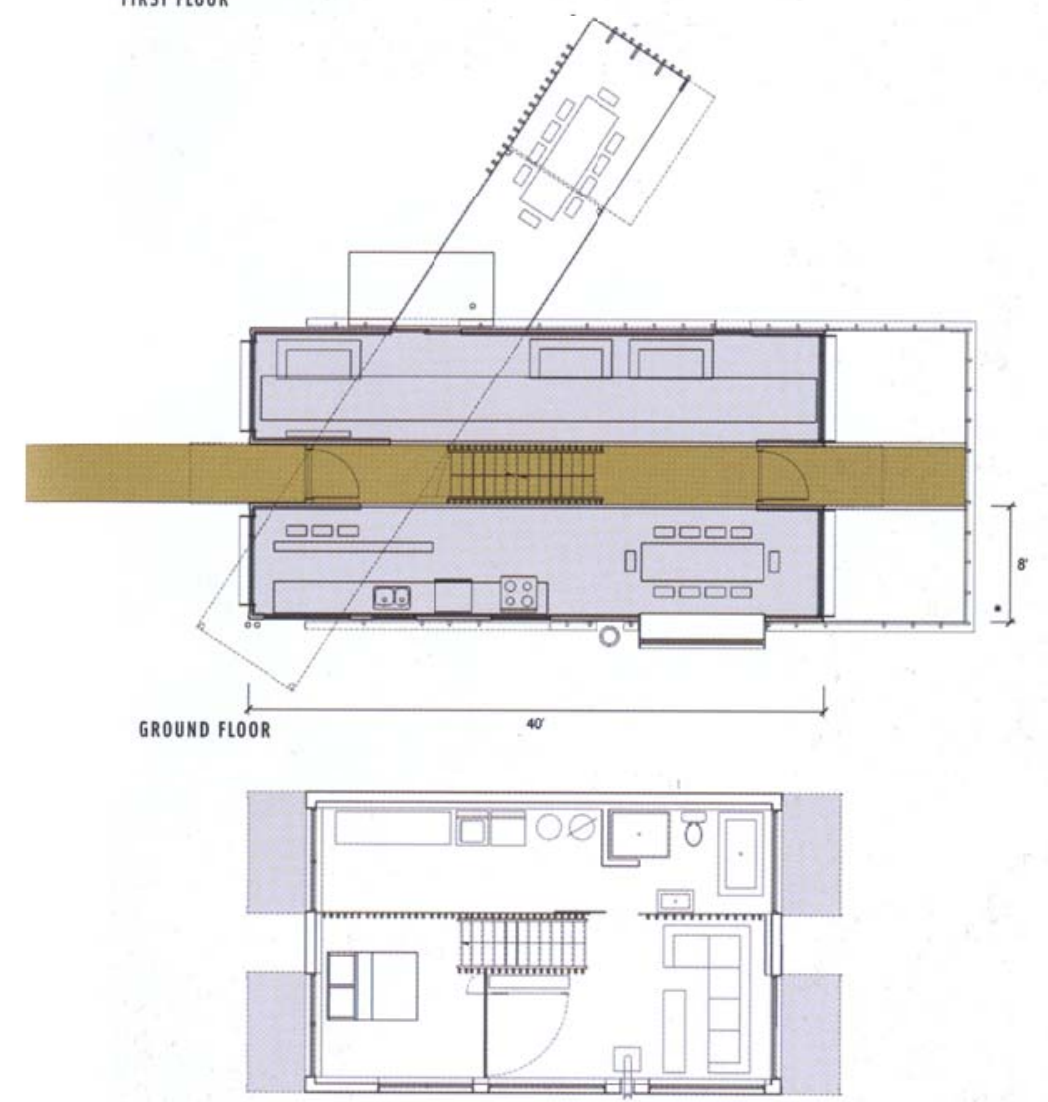

BASEMENT FLOOR

Image source: Container Architecture (Kotnik, 2008, p. 157) Figure N²4. 
Zigloo

Figures N²5-26-27-28

Zigloo is located in Victoria B.C., in Canada near to Vancouver. Weather conditions are a humid temperate climate, no dry season and cool summer. In addition, eight 20-foot freight containers were used to build this house.

According to architect Keith Dewey, Zigloo cost \$ 150 USD per square foot $\left(0.09 \mathrm{~m}^{2}\right)$.

In figure number 25 above, it can be seen that the structure was reinforced following the perimeter of the shipping containers (black beams) this has various effects:

1. Acoustic and thermal insulation can be achieved.

2. Plumbing can be set up between storeys

Traditional wooden structure for ceiling was used.

No technical data was available and construction process is unclear.

Image source: (www.zigloo.ca) Figures $\mathrm{N}^{\circ} 25-26$ and 27.

Image source: Container Architecture Kotnik, J. (2008, pp. 144-145) Figure N²8.
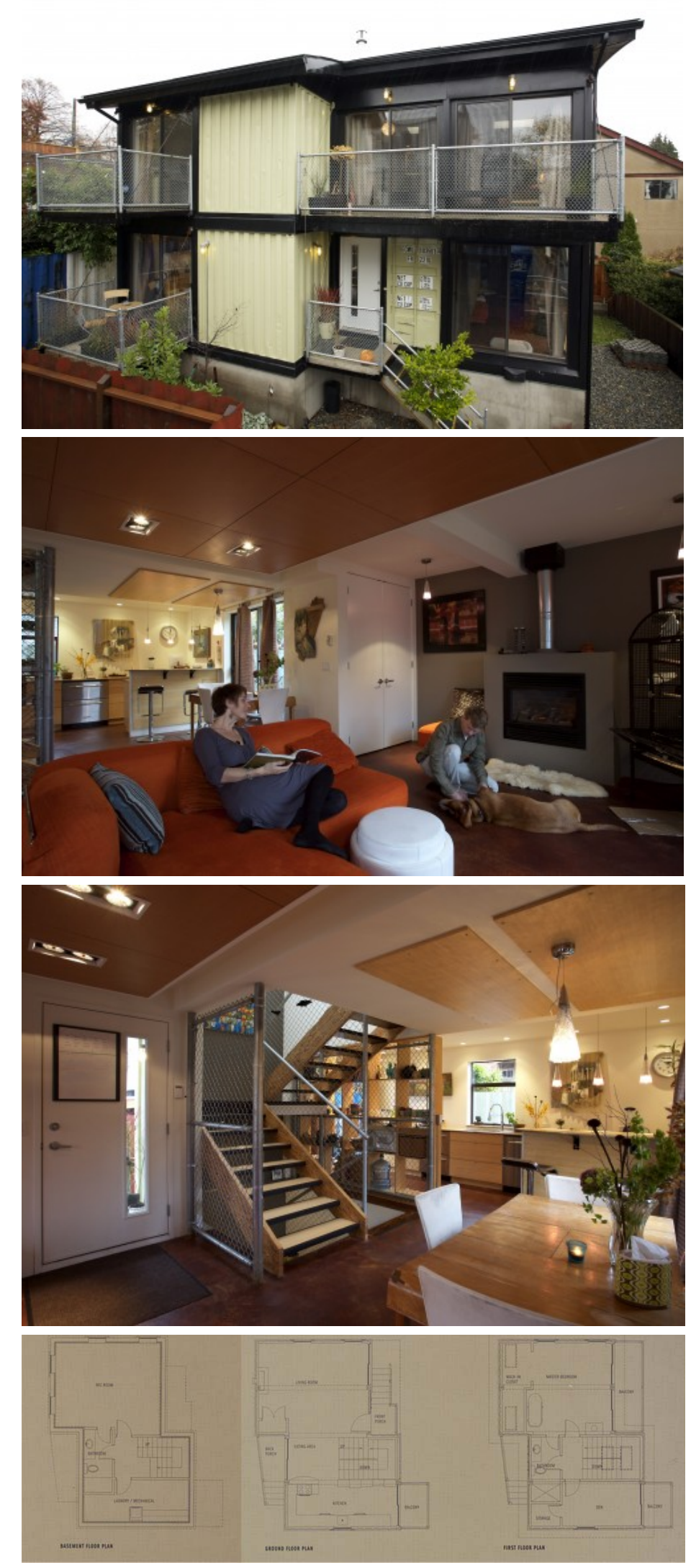
Cove Park is an international arts centre, located on the West Coast of Scotland and built in 2002. ${ }^{17}$ This project holds six 20foot freight containers and is arranged in three units, created as artist retreats. ${ }^{18}$ The units are connected and separated by standard container doors. ${ }^{19}$ According to (www.openarchitecturenetwork.org) each unit provides kitchen, sitting, bedroom and bathroom with shower spaces. The project is sited at the edge of Loch Long and each unit offers two sets of sliding glass doors that permit views and allow access to a balcony overlooking the lake.

The Köppen climate classification of Scotland is Cfb which means that it has a humid temperate climate with no dry season and a cool summer, similar to New Zealand.

This comparison arises in the fact that how the facade is modified, it seems to be a correct decision to take advantage of the corner posts in the rear end frame and use this surface to put the glassed area. Interesting also is the use of circular windows, which may have an advantage over standard windows in maintaining the structural integrity of the container.

In addition, according to (www.shippingcontainerarchitecture.com) due to the success of the first three units, three more have been commissioned. No technical data was found.
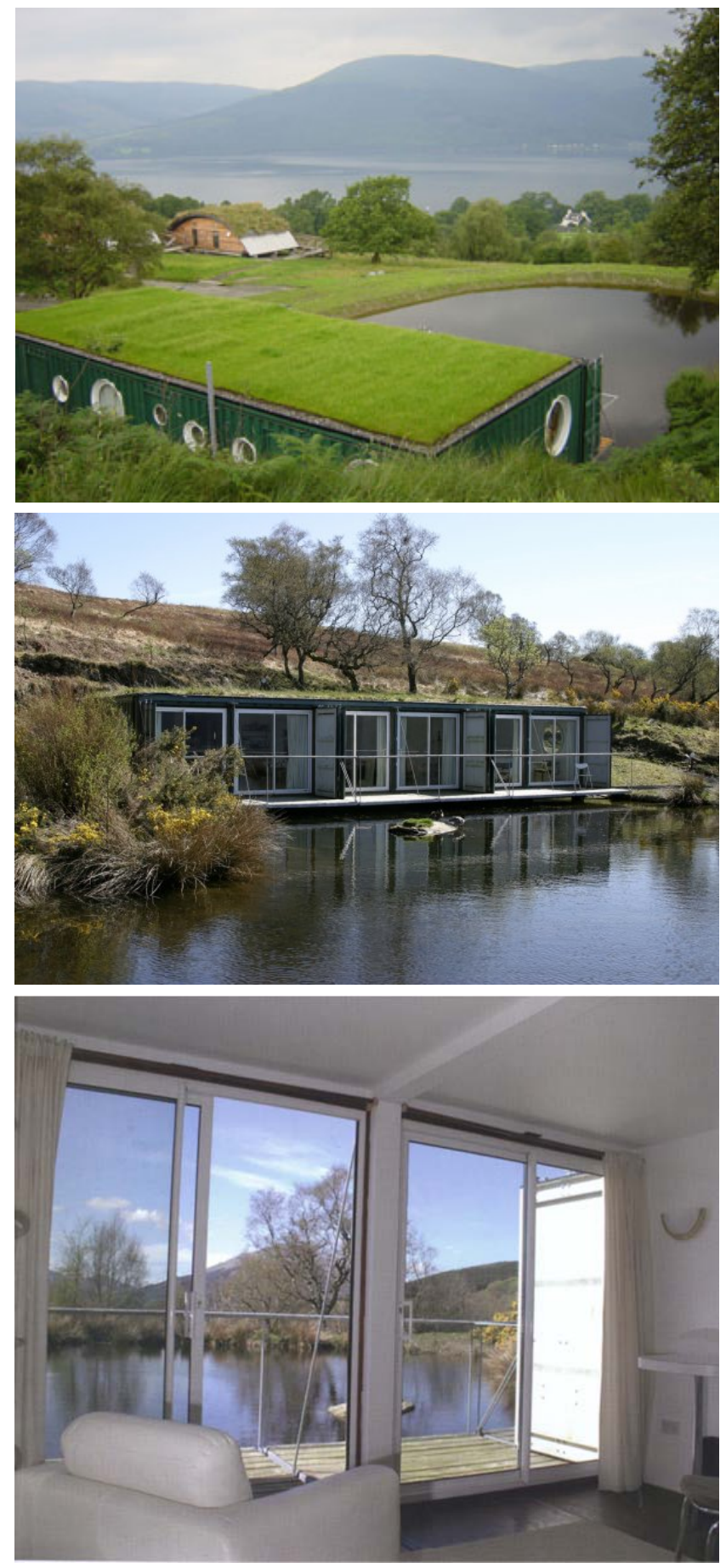

\footnotetext{
${ }^{17}$ Kotnik, J. (2008, p. 125)

${ }^{18}$ (www.shippingcontainerarchitecture.com)

${ }^{19}$ Kotnik, J. (2008, p. 125)
} 
Container city

This Lego city was built in 2001 and located in the dock area of London. The project is made up using twenty 20 -foot shipping containers. ${ }^{20}$

Technical data is given:

The containers are made of "corten" steel, the steel panels, walls and roof are all $2 \mathrm{~mm}$ thick. ${ }^{21}$

According to (www.zen.co.uk)

Planning: In the UK planning permission is required for any development involved.

Spaces: containers have been combined by stacking them and taking out the internal walls. Thus, the range of spaces created varies by 16, 24 or 32 foot wide rooms.

Fitting: any bathroom, toilet or kitchen can be included.

Stacking: when the containers are empty they can support 10 containers stacked up. This project has 5 storeys.

Engineering: the company has created a system which ensures that engineering problems are solved; this includes stresses, wind loads and foundations.

Construction:

Foundations: Pad foundations are needed at the nodes rather than deep piling. Typically a depth of $300 \mathrm{~mm}$ is needed depending on the ground conditions.

Services: It is recommended that electricity is used for heating.

Windows: using a circular window has a sensible engineering reason. No stress is put on the structure. But other shapes can be used.

Roof: for waterproofing, a flat roof with external insulation -the cheapest- or an industrial roof finish with integral insulation.

Insulation: the insulation is installed inside the external cladding and behind the plasterboard.
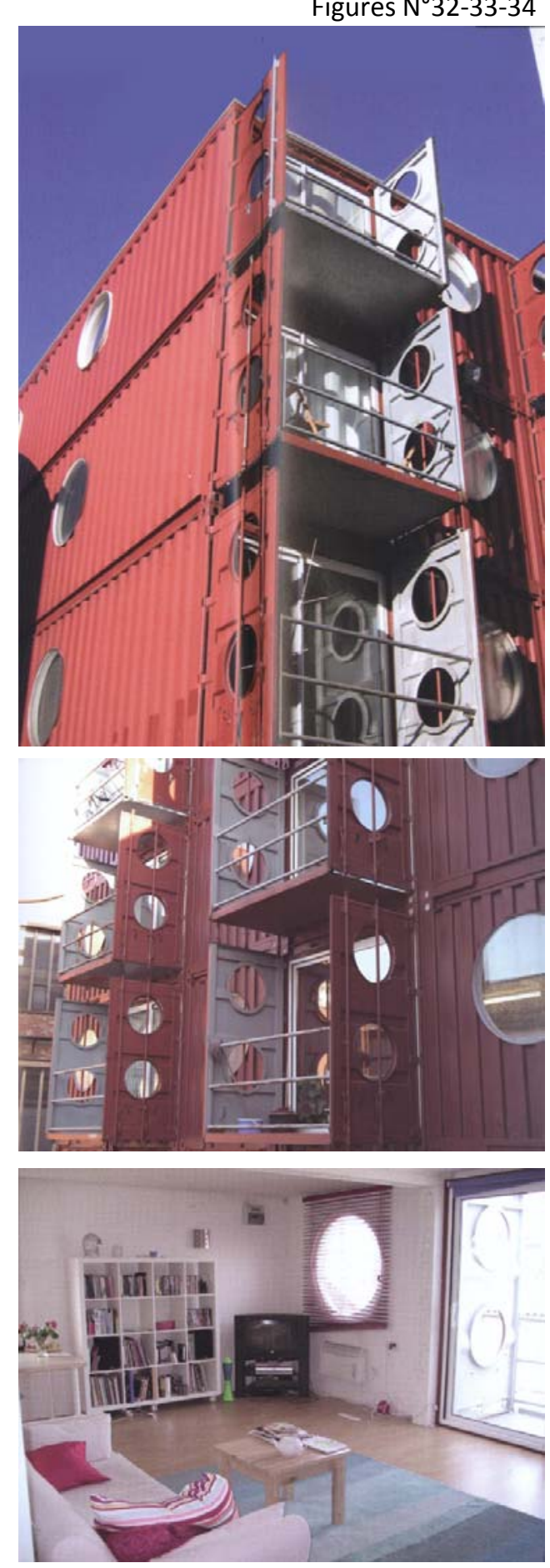

\footnotetext{
${ }^{20}$ Kotnik, J. (2008, p. 171)

${ }^{21}$ (www.zen.co.uk)
} 


\section{Container city II}

An icon, highly published and promoted, container city may be one of the most important buildings made of steel shipping trade boxes.

This project corresponds to the second stage, according

(www.containercity.com) "is both an extension and evolution" of the original container city. Finished in 2002 this structure is located adjacent to the first building. Thirty 40 -foot containers were used and 22 units were created. Installation time was completed in 8 days. $^{22}$

As can be seen in picture $\mathrm{N}^{\circ} 35$ above, steel posts were added in order to bear the projection of the unit (yellow and pale blue containers) on both sides of the building; the same might have been done for the second level in order to avoid stresses and torsion due to wind loads.

Image $\mathrm{N}^{\circ} 36$ shows that even doors at the end were used to generate a new space, a small balcony.
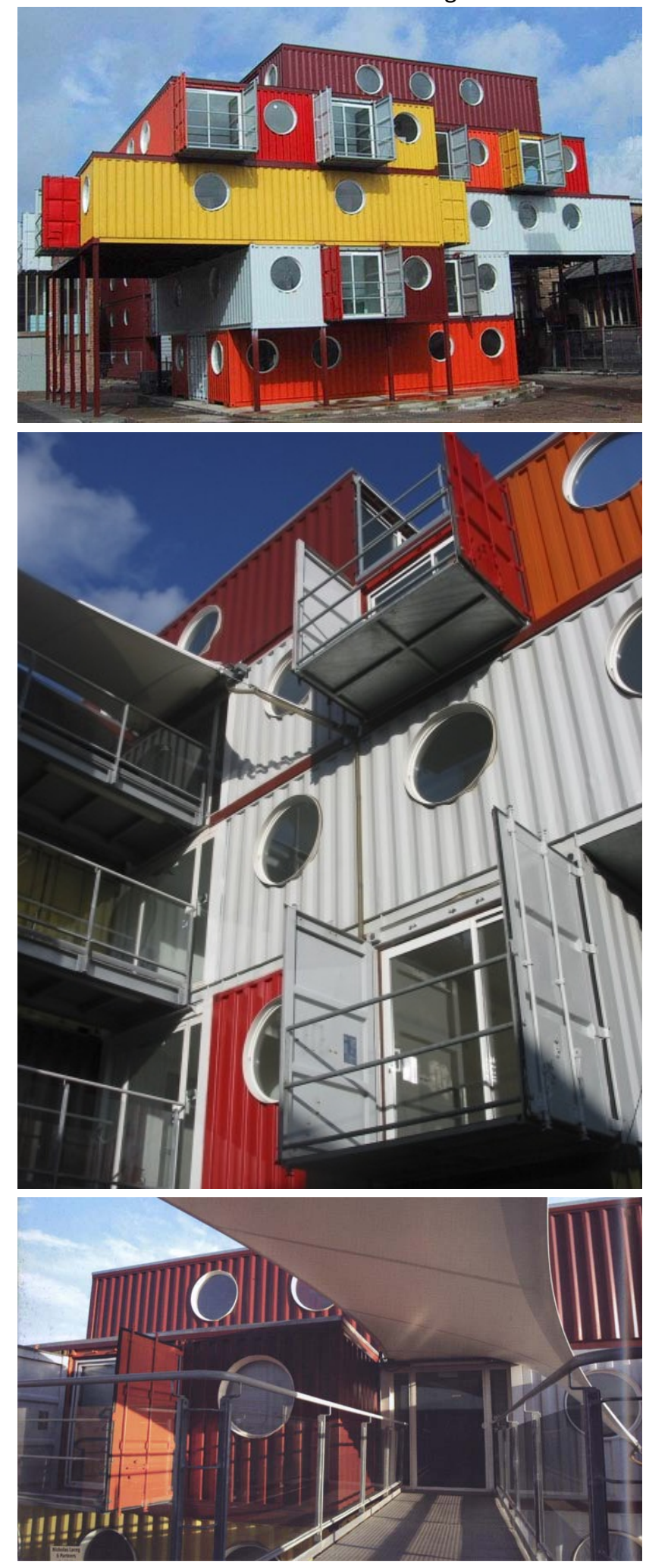

${ }^{22}$ (www.containercity.com) 
The Riverside Building

Figures $N^{\circ} 38-39-40-41$

This structure was designed and finished by the same company in charge of the first and second Container Cities in 2005. This building is located at Trinity Buoy Wharf in London's Docklands. ${ }^{23}$

According to (www.containercity.com) it is situated on the banks of the river Thames opposite the Millennium Dome. The Riverside Building is set over five floors and has created 22 office spaces.

Seventy three 40-foot containers were used for this project which blends offices and dwelling units. The assembly of the main components lasted eight days. ${ }^{24}$

From an aesthetic point of view, this building seems to be more rational than the first-two container city constructions.

Instead of the displacement of the units of the container cities, where additional steel posts were inserted into the main frame, the arrangement of this design is more sensitive from an engineering point of view, because, as the same example of the Stevens House in New Zealand, stresses and wind loads pass straight to the existing/intended connection points where the container structure may bear more easily these loads.

\footnotetext{
${ }^{23}$ (www.containercity.com)

24 (www.containercity.com)
}
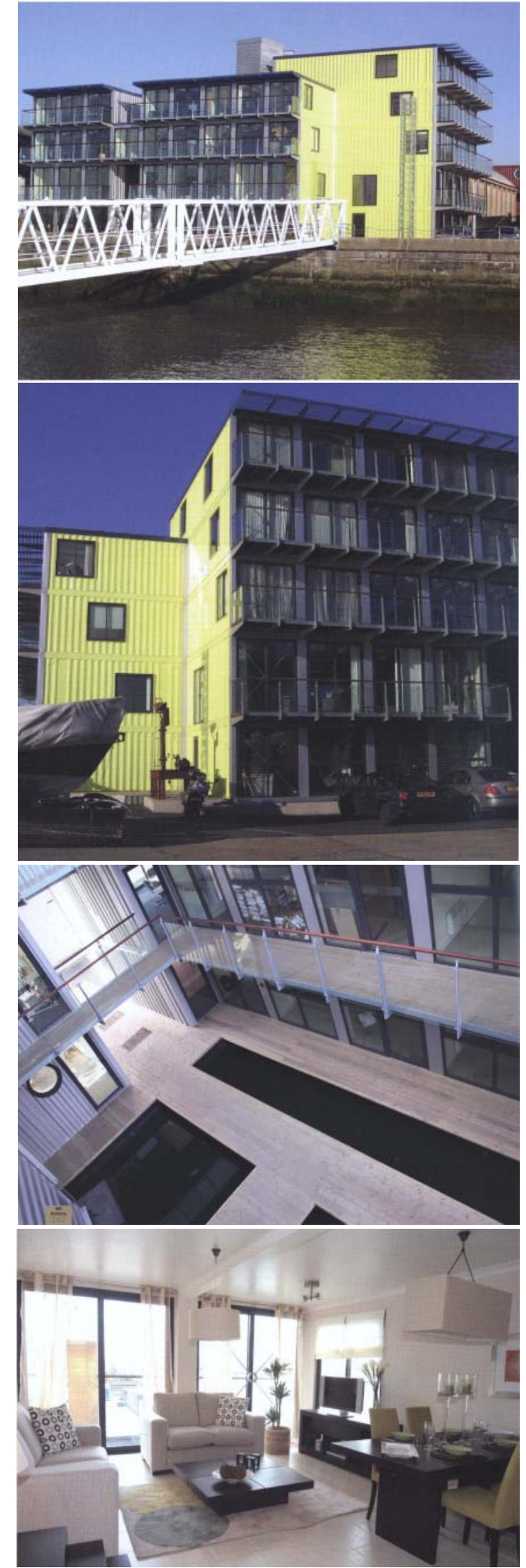
Qubic Houthavens

Figures $N^{\circ} 42-43-44$

In terms of scale this project is the second biggest complex currently which uses shipping containers as the main component of its structure.

The ideals of mass production are intrinsically carried out. One thousand and five 40-foot shipping steel boxes were used stacked up in three levels in Amsterdam, The Netherlands.

Each unit consists of a small kitchen and a toilet with a shower space and an open space which serves as a dormitory for student accommodation.

The facade of each unit changes and the shape seems to be designed for thermal control.

Six different facades with six different colours were chosen to make several combinations. $^{25}$

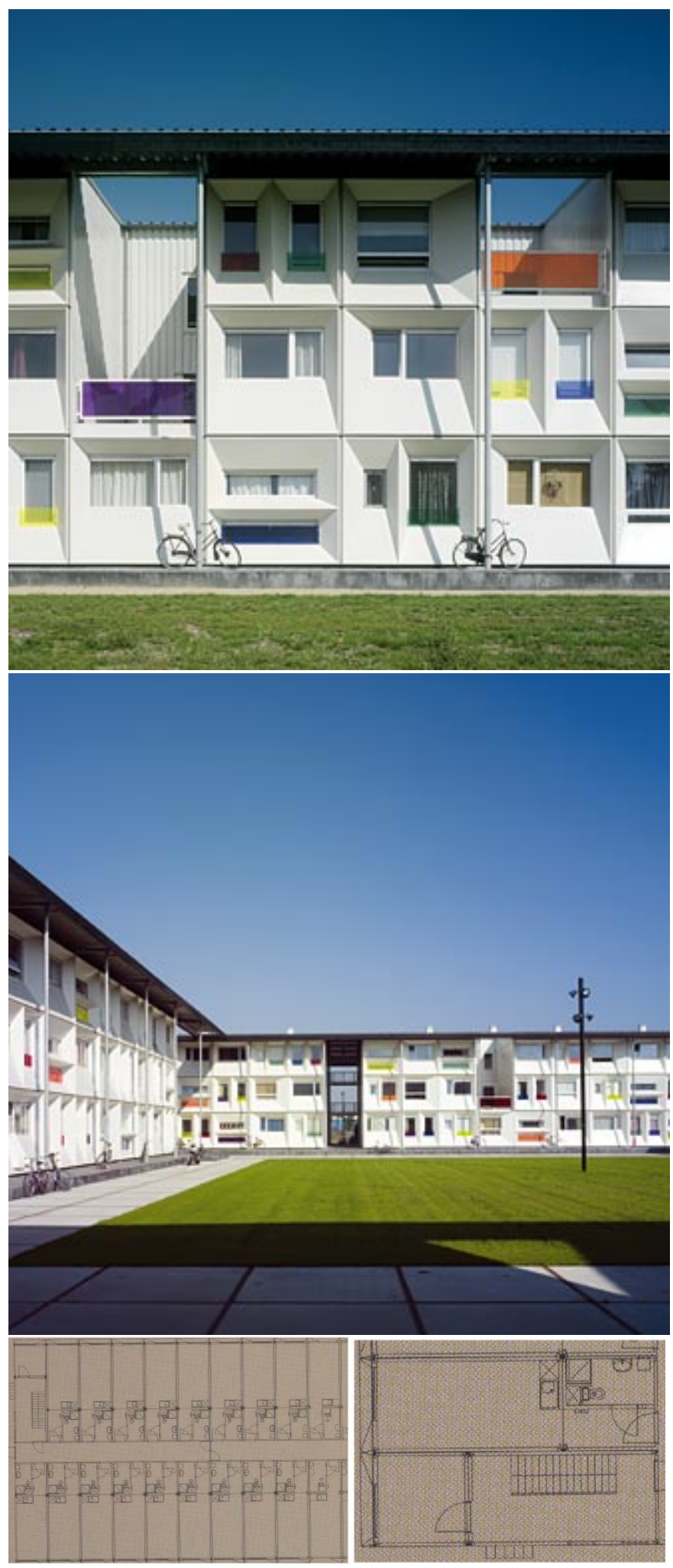

${ }^{25}$ (www.mimoa.eu) 
Tempohousing Keetwonen

Figures $N^{\circ} 45-46-47-48-49-50$

On the internet there is a website called www.fabprefab.com, in whose gallery called container bay, can be seen at least 50 different projects of architecture that use freight containers as components of construction in a wide range of ways.

Keetwonen, is the biggest container city in the world, 1,056 forty-foot new shipping container were used to build this student housing in Amsterdam, Netherlands, which provides 1000 units for the Dutch students. The project started at the end of 2005 and was completed in the middle of $2006 .^{26}$

"New" shipping containers were used to build this project.
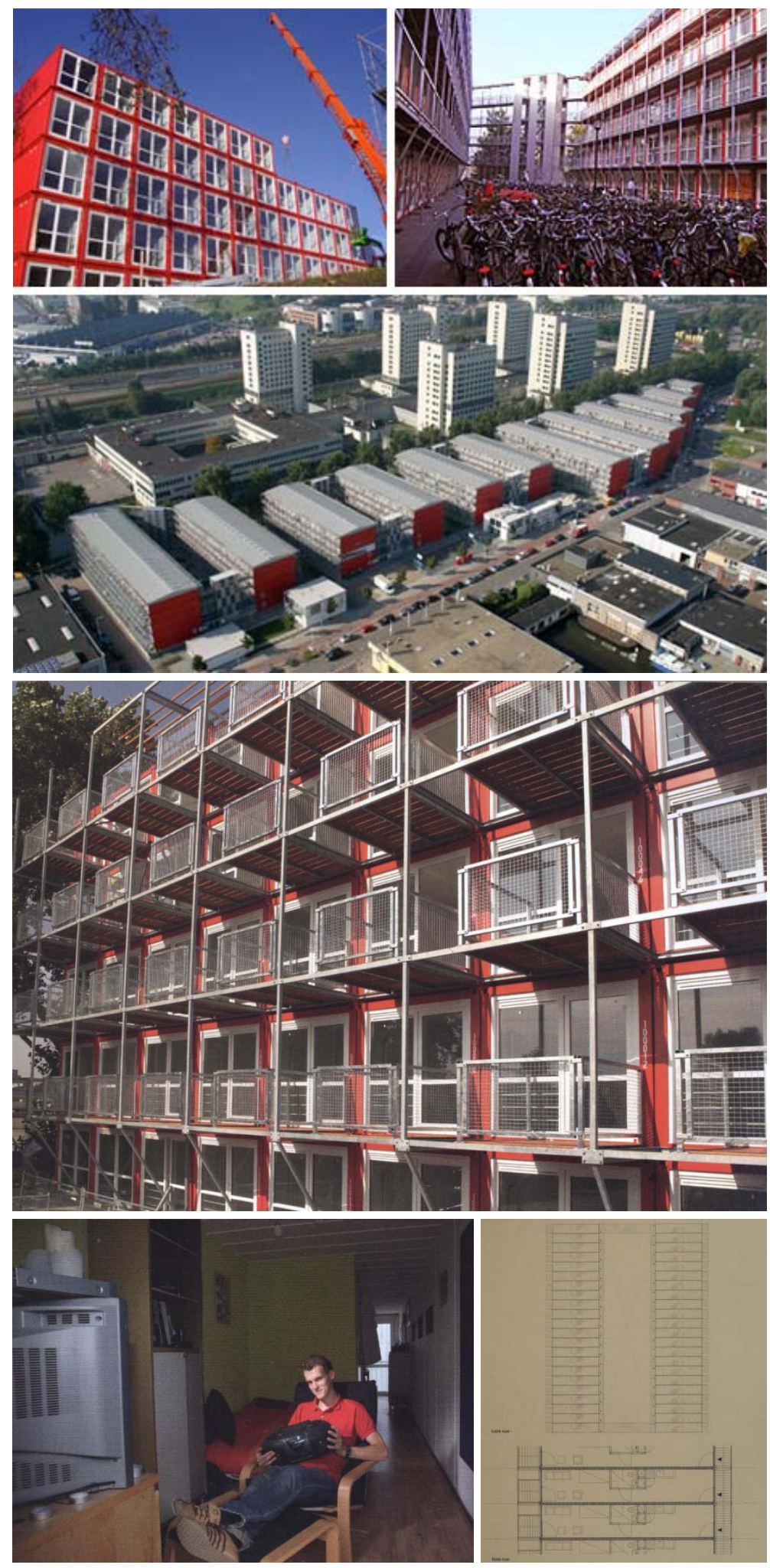

${ }^{26}$ Kotnik, J. (2008) 


\subsection{2. - Commercial structures}

Travelodge Uxbridge England

Figures $N^{\circ} 51-52-53-54$

According to (www.inhabitat.com) the completed design uses eighty six containers of various sizes that were retrofitted into bedrooms and bolted together onsite. The interior has been clad and fitted with windows, thus converting the assemblage into a seamless 120 -bedroom hotel.

According to (www.verbussystems.com) the hotel's modular assembly makes its construction $40-60 \%$ quicker than traditional building methods.

There was no technical data available and the construction process is unclear.

Image $\mathrm{N}^{\circ} 51$ Source: $w w w$. Inhabitat.com Retrieved on $8^{\text {th }}$ October 2009 from http://www.inhabitat.com/wpcontent/uploads/shippingcontainerhotel54.jpg

Image $N^{\circ} 52$ Source: www.Inhabitat.com Retrieved on $8^{\text {th }}$ October 2009 from http://www.inhabitat.com/wpcontent/uploads/shippingcontainerhotel34.jpg

Image $N^{\circ} 53$ Source: $w w w$. Inhabitat.com Retrieved on $8^{\text {th }}$ October 2009 from

http://www.inhabitat.com/wpcontent/uploads/travelodge3.jpg

Image $N^{\circ} 54$ Source: $w w w$. Inhabitat.com Retrieved on $8^{\text {th }}$ October 2009 from http://www.inhabitat.com/wpcontent/uploads/travelodge11.jpg
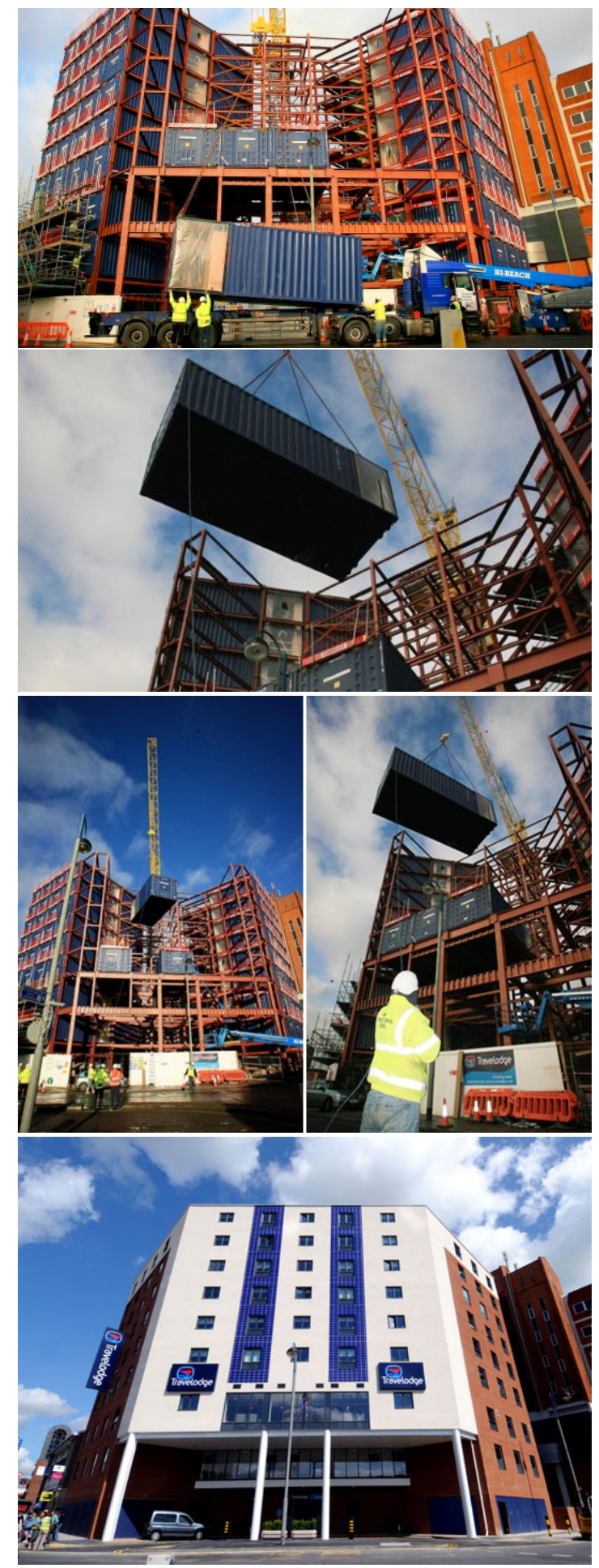


\subsection{3. - Temporary structures}

Nomadic Museum

Both, temporary and mobile: Nomadic Museum is an itinerant exhibition used to house the Ashes and Snow photography and film exhibition by Gregory Colbert.

This building was originally conceived as idea for a sustainable travelling museum.

As can be seen, picture $\mathrm{N}^{\circ} 55$ above shows the installation of the Museum located at that time in the New York harbour.

Picture $\mathrm{N}^{\circ} 56$ shows how the facades comprises four levels of shipping containers interspersed with each other, leaving a gap in which luminosity is treated with diagonal panels which cross those fissures.
Figures $N^{\circ} 55-56-57$
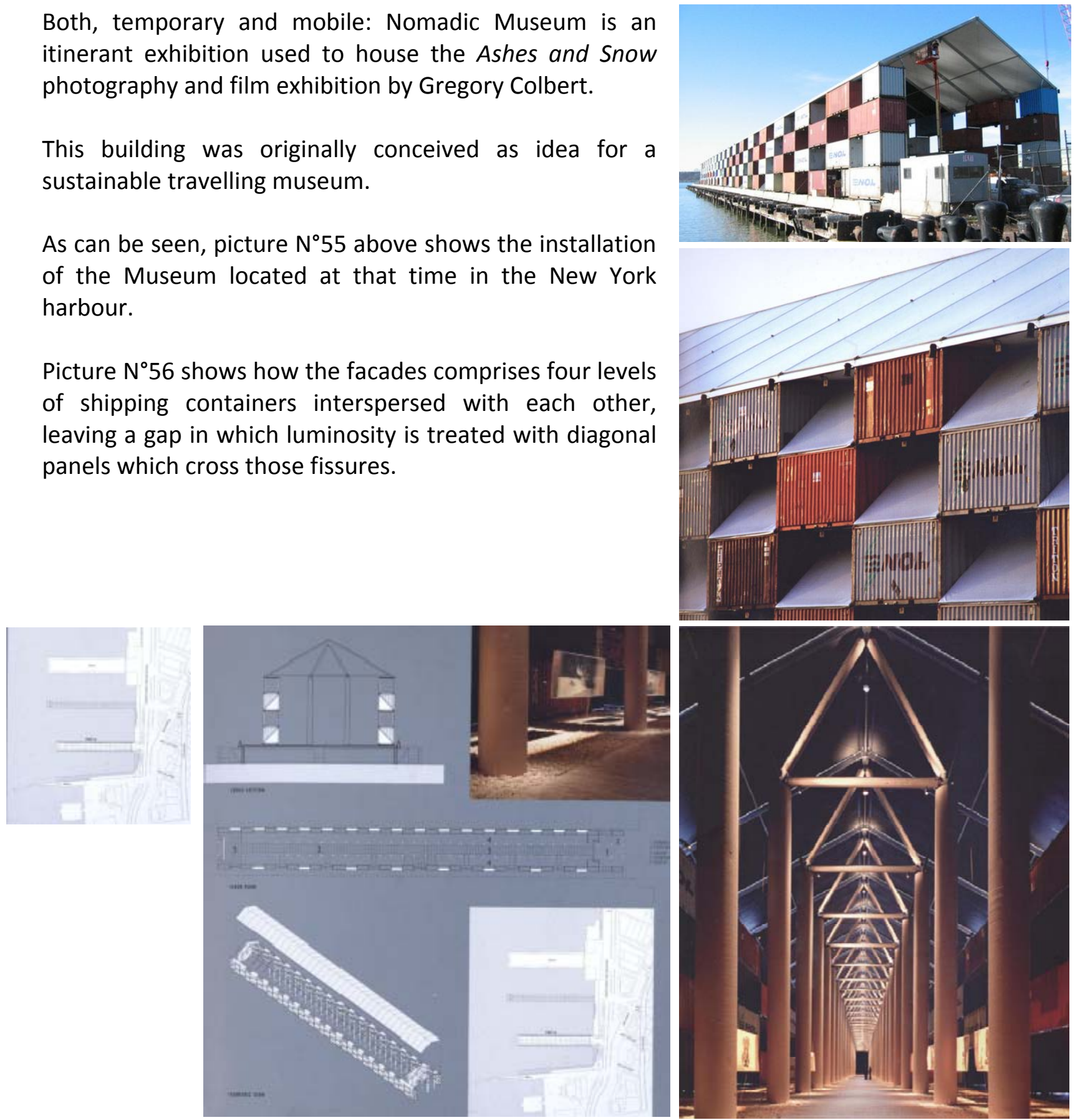


\subsection{4. - Mobile structures}

G.A.D. Gallery (Gallery of Australian Design)

Figures $N^{\circ} 58-59-60$

The Gallery of Australian Design (G.A.D.) aims to explore and promote Australian design through exhibitions and events around the world. According to Kotnik, J. (2008, p. 30) the gallery consists of ten ordinary steel containers composed in the manner of the "Jenga" game. The largest gallery space is on the ground floor, which consists of five 20-foot shipping containers. These support the first floor, this is where the gallery has its entrance, accessing is via an external staircase.

The Puma Gallery (itinerant)

Puma commissioned Lot-Ek to build a transportable gallery. ${ }^{27}$ Using twenty four 40-foot shipping containers the structure is divided into three different levels. The first level has been displaced from the rear structure and this may have generated the space for the access, the second level has been displaced too, allowing a large projecting area. The final storey has not been separated perhaps for structural requirements.

Image Source: www.vectroave.com Retrieved on $31^{\text {st }}$ March 2010 from http://vectroave.com/wpcontent/uploads/2010/01/GAD-GALLERYShipping-Container-Architecture.png

Image Source: www.2modern.blogs.com Retrieved on $31^{\text {st }}$ March 2010 from http://2modern.blogs.com/photos/uncategorize d/2007/05/17/img 4671.jpg
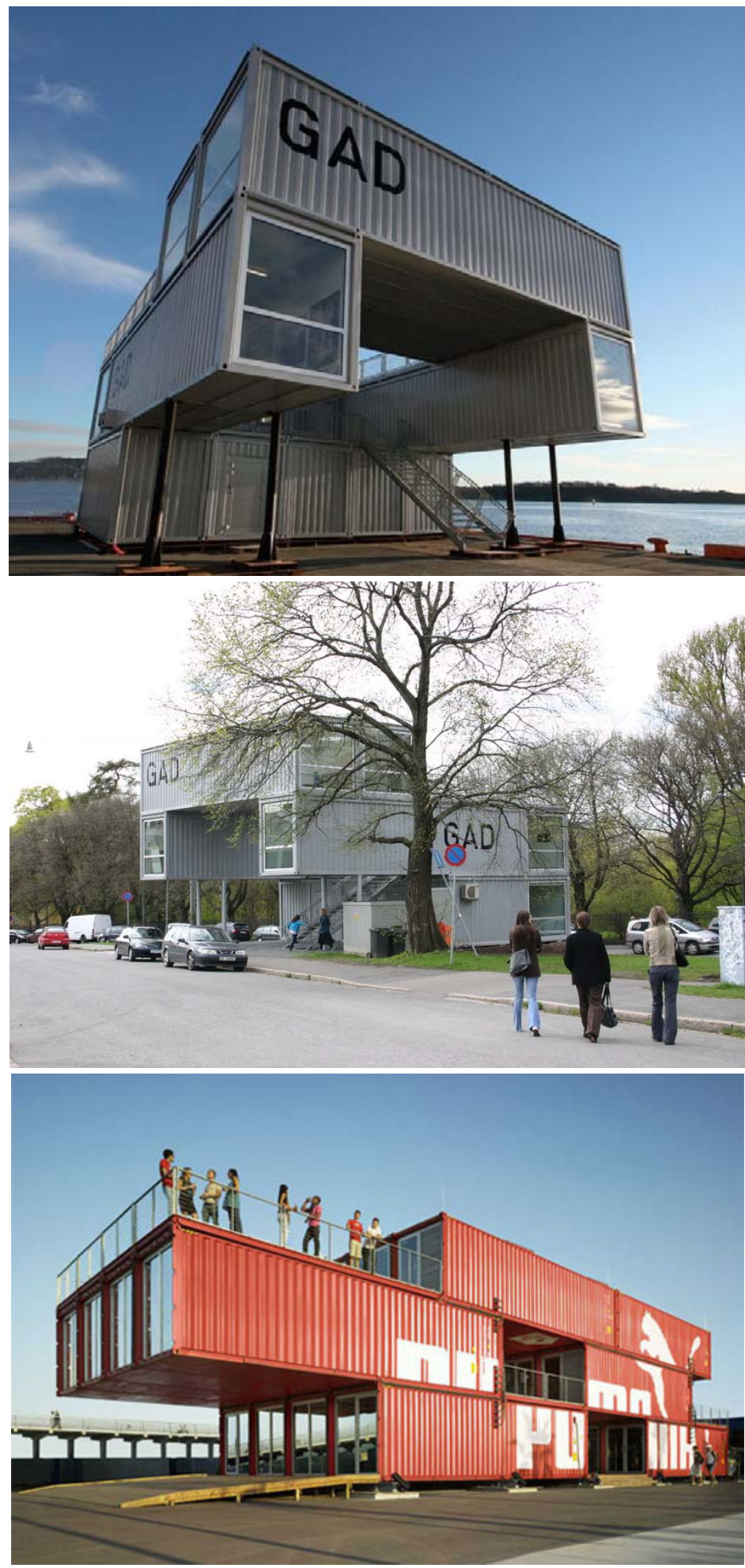

${ }^{27}$ (www.gliving.com) 
Located in London, this temporary school was built for children that had been diagnosed with autism. With two levels and an area of $600 \mathrm{~m}^{2}$ constructed the project is made up by 36 units of shipping containers. $^{28}$

One of the main features of this project is the wooden envelope.

Most of the shipping container walls are made of corrugated steel sheets of $2 \mathrm{~mm}$ each. It is widely recognised that steels $\mathrm{R}$-value is nil and lower than the concrete and timber R-values. ${ }^{29}$ On the other hand FRP Containers are made of Fiberglass Reinforced Panels (R-1.2 generally for $13 / 4$ " thick), which is still low for walls. New Zealand has a minimum of 1.5 R-values for walls of climates zones 1 and 2 .

From this project two things can be discussed:

1. - The need of an inner or external insulation due to the shipping containers features.

2. - An aesthetic response for the industrial image of these steel boxes.
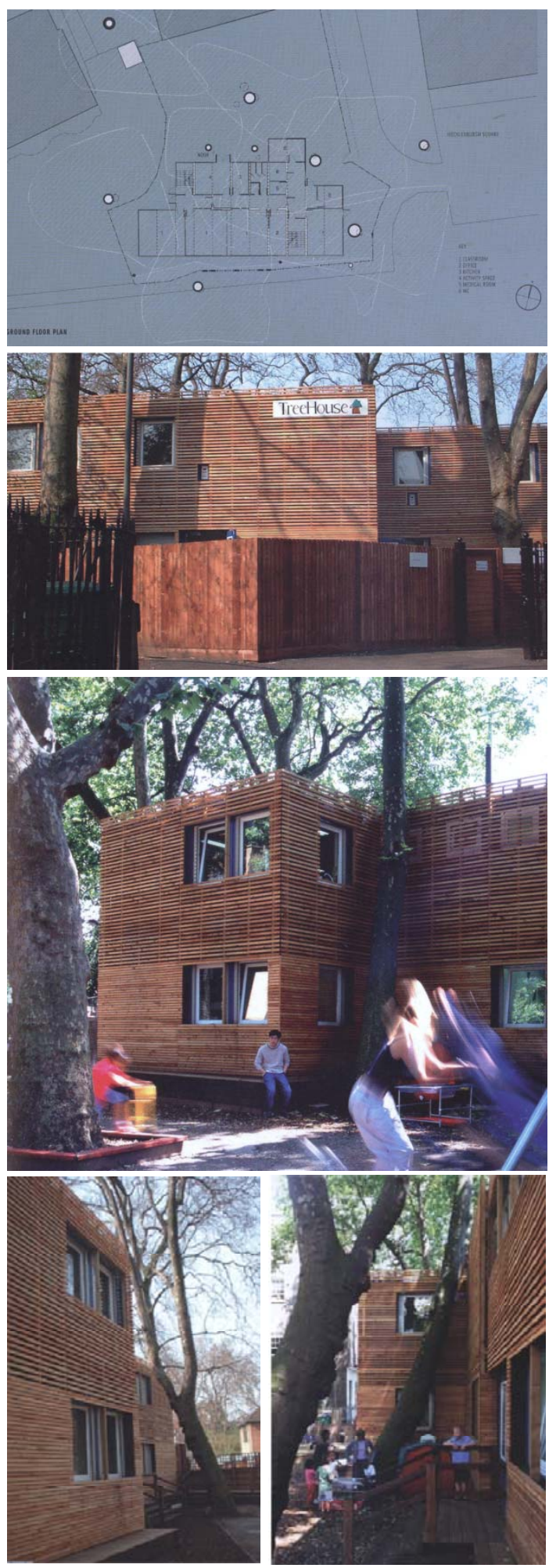

${ }^{28}$ Kotnik, J. (2008)

${ }^{29}$ BRANZ: Building Research Association of New Zealand (2005) 


\subsection{5. - Prototypes and other structures}

Future Shack

Figures $N^{\circ} 66-67-68$

A temporary structure, the Future Shack is a prototype for mass-produced emergency house. ${ }^{30}$

The unit is made up of a 20-foot container, solar panels, a parasol roof and a supporting structure. ${ }^{31}$

In (www.archmedia.com.au) a detailed description is given. The idea behind this model is that can be used after natural disasters have occurred, for example, earthquakes, flooding and tornados. The web page's document put emphasis on the fact that temporary structures can be delivered by road or rail. However, there is an important point that it has missed. An earthquake or other natural disaster usually affects the main infrastructure of a country such as roads, bridges, airports, etc. making this idea non viable.

Conhouse, designed by architect Jure Kotnik and author of the book "container architecture" presents his work. The house is sited in Slovenia. Due to its configuration this unit had a torsion problems generated by wind loads. It is perhaps for this reason that the containers have had to be reinforced with extra beams at the top and the bottom of the module.

Atelier Workshop had designed a prototype which was finally built for a New Zealand family. A mobile unit located in New Zealand, this example can be moved from place to place according to the needs of the customer.

Using a hydraulic system the wall folds down and can be used like a deck. A plastic roof is used to protect the unit from the rain. The problem is that New Zealand is a rainy country which makes it hard to maintain this type of temporary housing.

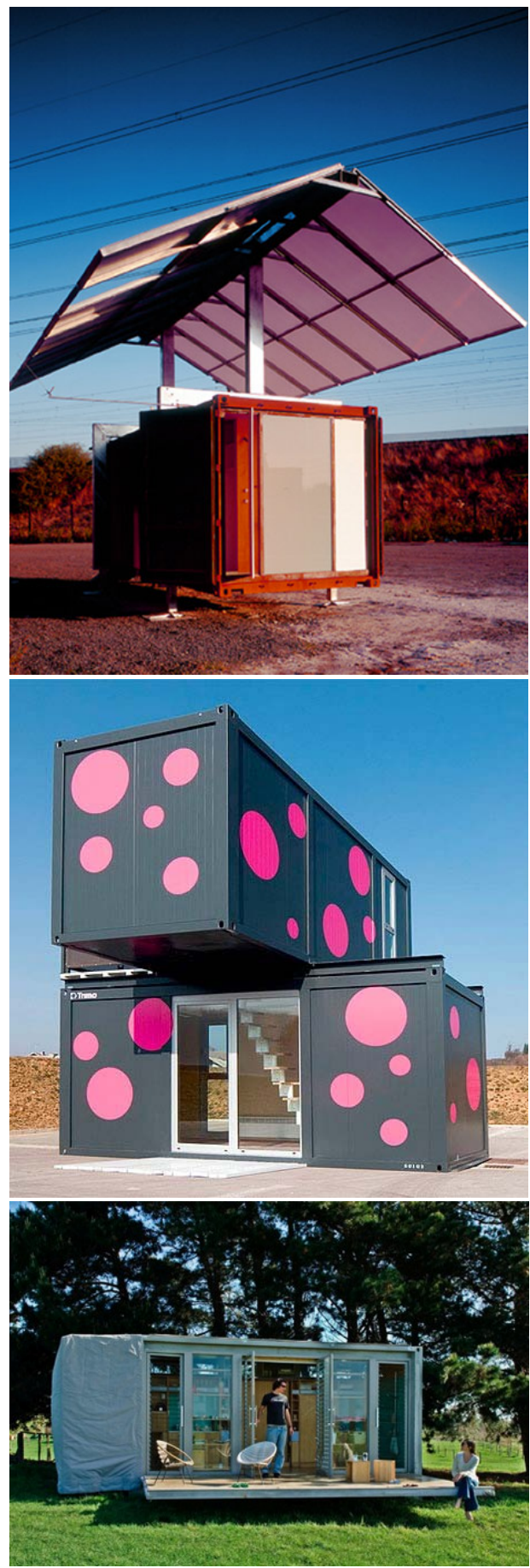

\footnotetext{
${ }^{30}$ (www.archmedia.com.au)

31 (www.archmedia.com.au)
} 


\subsection{Summary of the chapter}

- Prefabrication in architecture has both succeeded and failed.

- Most of the projects linked with shipping containers in the residential sector use them like bedrooms. This generates a sort of minimum dwelling. When this occurs the specification of the minimum dwelling must not be reduced below biological acceptable limits in order to achieve minimum environmental comfort requirements.

- Some of the disadvantages of projects related to containers are their lifespan. These buildings are estimated to last fifty years. This means one half of the life cycle of most of the traditional houses. One of the first projects created from these steel boxes was in 2001(Container City, London UK). It is expected to last until the year of 2050. No projects have crossed the threshold of age yet.

- Most of the container buildings are small houses. A few examples use them as a mass produced components. There are some high quality projects like the Keetwonen student accommodation in Amsterdam, The Netherlands.

- Most of the projects which use shipping containers for residential and nonresidential buildings are located in countries with harsh weather conditions.

- The container itself seems to be ideal for all of those projects which are continually moving around. There are some examples which use containers in their itinerant program.

- Most of the projects shown in this chapter do not have technical data related to their building process.

- The definition of the concept of "Life Cycle Analysis" has been assessed partially and it will be evaluated in depth in chapter six. It is not the aim of this research to study the entire complexity and long scope of the concept behind the (LCA). However, the study recognises the importance of the Life Cycle Assessment as a quantitative tool of measurement in which the hypothesis would be proved or rejected. 


\section{Chapter II-General Background}

\section{1. - Shipping Container History}

The creation, introduction and subsequent rise of globally standardised shipping containers into the ports and piers- of the United States of America in the middle of the twentieth century- changed forever the transportation industry and made possible increased world economic growth. However, this revolution also brought unlikely imbalances, which will be explained later. This chapter will provide details of the history behind the shipping container industry, what is it, how it works, which elements are involved and the implications of this revolution in terms of several approaches, such as architectural, political, social and economic aspects. In addition, this chapter will make clear the development of the transportation industry itself, and why standardisation and containerisation were so important for waterfront and other cities around the world. Thus, will be explained the general background related to the shipping container industry.

\section{2. - The beginning of shipping containers}

Freight containers for the intermodal transport of goods have been in use within individual countries for many years prior to their global application. Before 1956 most of the world's docks, ports and piers utilised break bulk or general cargo, as a common method of working. This traditional system in which items were loaded and unloaded individually and required many people to complete the tasks was old; also this system was expensive, unsafe and wasted time unnecessarily. ${ }^{1}$ On $26^{\text {th }}$ of April of 1956 a vessel filled with fifty eight shipping containers set out from the port of Newark to Houston. This simple act was the beginning of a transport revolution all over the world. According to Levinson, M. (2006, p. 51)

..."one hundred dignitaries enjoyed lunch at Port Newark and watched the crane place a container on the ideal-x every seven minutes. The ship was loaded in less than eight hours and set sail the same day."

The man behind modern shipping containers was a trucker entrepreneur from Maxton, North Carolina, a visionary, a man who had no idea about ships; his name was Malcom Mc Lean, known too as the father of containerisation. The idea was simple, Mc Lean realised that break bulk required too much time loading and unloading every simple item, his idea was to hook the trailers from his trucks and lift them straight onto the vessels, this principle would give more flexibility to freight cargo and one of the advantages could be that the cost of transporting cargo should fall.

\footnotetext{
${ }^{1}$ Levinson, M. (2006)
} 
Mc Lean was right. However he had to face many logistic troubles because at that time the technology was not available in ports, the ports themselves were too small; and vessels were designed to carry general cargo rather than modular containers.

\section{3. - The old and new transport system}

First, why are containers so important for the transport industry?

The old, inefficient and slow break bulk process was replaced by shipping containers and according to Levinson, M. (2006, p. 2)

..."the container is at the core of a highly automated system for moving goods from anywhere, to anywhere, with a minimum of cost and complication on the way."

Shipping containers are part of a complex intermodal system that permits the loading and unloading of freight cargo from vessels, trucks and trains, this combination makes it possible for goods to travel around the globe, cheaper, safer and quickly. According to Levinson, M. (2006, p. 10)

..."Containers were quickly adopted for land transportation, and the reduction in loading time and transhipment cost lowered rates for goods that moved entirely by land. As shipping lines built huge vessels specially designed to handle containers, ocean freight rates plummeted as container shipping became intermodal, with a seamless shifting of containers among ships and trucks and trains."

Before the intermodal system and containerisation, ports and piers around the world were too small in comparison to the current and advanced ports that today people know. But, for Mc Lean this was not the only problem, he also had to build special cranes to lift the trailers into the vessels. With the introduction of containers slowly all the infrastructure in ports started to change even though many people including port authorities, longshoremen's associations and other workers looked with resistance against automation and modernisation of ports. 


\section{4. - The steel box}

According to Levinson, M. (2006, pp. 1-2)

..."What is it about the container that is so important? Surely not the thing itself, a soulless aluminium or steel box held together with welds and rivets, with a wooden floor and two enormous doors at one end: the standard container has all the romance of a tin can. The value of this utilitarian object lies not in what it is, but how it is used."

In the transportation industry the container is part of an intermodal system, a steel box that can be carried by different modes of transport such as ships, trains and trucks.

According to Davies, C. (2005, p. 169)

..."the container is simply a stackable steel box sized to suit the transport networks of the world. It was not until the 1950s that Malcom McLean, an American trucking entrepreneur, persuaded port authorities and freight carriers to stop lading into the cavernous holds of ships and turn their attention instead to the long, narrow forms of the lorries, trains and barges that carried the goods to and from the port."

\section{5. - The intermodal system}

The intermodal system is the base of the current transport industry, in which the container is the core, by integrating the different transport modes of railways, roads and maritime shipping to facilitate trade flows. ${ }^{2}$

According to Davies, C. (2005, p. 169)

..."Mc Lean started by simply loading the trailers of his trucks onto the decks of ships instead of unloading small boxes one at a time from truck to hold. There were a lot of advantages to the new method. It was faster, more secure and required much less labour. But to get the most out of it, to achieve real transport "intermodality", investment was required in new handling equipment and bigger ships. In 1956 the first true container ship, the ideal-x, sailed from Newark, New Jersey, and the tooling-up of Port Elizabeth, the first true container port, began."

2 (Unescap)Retrieved 11 August 2009 from http://www.unescap.org/ttdw/Publications/TPTS_pubs/pub_2392/pub_2392_ch15.pdf 
The real achievement and the most important implication of introducing shipping containers in docks was the process of modernisation of the whole transport industry, this set off a chain reaction in many aspects and the consequences of that are now evident in the way that the world is running today. And that occurred only since modern shipping containers were created; this process was so fast spreading and changed the performance in ports, railways and roads forever.

Figure $\mathrm{N}^{\circ} 1$ shows the process of modernisation in the transport industry, represented as the big circle. Modernisation is the general idea, and the circles inside show the remaining concepts such as mechanisation, standardisation, containerisation and automation that are related to containers. These other topics will be explained separately.

This scheme shows the process of modernisation in docks of the United States after the introduction of shipping containers in 1956.

Figure $\mathrm{N}^{\circ} 1$ : Process of Modernisation in the Transport Industry

\section{snodersisalijon}

ssechessiseitjos

stanclarclisetijon

constajseriseijioss

autiossalijos

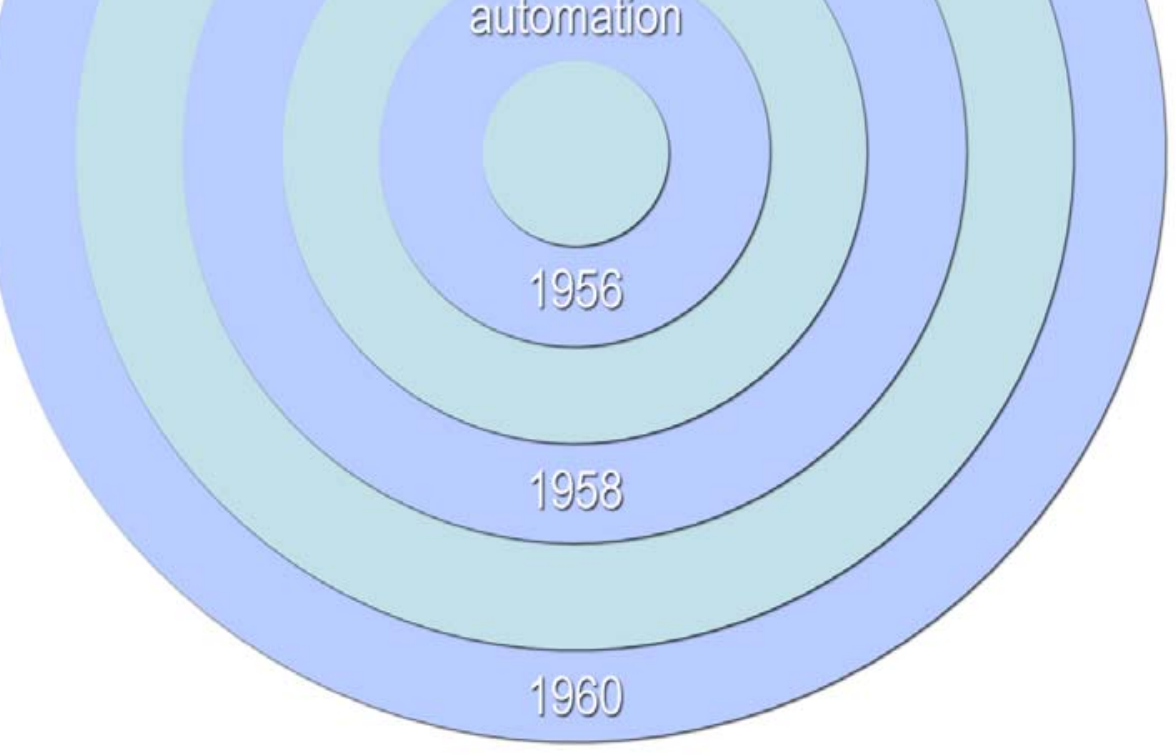

Image Source: Own scheme 


\section{6. - Containerisation}

According to Levinson, M. (2006, p. 52)

..."Rather than a revolution, the containerisation of the 1950s was a chapter in the history of development of maritime cargo transportation."

Containerisation was the process of modernisation of the transport industry from the worn-out break bulk system to a system using standard sized steel boxes or containers specially designed to carry goods and easy to interchange from ships to trucks and trains. But it was not a simple task to change from one system to another, Companies such as Sea Land (Malcom McLean) invested large sums of capital in the process of developing suitable shipping containers ${ }^{3}$. Again, McLean had to face the fact that every company related to the transport industry had their own measurement system, their own special chassis for special trucks; this was complicated because every crane had to be adapted for other designs of hooks.

According to Levinson, M. (2006, p. 57)

..."The combination of cells (containers) and gantry cranes allowed the containers to be handled with unprecedented speed. Once the first column of cells had been unloaded, the ship could be loaded and unloaded simultaneously, in assembly-line fashion: each time the crane travelled to the dock to deposit an incoming trailer on an empty chassis, it would pick up an outgoing trailer and place it into an empty cell."

Davies, C. (2005, p. 170)

...Containers have not changed much in essence in fifty years, although there are now different kinds for different cargoes: side-opening, end-opening, open-topped, collapsible, "flatracks", "hangertaivers", and air conditioned-refrigerated "reefers".

${ }^{3}$ Levinson, M. (2006) 


\section{7. - Standardisation}

Was Standardisation the forerunner of the evolution of Containerisation?

By the last years of the 1950s to the first years of the 1960s the use of shipping containers became more common in docks, railways and roads around North America, it was but not massive yet, at that time even the army of the United States was sending them to Europe. The difficulty was that Europe had their own types of wooden containers and they were in different sizes. ${ }^{4}$ The real problem was the diversity of containers in the world at that time. However, the United States Maritime Administration decided in 1958 to put an end to this incipient anarchy. ${ }^{5}$

According to Levinson, M. (2006, p. 130)

..."Container shipping was brand-new and pushing standardization before the industry developed might lock everyone into designs that would later prove undesirable."

The approach described by Levinson indicates that weight limits were crucial, because they would determine the lifting power required of cranes and the load that the bottom container in a stack might have to bear. ${ }^{6}$

\section{8. - Arithmetical relationship}

Why Shipping containers are so special to architects when they are used in construction.

According to Levinson, M. (2006, p. 134)

..."Dealing with container construction and fittings, the process of standardisation worked more smoothly. Members of the Marad committee (United States Maritime Administration) readily agreed that each container should be able to carry the weight of five fully loaded containers atop it, with the weight to be carried on the corner posts, rather than on container walls. All containers should be designed to be lifted by spreader bars or hooks engaging the top corners."

According to Levinson, M. (2006, p. 134)

..."Those decisions gave engineers the basic criteria to use in designing new containers. The committee also recommended that each ship be designed with various sizes of steel cells so that it could carry multiple sizes of containers."

\footnotetext{
${ }^{4}$ Levinson, M. (2006)

${ }^{5}$ Levinson, M. (2006, p. 128)

${ }^{6}$ Levinson, M. (2006, p. 131)
} 
According to Levinson, M. (2006, p. 134)

..."By the late summer of 1959, it had been agreed unanimously that "standard" containers would be 20-feet or 40-feet long and 8-feet high. The other lengths approved by the $\mathrm{MH}-5^{7}$ and Marad, and $81 / 2$-foot high boxes supported by some truckers and most shipping lines, would not be acceptable for military freight."

According to Levinson, M. (2006, p. 135)

..."Herbert Hall, the chair of the entire $\mathrm{MH}-5$ process, ${ }^{8}$ then intervened. Hall was a retired engineer at the Aluminium Company of North America, which made aluminium sheets used to manufacture containers. He had sparked the entire standardisation process with a presentation to an engineering society in 1957. Hall knew little about the economics of using containers, but he was fascinated by the concept of an arithmetical relationshippreferred numbers, he called it- among sizes. He believed that making containers in 10-2030 and 40 -foot lengths would create flexibility."

On the other hand according to Levinson, M. (2006, p. 145)

..."the large ones were too hard to fill- too few companies shipped enough freight between two locations to require an entire 40-foot container-and small ones required too much handling. As Matson executive vice president Norman Scott explained, "In economic transportation, there is no magic in mathematical symmetry."

Is clear to see how difficult it was for engineers and authorities to get a consensus about which would be the best size for shipping containers.

According to Levinson, M. (2006, p. 135)

..."A truck equipped to handle a 40-foot container could equally well pick up two 20-foot containers (their precise length was 19-feet 10.5 inches, to make it easy to fit two together in a 40-foot space), or one 20-foot container and two 10-footers."

According to Levinson, M. (2006, p. 137)

... "On April 14, 1961, 10-20-30 and 40-foot boxes were declared to be the only standard containers."

\footnotetext{
${ }_{8}^{7}$ MH-5: Materials Handling Sectional Committee 5 see Glossary of terms

${ }^{8}$ Idem
} 
According to Levinson, M. (2006, p. 147)

..." the key to automation is the existence of a standardized product. This fact made possible that the cost of freight cargo decreased radically."

According to Levinson, M. (2006, p. 160)

..."The containers were usually returned across the ocean empty, and that cost, too, had to be reflected in the rates charged for shipping freight."

According to Levinson, M. (2006, p. 184)

..."The full benefits of containerisation can only be derived from logistic systems designed with full use of containers in mind."

\section{9. - Modernisation in ports}

Most of the modernisation of ports can be explained by the development of the technology needed to handle shipping containers. To reduce freight costs, transportation companies needed to send more containers to sea, to do that, the requirements of space became evident, not only for a new kind of ships, bigger and stronger, also to carry more weight, but docks also had to consider new cranes and more space to deposit containers to store them. The combination of the container, plus the intermodal system, plus standardisation was so efficient that the transport of goods rose dramatically through 1956 to the 1960s. Transformation in ports is the consequence of the creation of shipping containers and the creation of the intermodal system; containerisation and standardisation were steps of the modernisation as a whole.

According to Levinson, M. (2006, p. 100)

..."Container technology developed far more quickly and affected transportation industries far more significantly than even its most ardent proponents had imagined."

According to Levinson, M. (2006, p. 103)

... "A containership can be loaded and unloaded in almost one-sixth of the time required for a conventional cargo ship and with about one-third of the labour." Malcom Mc Lean.

According to Levinson, M. (2006, p. 103)

..."The mechanisation in docks, and transport systems first started in the U.S.A., after that it was immediately extended to western Canada." 
2.10. - Imbalanced trade: imports versus exports

In economics, the balance of trade is the difference between the monetary value of exports and imports of output in an economy in a certain period of time. ${ }^{9}$ So the balance can be positive or negative, trade surplus or trade deficit. This research will not assess this issue in specifics. However, is it important because surplus or deficit in trade means more or less units of shipping containers in ports stacked up waiting for the next shipment.

\subsection{1. - Summary of the chapter}

- This chapter has shown the history behind the shipping container as an instrument of trade in historical, economical, and political approaches.

- Since their introduction in the middle of the 1950s these metal boxes have facilitated the achievement of the modernisation of ports and cities around the world.

- The best achievement was the economic one. The shipping costs have dropped by 97 percent in contrast with the past.

- The intermodal system in which containers are the core replaced the traditional break bulk cargo.

- They have evolved into the family of ISO cargo containers of 20, 30, 40 and 45-foot length and their size is according to the requirements for different and specific items.

- These steel trade boxes are mainly made of steel and aluminium, which are energy intensive materials.

\footnotetext{
${ }^{9}$ O'Sullivan \& Sheffrin (2006)
} 


\section{Chapter III - Physical characteristics of ISO containers}

This Chapter aims to enable the reader to understand the connections between the evolved shipping container and its main physical features. Moreover, it demonstrates their importance as fundamental part of an integrated system of cargo transport. Statistics are given for: 20-foot, 40-foot and 40-foot high-cube freight containers. Later in this section some disadvantages and problems in the usage of shipping containers as a building component are explained. The change of a trade box into a building is discussed.

Table $\mathrm{N}^{\circ} 1$ Energy use of various forms of freight transport

\begin{tabular}{ccc}
\hline Type of transport & $\begin{array}{c}\text { energy use } \\
(\mathrm{kWh} / \text { tonne-km) }\end{array}$ & $\begin{array}{c}\text { energy use } \\
(\mathrm{MJ} / \text { tonne-km) }\end{array}$ \\
\hline Container shipping & - & 0.12 \\
Coastal shipping & 100 & 0.36 \\
Rail freight & 200 & 0.72 \\
Lorry, Europe & - & 2.8 \\
\hline Lorry, New Zealand & 810 & 2.92 \\
Air freight & - & 9.7 \\
& & \\
Source: Vale (2009, p. 43): Time to eat the dog? & \\
\hline
\end{tabular}

Table $\mathrm{N}^{\circ} 1$ shows the energy use of various forms of freight transport. As can be seen from the table above, container shipping reaches 0.12 (MJ/tonne-km) one third of Coastal shipping and one sixth of Rail freight being the most efficient way for transportation of goods and products in terms of energy use. 


\section{1. - Shipping routes}

Figure $\mathrm{N}^{\circ} 1$ below shows the shipping trade's flow. There are some lessons to learn, one of which is that, world trade is unbalanced, the movements of goods and services, in comparison with southern hemisphere countries, are overwhelming largely among northern countries; such is the case of the USA, European Union and China as can be seen from the map. Energy consumption for shipping trade over the world could be significant. In 2007, international seaborne trade was estimated at 8.02 billion tons of goods. ${ }^{1}$ However, shipping by sea seems to be the most effective way for carrying goods, because the relationship of energy expended versus weight shipped remains small compared with other types of transport. ${ }^{2}$ (See Table $N^{\circ} 1$ ) On the other hand -It could be argued that- the availability of shipping containers (for use in architecture) is strongly linked with the problem of imbalanced trade, and the image presents this clearly. The map shows the world's imports evolution since 1948 to 2006.

Figure $\mathrm{N}^{\circ} 1$ Map of the boom in shipping trade

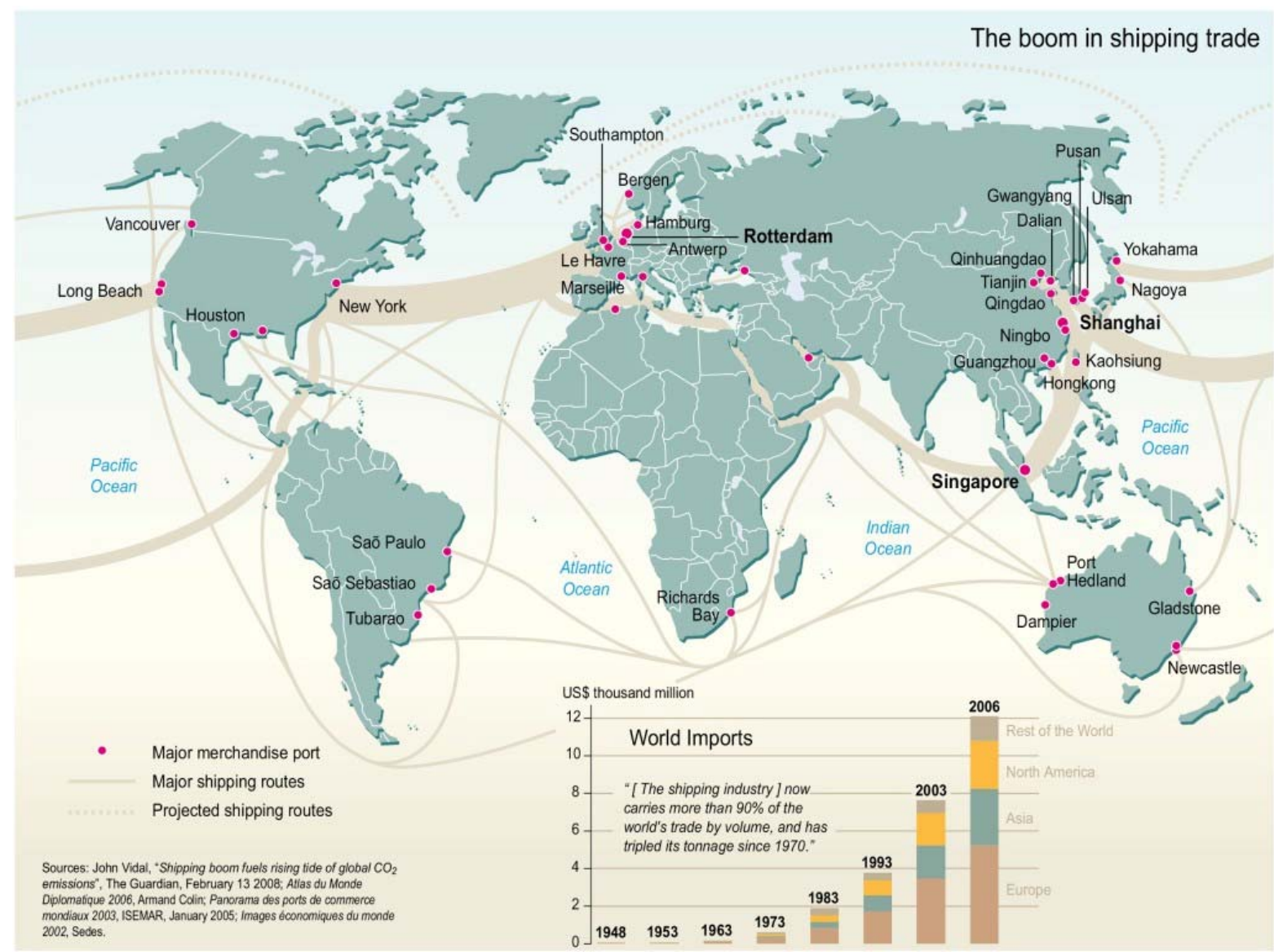

Image Source: http://www.grida.no/publications/vg/kick

\footnotetext{
${ }^{1}$ United Nations (2008, p. 5)

${ }^{2}$ Vale (2009, p. 43)
} 


\section{2. - Container statistics}

Worldwide movement of goods is almost entirely based on shipping containers. It is estimated by the United Nations (2008, p. xiii) that today, approximately over $80 \%$ of nonbulk cargo worldwide moves by containers stacked on transport ships. However, some studies estimate that approximately $90 \%$ of non-bulk cargo worldwide moves by containers stacked up in vessels. ${ }^{3}$

\section{Graph N¹ Freight cargo using shipping containers}

Containers $\quad$ Other trade modes

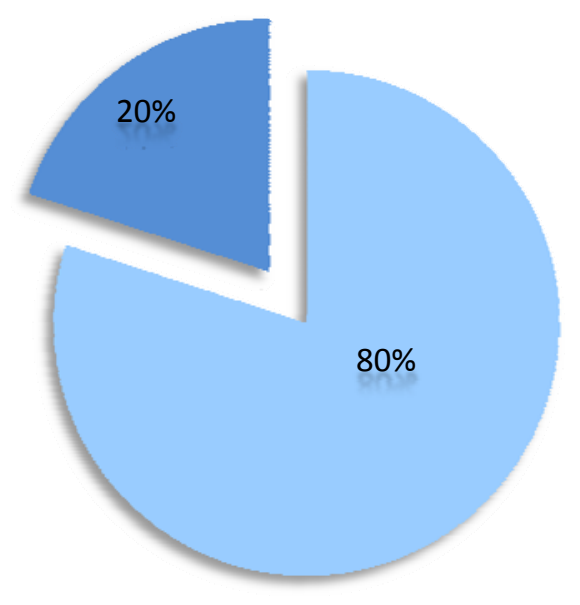

Image source: Own elaboration

Some estimation done in the United States concludes that today, 300 million 20-foot - long containers cross the world's oceans every year and the total value of world exports today is over \$12 trillion a year, equal to more than a quarter of world GDP Gordon, J. (2007). On the other hand, Ebeling, C. (2009) holds that more than 18 million containers made an estimated 200 million trips a year. However, this mis-match will be analysed in point 3.3, container fleet.

\footnotetext{
${ }^{3}$ Ebeling, C. (2009)
} 
3.3. - Container fleet

In 2008 Containerisation International through the world container census found out the global container TEU (Twenty-foot Equivalent Unit, will be explained in point 3.6) fleet grew by $11.4 \%$ in the year to mid- $2007 .{ }^{4}$ In addition, in 2008 the containership fleet grew by $12.7 \% .^{5}$

Table $N^{\circ} 2$ Change in container fleet for period 2001-2007

\begin{tabular}{cccccccc}
\hline Total & $\mathbf{2 0 0 1}$ & $\mathbf{2 0 0 2}$ & $\mathbf{2 0 0 3}$ & $\mathbf{2 0 0 4}$ & $\mathbf{2 0 0 5}$ & $\mathbf{2 0 0 6}$ & $\mathbf{2 0 0 7}$ \\
\hline & & & & & & & \\
& & & & & & & \\
\hline TEU & $15,365,404$ & $16,299,852$ & $17,429,819$ & $18,938,231$ & $20,981,253$ & $22,234,715$ & $24,779,724$ \\
Units & $10,221,317$ & $10,809,801$ & $11,532,291$ & $12,452,735$ & $13,735,885$ & $14,533,258$ & $16,188,065$ \\
\hline \multicolumn{7}{c}{ Source: (Containerisation International, 2008, p. 6) }
\end{tabular}

Table $N^{\circ} 2$ shows the Change in container fleet for period $2001-2007$. For 2005 nearly 14 million units were at sea, four million less than the 18 million shipping containers held by Ebeling, C. (2009). In terms of reliability, the hierarchy of sources should be led by the United Nations Conference on Trade and Development, Review of Marine Transport 2008, following by Containerisation International an online website expert in cargo industry information and finally the information given by Charles W. Ebeling author of "Integrated Packaging Systems for Transportation and Distribution (1990") and "An Introduction To Reliability And Maintainability Engineering (2000)". However, it is hard to find an accurate and reliable data source. The United Nations Report refers to the fleet in terms of growth of percentages, deadweight and TEUs moved but there is not a clear statistics for the different shipping container units. It is difficult finding the correct proportion of 20-30-40 or other special container units. This research will accept the first two sources.

\footnotetext{
${ }^{4}$ Containerisation International (2008, p. 6)

${ }^{5}$ United Nations (2008, p. 31)
} 
Graph $\mathrm{N}^{\circ} 2$ World fleet by principal vessel types, selected years

\begin{tabular}{|c|c|c|c|c|c|c|c|c|c|}
\hline \multicolumn{10}{|c|}{ Beginning of year figures, millons of $d w t$} \\
\hline \multirow{2}{*}{$\begin{array}{l}1200 \\
1000\end{array}$} & & & & & & & & & \\
\hline & & & & & & & & & \\
\hline \multicolumn{10}{|l|}{800} \\
\hline \multicolumn{10}{|l|}{600} \\
\hline 400 & & & & & & & & & \\
\hline 200 & & & & & & & & & \\
\hline 0 & 1980 & 1985 & 1990 & 1995 & 2000 & 2005 & 2006 & 2007 & 2008 \\
\hline Other & 31 & 45 & 49 & 58 & 75 & 49 & 53 & 63 & 69 \\
\hline Container & 11 & 20 & 26 & 44 & 64 & 98 & 111 & 128 & 145 \\
\hline General Cargo & 116 & 106 & 103 & 104 & 101 & 92 & 96 & 101 & 105 \\
\hline Dry Bulk & 186 & 232 & 235 & 262 & 276 & 321 & 346 & 368 & 391 \\
\hline Oil Tanker & 339 & 261 & 246 & 268 & 282 & 336 & 354 & 383 & 408 \\
\hline
\end{tabular}

Source: Compiled by the UNCTAD secretariat on the basis of data supplied by Lloyd's Register- Fairplay.

a Cargo carrying vessels of $100 \mathrm{GT}$ and above.

Graph $N^{\circ} 2$ shows the World Fleet by principal vessel types in selected years from 1980 to 2008. In proportion to the whole figure -in terms of deadweight- the container value is minor. Moreover, the number of shipping containers in the world has been growing over time. 
International seaborne trade increases currently about $4.8 \%$ per year and over the last three decades the annual average growth rate of world seaborne trade is estimated in $3.1 \%{ }^{6}$

According to the United Nations (2008, p. 22)

..."Since 1990, container trade (in TEUs) is estimated to have increased by a factor of five, which is equivalent to an average annual growth of $9.8 \%$ "

The following table shows the shipping containers in the world between 2005 and 2010 . Figures for the years 2008-2009 and 2010 have been calculated using an average growth rate of $4.8 \%$ given by the United Nations Report of Maritime Transport. Moreover, there are a wide series of factors that can influence the relationship of seaborne-growth and container-growth; such as bigger and faster vessels, volume of trade and many others.

Table $\mathrm{N}^{\circ} 3$ Amount of ISO shipping containers in the world by years

\begin{tabular}{ll}
\hline $\mathbf{2 0 0 5}$ & $13,735,885$ shipping containers \\
\hline $\mathbf{2 0 0 6}$ & $14,533,258$ shipping containers \\
\hline $\mathbf{2 0 0 7}$ & $16,188,065$ shipping containers \\
$\mathbf{2 0 0 8}$ & $16,965,092$ shipping containers * \\
$\mathbf{2 0 0 9}$ & $17,779,416$ shipping containers * \\
\hline
\end{tabular}

* The amount of shipping containers for 2008 to 2010 was estimated adding $4.8 \%$ each year.

Table elaborated upon the information available from the United Nations Conference on Trade and Development and corroborated with the China Freight Transport Report 2009.

The growth of shipping containers from 2005 to 2010 is estimated in approximations made from several reports and is explained in Table $\mathrm{N}^{\circ} 3$ above. The numbers in yellow were calculated, assuming that by 2007 the total seaborne freight reached 8.02 billion of tons of goods ${ }^{7}$, in addition this information was divided by 21 the number of T.E.U. that represent every single container using its maximum cargo capacity, then this number was divided by the number of average trips for every container $12-15^{8}$ per year and finally was corroborated by the China Freight Transport Report 2009, that predicts that freight cargo will grow by $6.5 \%$ between 2009 to $2013^{9}$, China produces more than $90 \%$ of containers of the world ${ }^{10}$. By 2010 the number of containers combined in the world, might reach about 18 million.

\footnotetext{
${ }^{6}$ United Nations (2008, p. xiii)

7 lbid

${ }^{8}$ (History Channel)

${ }^{9}$ International, Business Monitor (2009, p. 5)

${ }^{10}$ United Nations (2008, p. xiii)
} 


\section{4. - Container features}

Mass produced, modular, mobile, transportable, strong, stackable, light, cheap, too many adjectives for a single noun: the shipping container.

As can be seen from the first part of this research, freight containers represent the core of a highly and sophisticated method of transportation of goods called the intermodal system that makes possible the movement of containers by ships, trains, trucks and even aircraft. In addition, cargo containers made possible that societies could enjoy products and services from remote places and containerisation can be seen even as enhancing trade market growth in the future. However, shipping goods by containers represents the best way to carry products, being by far the most efficient way to move products with less negative environmental impact. ${ }^{11}$

The best word that exemplifies the meaning of the structure behind freight containers is "system", of which the definition is an assemblage or combination of things or parts forming a complex or unitary whole. ${ }^{12}$ The strength of the container lies in the arithmetic relationship of the parts; -length, width and height define the proportion of the form, -the dimensions define the size, - form and size define maximum cargo or vice versa.

\section{5. - Shipping container (steel manufacturing)}

A steel shipping container consists basically of: a steel frame, walls, roof, floor, doors and corner castings.

- Panels can be corrugated steel walls or FRP (Fiberglass Reinforced Panels) like the refrigerated containers.

- Generally a shipping container has a plywood floor.

Materials used

Containers are usually made of "corten" steel, the steel panels -walls and roof- are all of $2 \mathrm{~mm}$ thickness. ${ }^{13}$ The use of I beams for flooring is compulsory and the most common materials are steel and aluminium. ${ }^{14}$

\footnotetext{
${ }^{11}$ Vale $(2009$, p. 43)

12 (www.dictionary.com.)

${ }^{13}$ (www.zen.co.uk)

${ }^{14}$ Burg., G. V. (1975, pp. 61-65)
} 
Figure $\mathrm{N}^{\circ} 2$ : Shipping containers

Typical End-opening steel container

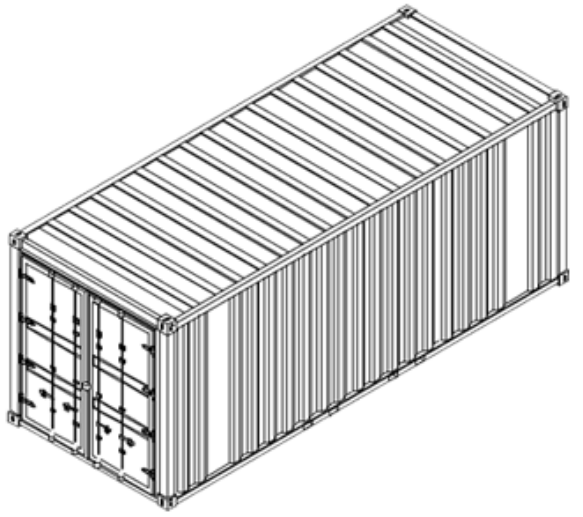

Typical Side-opening container

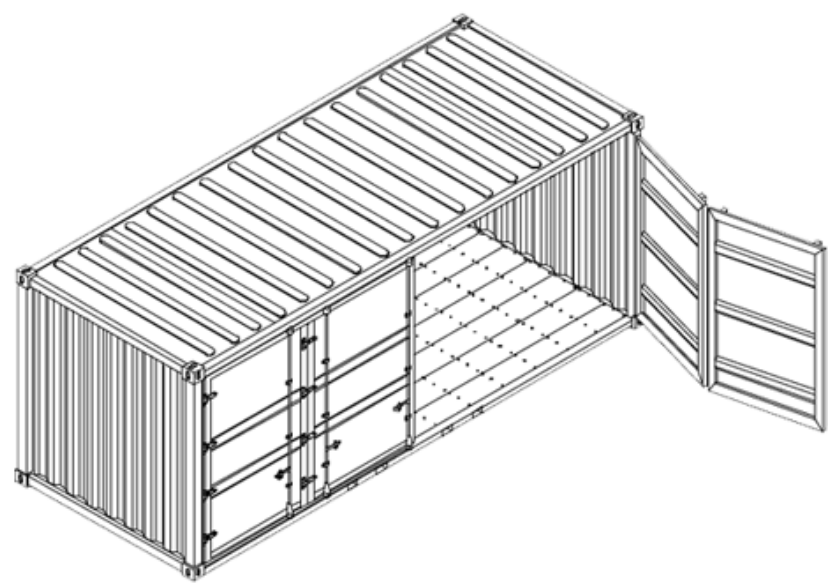

Typical Open-top container

Typical End-opening aluminium container

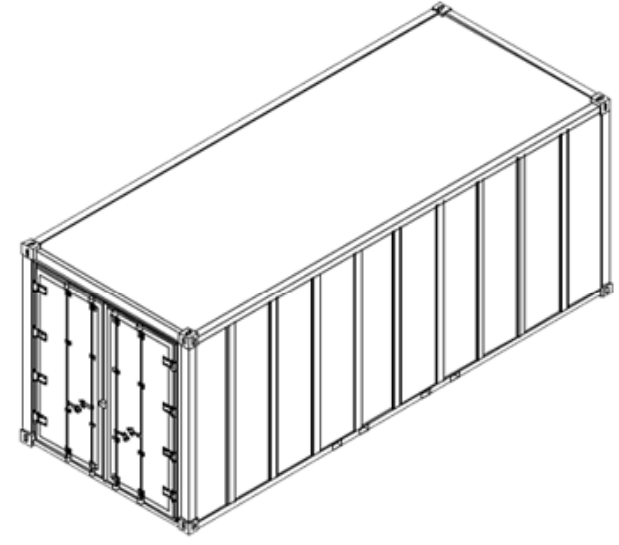

Typical End-opening FRP container

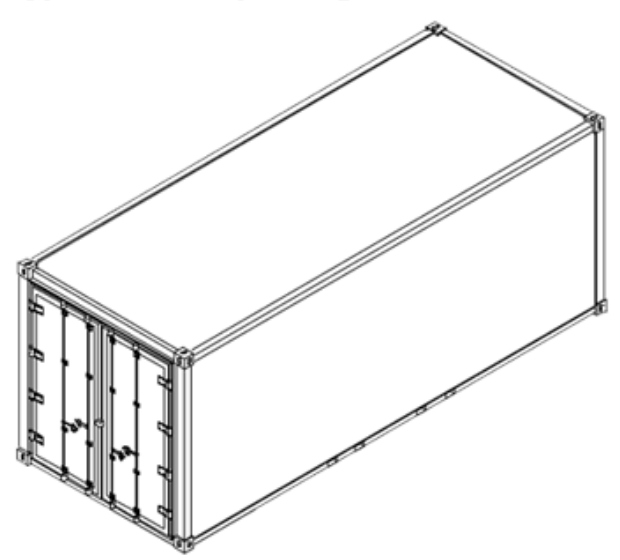

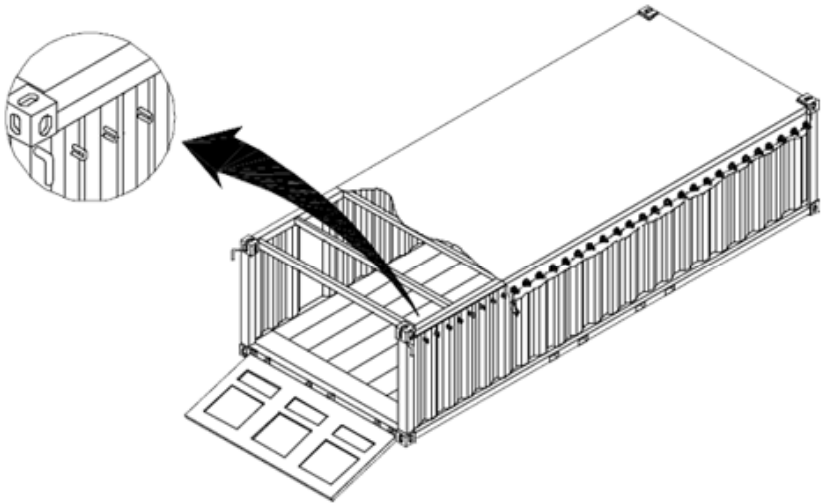

Typical High open-top container

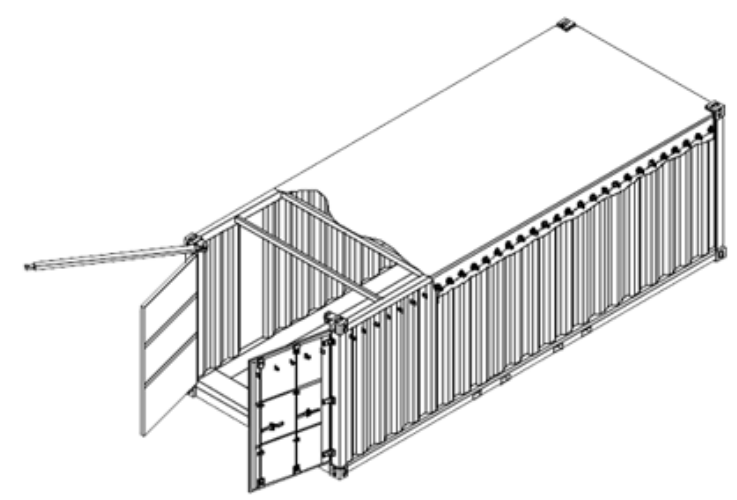

Image source: Own elaboration 


\section{6. - Units of measurement}

In the cargo-trade there exists a unit of measurement called T.E.U., or Twenty-foot Equivalent Unit. This is an inexact unit of cargo capacity, expressed in relation to the volume of a 20 foot- ISO container. While the TEU is not itself a measure of mass, some conclusions can be drawn about the maximum mass that a TEU can represent. The maximum gross mass for a 20 -foot $(6.1 \mathrm{~m})$ dry cargo container is 28,200 kilograms $(61,289 \mathrm{lb})$. Subtracting the tare mass of the container itself $(2,200 \mathrm{~kg})$, the maximum amount of cargo per TEU is reduced to approximately 26,000 kilograms $(57,320 \mathrm{lb})$

Figure $N^{\circ} 320$-foot ISO Shipping Container T.E.U.

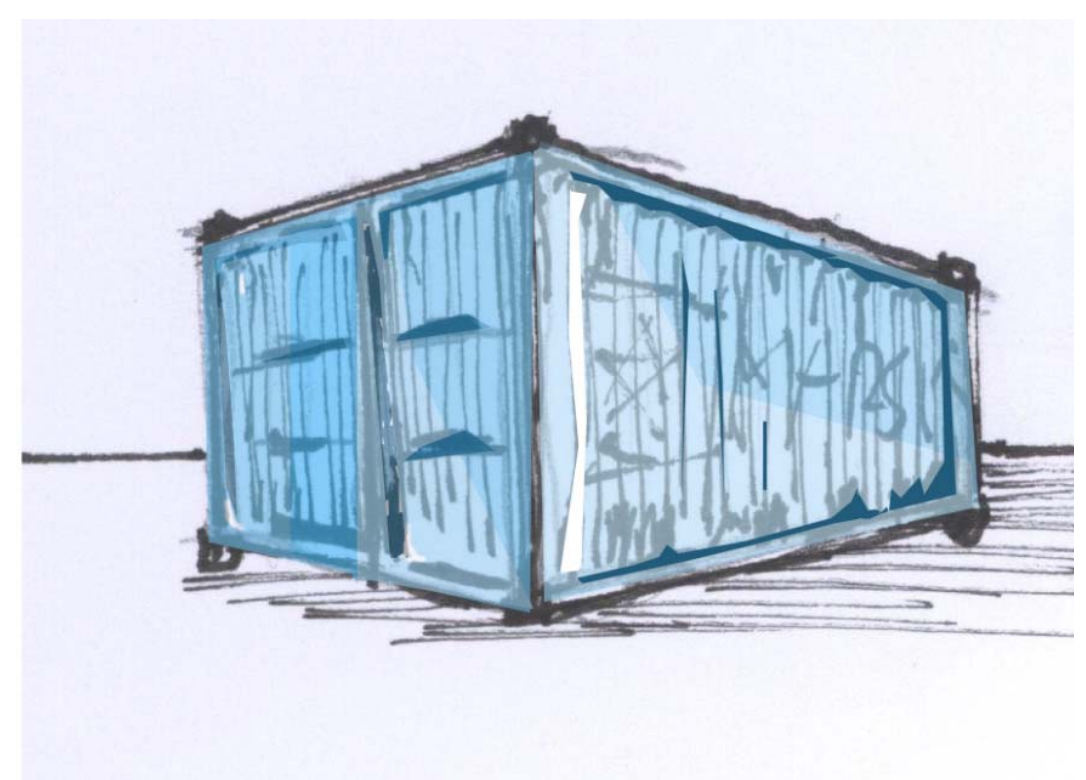

Image source: Own elaboration

Table $N^{\circ} 4$ TEU

$1 \mathrm{TEU}$ is equivalent to approximately

26,000 kilograms or $57,320 \mathrm{lbs}$.

For this research 1 TEU is expressed in kilograms as a maximum cargo capacity. (See table above). 


\section{7. - Container Dimensions}

Table $N^{\circ} 5,20$-foot ISO Shipping container of steel for general purpose (Dry Container)

\begin{tabular}{|c|c|c|c|c|c|c|c|c|c|}
\hline & \multicolumn{2}{|r|}{ container } & \multicolumn{2}{|r|}{ container } & \multicolumn{2}{|l|}{$\begin{array}{c}40 \text { ' high- } \\
\text { cube }\end{array}$} & \multicolumn{2}{|l|}{$\begin{array}{c}\text { 45' high- } \\
\text { cube }\end{array}$} \\
\hline & & imperial & metric & imperial & metric & imperial & metric & imperial & metric \\
\hline \multirow{3}{*}{$\begin{array}{c}\text { external } \\
\text { dimensions }\end{array}$} & length & $20^{\prime} 0^{\prime \prime}$ & $6.096 \mathrm{~m}$ & $40^{\prime} 0^{\prime \prime}$ & $12.192 \mathrm{~m}$ & $40^{\prime} 0^{\prime \prime}$ & $12.190 \mathrm{~m}$ & $45^{\prime} 0^{\prime \prime}$ & $13.716 \mathrm{~m}$ \\
\hline & width & $8^{\prime} 0^{\prime \prime}$ & $2.438 \mathrm{~m}$ & $8^{\prime} 0^{\prime \prime}$ & $2.438 \mathrm{~m}$ & $8^{\prime} 0^{\prime \prime}$ & $2.438 \mathrm{~m}$ & $8^{\prime} 0^{\prime \prime}$ & $2.438 \mathrm{~m}$ \\
\hline & height & $8^{\prime} 6^{\prime \prime}$ & $2.591 \mathrm{~m}$ & $8^{\prime} 6^{\prime \prime}$ & $2.591 \mathrm{~m}$ & $9^{\prime} 6^{\prime \prime}$ & $2.896 \mathrm{~m}$ & $9^{\prime} 6^{\prime \prime}$ & $2.896 \mathrm{~m}$ \\
\hline \multirow{3}{*}{$\begin{array}{c}\text { interior } \\
\text { dimensions }\end{array}$} & length & $18^{\prime} 105 / 16^{\prime \prime}$ & $5.758 \mathrm{~m}$ & $39^{\prime} 5$ 45/64" & $12.032 \mathrm{~m}$ & $39^{\prime} 4^{\prime \prime}$ & $12.000 \mathrm{~m}$ & $44^{\prime} 4^{\prime \prime}$ & $13.556 \mathrm{~m}$ \\
\hline & width & 7' 8 19/32" & $2.352 \mathrm{~m}$ & 7' 8 19/32" & $2.352 \mathrm{~m}$ & $7^{\prime} 7^{\prime \prime}$ & $2.311 \mathrm{~m}$ & 7' 8 19/32" & $2.352 \mathrm{~m}$ \\
\hline & height & 7' $957 / 64 "$ & $2.385 \mathrm{~m}$ & 7' 9 57/64" & $2.385 \mathrm{~m}$ & $8^{\prime} 9^{\prime \prime}$ & $2.650 \mathrm{~m}$ & $8^{\prime} 9$ 15/16" & $2.698 \mathrm{~m}$ \\
\hline & & & & & & & & & \\
\hline \multirow[t]{2}{*}{$\begin{array}{c}\text { door } \\
\text { aperture }\end{array}$} & width & 7' $8 \% 8^{\prime \prime}$ & $2.343 \mathrm{~m}$ & $77^{\prime} 81 / 8$ & $2.343 \mathrm{~m}$ & 7'6" & $2.280 \mathrm{~m}$ & 7' 8 1/" & $2.343 \mathrm{~m}$ \\
\hline & height & 7' 5 3/4" & $2.280 \mathrm{~m}$ & 7' 5 3/4" & $2.280 \mathrm{~m}$ & $8^{\prime} 5^{\prime \prime}$ & $2.560 \mathrm{~m}$ & 8' 5 49/64" & $2.585 \mathrm{~m}$ \\
\hline \multicolumn{2}{|l|}{ volume } & $1,169 \mathrm{ft}^{3}$ & $33.1 \mathrm{~m}^{3}$ & $2,385 \mathrm{ft}^{3}$ & $67.5 \mathrm{~m}^{3}$ & $2,660 \mathrm{ft}^{3}$ & $75.3 \mathrm{~m}^{3}$ & $3,040 \mathrm{ft}^{3}$ & $86.1 \mathrm{~m}^{3}$ \\
\hline \multirow{2}{*}{\multicolumn{2}{|c|}{$\begin{array}{l}\text { maximum } \\
\text { gross mass }\end{array}$}} & $66,139 \mathrm{lb}$ & $30,400 \mathrm{~kg}$ & $66,139 \mathrm{lb}$ & $30,400 \mathrm{~kg}$ & $68,008 \mathrm{lb}$ & $30,848 \mathrm{~kg}$ & $66,139 \mathrm{lb}$ & $30,400 \mathrm{~kg}$ \\
\hline & & & & & & & & & \\
\hline \multicolumn{2}{|l|}{$\begin{array}{l}\text { empty } \\
\text { weight }\end{array}$} & $4,850 \mathrm{lb}$ & $2,200 \mathrm{~kg}$ & $8,380 \mathrm{lb}$ & $3,800 \mathrm{~kg}$ & $8,598 \mathrm{lb}$ & $3,900 \mathrm{~kg}$ & $10,580 \mathrm{lb}$ & $4,800 \mathrm{~kg}$ \\
\hline \multicolumn{2}{|l|}{ net load } & $61,289 \mathrm{lb}$ & $28,200 \mathrm{~kg}$ & $57,759 \mathrm{lb}$ & $26,600 \mathrm{~kg}$ & $58,598 \mathrm{lb}$ & $26,580 \mathrm{~kg}$ & $55,559 \mathrm{lb}$ & $25,600 \mathrm{~kg}$ \\
\hline
\end{tabular}

Tables based on information from www.freightraders.co.nz ${ }^{15}$

According to table $\mathrm{N}^{\circ} 5$ shown above, in terms of empty weight a 20-foot empty shipping container weighs $2,200 \mathrm{~kg}$, in addition a 40 -foot empty shipping container weighs $3,800 \mathrm{~kg}$, this represents an increment of $72 \%$ of mass considering that a 40 -foot corresponds to twice over the space of a 20-foot container, this seems obvious but is important for vessels because this $28 \%$ of less mass means less deadweight and less deadweight means less energy, and less energy means more money. For this research comparing these two big boxes may determine which one is stronger than the other and it might be possible preliminarily to determinate which container is more efficient to be used as an instrument of construction. Another important approach is the maximum cargo of each steel container, as can be seen from Table $\mathrm{N}^{\circ} 5$, the maximum load for a 20 -foot container is around 28,200 $\mathrm{kg}$ meanwhile for a 40 -foot container the cargo limit is about $26,600 \mathrm{~kg}$, this represents a decline of $5.6 \%$ of total freight in regard to a 20 -foot container, considering there two times more space. First, it can be concluded that a 20-foot steel ISO shipping container is considerably stronger than a 40-foot steel ISO container in terms of maximum cargo that it can carry safely. Second, a 40-foot container is lighter but much more fragile than two 20foot shipping containers. This could be one of the main reasons that 20 -foot containers may be used more frequently in projects of architecture or simply because they are cheaper than 40-foot containers.

${ }^{15}$ (Freightraders) 


\section{8. - ISO (International Standard Organisation) container}

\section{Corrugated and insulated envelope}

The ISO steel shipping container is made from "weathering steel", also known as Cor-ten steel, a steel resistant to corrosion.

In addition a container's make up is formed by a main regular structure of beams, supported by posts in four points, the structure itself is an envelope, and corrugated walls give the strength to support the cargo weight.

\section{Structure of a container}

Figure $\mathrm{N}^{\circ}$ 4: 40-foot ISO shipping container isometric view

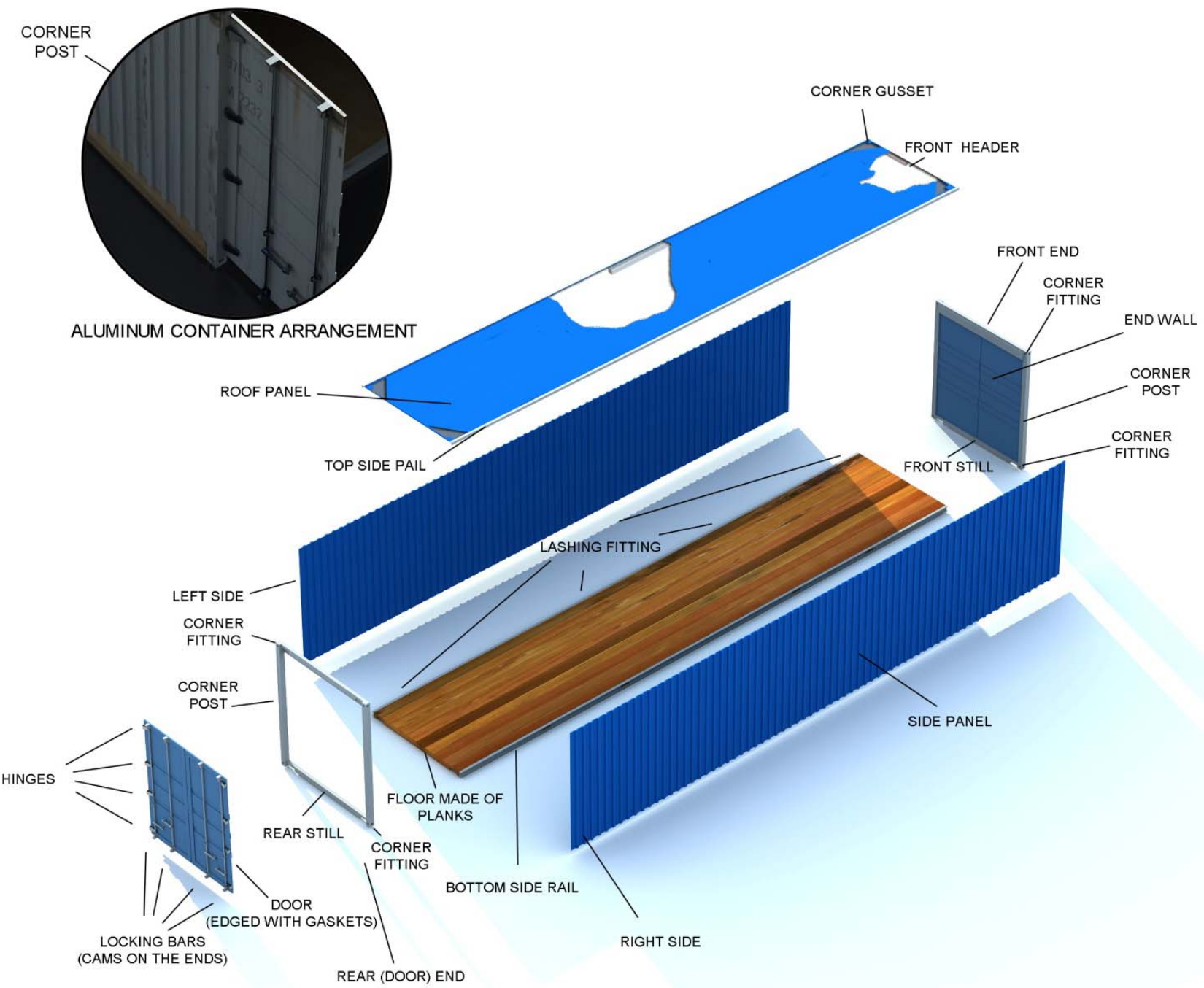




\section{Structure of a container}

Figure $\mathrm{N}^{\circ} 5: 20,40$-foot ISO shipping container isometric view

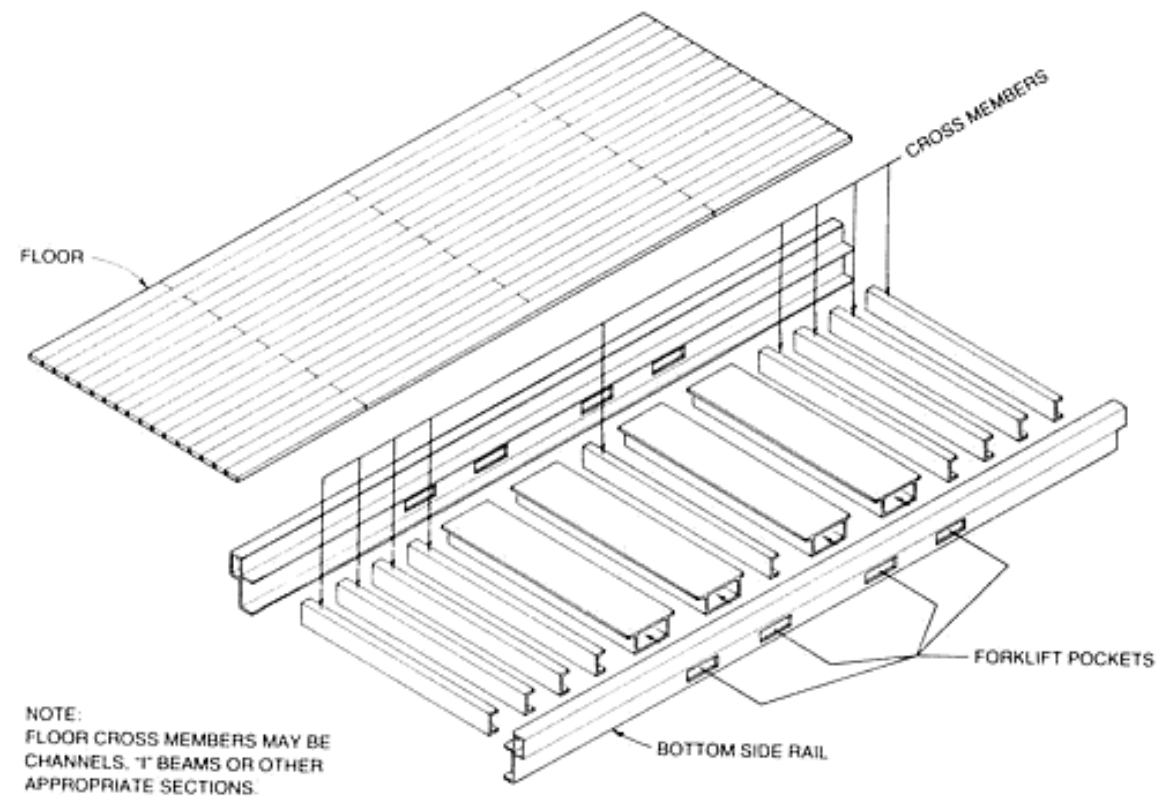

Figure $N^{\circ} 6:$ 20, 40-foot ISO shipping container front view

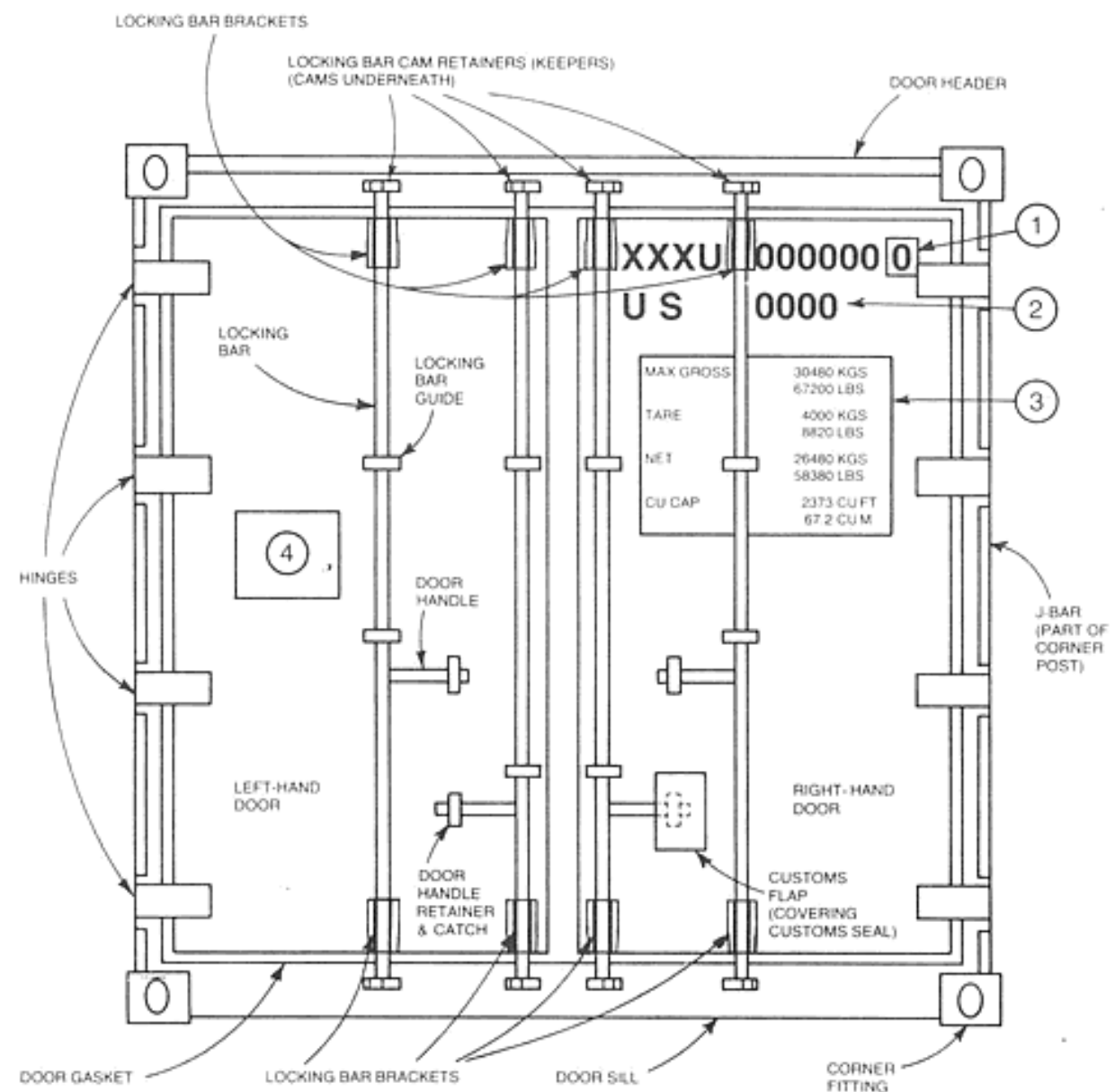

Image source: www.fireworkshk.com 


\section{Structure of a container}

Figure $N^{\circ} 7$ : 40-foot ISO shipping container isometric view Floor System

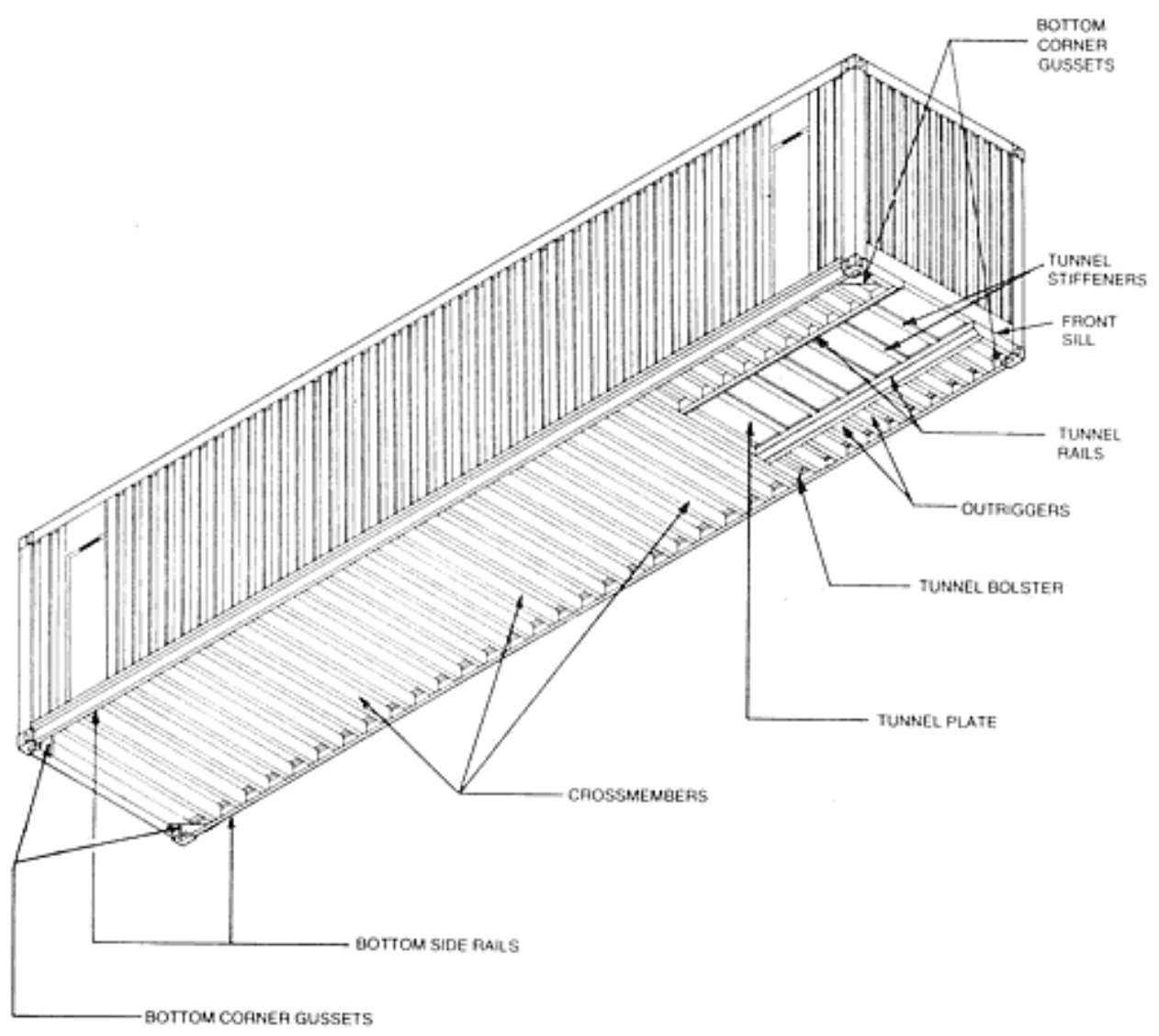

Image source: $\underline{w w w . f i r e w o r k s h k . c o m}$

\section{Structure of a container}

Figure $\mathrm{N}^{\circ} 8$ : 20-foot ISO shipping container parts

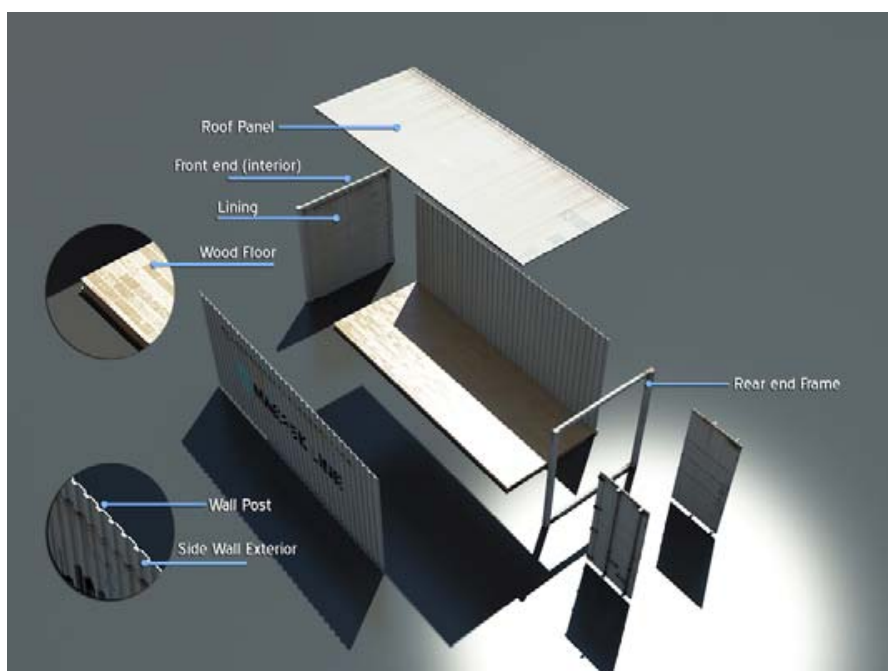

Image Source: Own scheme
Figure $\mathrm{N}^{\circ} 9$ : 20-foot vertical weight requirement

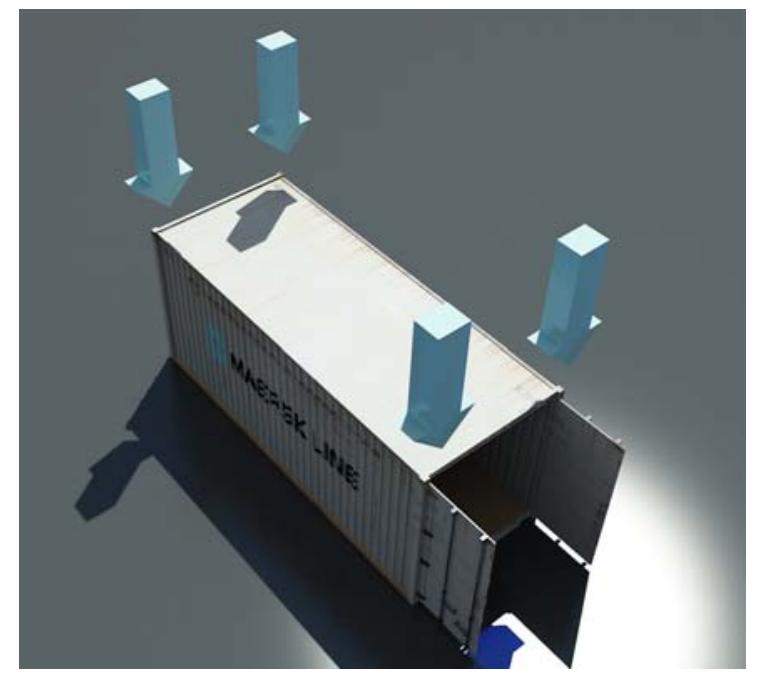




\section{9. - Types of ISO containers}

3.9.1. - Typical end-opening steel container of 20 -foot

A 20-foot steel shipping container for dry cargo is the most common in the family of ISO cargo containers, made up mainly of four components that set up the envelope. The percentages in Table $\mathrm{N}^{\circ} 6$ are based on inner dimensions and useful areas. Assuming that the end of the structure is closed, $50 \%$ of the total area corresponds to the walls, $21 \%$ for floor, another $21 \%$ for the roof and the remaining $8 \%$ corresponds to the doors.

Table $\mathrm{N}^{\circ} 620$-foot ISO Shipping container of steel for general purpose (Dry Container)

\begin{tabular}{|c|c|c|c|c|c|c|}
\hline 20-foot & length $\mathrm{m}$ & height $\mathrm{m}$ & $\begin{array}{c}\text { width } \\
\text { m }\end{array}$ & total area $\mathrm{m}^{2}$ & total per component $\mathrm{m}^{2}$ & $\%$ \\
\hline door 1 & & 2.385 & 1.176 & 2.804 & 5.608 & $8 \%$ \\
\hline door 2 & & 2.385 & 1.176 & 2.804 & & \\
\hline wall 1 & 5.758 & 2.385 & & 13.73 & 33.07 & $50 \%$ \\
\hline wall 2 & 5.758 & 2.385 & & 13.73 & & \\
\hline wall 3 & & 2.385 & 2.352 & 5.61 & & \\
\hline floor 1 & 5.758 & & 2.352 & 13.54 & 13.54 & $21 \%$ \\
\hline \multirow[t]{2}{*}{ roof 1} & 5.758 & & 2.352 & 13.54 & 13.54 & $21 \%$ \\
\hline & & & & & 65.758 & $100 \%$ \\
\hline
\end{tabular}

Graph N³, 20-foot ISO Shipping container make up for general purpose (Dry Container)

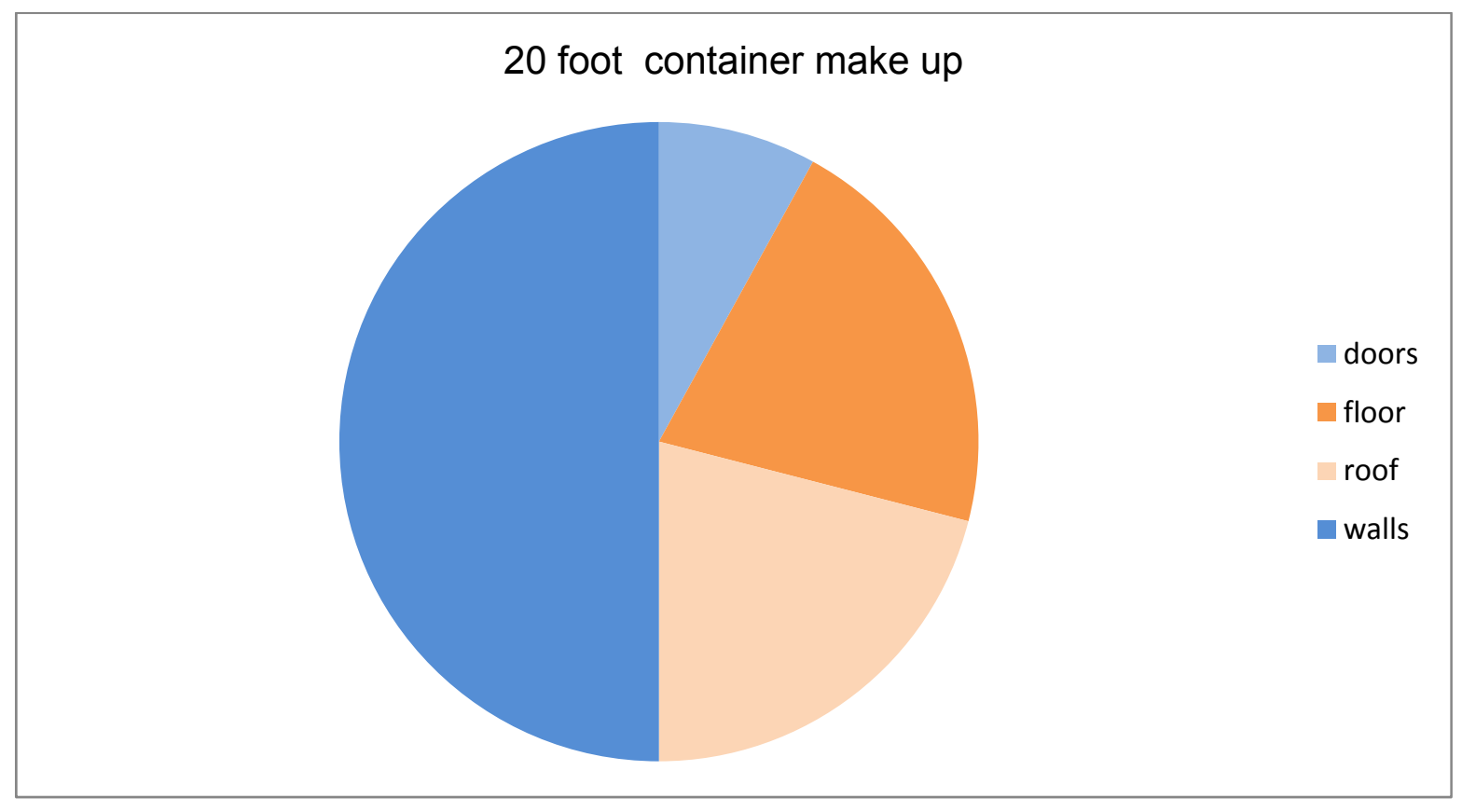


This assessment of the total surface of a container should be useful in order to:

1. Recognise which part of the main structure will be affected by future spatial decisions when the container is made into a building.

2. Calculate accurately the amount of energy and $\mathrm{CO}_{2}$ emissions generated in the process of transformation.

3. The necessity of light and air.

4. Possible connections between containers.

3.9.2. - Typical end-opening steel container of 40 -foot

Table $\mathrm{N}^{\circ} 7$ 40-foot ISO Shipping container of steel for general purpose (Dry Container)

\begin{tabular}{|c|c|c|c|c|c|c|}
\hline 40 foot & length $\mathrm{m}$ & height $\mathrm{m}$ & width $\mathrm{m}$ & total area $\mathrm{m}^{2}$ & total per component $\mathrm{m}^{2}$ & $\%$ \\
\hline door 1 & & 2.385 & 1.176 & 2.804 & 5.608 & $4 \%$ \\
\hline door 2 & & 2.385 & 1.176 & 2.804 & & \\
\hline wall 1 & 12.03 & 2.385 & & 28.69 & 62.98 & $50 \%$ \\
\hline wall 2 & 12.03 & 2.385 & & 28.69 & & \\
\hline wall 3 & & 2.385 & 2.352 & 5.6 & & \\
\hline floor 1 & 12.03 & & 2.352 & 28.29 & 28.29 & $23 \%$ \\
\hline \multirow[t]{2}{*}{ roof 1} & 12.03 & & 2.352 & 28.29 & 28.29 & $23 \%$ \\
\hline & & & & & 125.168 & $100 \%$ \\
\hline
\end{tabular}

3.10. - Lifespan of shipping containers

- The Lifespan of every container is around 10 years or 120 trips. $^{16}$

Complementary facts

- As more than $90 \%$ of the container production industry is located in China, market changes there may have a major impact upon future pricing. ${ }^{17}$

- Containers make between 10 and 15 trips every year. ${ }^{18}$

\footnotetext{
${ }^{16}$ (History Channel)

${ }^{17}$ United Nations (2008, p. 88)

${ }^{18}$ (History Channel)
} 


\subsection{1. - Costs of shipping containers.}

According to the United Nations Conference on Trade and Development (2008), Review of Marine Transport 2008..."During 2007, the price of new boxes was largely stable. The price of a 20-foot dry box, for example, started the year at a peak at \$2,050 on average in the first quarter of 2007, and then fell gradually toward $\$ 1,850$ in the third quarter, before recovering to $\$ 1,950$ by the end of the year".

Graph $\mathrm{N}^{\circ} 4$ Shipping container prices

Evolution of pieces of new containers

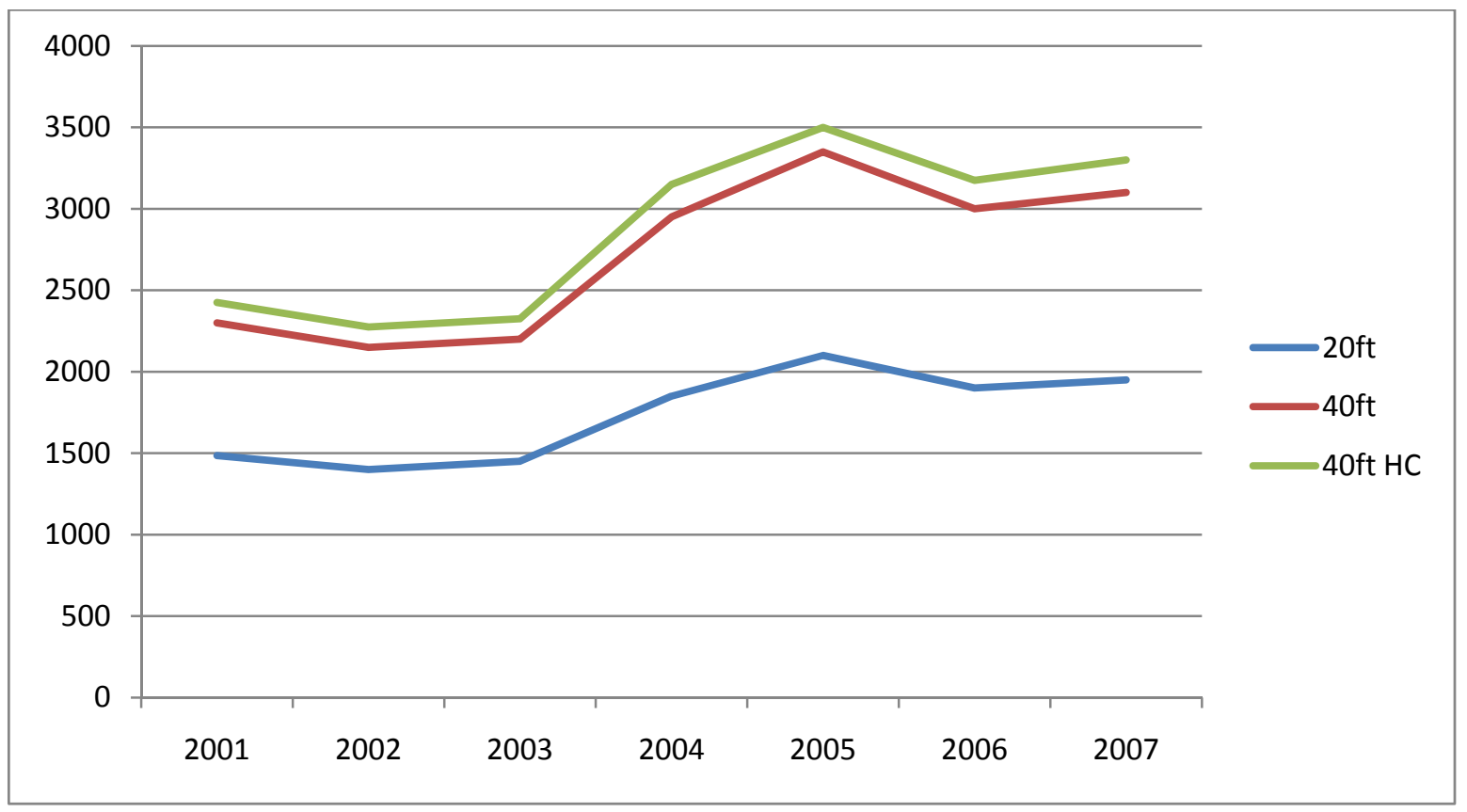

*Graph based on information from the United Nations Conference on Trade and Development, Review of Marine Transport 2008

The graph shows, a 20-foot steel shipping container destined for dry cargo represents the cheapest "steel box" among the family of containers, but not the cheapest per square metre of floor area. 


\section{0-foot steel shipping container prices}

The tables below have been made-up according to information linked to general prices of shipping containers found on internet. This information is organised into three different groups linked to the evolution of prices of new containers graph: the first is related to 20foot containers for cargo, the second, for $\mathbf{4 0 - f o o t ~ c a r g o ~ s h i p p i n g ~ c o n t a i n e r s ~ a n d ~ f i n a l l y ~ t h e ~}$ third is for $\mathbf{4 0 - f o o t ~ h i g h ~ c u b e ~ c a r g o ~ c o n t a i n e r s ~ ( w h i c h ~ o f f e r ~ g r e a t e r ~ i n t e r n a l ~ h e i g h t ) . ~}$

Prices in tables have been converted into NZ dollars to compare them. In addition, prices exclude GST or goods and services tax.

The main and most useful criterion for discrimination of shipping containers may be "usage", this may define the future purpose or not for human habitation depending on their trade history. Previously, this was explained based on the physical features but nevertheless an important concern is the likely content of these boxes before they became potentially available for use in architecture.

Table $N^{\circ} 8,20$-foot shipping container prices

\begin{tabular}{|c|c|c|c|c|c|c|c|}
\hline & $\begin{array}{l}\text { Storage Steel Shipping } \\
\text { Container }\end{array}$ & $\begin{array}{c}\text { Item } \\
\text { Condition }\end{array}$ & $\begin{array}{l}\text { US Dollar } \\
\text { Price }\end{array}$ & $\begin{array}{l}\text { N.Z. Dollar } \\
\text { Price }\end{array}$ & Item Location & Country & website \\
\hline & Size & & & & & & \\
\hline 1 & $20 \mathrm{ft}$ & used - older & 1,000 & 1,323 & Tampa, FL. & U.S. & www.ebay.com \\
\hline 2 & $20 \mathrm{ft}$ & used & 1,150 & 1,521 & New Jersey, N.J. & U.S. & www.ebay.com \\
\hline 3 & $20 \mathrm{ft}$ & used & 1,300 & 1,720 & St. Louis, MO. & U.S. & www.ebay.com \\
\hline 4 & $20 \mathrm{ft}$ & used & 1,400 & 1,852 & Columbus, $\mathrm{OH}$. & U.S. & www.ebay.com \\
\hline 5 & $20 \mathrm{ft}$ & used & 1,400 & 1,852 & Worcester, MA. & U.S. & www.ebay.com \\
\hline 6 & $20 \mathrm{ft}$ & used & 1,400 & 1,852 & Kansas, MO. & U.S. & www.ebay.com \\
\hline 7 & $20 \mathrm{ft}$ & used & 1,925 & 2,546 & Worcester, MA. & U.S. & www.ebay.com \\
\hline Total Average & & & 1,367 & 1,809 & & & \\
\hline
\end{tabular}

URL: http://shop.ebay.com/? from=R40\& trksid=p3907.m38.11311\& nkw=shipping+container\& sacat=See-All-Categories

Current prices excludes GST (Goods and Services Tax)

Calculations were done by using http://www.x-rates.com/calculator.htm website

Table $\mathrm{N}^{\circ} 8$ shows the prices for a 20-foot dry shipping container in the United States. The minimum price is $\$ 1,323 \mathrm{NZ}$ dollars and the highest registered for storage is $\$ 2,546 \mathrm{NZ}$ dollars. The average price for 20-foot shipping containers destined for storage of different goods is around $\$ 1,809 \mathrm{NZ}$ dollars or $\$ 133.60$ dollars per $\mathrm{m}^{2}$. 
40-foot steel cargo-shipping container prices

Table $\mathrm{N}^{\circ} 9$ 40-foot used shipping container price

\begin{tabular}{|c|c|c|c|c|c|c|c|c|}
\hline & $\begin{array}{c}\text { Cargo } \\
\text { Steel } \\
\text { Shipping } \\
\text { Container }\end{array}$ & $\begin{array}{c}\text { Item } \\
\text { Condition }\end{array}$ & US Dollar Price & N.Z. Dollar Price & Item Location & Country & website & $\begin{array}{l}\mathrm{NZ} \\
\text { exchange } \\
\text { rate }\end{array}$ \\
\hline & Size & & & & & & & \\
\hline 1 & 40ft Dry & used & 1,110 & 1,468 & $\begin{array}{c}\text { Columbus, } \\
\text { OH. }\end{array}$ & U.S. & www.ebay.com & 1.32304 \\
\hline 2 & 40ft Dry & used & 1,250 & 1,653 & $\begin{array}{c}\text { Long Beach, } \\
\text { CA. }\end{array}$ & U.S. & www.ebay.com & 1.32304 \\
\hline 3 & 40ft Dry & used & 1,400 & 1,852 & Norfolk, VA. & U.S. & www.ebay.com & 1.32304 \\
\hline 4 & 40ft Dry & used & 1,400 & 1,852 & Savannah, GA. & U.S. & www.ebay.com & 1.32304 \\
\hline 5 & 40ft Dry & used & 1,450 & 1,918 & Detroit & U.S. & www.ebay.com & 1.32304 \\
\hline 6 & 40ft Dry & used & 1,500 & 1,984 & Newark, NJ. & U.S. & www.ebay.com & 1.32304 \\
\hline 7 & 40ft Dry & used & 1,550 & 2,050 & $\begin{array}{c}\text { Cincinnati, } \\
\text { OH. }\end{array}$ & U.S. & www.ebay.com & 1.32304 \\
\hline 8 & $40 f t$ Dry & used & 1,550 & 2,050 & Cleveland, $\mathrm{OH}$. & U.S. & www.ebay.com & 1.32304 \\
\hline 9 & 40ft Dry & used & 1,550 & 2,050 & $\begin{array}{c}\text { Columbus, } \\
\text { OH. }\end{array}$ & U.S. & www.ebay.com & 1.32304 \\
\hline 10 & 40ft Dry & used & 1,550 & 2,050 & Memphis, TN. & U.S. & www.ebay.com & 1.32304 \\
\hline 11 & 40ft Dry & used & 1,600 & 2,116 & Oakland, CA. & U.S. & www.ebay.com & 1.32304 \\
\hline 12 & 40ft Dry & used & 1,600 & 2,116 & Houston, TX. & U.S. & www.ebay.com & 1.32304 \\
\hline 13 & 40ft Dry & used & 1,650 & 2,183 & Atlanta, GA. & U.S. & www.ebay.com & 1.32304 \\
\hline 14 & 40ft Dry & used & 1,650 & 2,183 & Chicago, IL. & U.S. & www.ebay.com & 1.32304 \\
\hline 15 & 40ft Dry & used & 1,650 & 2,183 & St. Louis, MO. & U.S. & www.ebay.com & 1.32304 \\
\hline 16 & 40ft Dry & used & 1,700 & 2,249 & Seattle, WA. & U.S. & www.ebay.com & 1.32304 \\
\hline 17 & 40ft Dry & used & 1,700 & 2,249 & $\begin{array}{l}\text { Minneapolis, } \\
\text { MN. }\end{array}$ & U.S. & www.ebay.com & 1.32304 \\
\hline 18 & 40ft Dry & used & 1,725 & 2,282 & $\begin{array}{c}\text { Jacksonville, } \\
\text { FL. }\end{array}$ & U.S. & www.ebay.com & 1.32304 \\
\hline 19 & 40ft Dry & used & 1,750 & 2,315 & $\begin{array}{c}\text { Kansas City, } \\
\text { MO. }\end{array}$ & U.S. & www.ebay.com & 1.32304 \\
\hline 20 & 40ft Dry & used & 1,750 & 2,315 & Louisville, KY. & U.S. & www.ebay.com & 1.32304 \\
\hline 21 & 40ft Dry & used & 1,800 & 2,381 & $\begin{array}{c}\text { Baltimore, } \\
\text { MD. }\end{array}$ & U.S. & www.ebay.com & 1.32304 \\
\hline 22 & 40ft Dry & used & 1,800 & 2,381 & Dallas, TX. & U.S. & www.ebay.com & 1.32304 \\
\hline 23 & 40ft Dry & used & 1,850 & 2,447 & Portland, OR. & U.S. & www.ebay.com & 1.32304 \\
\hline 24 & 40ft Dry & used & 2,000 & 2,646 & $\begin{array}{l}\text { Charleston, } \\
\text { SC. }\end{array}$ & U.S. & www.ebay.com & 1.32304 \\
\hline 25 & 40ft Dry & used & 2,100 & 2,778 & Denver, co. & U.S. & www.ebay.com & 1.32304 \\
\hline 26 & 40ft Dry & used & 2,150 & 2,844 & $\begin{array}{c}\text { Salt Lake City, } \\
\text { UT. }\end{array}$ & U.S. & www.ebay.com & 1.32304 \\
\hline 27 & 40ft Dry & used & 2,300 & 3,042 & Reno, NV. & U.S. & www.ebay.com & 1.32304 \\
\hline $\begin{array}{c}\text { Total } \\
\text { Average }\end{array}$ & & & 1,669 & 2,209 & & & & \\
\hline
\end{tabular}

URL: http://shop.ebay.com/? from=R40\& trksid=p3907.m38.|1311\& nkw=shipping+container\& sacat=See-All-Categories

Current prices excludes GST( Goods and Services Tax)

Calculations were done by using http://www.x-rates.com/calculator.htm website

Table $N^{\circ} 9$ above, shows the prices for cargo-containers in the United States of America according to e-bay.com, the lowest price is $\$ 1,468 \mathrm{NZ}$ dollars and the highest price rose to $\$ 3,042 \mathrm{NZ}$ dollar. The average price for a 40 -foot cargo container is around $\$ 2,209 \mathrm{NZ}$ dollars. 
40-foot high cube Dry steel shipping container prices

Table $N^{\circ} 10,40$-foot high cube shipping container price

\begin{tabular}{|c|c|c|c|c|c|c|c|c|}
\hline & $\begin{array}{l}\text { 40-foot High-cube } \\
\text { Shipping Container }\end{array}$ & $\begin{array}{c}\text { Item } \\
\text { Condition }\end{array}$ & $\begin{array}{l}\text { US Dollar } \\
\text { Price }\end{array}$ & $\begin{array}{l}\text { N.Z. Dollar } \\
\text { Price }\end{array}$ & $\begin{array}{c}\text { Item } \\
\text { Location }\end{array}$ & Country & website & $\begin{array}{l}\mathrm{NZ} \\
\text { exchange } \\
\text { rate }\end{array}$ \\
\hline & Size & & & & & & & \\
\hline 1 & 40ft Dry & used & 1,955 & 2,582 & Newark, NJ. & U.S. & www.ebay.com & 1.32304 \\
\hline 2 & 40ft Dry & used & 2,300 & 3,037 & $\begin{array}{l}\text { Victorville, } \\
\text { CA. }\end{array}$ & U.S. & www.ebay.com & 1.32304 \\
\hline 3 & 40ft Dry & used & 2,400 & 3,175 & $\begin{array}{l}\text { Henderson } \\
\text { co. }\end{array}$ & U.S. & www.ebay.com & 1.32304 \\
\hline 4 & 40ft Dry & used & 1,700 & 2,250 & $\begin{array}{c}\text { Cincinnati, } \\
\text { OH. }\end{array}$ & U.S. & www.ebay.com & 1.32304 \\
\hline 5 & 40ft Dry & used & 1,700 & 2,250 & Tampa, FL. & U.S. & www.ebay.com & 1.32304 \\
\hline 6 & 40ft Dry & used & 2,150 & 2,845 & $\begin{array}{l}\text { Victorville, } \\
\text { CA. }\end{array}$ & U.S. & www.ebay.com & 1.32304 \\
\hline 7 & 40ft Dry & used & 1,950 & 2,580 & Ventura, CA. & U.S. & www.ebay.com & 1.32304 \\
\hline 8 & 40ft Dry & used & 1,800 & 2,381 & Atlanta, GA. & U.S. & www.ebay.com & 1.32304 \\
\hline 9 & 40ft Dry & used & 1,900 & 2,513 & $\begin{array}{c}\text { Minneapolis } \\
\text { MN. }\end{array}$ & U.S. & www.ebay.com & 1.32304 \\
\hline $\begin{array}{c}\text { Total } \\
\text { Average }\end{array}$ & & & 1,984 & 2,624 & & & & \\
\hline
\end{tabular}

URL: http://shop.ebay.com/? from=R40\& trksid=p3907.m38.|1311\& nkw=shipping+container\& sacat=See-All-Categories

Current prices excludes GST (Goods and Services Tax)

Calculations were done by using http://www.x-rates.com/calculator.htm website

Table $\mathrm{N}^{\circ} 10$ shows 40 -foot high-cube shipping containers prices in different parts of the United States, the lowest price is $\$ 2,250$ and the highest is $\$ 3,135 \mathrm{NZ}$ dollars. The average price is around $\$ 2,624 \mathrm{NZ}$ dollars, if it is compared with the average price for a 20 -foot shipping container $(\$ 1,809)$, it will not be found a significant increment of these steel boxes considering two times more space.

Normalised into square meters gives the following figures:

- 20-foot container $133 \mathrm{NZ}$ dollar/m $\mathrm{m}^{2}$

- 40-foot container $78 \mathrm{NZ}$ dollar/m²

- 40-foot high-cube container $93 \mathrm{NZ}$ dollar $/ \mathrm{m}^{2}$

Due to this fact, it could be argued now that -for human-habitable purposes- 40 -foot shipping containers are potentially more efficient in terms of cost because, overall, buying a single 40-foot shipping container is far more economic than buying two 20-foot containers, even when in terms of maximum weight cargo, 40-foot "boxes" are much more fragile but lighter than 20-foot containers. The problem that may have to be faced now is choosing reliable structures. 


\subsection{2. - Problems and disadvantages of shipping containers.}

It is easy to find buildings with steel freight containers used as the main components on the internet and it may be easier to find all of those people who promote them and promote their usage. On the other hand, little is known about the processes that these people use to modify a container so that can serve as a building. In addition, plans and images that anyone can find on the web have little or no information about how to structurally support the fanciful designs or any construction details (connections, roofing materials, wall cross sections) ${ }^{19}$

According to Engineer Mr. George Runkle:

"Building a shipping container building is not as easy as drawing a picture of what you think would be a nice structure, there is a significant amount of architecture and engineering involved."

However, according to Runkle Consulting Inc -a company of engineering experts in steel structures for residential uses- and experts in the shipping container house design ${ }^{20}$ they have deeply studied the performance of a container when this has been modified. Looking through this useful website of engineering (http://www.runkleconsulting.com) the author gives a series of criteria about how a shipping container should be used and chosen.

For example: The most common of the family of the ISO containers are the 8'x 8'x 20 foot unit and the 8'x 8' x 40 foot unit. According to Runkle (http://www.runkleconsulting.com) the $8^{\prime} \times 9 \frac{1}{2} \times 40^{\prime}$ high-cube units are much more suitable for buildings because the height will let designers hide duct work, electrics, and plumbing above the ceiling.

Containers are generally made from steel corner posts, steel side rails top and bottom, and corrugated steel sides and roof. The floor is steel sheeting with top hat sections stamped in it, covered with sheets of plywood. The plywood is treated for insects and smells -in factnasty. $^{21}$

Another problem is the roof, the containers are supposed to be water tight, but in time the roof of the containers gets beaten in, and water does not run off like it is supposed to. A roof has to be put on the buildings. ${ }^{22}$

\footnotetext{
${ }^{19}$ (Runkle, www.runkleconsulting.com)

${ }^{20} \mathrm{Ibid}$

${ }^{21} \mathrm{Ibid}$

${ }^{22}$ Ibid
} 
Loads

From an engineering point of view, loads need to go through the connection points. This allows a lot of flexibility and makes foundation construction much easier because loads can be transferred to the foundations at the corners of the container. ${ }^{23}$

Another issue is the fact that container houses are a non-standard structure; this means that permitting the construction of the structure may be difficult.

\section{Construction}

Construction results are relatively easy except for residential construction, which is the main topic of this research, because designers will run into issues with the skills and capabilities of the labour force. They (labour force) have to unload the containers and place them with a crane, which is unfamiliar equipment to many residential contractors. In addition, there is significant steelwork required when the walls of the containers are cut because there may have to be welded in pieces of steel to reinforce the main frame after they have been cut into. ${ }^{24}$ Again, this is not a common skill among residential builders.

The sequence is basic, the foundations are built first. Then the containers are hauled to the site. Secondly, they are cut as needed or have already been cut, and lifted into place using a crane. Additional steel may be required depending on the complexity of the structure and depending how the container has been cut.

A lot of sites on the internet make the design look very simple. However, these "designs" are not complete by any manner.

According to (Runkle, http://www.runkleconsulting.com)

..."the whole idea of building with shipping containers is ease of construction, low cost, and recycling (green building)." ... "These ideas are hard to accomplish if you design like gravity doesn't exist". In addition, some tips are given:

- "Slicing the container in different ways is not reasonable, leave it alone".

- "Preserve the Corner Posts, Top, and Bottom Rails".

- "Cantilevers are difficult and expensive".

- "Stack the containers right side up".

- "When you remove the sides, the container loses strength".

- "Stack containers along the same axis".

\footnotetext{
${ }^{23} \mathrm{Ibid}$

${ }^{24}$ (Runkle, www.runkleconsulting.com)
} 
Figure $\mathrm{N}^{\circ} 10$ an experimental container house

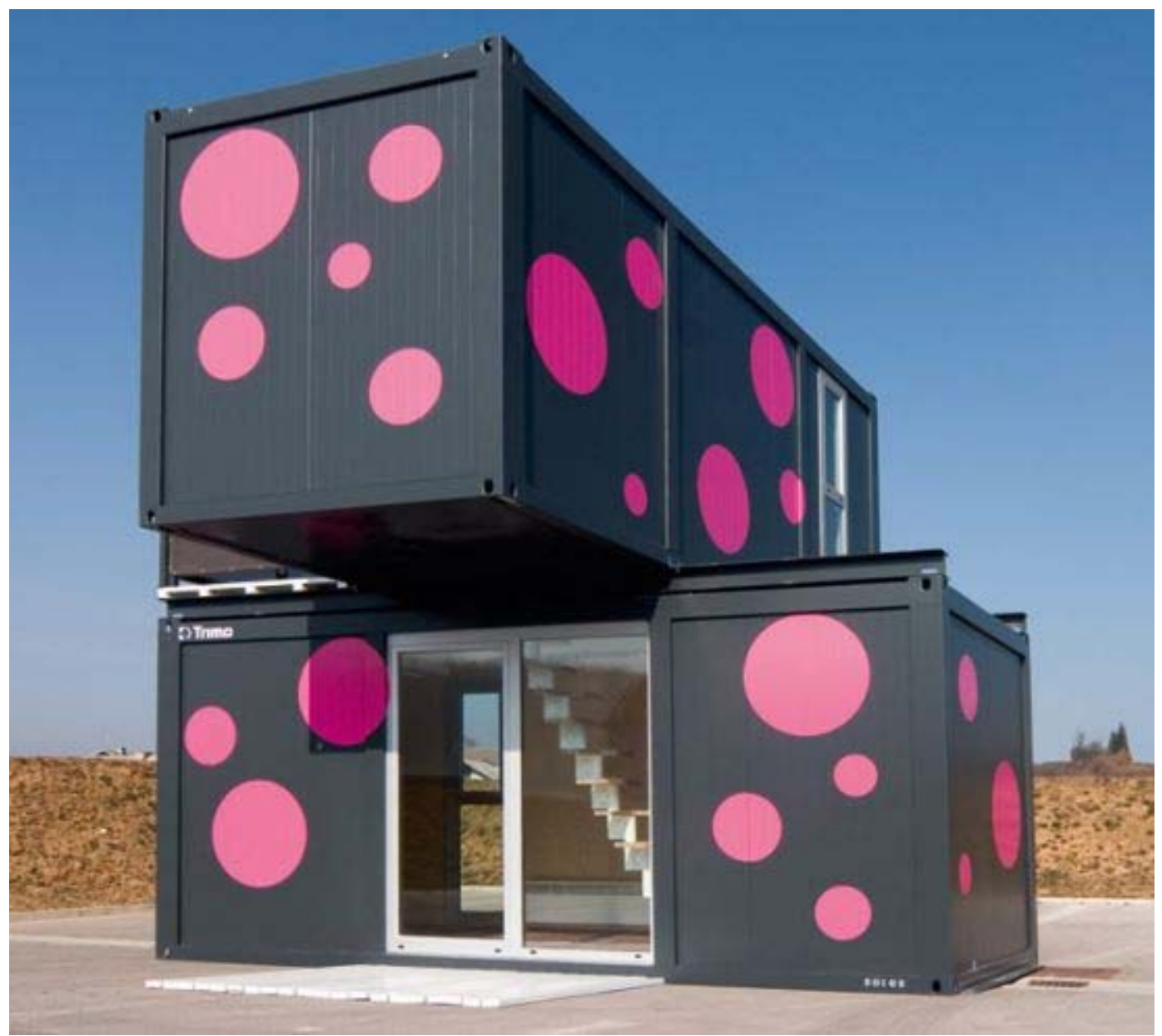

Image Source: http://www.runkleconsulting.com/ShippingContainerHouses/InformationForArchitects.htm

For this project shown in the photograph beams had been added on the top of the first container in order to avoid the torsion due to wind loads. In addition, more columns were added in the top and the bottom containers at the connection points to add strength. ${ }^{25}$ Moreover, containers do have a standard design at the connection points so that it is possible to tie them down on vessels, trains, and trucks in a uniform manner.

A freight container is an object designed to carry things: raw materials, televisions, shoes, weapons, etc. some of them are specially designed to carry toxic substances, or some of them are designed to carry other kinds of loads, such is the case for meat, fruits or all of those things that require a specific temperature to not damage their content and performance.

${ }^{25}$ (Runkle, www.runkleconsulting.com) 
Engineering a Shipping container building

Unfortunately, there is no literature review or studies of engineers or indeed nothing definitive on shipping containers where engineering is concerned. ${ }^{26}$ One of the disadvantages is that unfortunately, there is no "standard" shipping container design. There is an ISO standard for their load carrying capacity (see beginning of chapter 3 ) and that has resulted in most containers being the same regardless of manufacturer. ${ }^{27}$

Runkle declares: What happens when you take off the skin to open the container up?

The answer is, when the lateral bracing disappears, so does a significant amount of its ability to carry a vertical load too. ${ }^{28}$ This is the dilemma of cutting or not cutting the walls. On the one hand, no one can live in an empty, dark and non-ventilated box. On the other hand, cutting walls means diminishing the strength of the structure as a whole.

When this happens, the container itself does not have real strength after being cut and a lot of steel must to be put into it to make it strong again. This can be expensive. The following model shows how a shipping container deflects (exaggerated) under a wind load and an interior live load. This container is supported at the connection points. The roof ends up in compression, as well as the bottom and the sides. ${ }^{29}$

Figure $\mathrm{N}^{\circ} 11$ Container deflection

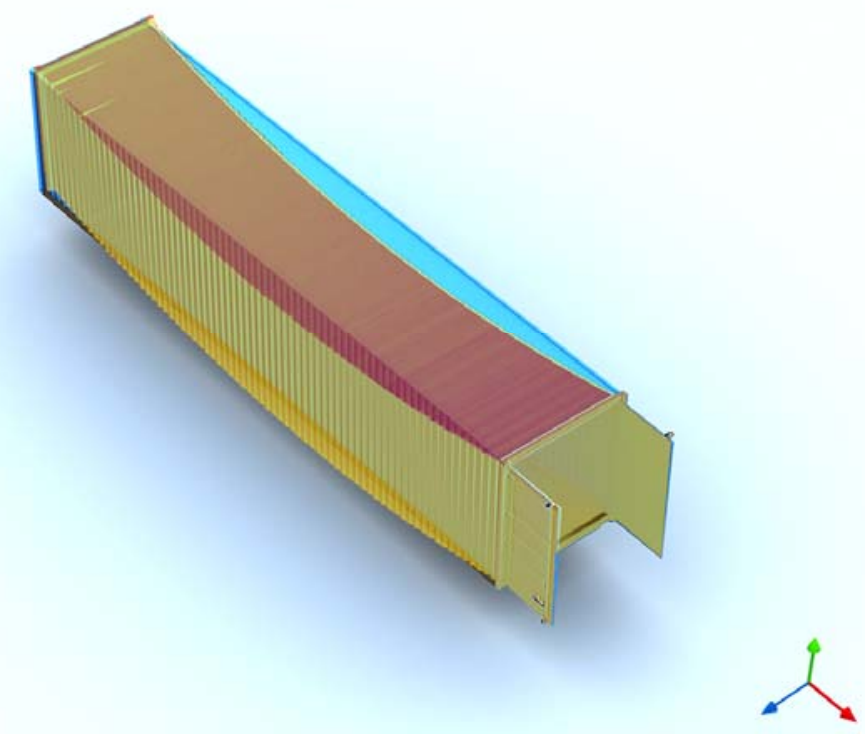

Image source: Based on image found in www.runkleconsulting.com

\footnotetext{
${ }^{26}$ (Runkle, www.runkleconsulting.com)

27 Ibid

${ }^{28} \mathrm{Ibid}$

${ }^{29}$ Ibid
} 
Figure $\mathrm{N}^{\circ} 12$ Container deflection

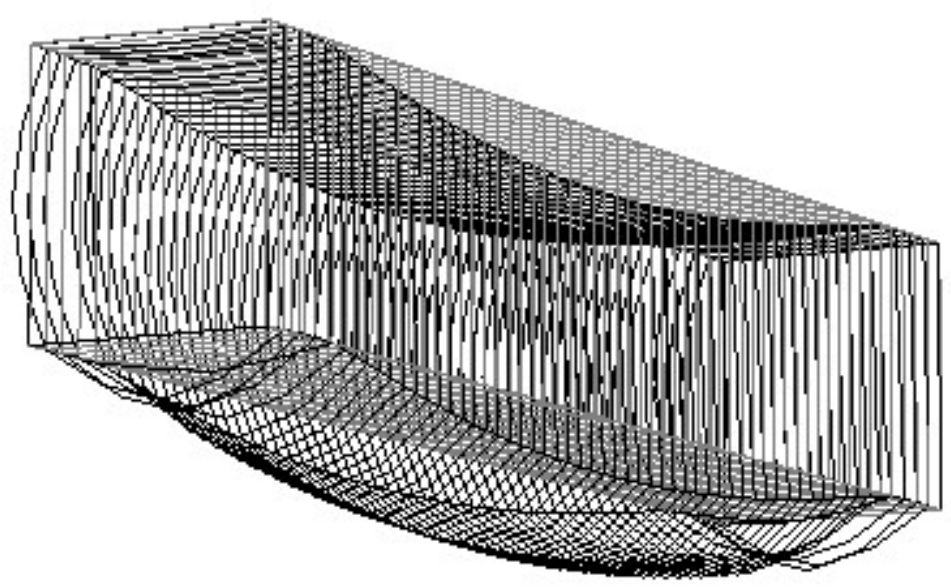

Image source: original image found in www.runkleconsulting.com

Figure $\mathrm{N}^{\circ} 13$ Container deflection

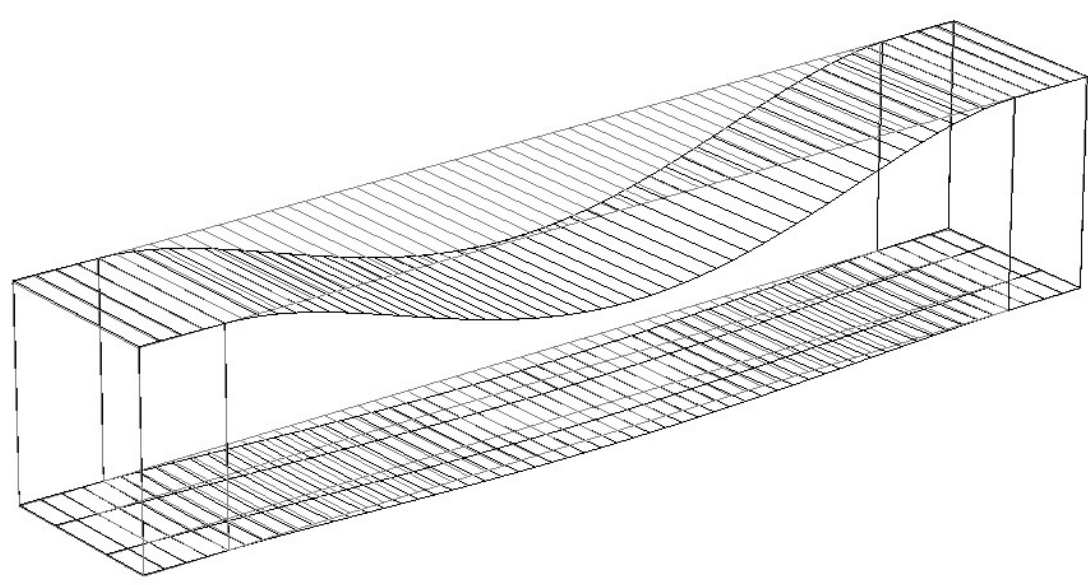

Image source: original image found in www.runkleconsulting.com

Image above shows the deflection with sides removed. 


\subsection{3. - Summary of the chapter}

- Container shipping seems to be the most efficient way for the transport of goods because the relationship of energy expended versus weight shipped is small in contrast with other types of transport.

- The total amount of containers in the world was estimated to be around 16 million by 2007.

- China produces around $90 \%$ of shipping containers of the world.

- The availability of containers to be used in architecture is linked to World Trade Routes.

- In terms of deadweight containers represent a small proportion of the total fleet (vessels, general cargo, and so on)

- It is difficult tracing with extreme accuracy the total amount of containers organised by size and type. However, this investigation predicts that by 2010 the amount of containers of the world may reach around 18 million.

- The success of the container itself is the arithmetic relationship of the parts between, form, size and proportion.

- The T.E.U. or twenty-foot equivalent unit is an inexact unit of cargo capacity.

- Most of ISO containers are 20, 30, 40-foot, 40 high-cube and 45 high cube foot.

- In terms of costs the price of containers over the years has grown irregularly.

Problems and disadvantages of shipping containers as buildings

- There is a significant amount of architecture and engineering involved.

- From an engineering point of view loads need to go through the connection points. The containers should be stacked along the same axis in order to avoid torsion due to wind loads.

- Higher containers are much more suitable for buildings because the height will let designers hide duct work, electrics, and plumbing above the ceiling.

- The labour force is not used to the construction of buildings which use containers for the residential sector.

- When the walls of the containers are modified or removed the entire structure loses its inherent strength.

- Insulation / Ventilation

- Waterproofing: the roofs of the containers are supposed to be water tight, but in time they get beaten in. 
Chapter IV - Energy Generation, energy consumption and environmental issues in the construction sector

This Chapter aims to provide information from the open and general to more specific data of world energy supply versus world energy consumption. In addition, this section sets up the bond between other elements, such as the diverse types of fuels, how much is produced, where they are produced, who consumes energy and how it is consumed. But, more important this chapter shows the evolution of energy generation and consumption patterns over time, setting new parameters according to the present day.

\section{1. - Climate change}

Climate change is the most important issue of our era and reduction of green house gases at the same time is the most important challenge.

\section{2. - Total primary energy supply and fossil fuels}

In recent years world total primary energy supply has grown sharply. By 2007 generation of primary energy was more than twice the 1973 production. Evolution of primary energy supply during the period of 1971 to 2007 by item shows that after all these years the fuel types distribution patterns have been increasing in consumption although some of them have decreased in percentage terms.

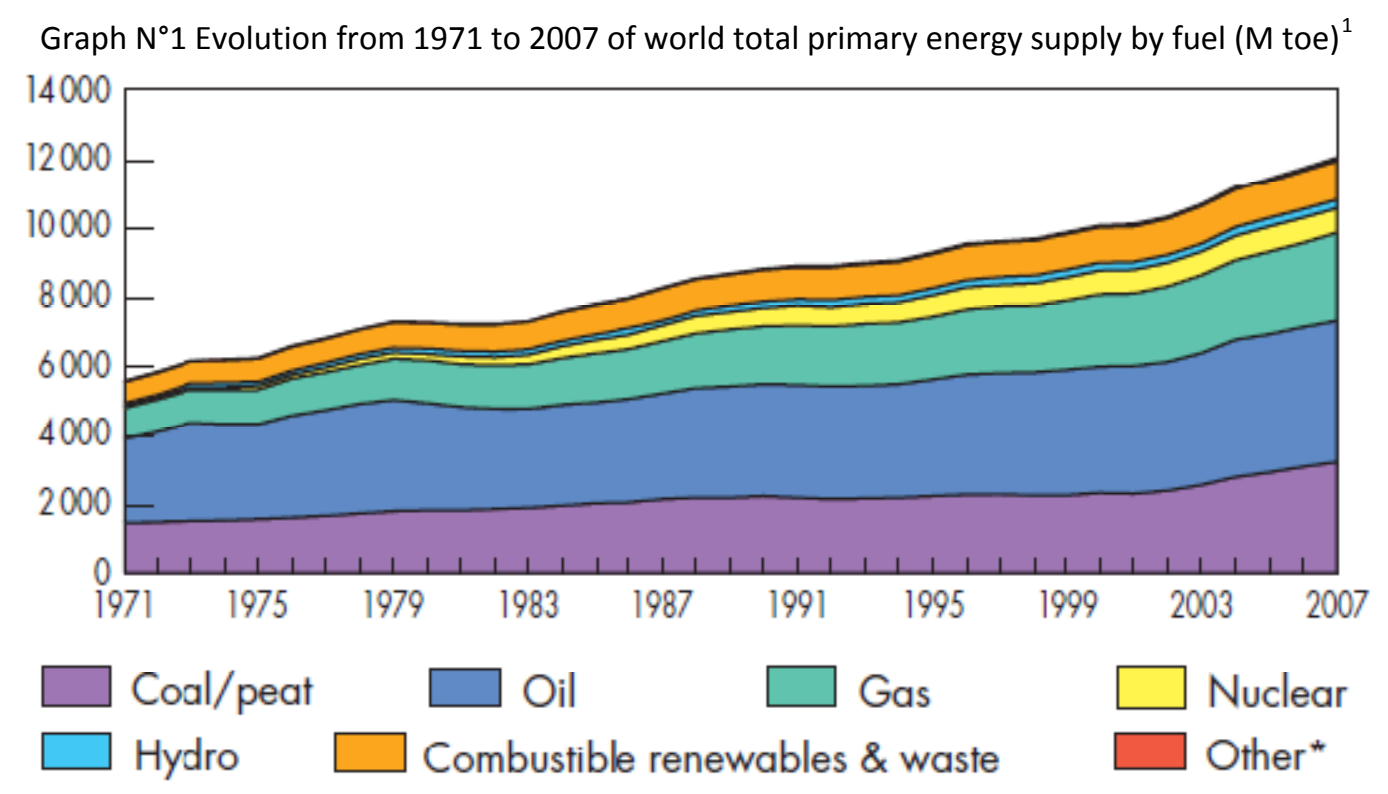

Image source: International Energy Agency Report

\footnotetext{
${ }^{1}$ International Energy Agency $(2009$, p. 6)

*Other includes geothermal, solar, wind and heat.
} 
Table $N^{\circ} 1$ Evolution from 1971 to 2007 of world total primary energy supply by fuel ( $\mathrm{M}$ toe $)^{2}$

\begin{tabular}{|ccc|}
\hline Fuel type & Year & Year \\
\hline \% & 1973 & 2007 \\
\hline Coal / peat & $24.5 \%$ & $26.5 \%$ \\
\hline Oil & $46.1 \%$ & $34 \%$ \\
\hline Gas & $16 \%$ & $20.9 \%$ \\
\hline Nuclear & $0.9 \%$ & $5.9 \%$ \\
\hline Hydro & $1.8 \%$ & $2.2 \%$ \\
\hline Combustible renewable and waste & $10.6 \%$ & $9.8 \%$ \\
\hline Geothermal, solar and wind & $0.1 \%$ & $0.7 \%$ \\
\hline Percentage & $100 \%$ & $100 \%$ \\
\hline & & \\
\hline World Total Supply in M toe & $\mathbf{6 1 1 5}$ & $\mathbf{1 2 0 2 9}$ \\
\hline
\end{tabular}

Table $\mathrm{N}^{\circ} 1$ shows the World Total Primary Energy Supply make up. Combustion of fossil fuels leads by far the total primary energy supply counting for about $86.6 \%$ of the total in 1973 and $81.4 \%$ of the total in 2007 . However, over the years only a $5.2 \%$ increase of independence of fossil fuels has been achieved (in percentage terms).

Renewable fuels rose slightly from $12.5 \%$ in 1973 to $12.7 \%$. Nevertheless its growth was a scarce $0.2 \%$ over all the years in terms of proportion. In terms of $\mathrm{M}$ toe (million tons of oil equivalent) the growth was from $764 \mathrm{M}$ toe in 1973 to $1,527 \mathrm{M}$ toe by 2007 , a doubling over the years of the study.

Oil consumption has increased. By 1973 oil burning up was nearly to $2,819 \mathrm{M}$ toe and by the year of 2007 oil consumption reached 4,089 $\mathrm{M}$ toe. On the other hand, the proportion in the use of oil declined from $46.1 \%$ in 1973 to $34 \%$ by 2007 but not the consumption. The third most important trend is that nuclear energy production has increased slightly, from a minimal $0.9 \%$ in 1973 to $5.9 \%$ in 2007.

\footnotetext{
${ }^{2}$ International Energy Agency $(2009$, p. 6)
} 


\section{3. - World total energy consumption}

As can be seen, graph $\mathrm{N}^{\circ} 2$ shows the growth from 1971 to 2007 of world total primary energy consumption by fuel. The trend proves that after all these years primary energy use patterns have been growing constantly, reaching almost two times the amount of energy required by 2007 in comparison with 1973.

In contrast with 1973, energy uses in 2007, and consumption patterns have remained similar. However, total fossil fuel dependency has diminished from $75.7 \%$ to $67 \%$ only in terms of its proportion among the rest of the items. On the other hand, the amount of fossil fuel burned nowadays is more than in the past, so fossil fuel consumption has risen in spite of the slight decrease in dependency.

Graph $N^{\circ} 2$ Evolution from 1971 to 2007 of world total primary energy consumption by fuel (M toe $)^{3}$

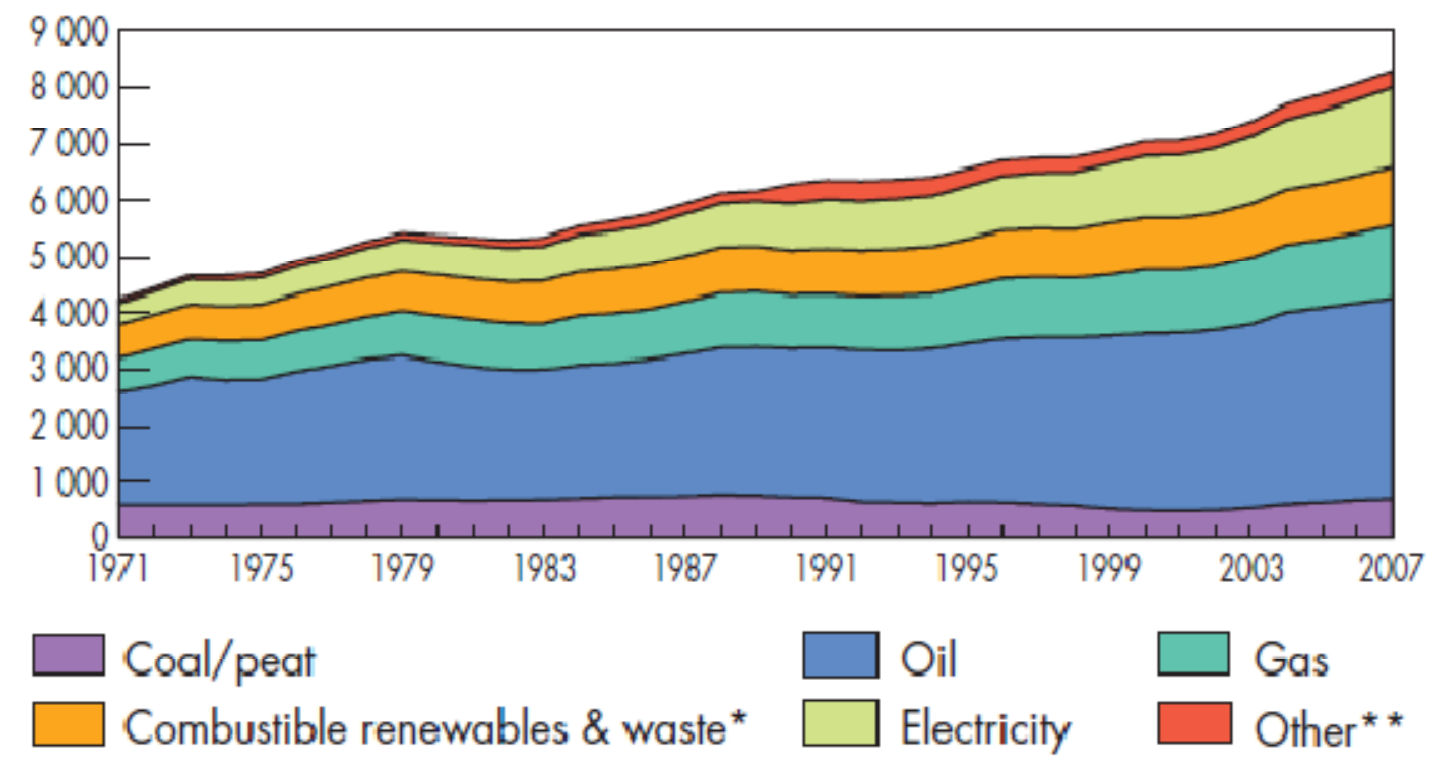

Image source: International Energy Agency Report

\footnotetext{
${ }^{3}$ International Energy Agency (2009, p. 28)

** Other includes geothermal, solar, wind and heat.
} 
Table $N^{\circ} 2$ Evolution from 1971 to 2007 of world total primary energy consumption by fuel (M toe $)^{4}$

\begin{tabular}{ccc}
\hline Fuel type & Year & Year \\
\hline$\%$ & 1973 & 2007 \\
\hline Coal / peat & & \\
\hline Oil & $13.2 \%$ & $8.8 \%$ \\
\hline Gas & $48.1 \%$ & $42.6 \%$ \\
\hline Combustible renewable and waste & $14.4 \%$ & $15.6 \%$ \\
\hline Electricity & $13.2 \%$ & $12.4 \%$ \\
\hline Geothermal, solar and wind & $9.4 \%$ & $17.1 \%$ \\
\hline Percentage & $1.7 \%$ & $3.5 \%$ \\
\hline & $100 \%$ & $100 \%$ \\
\hline World Total Consumption in M toe & $\mathbf{4 , 6 7 5}$ & \\
\hline
\end{tabular}

The burning of fossil fuels leads the total primary energy consumption counting for about $75.7 \%$ of the total in 1973 and $67 \%$ of the total in 2007.

Renewable fuels increased from $24.3 \%$ in 1973 to $33 \%$. In terms of $M$ toe the growth was from 1,136 $M$ toe in 1973 to 2,734 M toe by 2007, two times more than in the past years.

Oil consumption has increased. By 1973 oil burning up was nearly to 2,248 $\mathrm{M}$ toe and by the year of 2007 oil consumption reached the worth of 3,529 $\mathrm{M}$ toe. On the other hand, the percentage in the use of oil declined from $48.1 \%$ in 1973 to $42.6 \%$ by 2007 .

\footnotetext{
${ }^{4}$ International Energy Agency (2009, p. 28)
} 


\section{4. - Environmental effects of energy use}

World total primary energy supply in 2007 reached 12,029 $\mathrm{M}$ toe and the same year world total primary energy consumption was about 8,286 $\mathrm{M}$ toe. In order to produce energy that can be consumed, 3,743 $\mathrm{M}$ toe are lost, which represents almost one third or $31 \%$ of the total energy supply wasted.

Both world total energy supply and consumption have grown over the years.

If the figures for burning fossil fuels are compared the following table can be drawn.

Table $\mathrm{N}^{\circ} 3$ Combustion of fossil fuels

\begin{tabular}{ccc}
\hline & $\begin{array}{c}\text { World energy supply } \\
\text { combustion } \\
\text { of fossil fuels }\end{array}$ & $\begin{array}{c}\text { World energy consumption } \\
\text { combustion } \\
\text { of fossil fuels }\end{array}$ \\
\hline 1973 & $86.6 \%$ & $75.7 \%$ \\
\hline 2007 & $81.4 \%$ & $67 \%$ \\
\hline
\end{tabular}

Burning of fossil fuels was $86.6 \%$ in 1973 related to the world total energy supply and $75.7 \%$ in 1973 linked to the world total energy consumption. Combustion of fossil fuels was $81.4 \%$ in 2007 associated with the energy supply and $67 \%$ in 2007 related to the energy consumption.

The proportion of the burning of fossil fuels remains high in comparison with the percentages of renewable sources of energy.

In the last thirty seven years the proportion of burning of fossil fuels seems to have declined in both lines; energy supply and energy consumption. Nevertheless, this is an unrealistic affirmation because overall trends had grown sharply over this period. By comparison, world population grew from 3,942 million in 1973 to 6,831 million in 2010 (data from US Census Bureau at http://www.census.gov/ipc/www/idb/worldpop.php viewed 27 Apr 2010). 
4.5. - Energy consumption by region (total final world consumption)

As can be seen, graph $\mathrm{N}^{\circ} 3$ shows the development from 1971 to 2007 of world total energy use by region. The OECD means the Organisation for Economic Co-operation and Development ${ }^{5}$ which leads the group of regions in terms of energy consumption. Like most of the graphs shown in this chapter of the thesis, if world energy supply and world energy consumption have risen is obvious that energy consumption per region has grown as well.

Graph $N^{\circ} 3$ Evolution from 1971 to 2007 of world total energy consumption by region (M toe) ${ }^{6}$

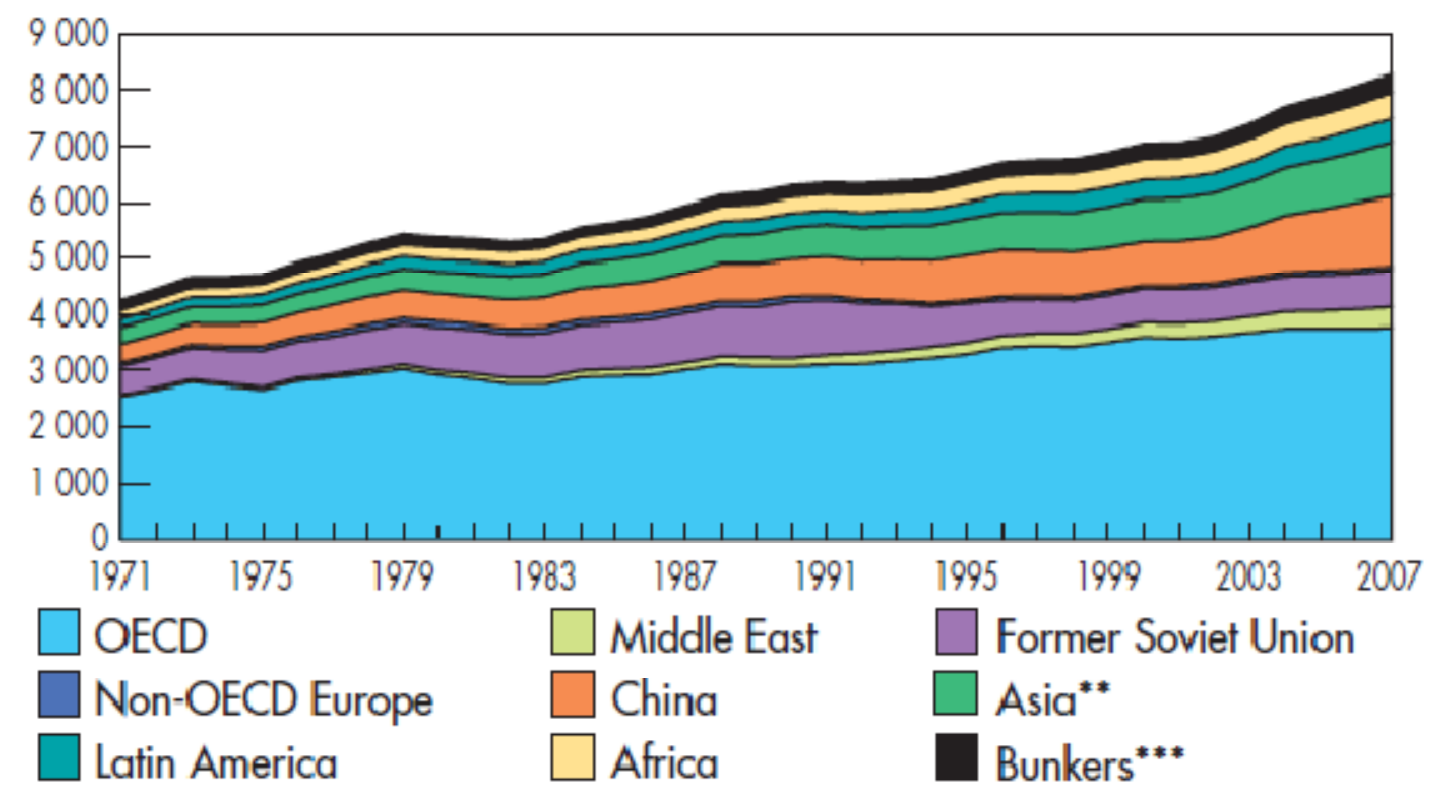

* Prior to 1994 combustible renewable \& waste final consumption has been estimated.

** Asia excludes China.

*** Includes International aviation and international marine bunkers.

${ }^{5}$ (www.oecd.org)

${ }^{6}$ International Energy Agency (2009, p. 30) 
Table $\mathrm{N}^{\circ} 4$ Evolution from 1971 to 2007 of world total energy consumption by region (M toe) ${ }^{7}$

\begin{tabular}{|c|c|c|}
\hline Region & Year & Year \\
\hline & 1973 & 2007 \\
\hline OECD & $60.1 \%$ & $45.5 \%$ \\
\hline Middle East & $0.8 \%$ & $4.4 \%$ \\
\hline Former Soviet Union & $12 \%$ & $7.9 \%$ \\
\hline Non OECD Europe & $1.5 \%$ & $0.8 \%$ \\
\hline China & $7.9 \%$ & $15.2 \%$ \\
\hline Asia** & $6.4 \%$ & $11.5 \%$ \\
\hline Latin America & $3.7 \%$ & $5.15 \%$ \\
\hline Africa & $3.7 \%$ & $5.6 \%$ \\
\hline Bunkers*** & $3.4 \%$ & $4 \%$ \\
\hline Percentage & $100 \%$ & $100 \%$ \\
\hline World total final consumption & 4,675 & 8,286 \\
\hline $\mathrm{M}$ toe & & \\
\hline
\end{tabular}

Developed countries have the biggest impact in energy consumption over developing economies. In the 1970 s the OECD consumed $60.1 \%$ of world total energy. By comparison, nowadays OECD consumption has dropped a quarter in contrast with the past, reaching the $45.1 \%$, but only in proportion, because use has not fallen.

\footnotetext{
${ }^{7}$ International Energy Agency (2009, p. 30)
} 


\section{6. - Energy consumption by sector}

The energy expenditure by different sectors will be presented in this section. Four areas are introduced: Industry, transport, other sectors, (including agriculture, commercial \& public services, residential and non-specified other sectors) and non-energy use. Four types of fuels will be assessed and discussed: Coal, oil, gas and electricity. Other energy sources were ignored because these four represent the most common fuels in the energy consumption sphere.

Graph N4 Evolution from 1971 to 2007 of world total coal consumption by sector (M toe) ${ }^{8}$

\section{Coal*}

\section{Evolution from 1971 to 2007 of total final consumption by sector (Mtoe)}

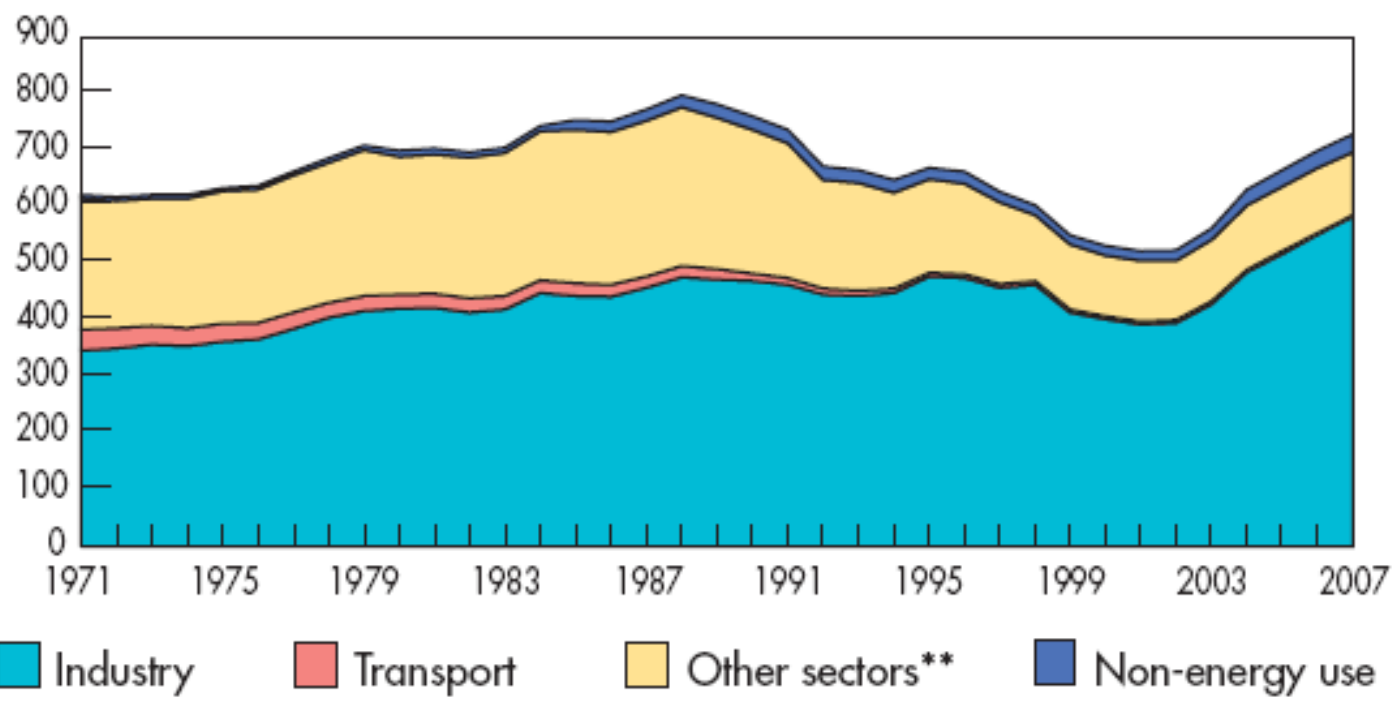

* Coal refers to coal / peat

** Includes agriculture, commercial \& public services, residential and non-specified other sectors.

As can be seen from graph $\mathrm{N}^{\circ} 4$ burning of coal does not show a lineal or regular growth, but an irregular development over the years, with a rapid rise in the $21^{\text {st }}$ century.

\footnotetext{
${ }^{8}$ International Energy Agency (2009, p. 32)
} 
Table N5 Evolution from 1971 to 2007 of world total coal consumption by sector (M toe) ${ }^{9}$

\begin{tabular}{ccc}
\hline Sector & Year & Year \\
\hline & 1973 & 2007 \\
\hline Industry & $57.5 \%$ & $80 \%$ \\
\hline Transport & $5.3 \%$ & $0.5 \%$ \\
\hline Other sectors* & $36.2 \%$ & $15.1 \%$ \\
\hline Non energy use & $1 \%$ & $4.4 \%$ \\
\hline Percentage & $100 \%$ & $100 \%$ \\
\hline World total coal consumption & & \\
\hline M toe & $\mathbf{6 2 1}$ & $\mathbf{7 2 9}$ \\
\hline
\end{tabular}

* Coal refers to coal / peat

** Includes agriculture, commercial \& public services, residential and non-specified other sectors.

Coal consumption grew slightly. In comparison with the other three main energy sources, the amount of million tons of oil equivalents in 1973 was $621 \mathrm{M}$ toe meanwhile the quantity increased reaching $729 \mathrm{M}$ toe by 2007. The peak in the usage of this fuel occurred in the early 1990s. The difference between the first measurement in respect of the last one is about $108 \mathrm{M}$ toe consumed. This is significantly less than the rest of the figures. Possible reasons for this fact are the development of hydro power and other nonand-renewable energy sources.

The cause of why the Industry sector grew in its overall percentage can be explained by the fact that all other sectors declined in the coal expenditure figure over the period of 1971 to 2007. Among the rest of the items, the reduction in the usage of coal for transportation decreased considerably. Many factors can explain this fact; such as the development of new technologies, more efficient engine designs, etc. On the other hand, in the last few years the production and consumption of coal has recovered.

\footnotetext{
${ }^{9}$ International Energy Agency (2009, p. 32)
} 
Oil is probably the most important fuel among the fossil fuels and might represent the most common source of energy. The consumption of oil for every sector is large and diverse.

\section{Graph N5 Evolution from 1971 to 2007 of world total oil consumption by sector (M toe) ${ }^{10}$}

\section{Oil}

\section{Evolution from 1971 to 2007 of total final consumption by sector (Mtoe)}

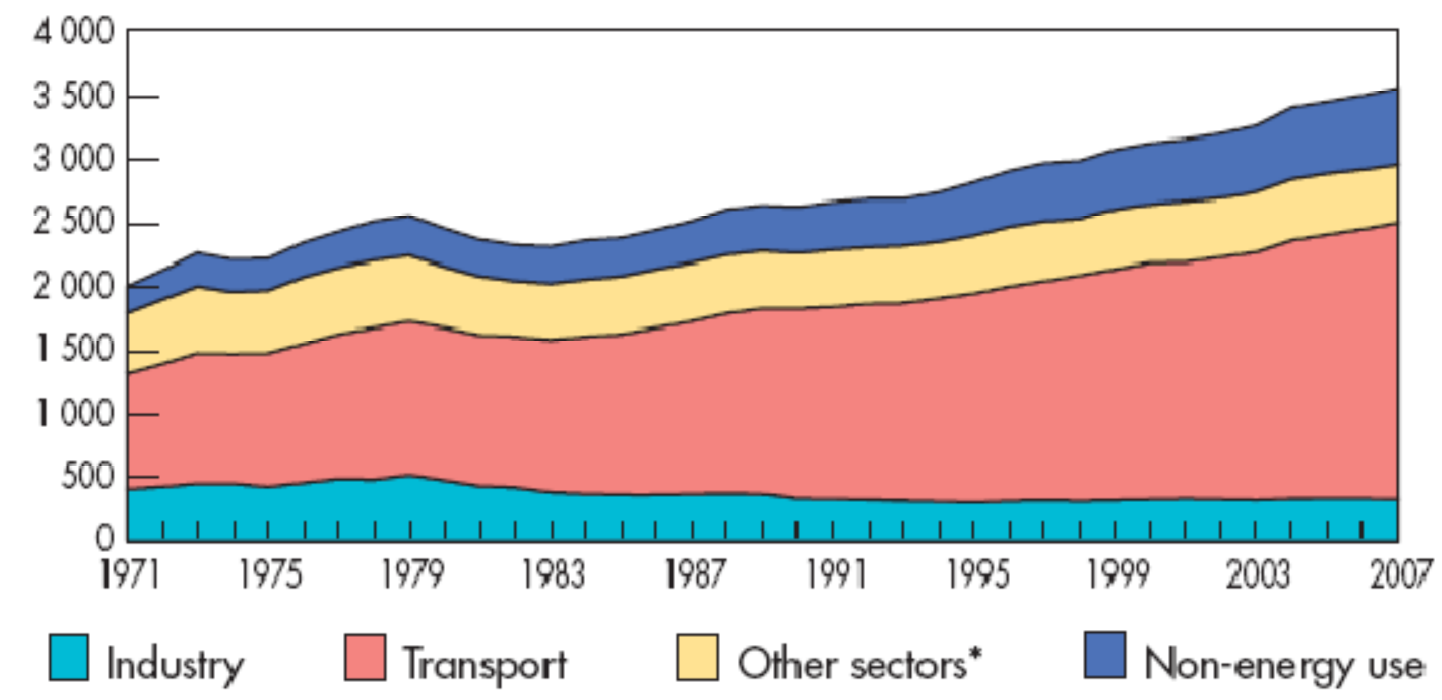

*Includes agriculture, commercial \& public services, residential and non-specified others sectors.

As can be seen from graph $\mathrm{N}^{\circ} 5$, the amount of oil used in most activities grew with the exception of industry and "other sectors". At the same time, the biggest sector is transport.

\footnotetext{
${ }^{10}$ International Energy Agency (2009, p. 33)
} 
Table $N^{\circ} 6$ Evolution from 1971 to 2007 of world total oil consumption by sector (M toe $)^{11}$

\begin{tabular}{ccc}
\hline Sector & Year & Year \\
\hline & 1973 & 2007 \\
\hline Industry & $19.9 \%$ & $9.2 \%$ \\
\hline Transport & $45.4 \%$ & $61.2 \%$ \\
\hline Other sectors* & $23.2 \%$ & $12.8 \%$ \\
\hline Non energy use & $11.5 \%$ & $16.8 \%$ \\
\hline Percentage & $100 \%$ & $100 \%$ \\
\hline World total oil consumption & $\mathbf{2 , 2 4 8}$ & \\
\hline M toe & & \\
\hline
\end{tabular}

*Includes agriculture, commercial \& public services, residential and non-specified others sectors.

Oil consumption has grown all over the years. Oil consumption grew from 2,248 $\mathrm{M}$ toe in 1973 to $3,532 \mathrm{M}$ toe, which represents an increment of $57 \%$ of $\mathrm{M}$ toe burned over the period to 2007.

Transport is the biggest sector involved in the usage of oil. By comparison, in 1973 transport counted for almost the half of oil consumption, making up $45.5 \%$ of the total, but in fact, this figure increased by 2007 reaching 61.2\%. In other words, in 1973 the transport sector consumed 1,020 Million of tons of oil equivalents and in the year of 2007 the consumption was 2,161 M toe, an increment of $111 \%$ with respect to 1973.

The usage of oil in the industry sector had declined, both in proportion and in consumption. In 1973, the percentage was about $19.9 \%$ and by 2007 the percentage shrank by half or $9.2 \%$, from $447 \mathrm{M}$ toe in 1973 to $325 \mathrm{M}$ toe in 2007.

The consumption of oil in other sectors including agriculture, commercial \& public services, residential and non-specified others sectors had diminished in percentages and values, $23.2 \%$ in 1973 against $12.8 \%$ in 2007, or $521 \mathrm{M}$ toe versus $452 \mathrm{M}$ toe by 1973 and 2007 respectively.

11 International Energy Agency (2009, p. 33) 
As can be seen from graph $\mathrm{N}^{\circ} 6$ Gas consumption over the years has doubled. This represents the second biggest growth among the four types of fuels after the electricity expansion of use. Other sectors and industry are the biggest areas. In addition, other sectors grew more than the rest. In the early 1990s there is a fall in consumption of fuel.

Graph N6 Evolution from 1971 to 2007 of world total gas consumption by sector (M toe) ${ }^{12}$

Gas

\section{Evolution from 1971 to 2007 of total final consumption by sector (Mtoe)}

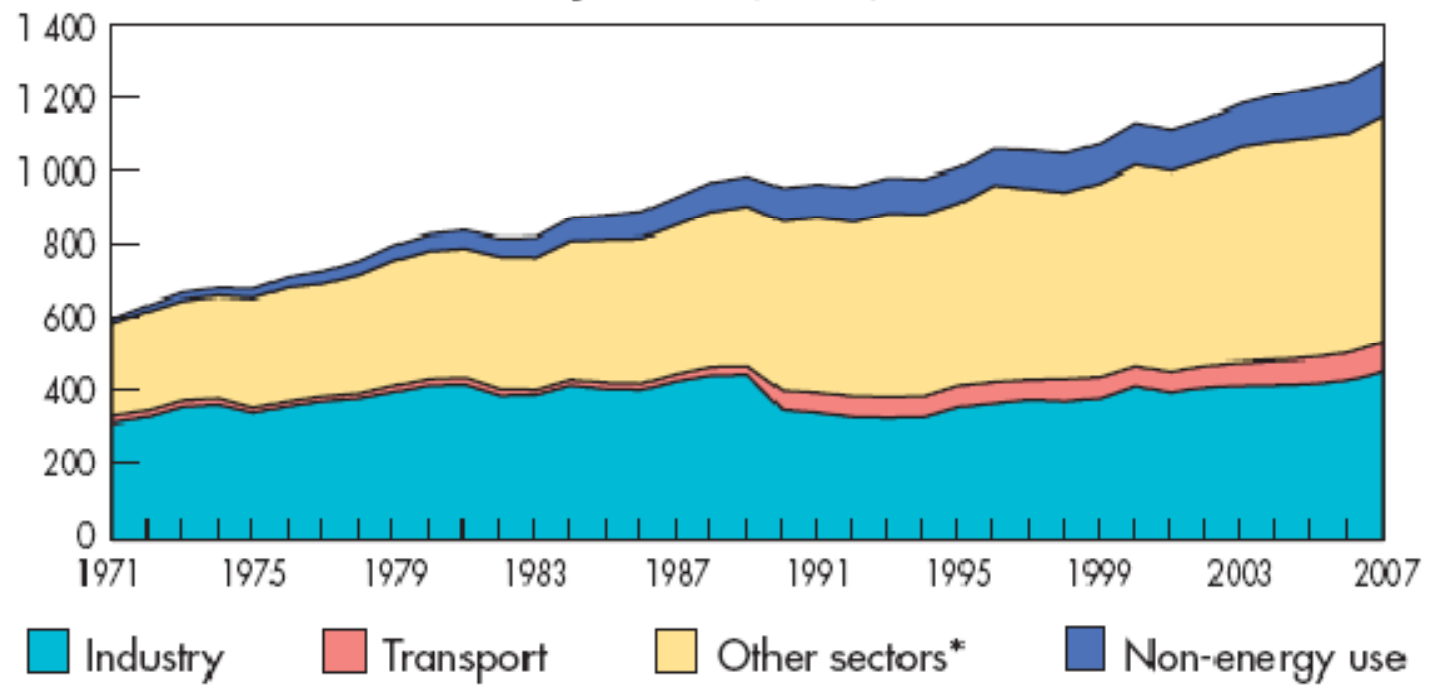

*Includes agriculture, commercial \& public services, residential and non-specified others sectors.

\footnotetext{
12 International Energy Agency (2009, p. 34)
} 
Table $N^{\circ} 7$ Evolution from 1971 to 2007 of world total gas consumption by sector (M toe $)^{13}$

\begin{tabular}{|ccc|}
\hline Sector & Year & Year \\
\hline & 1973 & 2007 \\
\hline Industry & $54 \%$ & $35.6 \%$ \\
\hline Transport & $2.6 \%$ & $5.8 \%$ \\
\hline Other sectors* & $40.7 \%$ & $47.4 \%$ \\
\hline Non energy use & $2.7 \%$ & $11.2 \%$ \\
\hline Percentage & $100 \%$ & $100 \%$ \\
\hline & & \\
\hline World total gas consumption & 671 & 1,296 \\
\hline M toe & & \\
\hline
\end{tabular}

*Includes agriculture, commercial \& public services, residential and non-specified others sectors.

World total gas consumption has risen more than two times by 2007 in comparison with the usage of 1973. In 1973 gas consumption reached $671 \mathrm{M}$ toe and by 2007 the amount was about 1,296 $\mathrm{M}$ toe. Transport, Other sectors $\left({ }^{*}\right)$ and non-energy use rose. On the other hand, in terms of proportion, the usage of gas in industry fell down. By 1973, the percentage used was $54 \%$, which represents $362 \mathrm{M}$ toe burned at that time; meanwhile in 2007 the percentage was about $35.6 \%$ or $461 \mathrm{M}$ toe employed. In spite of the fall in percentage of total consumption, the consumption of gas in industry increased.

Other sectors $(*)$ have grown up constantly. In $197340.7 \%$ of gas consumption was related to those areas. By 2007 the percentage reached almost the half of the total figure among other segments its percentage was about $47.4 \%$. In other words, $273 \mathrm{M}$ toe were used in 1973 and $614 \mathrm{M}$ toe were consumed in 2007, an increment of $125 \%$ with respect to the consumption in 1973.

Possible reasons for that can be the increment in world population growth, which enhances the expansion of industry, transport, agriculture, services and so on.

\footnotetext{
${ }^{13}$ International Energy Agency (2009, p. 34)
} 
None of the other sources of energy grew faster than the consumption of electricity. Electricity can be generated by the combustion of fossil fuels such as burning coal, oil or gas. It also can be produced using nuclear power, or can be produced by hydro electric power and many other sources with inherent advantages and disadvantages. ${ }^{14}$

Graph $N^{\circ} 7$ Evolution from 1971 to 2007 of world total electricity consumption by sector (M toe) $)^{15}$

*Includes agriculture, commercial \& public services, residential and non-specified others sectors.

\section{Electricity}

Evolution from 1971 to 2007 of total final consumption by sector (Mtoe)

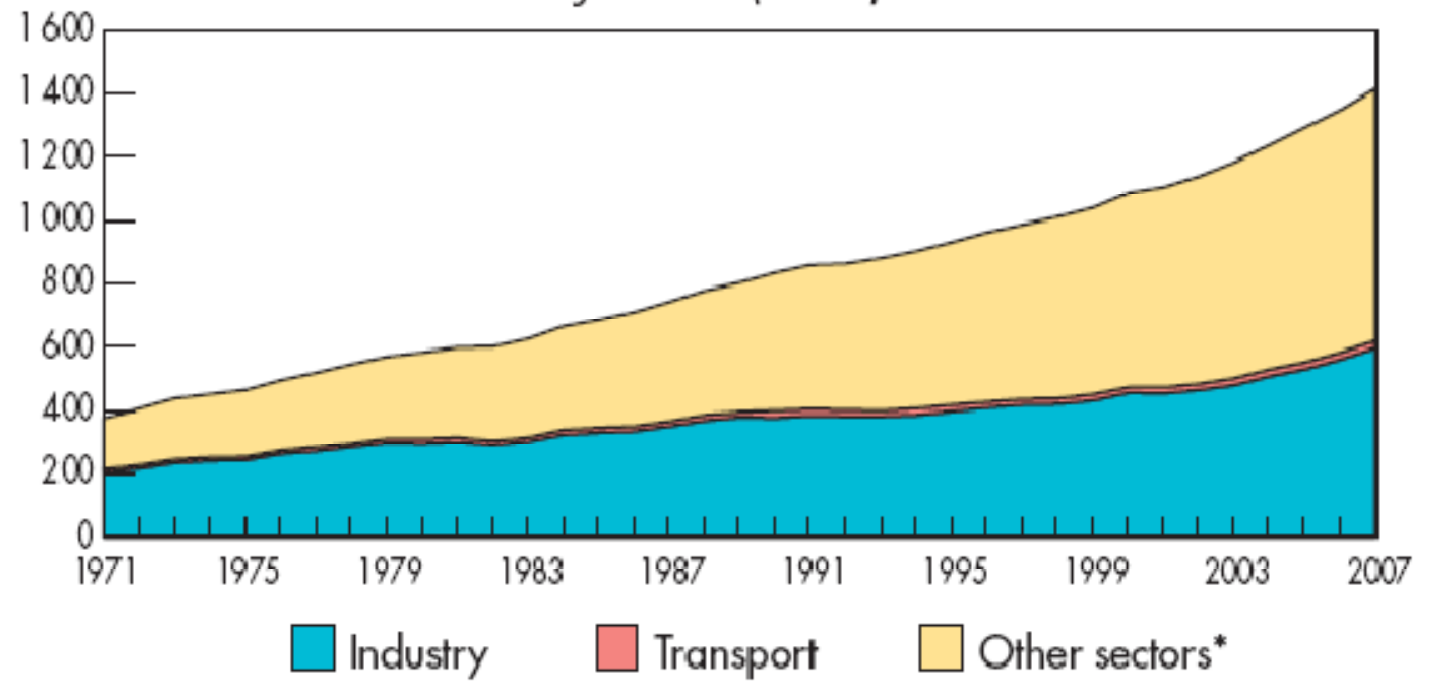

Unlike the other fuels, coal, oil and gas, electricity final consumption grew more than three times in comparison with 1973. As can be seen from graph $\mathrm{N}^{\circ} 7$ electricity growth is constant, a similar pattern of development remains in each sector. Other sectors $\left({ }^{*}\right)$ have grown sharply.

\footnotetext{
${ }^{14}$ (www.aboutnuclear.org)

15 International Energy Agency (2009, p. 35)
} 
Table N8 Evolution from 1971 to 2007 of world total electricity consumption by sector (M toe) ${ }^{16}$

\begin{tabular}{ccc}
\hline Sector & Year & Year \\
\hline & 1973 & 2007 \\
\hline Industry & & \\
\hline Transport & 53.4 & 42.2 \\
\hline $\begin{array}{c}\text { Other sectors* } \\
\text { Percentage }\end{array}$ & 2.4 & 1.6 \\
\hline & 44.2 & 56.2 \\
\hline World total electricity \\
consumption & 100 & 100 \\
M toe & 439 & 1,414 \\
\hline
\end{tabular}

*Includes agriculture, commercial \& public services, residential and non-specified others sectors.

By comparison, in 1973 electricity consumption was about $439 \mathrm{M}$ toe, meanwhile in 2007 were consumed 1,414 Million of tons of oil equivalents, which represents an increment around 222\% with respect to 1973 electricity consumption, being the highest increase between fuels use by different sectors.

Industry and other sectors (including agriculture, commercial \& public services, residential and non-specified others sectors) make up the two main final consumption sectors for electricity. Industry final consumption increased, from $234 \mathrm{M}$ toe in 1973 to $596 \mathrm{M}$ toe in 2007 respectively. For other sectors (*) the development was from $194 \mathrm{M}$ toe in 1973 to 794 in 2007.

Possible reasons for that is the development of new technologies oriented to the usage of electricity in every sector and another factor is the case of the increase of consumption in all societies.

\footnotetext{
${ }^{16}$ International Energy Agency (2009, p. 35)
} 


\section{7. - Greenhouse gases}

The greenhouse gases are those gases that absorb and emit radiation within the spectrum of thermal infrared radiation. ${ }^{17}$ According to United Nations (2008, p. 14) Carbon dioxide is the most abundant greenhouse gas humans are adding to the atmosphere, but it is not the only one. Main greenhouse gases or GHGs, produced by human activities are: carbon dioxide $\left(\mathrm{CO}_{2}\right)$, methane $\left(\mathrm{CH}_{4}\right)$, nitrous oxide $\left(\mathrm{N}_{2} \mathrm{O}\right)$, hydro-fluorocarbons (HFC), perfluorocarbons (PFC), and surplus hexafluoride $\left(\mathrm{SF}_{6}\right){ }^{18}$

Graph N8 GHGs make up

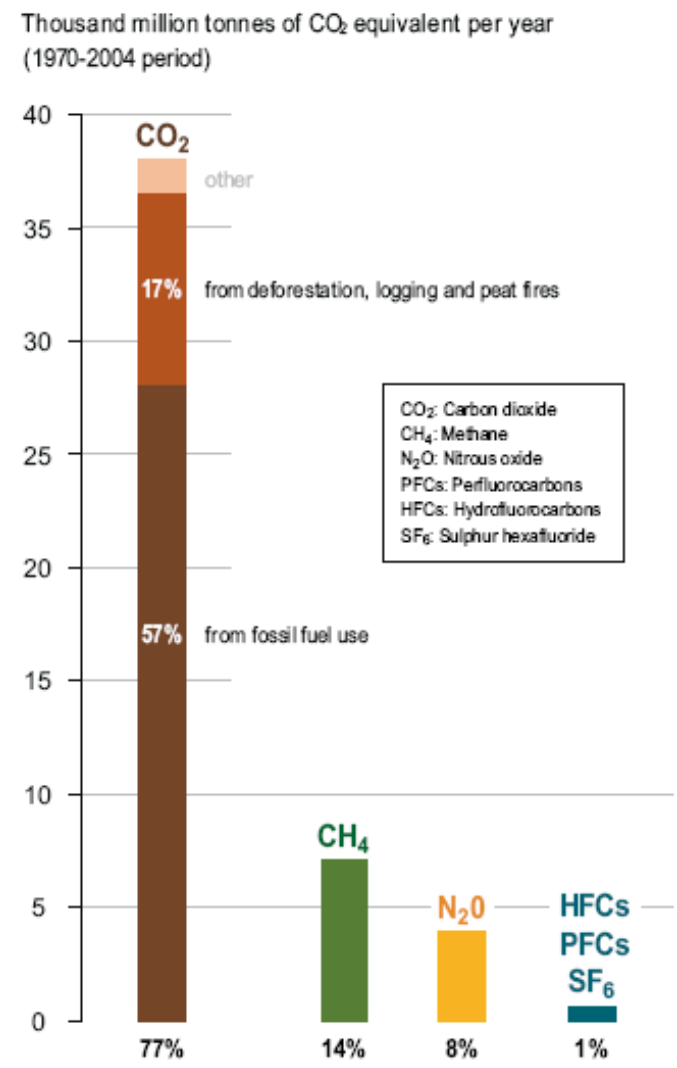

Image source: IPCC Fourth Assessment Report, Working Group III Report: Mitigation of Climate Change 2007 (figure adapted from Oliver, et al, 2005, 2006; Hoojer et al, 2006).

Graph $N^{\circ} 8$ shows the main six greenhouse gases in proportion.

${ }^{17}$ (www.ipcc.ch)
${ }^{18}$ United Nations (2008, p. 14) 
4.8. - $\mathrm{CO}_{2}$ emissions by fuel

Graph $N^{\circ} 9$ Evolution from 1971 to 2007 of world * total $\mathrm{CO}_{2}$ emissions $* *$ by fuel (Million tons) ${ }^{19}$

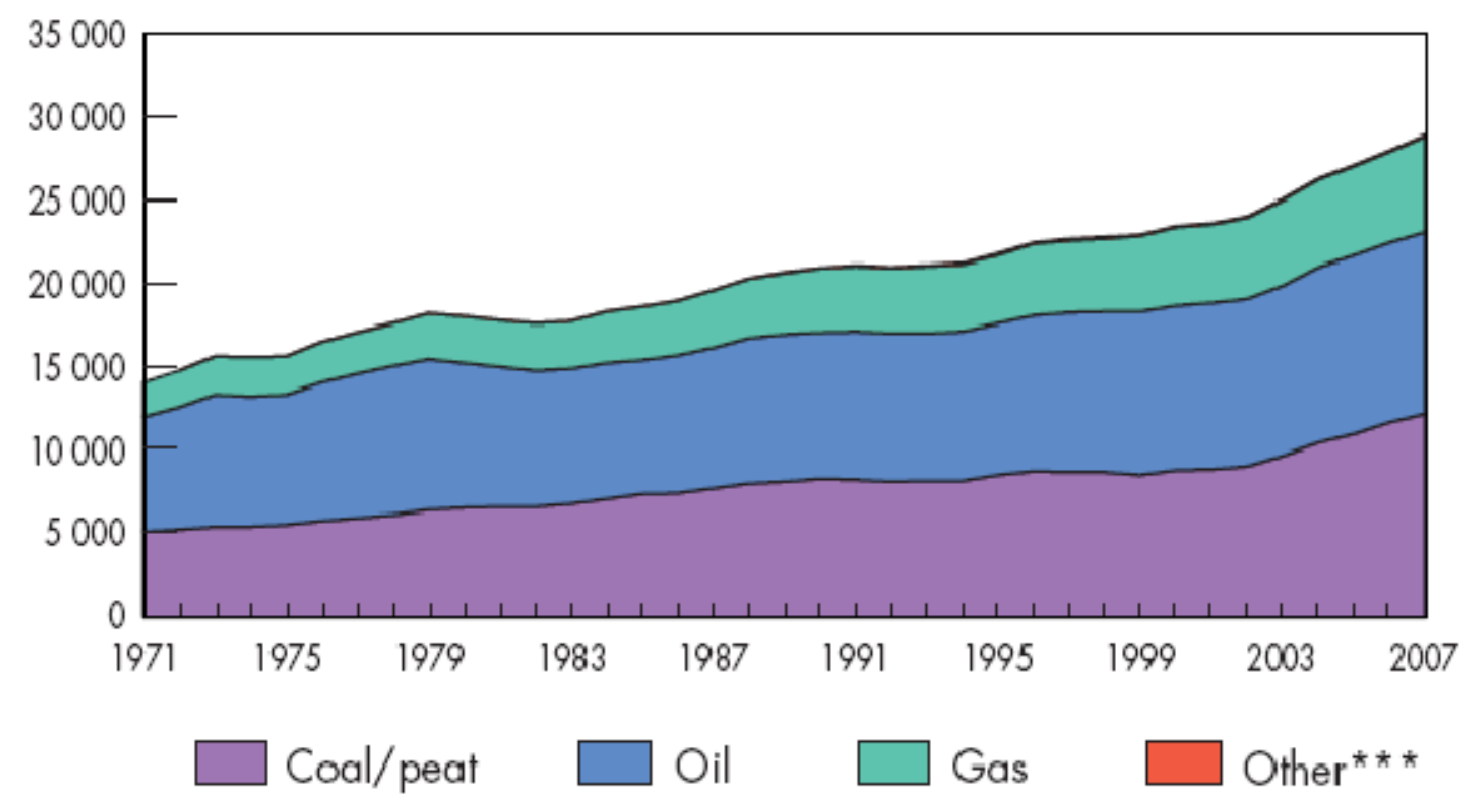

* World includes international aviation and international marine bunkers.

**Calculated using the IEA's energy balances and the Revised 1996 IPCC Guidelines.

$\mathrm{CO}_{2}$ emissions are from fuel combustion only.

*** Other includes industrial waste and non-renewable municipal waste.

As can be seen from the graph $\mathrm{N}^{\circ} 9$, over the years $\mathrm{CO}_{2}$ emissions by fuel have been increasing constantly: coal / peat and oil are the most influential fuels.

${ }^{19}$ International Energy Agency (2009, p. 44) 
Table $\mathrm{N}^{\circ} 9$ Evolution from 1971 to 2007 of world * total $\mathrm{CO}_{2}$ emissions ** by fuel (Million tons) ${ }^{20}$

\begin{tabular}{|ccc}
\hline Fuel & Year & Year \\
\hline & & \\
\hline Coal / peat & 1973 & 2007 \\
\hline Oil & $34.9 \%$ & $42.2 \%$ \\
\hline Gas & $50.6 \%$ & $37.6 \%$ \\
\hline Other & $14.4 \%$ & $19.8 \%$ \\
\hline Percentage & $0.1 \%$ & $0.4 \%$ \\
\hline & $100 \%$ & $100 \%$ \\
\hline World total CO2 emissions & 15,640 & \\
\hline M t of CO2 & & \\
\hline
\end{tabular}

* World includes international aviation and international marine bunkers. **Calculated using the IEA's energy balances and the Revised 1996 IPCC Guidelines. $\mathrm{CO}_{2}$ emissions are from fuel combustion only. *** Other includes industrial waste and non-renewable municipal waste.

World total $\mathrm{CO}_{2}$ emissions by 1973 were about 15,640 Mt and by the year of 2007 the amount of $\mathrm{CO}$ released into the atmosphere was $28,962 \mathrm{Mt}$, which represents an increment of $85 \%$ respect 1973 . Coal grew up steadily in proportion and amount of Mt, had a slight slowdown in the early 1980s to finally recover until nowadays. By 1973 Oil contributed half $-50.6 \%$ - of the emissions of $\mathrm{CO}_{2}$ to the atmosphere and by 2007 the proportion was about 37.6\%. By contrast, in 1973 there was about 7,913 Mt and by 2007 was about 10,889 Mt released to the environment from the use of oil. The reason coal appears high is its use for generating electricity.

${ }^{20}$ International Energy Agency (2009, p. 44) 


\section{9. - $\mathrm{CO}_{2}$ emissions by region}

As can be seen graph $\mathrm{N}^{\circ} 10$ shows the world total $\mathrm{CO}_{2}$ emissions broken down by regions. The countries in the OECD represent the most important contribution in $\mathrm{CO}_{2}$ emissions, followed by the former Soviet Union and China and Asia respectively. The rest of the regions have a minor participation in the emission of $\mathrm{CO}_{2}$ into the atmosphere. However, the trend shows an important increment of $\mathrm{CO}_{2}$ released over the last thirty six years.

Graph $\mathrm{N}^{\circ} 10$ Evolution from 1971 to 2007 of world * total $\mathrm{CO}_{2}$ emissions ** by region (M toe) ${ }^{21}$

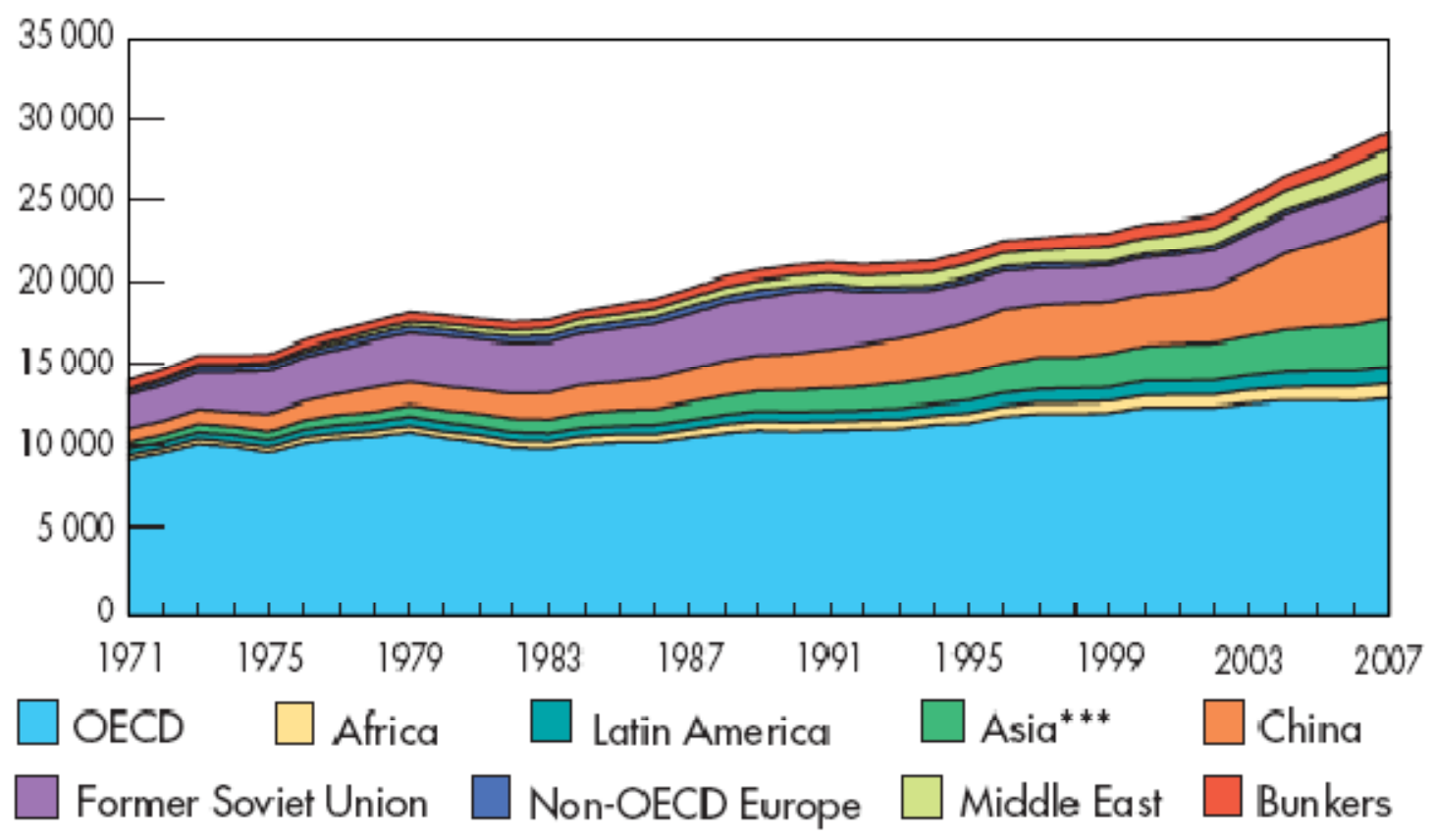

* World includes international aviation and international marine bunkers.

**Calculated using the IEA's energy balances and the Revised 1996 IPCC Guidelines. $\mathrm{CO}_{2}$ emissions are from fuel combustion only.

*** Asia excludes China.

${ }^{21}$ International Energy Agency (2009, p. 45) 
Table $N^{\circ} 10$ Evolution from 1971 to 2007 of world * total $\mathrm{CO}_{2}$ emissions ** by region (Million tons) ${ }^{22}$

\begin{tabular}{ccc}
\hline Region & Year & Year \\
\hline & 1973 & 2007 \\
\hline OECD & & \\
Africa & $65.8 \%$ & $44.9 \%$ \\
\hline Latin America & $1.9 \%$ & $3.1 \%$ \\
*** Asia & $2.7 \%$ & $3.5 \%$ \\
China & $3 \%$ & $10 \%$ \\
\hline Former Soviet Union & $5.7 \%$ & $21 \%$ \\
\hline Non- OECD Europe & $14.4 \%$ & $8.3 \%$ \\
\hline Middle East & $1.7 \%$ & $0.9 \%$ \\
\hline Bunkers & $1 \%$ & $4.8 \%$ \\
\hline Percentage & $3.8 \%$ & $3.5 \%$ \\
\hline World total CO2 emissions per region & $100 \%$ & $100 \%$ \\
\hline Mt of CO2 & & \\
\hline
\end{tabular}

* World includes international aviation and international marine bunkers.

**Calculated using the IEA's energy balances and the Revised 1996 IPCC Guidelines. $\mathrm{CO}_{2}$ emissions are from fuel combustion only.

*** Asia excludes China.

Countries from the OECD released in 1973 about 10,291 Mt and by 2007 the amount reached the level of 13,003 $\mathrm{Mt}$. China grew strongly, both, in proportion and amount of $\mathrm{CO}_{2}$ released. Since the early 1970s China has experienced an accelerated growth through the years, from $5.7 \%$ in 1973 to $21 \%$ in 2007 . This means, in 1973 China produced $891 \mathrm{Mt}$ against $6,082 \mathrm{Mt}$ by 2007 . The Middle East grew too. From $1 \%$ to $4.8 \%$ over the years, this means that by $1973 \mathrm{CO}_{2}$ emissions encompassed about $156.4 \mathrm{Mt}$ and by 2007 the quantity was $1,390 \mathrm{Mt}$ in total.

22 International Energy Agency (2009, p. 45) 
4.10. $-\mathrm{CO}_{2}$ emissions by sector ${ }^{23}$

One of the main problems in gathering the information related to $\mathrm{CO}_{2}$ emission is the wide diversity of sources and the same diversity of criteria in which the different sectors have been established. However, this research will follow the same conditions that the report of the International Energy Agency (2009) has used.

According to Fulton, Unarder, Schipper, \& Difiglio (2000, p. 2) emissions from transport, residential and services sectors made up about 42\% of total IEA emissions in 1997.

The differences between countries are large. Transport emissions range varies from less than $15 \%$ share to more than $40 \%$, while residential and services sectors emissions made up from about $10 \%$ to $40 \%$ of countries total emissions. ${ }^{24}$

Electricity generation is the single most important activity resulting in Greenhouse gas emissions, in particular because most of it is produced from fossil fuels such as oil, gas and coal. United Nations (2008, p. 30)

According to the United Nations (2008, p. 36) Transport, personal and commercial transport consumes about $20 \%$ of the global energy supply, $80 \%$ of which comes from fossil fuels. Transport is divided into four categories: road which produces $79.5 \%$ of the total emissions, followed by air with $13 \%, 7 \%$ is related to sea transportation and rail, for which the figure is about $0.5 \%$ of the total. Emissions from ships generated 1,120 million tons of $\mathrm{CO}_{2}$ in $2007 .^{25}$

Housing: According to the United Nations (2008, p. 38) buildings are responsible for more than $40 \%$ of energy use in OECD countries and at a global level they account for about $30 \%$ of GHG emissions. In addition, heating, cooling and lighting homes and using household appliances absorbs $11 \%$ of global energy.

\section{Agriculture}

Agriculture is an important contributor to climate change with GHG emissions comparable in volume to the transport sector. On the other hand, the main GHGs emitted in agriculture are methane and nitrous oxide. ${ }^{26}$

\footnotetext{
${ }^{23}$ In Fulton, Unarder, Schipper, \& Difiglio (2000) paper, the term residential will be used to denote energy use in households, while service sector will be used denote energy use and commercial buildings.

${ }^{24}$ Fulton, Unarder, Schipper, \& Difiglio (2000, p. 2)

${ }^{25}$ United Nations (2008, p. 9)

${ }^{26}$ United Nations (2008, pp. 38,42)
} 


\subsection{1. - Architecture (buildings) and energy}

This chapter has provided the background of energy generation, energy consumption and now it considers some environmental issues in the construction sector.

This chapter has analysed how much energy is needed in order to provide more "energy" in other words- how much energy is generated and consumed. In addition it was explained where this energy is consumed and what type of fuels are used. Finally it explained who (in terms of regions of the world) consumes the sources of power. Turning now to the built environment the relationships in how buildings use energy have changed over the years. Energy is delivered to buildings in the form of fuels. ${ }^{27}$

Energy transfer processes in buildings: According to Isaacs, Lee, \& Donn (1995, p. 4) there are three ways for heat flow to occur: conduction, convection and radiation. (It will be assessed in chapter five)

\subsection{2. - Building materials}

In relation to $\mathrm{CO}_{2}$ emissions by building materials (Alcorn, 2003) established the following values for most of the traditional construction elements. According to (Alcorn, 2003, p. 5) the principal source of $\mathrm{CO}_{2}$ in building materials is the combustion of fossil fuel in their production.

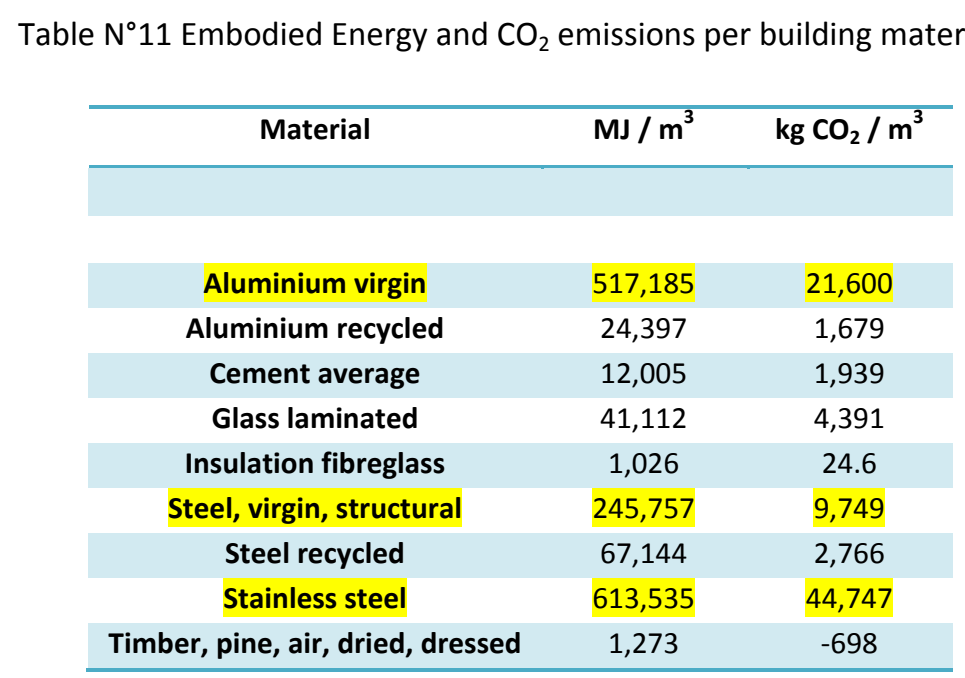

As can be seen from table $\mathrm{N}^{\circ} 11$ Embodied Energy and $\mathrm{CO}_{2}$ emissions per building material, extraction of minerals have the biggest impact in energy required and $\mathrm{CO}_{2}$ emissions. However, once they are recycled, embodied energy and emissions of carbon dioxide decrease considerably.

\footnotetext{
${ }^{27}$ Isaacs, Lee, \& Donn (1995, p. 3)

${ }^{28}$ Alcorn (2003)
} 
4.13. - Summary of the chapter

Total primary energy supply

- The world total primary energy supply has grown sharply in recent years.

- Renewable fuels have grown slightly in percentage from 1973 to 2007 . In 2007, primary energy supply of renewable fuels was two times the production of 1973.

- Oil consumption has increased and the proportion in the use of oil has declined, but not the consumption.

- Nuclear energy production has increased slightly.

World total energy consumption

- The world total energy consumption has grown sharply in recent years.

- Renewable fuels have grown in percentage from 1973 to 2007. In 2007, energy consumption of renewable fuels was more than two times the production of 1973.

- Oil consumption has increased and the proportion in the use of oil has declined, but not the consumption.

Environmental effects of energy use

- In order to produce energy that can be consumed, 3,743 $\mathrm{M}$ toe are lost, which represents almost one third or $31 \%$ of the total energy supply wasted.

Energy consumption by region

- OECD (Organisation for Economic Co-operation and Development) countries lead the group of regions in terms of energy consumption.

- Developed countries have the biggest impact in energy consumption over developing economies

Energy consumption by sector and by type of fuels

- Oil consumption has grown over all the years.

- Transport is the biggest sector involved in the usage of oil.

- Gas consumption over the years has doubled.

- The consumption of electricity grew faster than the other sources of energy.

$\mathrm{CO}_{2}$ emissions by fuel

- World total $\mathrm{CO}_{2}$ emissions released into the atmosphere by the year of 2007 were 85\% bigger with respect to 1973.

$\mathrm{CO}_{2}$ emissions by region

- The countries in the OECD represent the most important contribution in $\mathrm{CO}_{2}$ emissions

$\mathrm{CO}_{2}$ emissions by sector

- Emissions from transport, residential and services sectors made up about $42 \%$ of total IEA emissions in 1997.

- Energy generation is the single most important activity resulting in Greenhouse gas emissions.

- Buildings are responsible for more than $40 \%$ of energy use in OECD countries. 


\section{Chapter V - Energy use in residential buildings}

Feeds off previous chapter; this section establishes relationships between energy end-use and residential buildings. Its function is to select a suitable study area for the following case studies. This chapter will discuss the residential sector and its use of energy.

\section{1. - Background: Urban development and residential constructions}

A city probably is the most complex and the most important creation in the history of mankind; it is the place where he lives, where he works, where he circulates and where he rests. Moreover, recent years have seen a sharp growth of human population. ${ }^{1}$ This growth is encompassed by urban development and this urban development leads to a trail of energy use and a consequent series of GHG emissions.

Thus, buildings are found in three main groups or sectors of the economy related to their use of energy. They are the residential and commercial (often called the building area), industrial and transportation sectors. These three groups are called the sectors of the economy ${ }^{2}$ and they are widely used.

The United Nations Environment Programme classifies these sectors as transport, industrial processes, agriculture and housing. ${ }^{3}$ However, energy consumption varies from country to country, by demography, by weather conditions, by social groups, by social behaviors; it varies by each architectural program and perhaps varies by a wide diversity of other external factors.

\section{2. - Building fuel use}

According to Isaacs, Lee, \& Donn, (1995, p. 3)

..."Energy is delivered to buildings in the form of fuel. Fuel is in turn purchased from a supplier, kilograms of coal, liters of oil, cubic meters of natural gas, kilowatt hours (kWh) of electricity, etc. Energy is a measure of the potential of the fuel to do work".

\footnotetext{
${ }^{1}$ United Nations (2004, p. 1)

${ }^{2}$ (www.need.org)

${ }^{3}$ United Nations Environment Programme (2008)
} 


\section{3. - Energy end uses}

Energy use in buildings continues to be much higher than necessary. ${ }^{4}$ Likewise, fuels are used for a range of purposes or end-uses within sectors and buildings. ${ }^{5}$

The literature related to energy end-use in residential buildings is large and diverse. International studies, especially from Europe, New Zealand, the United States and Asia make up an extensive and transversal diversity of topics all linked to energy and buildings. Nevertheless the scope of this chapter is committed to explore energy end-uses in buildings -in the first instance- from a general to a specific perspective in line with understanding the energy consumption patterns, prior to understanding comprehensively and holistically the New Zealand residential building patterns.

The building sector (domestic and commercial combined) accounts for the largest percentage of the total energy consumption in the United States.

In 2001, the United States residential sector consumed around 18.6EJ (exajoule) of energy and was responsible for emission of $1,155 \mathrm{Gt}$ of $\mathrm{CO}_{2}$. In addition, this amount represents $18 \%$ of national energy requirements and national $\mathrm{CO}_{2}$ emissions. ${ }^{6}$ In Europe, the residential sector also accounts for a large part of the primary energy use, which results in GHGs including $\mathrm{CO}_{2}$ and a negative environmental impact. ${ }^{7}$

Pie Charts, The energy consumption per sector in the United Kingdom Pie Chart $\mathrm{N}^{\circ} 1$ and the United States Pie Chart $N^{\circ} 2$

United Kingdom 2001

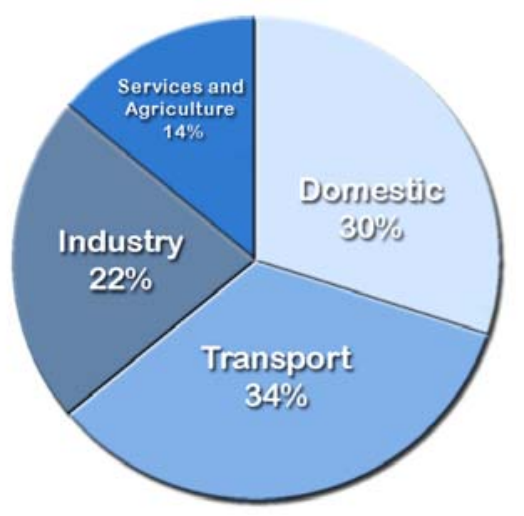

Source: (Department of Trade and Industry, 2001, p. 11) Pie Chart N 1 Source: www.netl.doe.gov/newsroom/features/08-2009.html Pie Chart N²
United States 2008

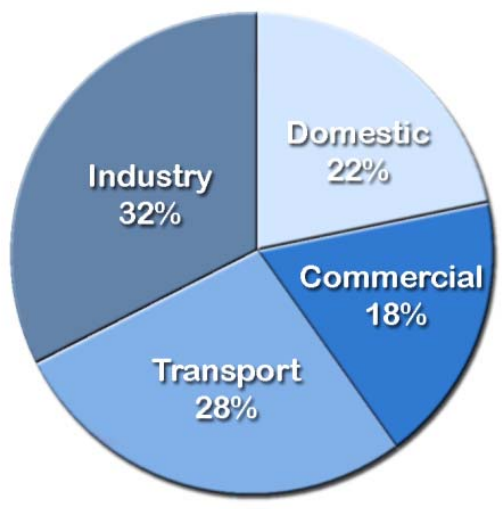

\footnotetext{
${ }^{4}$ Metz, Davidson, Bosch, Dave, \& Meyer, (2007, p. 391)

${ }^{5}$ Isaacs, Lee, \& Donn, (1995, p. 3)

${ }^{6}$ Upton, Miner, Spinney, \& Heath, (2007, p. 1)

${ }^{7}$ Gustavsson \& Joelsson, (2009, p. 210)
} 
The two Pie Charts on page $\mathrm{N}^{\circ} 102$ show the energy end-use by sector in the United Kingdom in 2001, and the United States in 2008. As can be seen from the graphs, energy consumption by sectors is dissimilar. The largest figure for the UK is transport with $34 \%$, followed by domestic at $30 \%$ and industry at $22 \%$. In the case of the USA, industry is the biggest sector with $32 \%$ of the total, followed by transport at $28 \%$ and domestic sector using $22 \%$.

A residential building, through their life cycle, becomes part of different sectors, for instance, production of raw materials (or embodied energy) -in order to begin the construction's phases-. Energy consumption would be part of the figure related to industry and part of it should be shared with transport. On the other hand, operating energy through a building's lifespan, retrofits (or recurrent embodied energy) and so on, set up a complex model in which "boundaries" of energy consumption sometimes would not be clear.

\section{4. - Energy end-uses in residential buildings}

For residential and non-residential structures, energy end-uses are defined in the way that energy is consumed. Energy end-uses in residential buildings are divided mainly into: space heating, space cooling, water heating, lighting, appliances, refrigeration and other uses. In addition, figures change by countries, economies, societies, social groups and so on.

But, how much energy is used in residential buildings?

According to (United Nations, 2008, p. 38)

...buildings are responsible for more than $40 \%$ of energy use in OECD countries and at a global level they account for about 30\% of GHG emissions. In addition, heating, cooling and lighting homes and using household appliances absorbs $11 \%$ of global energy. 
Pie Charts, The energy consumption per sector in the United States Pie Chart $\mathrm{N}^{\circ} 3$ and The energy consumption per sector in China Pie Chart N ${ }^{\circ} 4$
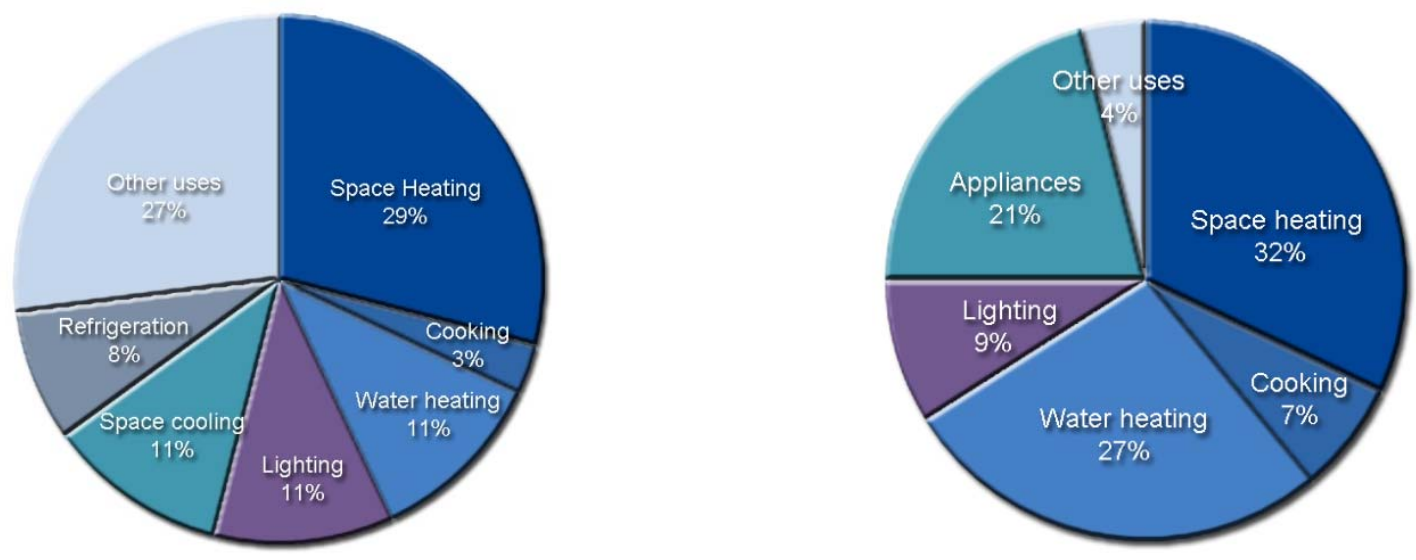

Source: Contribution of Working Group III to the Fourth Assessment Report of the Intergovernmental Panel on Climate Change, 2007 p 393.

The Pie Charts above compare the energy end-use in the United States in 2005 and China in 2000. Energy uses are dissimilar. However, both cases share similar patterns in space heating consumption and lighting consumption. The largest use of energy is for space heating in both scenarios, reaching $29 \%$ in USA and $32 \%$ in China. Water heating in China in percentage terms is more than two times the United States figure. Energy used in lighting is a similar percentage in both countries. On the other hand, in the United States figure, refrigeration accounts for approximately $8 \%$ of the total energy use. Refrigeration figure for China may be included in appliances, and the other uses category in the United States may correspond roughly to appliances in China. 


\section{5. - Comparison between residential and commercial buildings}

Residential and commercial buildings sometimes are classified together. On the other hand, they may not share similar patterns in energy end-uses, meaning space heating and cooling, lighting, heating water and operating appliances. ${ }^{8}$ This is shown in the image below, representing buildings in the United States. In terms of the study of energy efficiency for residential structures, Isaacs, Lee, \& Donn, (1995) found that residential buildings have reasonably consistent use patterns, but non-residential uses have such variation that no single building energy performance index is likely to be of use.

Pie Chart $\mathrm{N}^{\circ} 5$, The energy consumption per sector in the United States

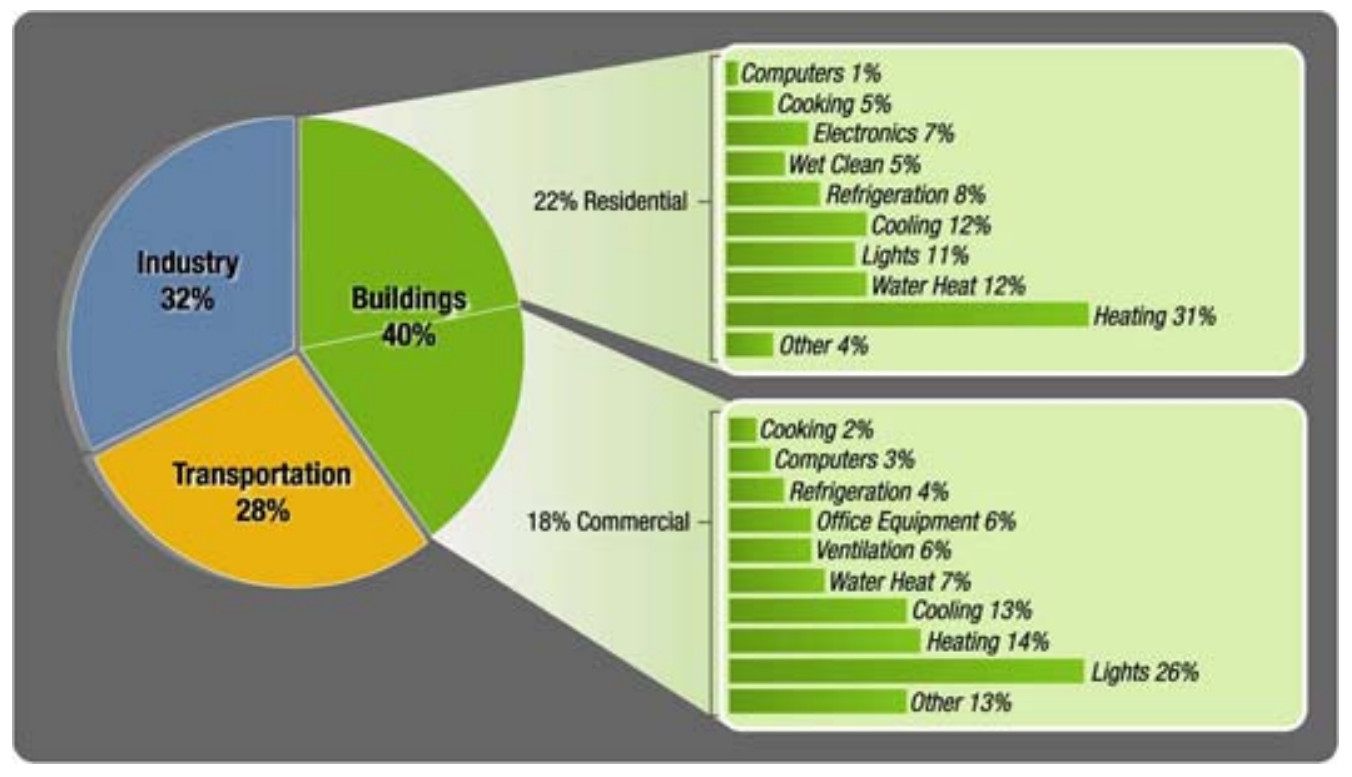

Image source: www.netl.doe.gov/newsroom/features/08-2009.html

Residential and commercial buildings consume $22 \%$ of the energy used in New Zealand. ${ }^{9}$

Of the energy used in commercial buildings, about one third is used for lighting, one third for heating and cooling, and one third to power equipment. ${ }^{10}$

\footnotetext{
${ }^{8}$ (www.need.org)

${ }^{9}$ Department of Building and Housing (2007, p. 12)

${ }^{10}$ Ibid
} 


\section{6. - Sizes of houses}

The scope of this subject is to discuss the average size of the houses in different places. International studies often refer to energy and buildings, life cycle analysis, energy consumption and so on. This section will discuss the sizes of houses in various places in order to understand patterns of energy consumption.

Buildings, particularly commercial buildings are classified as being small or large. The definition of a small building is any structure or building with a net lettable area (NLA can be defined as the area for which a tenant could be charged for occupancy under a lease) ${ }^{11}$, no greater than $300 \mathrm{~m}^{2}$. As can be seen from the image below, international sizes of houses are dissimilar. The United Kingdom has the lowest floor area with $76 \mathrm{~m}^{2}$. The largest houses correspond to the United States and Australia.

According to (www.demographia.com) in comparison with new houses internationally, New Zealand averages around 176 square metres, more than two times the space of a new house in England and exactly one third more than a new Japanese house, The United States and Australia lead the figure with $203 \mathrm{~m}^{2}$ and $206 \mathrm{~m}^{2}$ respectively.

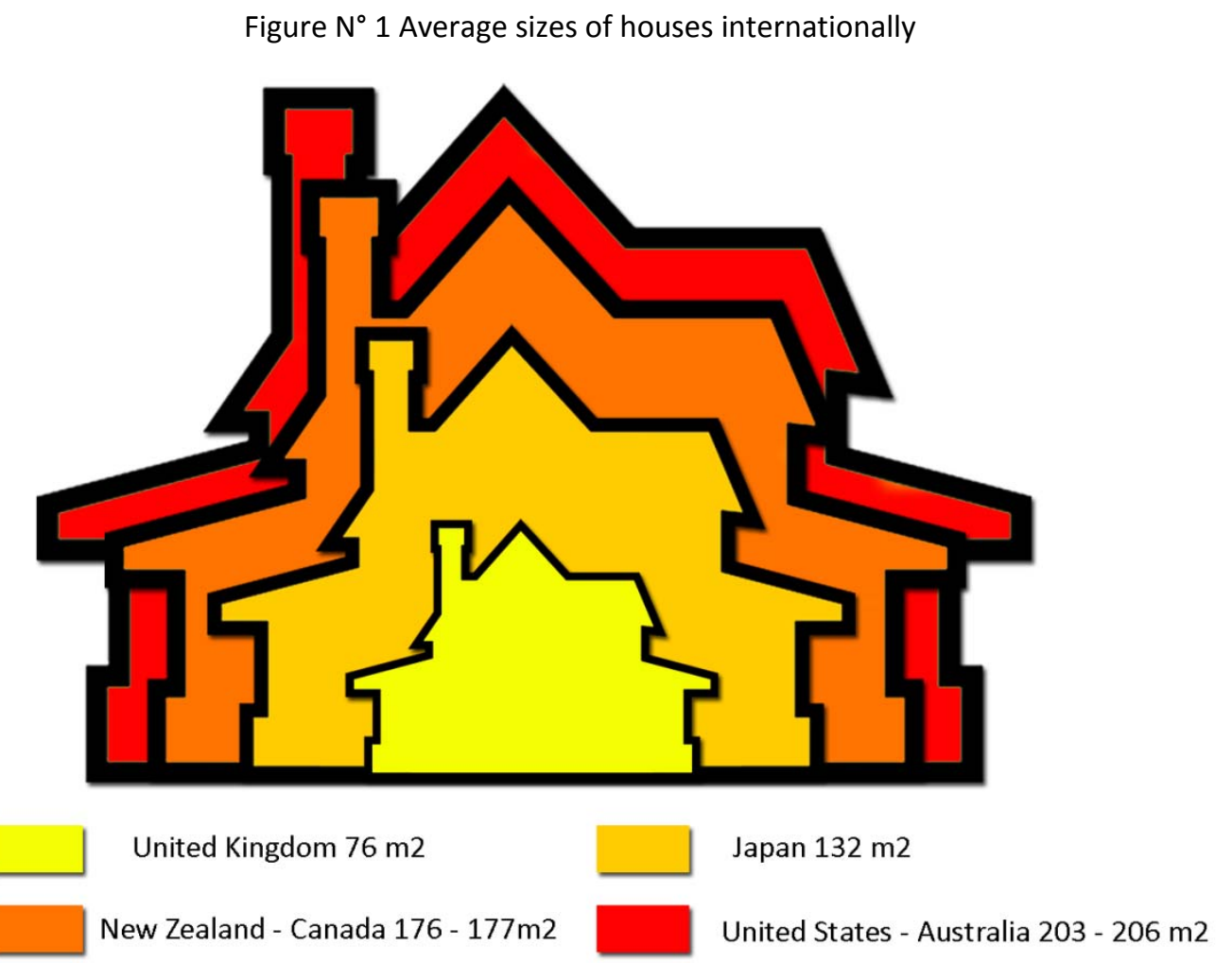

Image source: Own elaboration each outline represents the volume of the respective houses, being the average floor area multiplied by a ceiling height of 2.4 metres

${ }^{11}$ (www.tefma.com) 
In comparison with Europe, housing conditions in the United States are definitely more generous. In almost a half of the households in the U.S., a living area of 250 square metres or more is considered a foregone conclusion. ${ }^{12}$ New Zealand's house sizes are closer to Canada's house sizes.

\section{7. - Sizes of houses and energy consumption}

The Household Energy End-Use Project (HEEP) in its $6^{\text {th }}$ executive summary discussed for international comparisons, the following values:

Table $\mathrm{N}^{\circ} 1$ Sizes of houses and energy consumption

\begin{tabular}{ccc}
\hline Country & square metres & Household energy use \\
\hline & $\mathrm{m}^{2}$ & $(\mathrm{kWh} /$ year $)$ \\
\hline United Kingdom & 76 & 22,200 \\
\hline Japan $\left(^{*}\right)$ & 132 & 8,900 \\
New Zealand & 176 & 10,500 \\
Canada & 177 & 39,700 \\
\hline United States & 203 & 26,700 \\
Australia & 206 & 16,400 \\
\hline
\end{tabular}

$\left(^{*}\right)$ Value of Japan was found as one third of the Unites States energy consumption in 1988 Dzioubinski \& Chipman, (1999, p. 15). However, the figure has changed slightly over the years and for an easy comparison the value of Japan will remain in 1988 meanwhile the rest of the values are given by the HEEP year six executive summary. BRANZ (2002, p. ii)

The largest country is Canada in terms in energy consumption with approximately 39,700 $\mathrm{kWh} / \mathrm{yr}$. The smallest is Japan with $8,900 \mathrm{kWh} / \mathrm{yr}$. The rest of the countries are made up by New Zealand with $10,500 \mathrm{kWh} / \mathrm{yr}$, Australia with $16,400 \mathrm{kWh} / \mathrm{yr}$, followed by the United Kingdom with 22,200 kWh/yr and the United States with 26,700 kWh/yr.

On the other hand, increasing the space does not necessarily mean increasing in energy consumption in an exponential manner.

Isaacs, Lee, \& Donn, (1995, p. 31) found that there is not a strong relationship between increasing building floor area and increasing energy.

\footnotetext{
${ }^{12}$ Tamborini, S. (1999, p. 16)
} 
As can be seen, figure $\mathrm{N}^{\circ} 2$, shows the relationship between the sizes of houses in different countries and the energy consumption per year in those countries. It is interesting the fact that energy expenditure and the amount of square metres do not have a linear correlation.

Figure $\mathrm{N}^{\circ} 2$ Sizes of houses and energy consumption

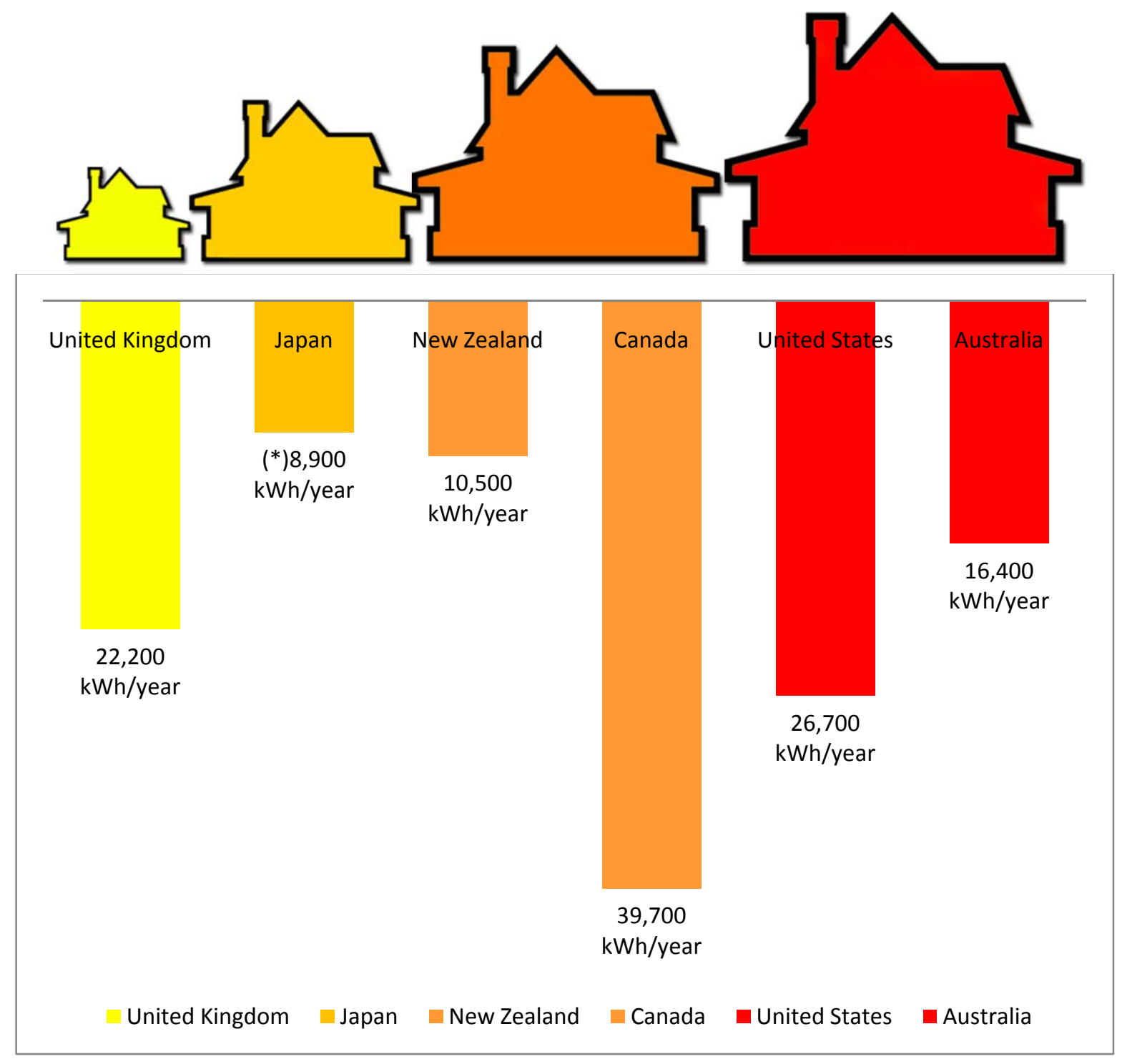

Japan has the lowest household consumption of energy in comparison with other countries. In 1988 annual energy use in Japan was about one-third of the consumption in the United States. ${ }^{13}$ Recent studies Zhang, Q. (2004, p. 1224) found that in terms of energy consumption $(\mathrm{kWh})$, per household between Japan and the United States the gap between them has shrunk to two and half in contrast to the 1980s figure.

${ }^{13}$ Dzioubinski \& Chipman, (1999, p. 15) 
The image above shows that New Zealand and Canada have practically the same average house size. But energy consumption per household per year is completely dissimilar.

On average, New Zealand houses are about 176 square metres, its counterpart the Canadian house is slightly bigger at $177 \mathrm{~m}^{2}$. In terms of household energy use, Canada is the largest country of the list and its energy use is almost four times bigger than New Zealand homes.

Possible reasons for that is the fact that Canada has a much colder climate than New Zealand, leading to the need for a larger amount of winter heating.

Likewise, the United States and Australia share almost the same size condition with 203 $\mathrm{m}^{2}$ and $206 \mathrm{~m}^{2}$ respectively. Household energy use is -again- dissimilar. 26,700 kWh/year against $16,400 \mathrm{kWh} /$ year respectively.

The United Kingdom is the third country on the list after Canada and the United States in household energy use. On the other hand it is the smallest in house size.

According to BRANZ (2002, p. ii) the average New Zealand household uses $30 \%$ less energy than Australia, close to $50 \%$ less than the UK, and $70 \%$ less than Canada.

The strongly visible differences among those countries may be useful to draw an early conclusion. That potentially some identical container houses would be more efficient than others if they are located in a country with "low energy consumption per house", in this case, location may be one of the main factors that can contribute to the possibility that container houses can be called efficient units.

The highest household energy use per square metre on the list is the United Kingdom. The lowest is New Zealand, where households use less energy than those in other developed countries. ${ }^{14}$

Households in the United Kingdom need $292 \mathrm{kWh} / \mathrm{m}^{2} / \mathrm{year}$, meanwhile in the much colder climate of Canada $224 \mathrm{kWh} / \mathrm{m}^{2} /$ year are required to satisfy the necessities of households. The United States use $132 \mathrm{kWh} / \mathrm{m}^{2} /$ year per household while its counterpart in house size, Australia, needs only $80 \mathrm{kWh} / \mathrm{m}^{2} /$ year, Japan uses $68 \mathrm{kWh} / \mathrm{m}^{2} /$ year and finally New Zealand $60 \mathrm{kWh} / \mathrm{m}^{2} /$ year.

\footnotetext{
${ }^{14}$ BRANZ (2002, p. ii)
} 
Table $N^{\circ} 2$ Household energy consumption per square metre per year

\begin{tabular}{cccc}
\hline Country & square metres & Household energy use & Household energy use \\
\hline & $\mathrm{m}^{2}$ & $(\mathrm{kWh} / \mathrm{year})$ & $\left(\mathrm{kWh} / \mathrm{m}^{2} /\right.$ year $)$ \\
\hline United Kingdom & 76 & 22,200 & 292.1 \\
\hline Japan $\left(^{*}\right)$ & 132 & 8,900 & 67.4 \\
\hline New Zealand & 176 & 10,500 & 59.7 \\
Canada & 177 & 39,700 & 224.3 \\
\hline United States & 203 & 26,700 & 131.5 \\
\hline Australia & 206 & 16,400 & 79.6 \\
\hline
\end{tabular}

Graph $N^{\circ} 1$ Household energy consumption per square metre per year

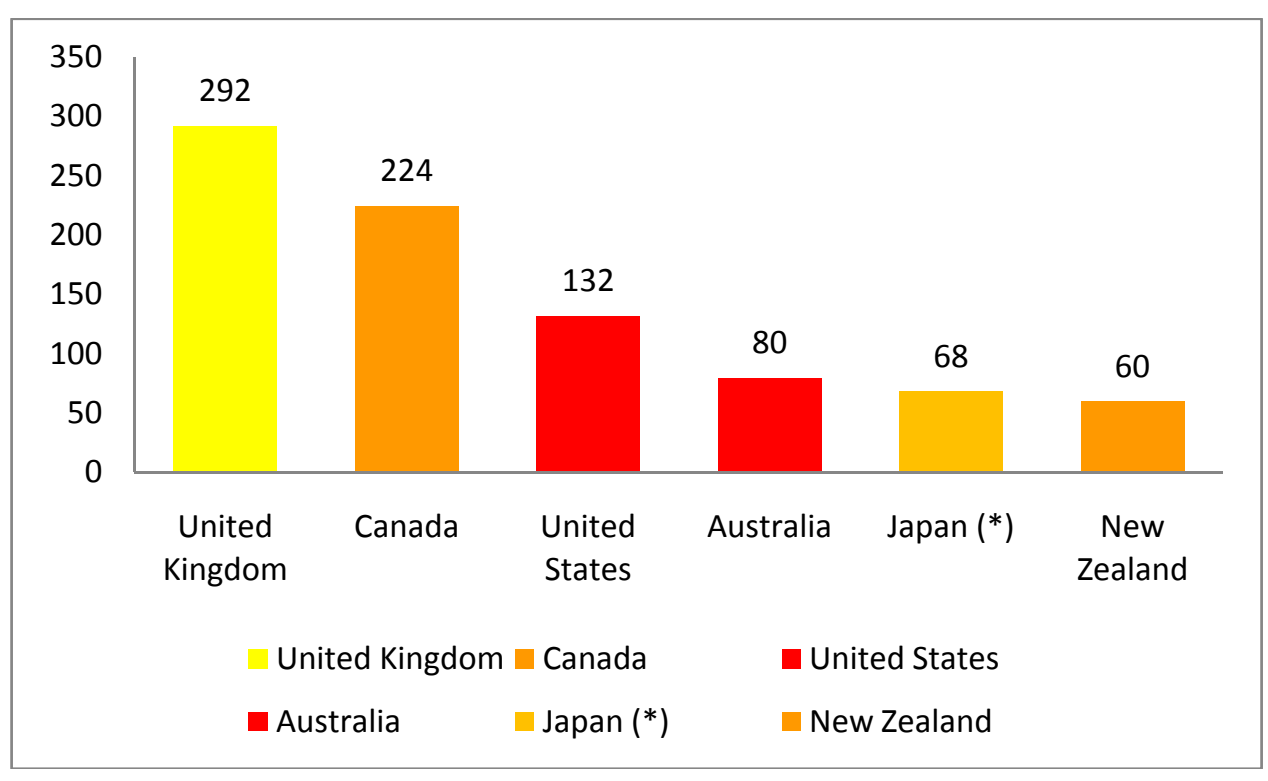

The average New Zealand household (in terms of energy/square metres) uses $25 \%$ less energy than Australia, close to $55 \%$ less than the United States, almost $75 \%$ less than Canada and near to $80 \%$ less than the UK. 


\section{8. - Climate dependency}

It was found that different house sizes do not necessarily mean an increase in household energy consumption. Different houses meet different climate conditions.

\section{9. - Exterior envelope and thermal mass}

According to Isaacs \& Donn, (1994, p. iii) there are four key factors in the design of energy efficient domestic buildings:

- Orientation

- Glazing

- Thermal mass

- Thermal insulation

The increment of the thermal mass by the replacement of different building materials such as is the case of changing from timber to concrete reduces internal air temperature fluctuations and in summer season reduces the overheating. In addition, internal temperature fluctuations can be reduced for inside surfaces of external walls. ${ }^{15}$

According to Isaacs \& Donn, (1994, p. iii) ..."for New Zealand climates, concrete alone does not reduce energy use. The use of concrete walls instead of timber framed walls resulted in increased energy use."

Isaacs \& Donn, (1994, p. iii) found that the heating regime is crucial to the energy benefits of additional thermal mass. In addition, it was found that when energy use is intermittent, the energy difference between high mass (concrete) and low mass (timber) construction was not large enough to suggest that the use of high mass can bring some energy benefits in most of New Zealand climates. On the other hand a study carried out in the UK Hacker, De Saulles, Minson, \& Holmes (2006, p. 376) states that thermal mass is a crucial part of wintertime passive heating. This may be where the difference lies, as Isaacs et al are considering actively heated spaces as opposed to passive design. Moreover, it was recognised that that house orientation affects both heating energy (a cost issue) and ventilation energy (comfort issue) regardless of the building mass.

\footnotetext{
${ }^{15}$ Isaacs \& Donn, (1994)
} 


\subsection{0. - Thermal insulation of exterior envelope}

Thermal insulation plays a major role in energy efficiency.

According to Isaacs, Lee, \& Donn, (1995, p. 36)

..."Research into residential building energy use showed that when thermal mass was used in conjunction with thermal insulation, thermal efficiency benefits were obtained. However, by itself thermal mass gave no energy efficiency benefits, but did consistently provide improved thermal comfort by smoothing peak day temperatures and slowing down overnight cooling".

According to (Peeters, de Dear, Hensen, \& D'haeseleer, 2008, p. 779) ..."Thermal comfort in residential buildings shows a strong dependency on weather data, more specifically on recent outdoor temperatures".

\subsection{1. - Thermal control}

According to the Department of Building and Housing, (2007)

..."The New Zealand Building Code has a requirement that a minimum indoor air temperature of $16^{\circ} \mathrm{C}$ is able to be maintained in aged care facilities and early childhood centres only. The Building Code does not specify a minimum indoor air temperature requirement for other buildings, and there is no requirement for a maximum indoor temperature. The World Health Organisation recommends a minimum indoor temperature for health of $18^{\circ} \mathrm{C}$ with up to $20-21^{\circ} \mathrm{C}$ for more vulnerable groups such as older people and young children".

\subsection{2. - Minimum floor space requirements}

Isham \& Lakewood, $(2004$, p. 82$)$ found that there needs to be a minimum requirement of about 140 square feet for single-person households. In square metres this is the equivalent to $13 \mathrm{~m}^{2}$.

\subsection{3. - Summary of the chapter}

- Buildings are categorized in three main groups or sectors of the economy related to their use of energy. They are the residential and commercial (often called the building area), industrial and transportation sectors.

- Energy consumption varies from country to country.

- Energy is delivered to buildings in the form of fuel.

- Energy use in buildings continues to be much higher than necessary.

- Residential buildings through their life cycle become part of different sectors (construction, maintenance, operating and waste treatment and disposal stages) 
- Energy end-uses in residential buildings are divided mainly into: space heating, space cooling, water heating, lighting, appliances, refrigeration and other uses.

- Buildings are responsible for more than $40 \%$ of energy use in OECD countries and at a global level they account for about $30 \%$ of GHG emissions.

- Residential buildings have a reasonably consistent use pattern.

- Residential and commercial buildings consume $22 \%$ of the energy used in New Zealand.

Size of houses

- International sizes of houses are dissimilar.

- New houses in New Zealand average around 176 square metres or more than two times the size of a new house in England and exactly one third more than a Japanese new house.

- New Zealand's house sizes are close to Canada's house sizes.

- There is not a strong relationship between increasing building floor area and increasing energy use.

- The highest household energy use per square metre of the list is the United Kingdom or $292 \mathrm{kWh} / \mathrm{m}^{2} /$ year.

- The lowest household energy use per square metre of the list is New Zealand or 60 $\mathrm{kWh} / \mathrm{m}^{2} /$ year.

- Houses meet different climate conditions.

Exterior envelope and thermal mass

- There are four key factors in the design of energy efficient domestic buildings: Orientation, Glazing, Thermal mass and Thermal insulation.

- The increment of the thermal mass by the replacement of different building materials such as is the case of changing from timber to concrete reduces internal air temperature fluctuations.

- Heating regime is crucial to the energy benefits of additional thermal mass.

- When thermal mass was used in conjunction with thermal insulation, thermal efficiency benefits were obtained. 


\section{Chapter VI- Life cycle assessment}

Chapter six aims to set up the methodology and selection criteria in which case studies will be assessed.

\section{1. - Life cycle analysis methodology}

Since 1973 world energy supply, world energy consumption and world population have grown sharply. (See chapter 4). However, in comparison with recent years the amount of energy needed in order to manufacture products and services may have decreased in some areas taking advantage of the continuous development of technologies in making more efficient production processes and so on.

Nevertheless, some time ago there was created a quantitative system which would permit the bringing into the light of the potential negative effects of human activities. This was allowed by the development of environmental Life-cycle Assessment techniques, (commonly denominated as LCA) which took place in the mid 1970s. ${ }^{1}$

Eaton \& Amato, (1998, p. 5) present the definition of LCA made by the Society of Environmental Toxicology \& Chemistry (SETAC):

"Life-cycle Assessment is a process to evaluate the environmental burdens associated with a product, process or activity by identifying and quantifying energy and materials used and wastes released to the environment; to assess the impact of those energy and material uses and releases to the environment; and to identify and evaluate opportunities to effect environmental improvements. The assessment includes the entire life-cycle of the product, process or activity, encompassing extracting and processing raw materials; manufacturing, transportation and distribution; use, re-use, maintenance, recycling and final disposal."

\footnotetext{
${ }^{1}$ Eaton \& Amato, (1998, p. 5)
} 


\section{2. - Life cycle analysis of residential structures}

From a life cycle assessment point of view, most buildings may share the same characteristics in their lifespan processes, -meaning; they are constructed, used, refurbished and demolished no matter the sector they belong. (Non-residential, commercial, office, residential and other uses of buildings). However, only the residential sector has remarkably consistent energy-use patterns. On the other hand non-residential buildings energy-uses have a wide diversity of performances. ${ }^{2}$

Cole \& Kernan, (1996, p. 307) set up four main stages for the LCA that can be applied for architectural-environmental studies and most international analyses agree with these stages for the residential sector.

- Initial embodied energy: related to the energy employed for the production of the building itself.

- Operating energy: is the energy needed in order to operate the building. In addition, it is usually the highest figure of the LCA in architecture.

- Recurrent embodied energy: is the energy required to refurbish and maintain the building through its lifespan.

- Demolition energy: is the energy used to demolish and dispose of the building at the end of its life.

Probably one of the most important problems with the life cycle analysis of residential structures is setting up the boundaries. Following this idea according to Nassen, Holmberg, Wadeskog, \& Madeleine,(2006, p. 1600) ..."the process LCA methodology suffers from systematic truncation errors due to the inescapable definition of system boundaries".

The LCA is a mechanism that aims to investigate, study and explore, all the necessary information related to those activities that consume energy and produce $\mathrm{CO}_{2}$ emissions created by human actions in order to learn and to improve them, to achieve better results that can be traced in the reduction of fossil fuel consumption and the consequent benefits to the environment from that.

But there are some disadvantages too. International studies differ largely in terms of initial embodied energy (see table 1). Operating energy represents the highest figure among the rest, household behaviors are crucial and this could affect computer modeling accuracy.

\footnotetext{
${ }^{2}$ Isaacs, Lee, \& Donn, (1995, p. vii)
} 


\section{3. - Life cycle energy analyses}

This assessment establishes the total energy attributable to a house over its lifespan. This quantitative method can be divided in two parts in terms of energy use. On the one hand, the energy required for the production of construction materials, which most of the time is called embodied energy and, on the other hand, the consumption of energy related to occupancy, which is called operating energy. ${ }^{3}$ (See diagram in page $\mathrm{N}^{\circ} 118$ )

According to Mithraratne, Vale, \& Vale,(2007, pp. 34-35-36) there are a series of assessments regarding the scope of any energy analysis, and these are discussed below.

Statistical analysis

According to Mithraratne, Vale, \& Vale, (2007, p. 35) ..."This analysis relies on the published data on energy use by individual industries. The energy is then transferred to the proportions of products made by those industries".

Process analysis

This is regarded as the most accurate and most common method of energy analysis. Alcorn, A. (1996, p. 7)

According to Mithraratne, Vale, \& Vale, (2007, p. 36) ..."The analysis begins with establishing the direct energy inputs to the production process under consideration and then traces back all the other contributory processes with their raw material requirements. Since all the direct energy requirements of all processes within the system are considered, this provides a reasonably accurate result".

Input-output analysis

According to Mithraratne, Vale, \& Vale, (2007, p. 36) ..."This method uses national statistical information on inter-industry monetary flows, in terms of input-output tables. These provide information on economic contributions to and from a sector to the national economy".

Hybrid analysis

According to Mithraratne, Vale, \& Vale, (2007, p. 36) ..."This method is a combination of the useful features of the process and input-output analysis methods. Analysis begins with process analysis for direct energy requirements and when the effort required to acquire data for process analysis outweighs the accuracy, the analysis reverts to the input-output method".

\footnotetext{
${ }^{3}$ Mithraratne, Vale, \& Vale, (2007, p. 34)
} 


\section{4. - Embodied energy analysis}

Embodied energy analysis is a more specific assessment, this is an evaluation of the energy required to produce a particular product or service. Table $\mathrm{N}^{\circ} 1$ shows the difference between international studies, in which the relationship between embodied energy per square metre per country disagrees largely. This can be explained-again- in terms of a series of factors such as the case of energy generation that was discussed in chapter 4. Construction processes, climate conditions, household behaviors, effects of thermal mass on house energy end use ${ }^{4}$, or even some assumption errors in modeling input-output can drive divergences in many cases.

Table $\mathrm{N}^{\circ} 1$ Literature on energy use in the production phase of residential buildings

\begin{tabular}{|c|c|c|c|c|c|c|}
\hline Reference & Country & Apartments & Floors & Material & Method & $\mathrm{GJ} / \mathrm{m}^{2}$ \\
\hline \multirow[t]{3}{*}{ Adalberth } & SE & 1 & 1 & Wood & Process LCA & 3.7 \\
\hline & SE & 1 & 1 & Wood & Process LCA & 3.5 \\
\hline & SE & 1 & 2 & Wood & Process LCA & 2.9 \\
\hline \multirow[t]{4}{*}{ Adalberth } & SE & 6 & 2 & Concrete & Process LCA & 3.2 \\
\hline & SE & 8 & 3.5 & Concrete & Process LCA & 3.5 \\
\hline & SE & 16 & 4 & Wood & Process LCA & 4.5 \\
\hline & SE & 15 & 4 & Steel / concrete & Process LCA & 3.4 \\
\hline Thormark & SE & 1 & 2 & Wood & Process LCA & 6.2 \\
\hline Winther & NO & 1 & 2 & Wood & Process LCA & $1.5-3.1$ \\
\hline \multirow[t]{5}{*}{ Nielsen } & DK & 1 & 1 & Brick / concrete & Process LCA & 3.2 \\
\hline & DK & 1 & 1 & Brick / concrete & Process LCA & 2.8 \\
\hline & DK & 1 & 2 & Concrete & Process LCA & 4 \\
\hline & DK & 9 & 3 & Brick / concrete & Process LCA & 3.4 \\
\hline & DK & 1 & 1 & Concrete & Process LCA & 5.4 \\
\hline \multirow[t]{2}{*}{ Keoleian } & US & 1 & 2 & Wood frame & Process LCA & $6.6-7.3$ \\
\hline & US & 1 & 2 & Wood frame & Process LCA & 7.3 \\
\hline \multirow[t]{4}{*}{ Buchanan \& Levine } & NZ & 1 & 1 & Steel / brick & Process LCA & 4.7 \\
\hline & NZ & 1 & 1 & Concrete & Process LCA & 3.4 \\
\hline & NZ & 1 & 1 & Wood & Process LCA & 1.7 \\
\hline & NZ & 1 & 1 & Wood / brick & Process LCA & 3.9 \\
\hline \multirow[t]{3}{*}{ Stein } & US & 1 & & US average & 10 analysis & 8.1 \\
\hline & US & $2-4$ & & US average & 10 analysis & 7.2 \\
\hline & US & (high rise) & & US average & 10 analysis & 8.5 \\
\hline \multirow[t]{2}{*}{ Treloar } & $A U$ & & & $\begin{array}{c}\text { Australia } \\
\text { average }\end{array}$ & 10 analysis & 6.8 \\
\hline & $\mathrm{AU}$ & 6 & 2 & Brick & Hybrid IO / LCA & 14.3 \\
\hline Fay et al. & $\mathrm{AU}$ & 1 & 2 & Brick & Hybrid IO / LCA & 14.1 \\
\hline RMIT case study & $A U$ & & & & Hybrid IO / LCA & $9.8-15.1$ \\
\hline
\end{tabular}

${ }^{4}$ Isaacs \& Donn, (1994) 
Figure $\mathrm{N}^{\circ} 1$

Indicative components of embodied and operating energy over an illustrative building life cycle

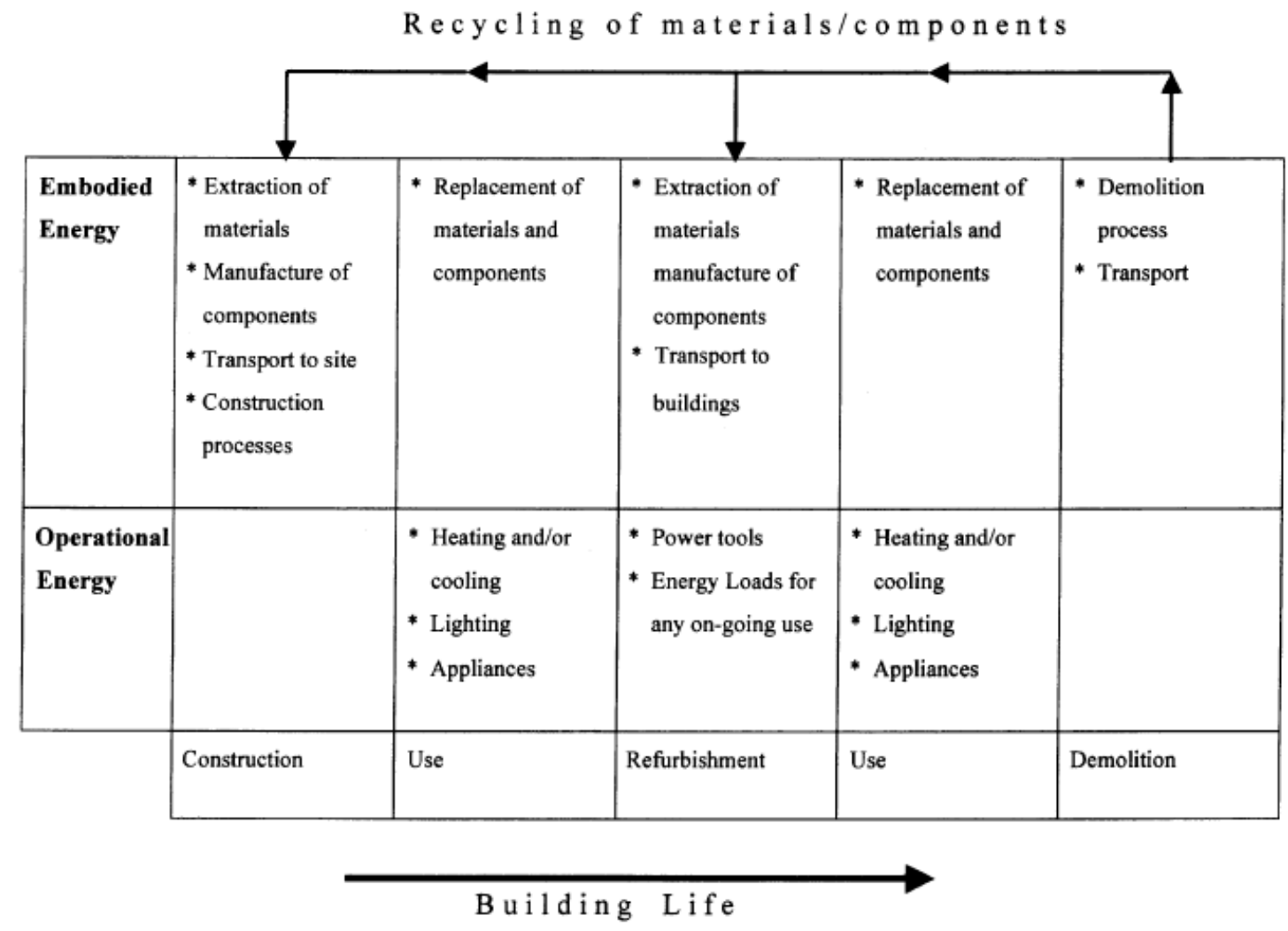

Image source: Yohanis \& Norton (2002, p. 78)

Figure $\mathrm{N}^{\circ} 1$ shows the life-cycle of a building in its different stages. This scheme illustrates that LCA has two main stages in terms of energy use. On the one hand embodied energy, which matches the construction process and links it with the extraction of materials, the manufacture of the components, the transport of those components to the site and finally the construction process itself. On the other hand, operational energy in the construction stage is not used.

Through the phase of use, energy is divided into embodied energy for the replacement of materials and components (this stage is also called recurrent embodied energy) and the use of energy in order to run the building, space heating, space cooling, water heating, lighting and so on.

For major refurbishment embodied energy increases (or recurrent energy) because new processes are required such as the extraction of new materials, the manufacture of components and the transport of those components to buildings. Finally, the energy used in the demolition process and transport of rubble matches with the embodied energy process and this means the end of the life of the building. 
Operational and embodied energy as a function of building life

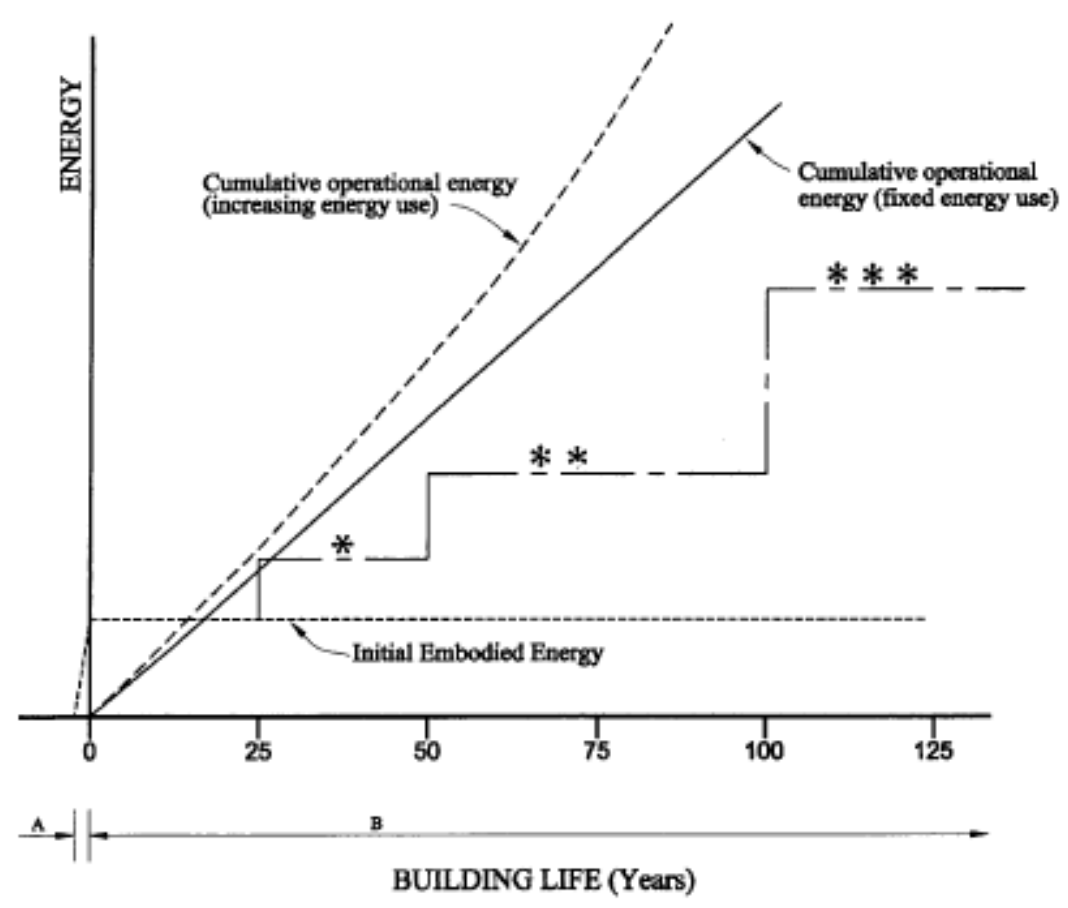

*Initial embodied energy plus recurring embodied energy over 25 years*, 50 years**, and 100 years***. A, Construction Phase; B, Operation Phase

Image source: Yohanis \& Norton, $(2002$, p. 78)

The scheme in Figure $N^{\circ} 2$ shows the energy flows in the different stages that make up the life cycle of a building. Initial embodied energy grows sharply from zero in " $A$ " (or construction phase) and finishes when the building life begins (or operation phase " $\mathrm{B}$ "). Then, its development in time remains as a straight line. In contrast with operational energy, the initial embodied energy is smaller and represents a small portion of the total. Through the passing of the years recurrent embodied energy increases considerably as the building is maintained and refurbished.

Cumulative operational energy with increasing annual energy use (caused by additional demands from new appliances and technologies) goes up in time increasingly. Conversely, operational energy assuming fixed annual energy use increases as a straight line. This difference in energy values produces a gap between both trends. 


\section{5. - Operating energy analysis}

For the residential sector operating energy analysis can be done by dividing the national domestic sector energy use by the population or the number of houses, or by monitoring a group of houses over a certain period of time. ${ }^{5}$ Operating energy is an important issue because of the highest energy figure and is related to the energy end-uses, which for residential structure tend to have consistent use patterns. ${ }^{6}$

Moreover, through the lifespan of a building (New Zealand houses have a life expectancy of around 100 years) ${ }^{7}$ operating energy increases. In comparison with the initial embodied energy used in the construction of any structure, the operational energy outweighs by far the first item (embodied energy) Operating and energy end use seems to be the same, meaning, the total consumption of energy delivered in order to be used in heating water, space heating and cooling, lighting, cooking and so on.

Again, operating energy or energy end-use patterns are elements that measure behaviors and they change from country to country. That can be explained by a series of factors such as the weather conditions, some countries are colder than others, for example. Operating energy varies from richer countries in comparison with those developing countries; it also varies by the use of technologies and by many other issues.

According to Metz, Davidson, Bosch, Dave, \& Meyer,(2007, p. 394)

..."The energy use of a building also depends on the behavior and decisions of occupants and owners. Some studies found a variation of $40 \%$ in gas consumption and $54 \%$ in electricity consumption in identical homes in a small area in London. When those in charge of the homes knew that their consumption was being monitored, the consumption fell."

\section{6. - Recurrent embodied energy}

The recurrent embodied energy can be defined by the energy used in the maintenance and replacement that can occur in a building periodically over its lifespan. ${ }^{8}$

\footnotetext{
${ }^{5}$ Mithraratne, Vale, \& Vale (2007, p. 37)

${ }^{6}$ Isaacs, Lee, \& Donn, (1995, p. vii)

${ }^{7}$ Mithraratne \& Vale, (2003, p. 487)

${ }^{8}$ Cole \& Kernan, (1996, p. 311)
} 


\section{7. - Embodied energy for steel structures}

The following sections are dedicated to those elements which make up the group of most common and classical materials in domestic construction. One of the disadvantages of steel in comparison with other building materials is that in order to produce it a large amount of energy is required. According to Baird, Alcorn, \& Haslam, (1997, p. 49) steel is one material which seems to be fairly consistent in energy requirements around the world.

Figure $\mathrm{N}^{\circ} 3$ shows the embodied energy of wall construction systems per element area. As can be seen from the graph, steel faced sandwich panel and aluminium curtain wall are on the top of the list in terms of MJ per square metre. In addition, it should be noted that shipping containers are made by using these systems and materials. For containers, the advantage of aluminium over steel is the low deadweight and relatively superior corrosion resistance. ${ }^{9}$

Figure $\mathrm{N}^{\circ} 3$

Embodied energy of wall construction systems per element area

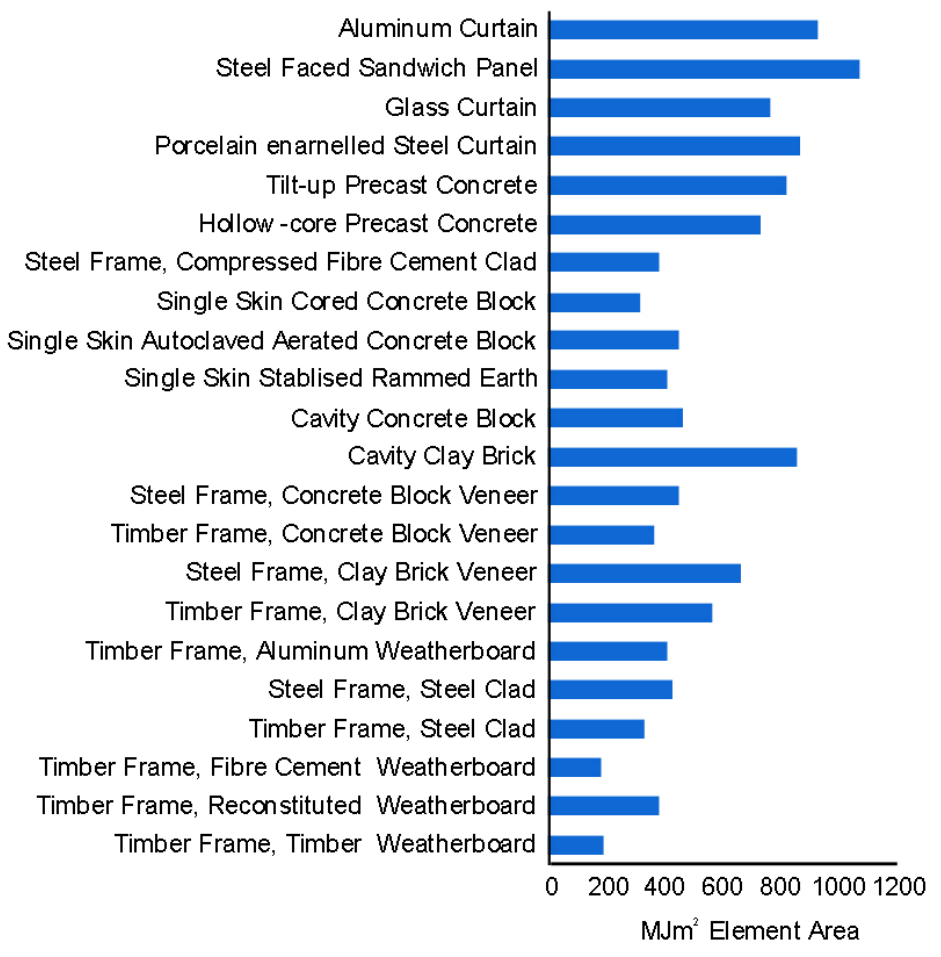

Image source: (Yohanis \& Norton, 2002, p. 90)

In terms of raw material Alcorn, A. (1996, p. 24) establishes for steel (virgin-general) $32 \mathrm{MJ} / \mathrm{kg}$ and $251,200 \mathrm{MJ} / \mathrm{m}^{3}$. In addition, when this raw material is turned into architecture a New Zealand study -one apartment, one floor- Buchanan \& Levine, (1999) found a value of $4.7 \mathrm{GJ} / \mathrm{m}^{2}$ for a house made of Steel/brick, following the same line of

${ }^{9}$ Burg, G. V. (1975, p. 64) 
analysis a Japanese study Suzuki, Oka, \& Okada, (1994, p. 167) found that for a lightweight steel-structure single family house $4.5 \mathrm{GJ} / \mathrm{m}^{2}$ were used. A third Swedish study Adalberth, $\mathrm{K}$. (2000) found a steel/concrete house has a value of $3.4 \mathrm{GJ} / \mathrm{m}^{2}$, which is the lowest figure among these studies.

\section{8. - Embodied energy for concrete structures}

In terms of primary embodied energy, concrete seems to have the highest energy requirements, even higher than steel. One of the advantages of concrete over other materials is the fact that concrete can offer a wide range of products for different applications. According to Alcorn, A. (1996) concrete is available in the following forms:

Table $\mathrm{N}^{\circ} 2$ Embodied energy of concrete building materials

\begin{tabular}{lc}
\hline \multicolumn{1}{c}{ Concrete } & $\mathrm{MJ} / \mathrm{kg}$ \\
\hline block & 0.94 \\
\hline brick & 0.97 \\
GRC & 7.6 \\
paver & 1.2 \\
pre-cast & 2 \\
\hline ready mix $\mathbf{1 7 . 5} \mathrm{MPa}$ & 1 \\
ready mix $\mathbf{3 0} \mathrm{MPa}$ & 1.3 \\
\hline ready mix $\mathbf{4 0} \mathrm{MPa}$ & 1.6 \\
\hline
\end{tabular}

Table $\mathrm{N}^{\circ} 2$ shows the diversity of concrete products and their energy requirements per kilogram. The list is made up by -perhaps-the most common building materials such is the case of block and brick. In addition, there is the family of pre-cast concretes: GRC which means Glass-fibre Reinforced Concrete which has $20 \%$ of the weight of pre-cast concrete, ${ }^{10}$ paver concrete which is related to floor products, pre-cast and finally the group of ready mix concretes. MPa or Mega Pascal is a unit of pressure. ${ }^{11}$ This means that the stronger is the ready mix denomination (they vary from 17.5 . 30 and $40 \mathrm{MPa}$ ) the more energy is required per kilogram. Again, when these raw materials are turned into architecture; literature on energy use in the production phase of residential buildings shows a study Adalberth, K. (2000) that found a value of 3.2 and $3.5 \mathrm{GJ} / \mathrm{m}^{2}$ for two apartments respectively. In addition, a Danish research found a value of $4 \mathrm{GJ} / \mathrm{m}^{2}$. On the other hand a Japanese study Suzuki, Oka, \& Okada, (1994, p. 167) disagrees, finding that for a multi-family concrete house $8-10 \mathrm{GJ} / \mathrm{m}^{2}$ were used. These remarkable differences could be explained by the type of analysis, LCA (first two studies) versus input-output data (Japanese study). However, it is unclear why these studies did not show similar values for houses made of concrete.

\footnotetext{
${ }^{10}$ (www.bcmgrc.com)

11 (www.convertunits.com)
} 


\section{9. - Embodied energy for wooden structures}

New Zealand studies suggest that in typical forms of building construction wood or timber-based buildings require much lower process energy, which consequently results in lower carbon emission in comparison with those buildings which use other materials such as brick, aluminum, steel and concrete. ${ }^{12}$

Alcorn, A. (1996) sets up the following list:

Table $\mathrm{N}^{\circ} 3$ List of materials and primary energy used per kilograms and cubic meter

\begin{tabular}{ccc}
\hline Timber softwood & $\mathrm{MJ} / \mathrm{kg}$ & $\mathrm{MJ} / \mathrm{m}^{3}$ \\
\hline air dried, rough sawn & 0.3 & 165 \\
\hline kiln dried rough sawn & 1.6 & 880 \\
\hline air dried, dressed & 1.16 & 638 \\
\hline kiln dried dressed & 2.5 & 1,380 \\
mouldings & 3.1 & 1,710 \\
hardboard & 24.2 & \\
MDF & 11.9 & 8,330 \\
glulam & 4.6 & 2,530 \\
particle bd & 8 & \\
plywood & 10.4 & \\
shingles & 9 & \\
\hline Timber hardwood & & \\
\hline air dried, rough sawn & 0.5 & 388 \\
\hline kiln dried rough sawn & 2 & 1,550 \\
\hline
\end{tabular}

Table $\mathrm{N}^{\circ} 3$ shows different types of wood-based products and their energy requirement by weight and volume. Again, when these raw materials are turned into architecture; literature on energy use in the production phase of residential buildings shows a study by Adalberth, K. (2000) that found a value of $4.5 \mathrm{GJ} / \mathrm{m}^{2}$ for one apartment made of wood. This represents the highest figure in comparison with concrete and steel-made houses of this research. In a New Zealand study, Buchanan \& Levine, (1999) found in their comparative life cycle analysis a value of $1.7 \mathrm{GJ} / \mathrm{m}^{2}$ for a timber-based house. This is the lowest value between wood, concrete and steel houses. In addition, Suzuki, Oka, \& Okada, (1994, p. 167) found that for a wooden single family house $3 \mathrm{GJ} / \mathrm{m}^{2}$ were used. This represents the lowest figure between houses built by using these three building materials. Both, Buchanan \& Levine, (1999) and Suzuki, Oka, \& Okada, (1994) agree that the wooden house has the lowest consumption of energy per square meter. However, Adalberth, K. (2000) differs that the wooden house has the lowest value of the research. The results show a great difference between the first two studies. Again, it is unclear why these investigations did not show similar patterns.

\footnotetext{
12 Buchanan \& Levine, (1999, p. 427)
} 


\subsection{0. - Comparison of steel, concrete and wood-based structures}

In terms of embodied energy of raw material, steel has the highest figure for both: $\mathrm{MJ} / \mathrm{kg}$ and $\mathrm{MJ} / \mathrm{m}^{3}$. Concrete blocks show a low embodied energy for $\mathrm{MJ} / \mathrm{kg}$ and units $\mathrm{MJ} / \mathrm{m}^{3}$. Reasons may be related to extraction processes of steel and manufacture in the case of concrete, concrete primary raw material is Portland cement and aggregates. ${ }^{13}$

Table $\mathrm{N}^{\circ} 4$ List of materials and primary energy used per kilograms and cubic meter

\begin{tabular}{ccc}
\hline Material & $\begin{array}{c}\text { Alcorn } \\
\mathbf{2 0 0 3}\end{array}$ \\
\hline & $\mathbf{M J} / \mathbf{~ k g}$ & $\mathbf{M J} / \mathbf{~ m 3}$ \\
\hline & & \\
\hline Aluminium virgin & 192 & 517,185 \\
\hline Steel virgin & 31.3 & 245,757 \\
\hline Ready mix concrete 17.5 MPa & 0.9 & 2,019 \\
\hline Concrete block & 0.9 & 12.5 unit \\
\hline Timber softwood & 2.8 & 1,179 \\
\hline MDF & 11.9 & 8,213 \\
\hline
\end{tabular}

However, the different ways that materials are used mean that weight and volume may be an inadequate way to compare them, because it is possible, for example, to have steel in thin sheets while concrete is less able to be used in this way. A United Kingdom study Eaton \& Amato, (1998, p. vii) compared steel, composite, reinforced and precast concrete options for the structure of a commercial building. The study found that there is not a significant difference between various types of construction with regard to:

- the embodied energy

- operational energy

- the total life cycle energy

The key results of Eaton \& Amato, (1998) potentially would apply to a wider range of building forms, but care should be done when these results are extrapoled to other climate conditions and/or services systems, such is the case of this research.

\footnotetext{
${ }^{13}$ Kernan, P. (1996, p. 30)
} 


\subsection{1. - $\mathrm{CO}_{2}$ emissions}

This figure shows the results of the $\mathrm{CO}_{2}$ emissions for two scenarios produced by the residential sector worldwide. According to Metz, Davidson, Bosch, Dave, \& Meyer, (2007, p. 393) in scenario $\mathrm{N}^{\circ} 2$, which has lower economy growth, especially in the developing world (except China), two regions account for the largest portion of increased $\mathrm{CO}_{2}$ emissions from 2004 to 2030: North America and developing Asia.

Figure $\mathrm{N}^{\circ} 4 \mathrm{CO}_{2}$ emissions possible scenarios
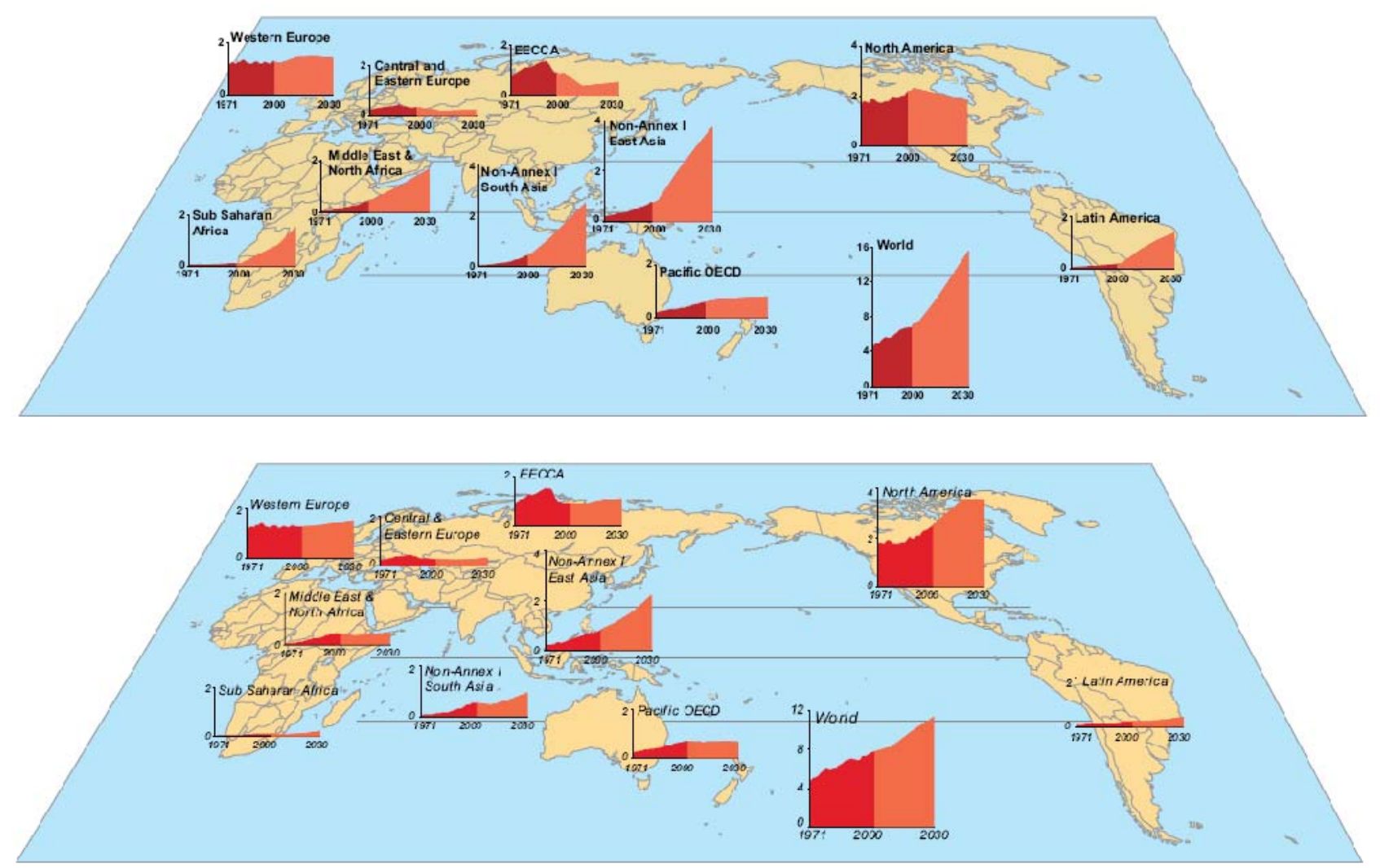

These two images show two possible scenarios in where the concentrations of $\mathrm{CO}_{2}$ are released into the atmosphere depending on the differences in the development of the economies of the world.

\subsection{2. - Recurrent $\mathrm{CO}_{2}$ emissions}

The energy and emissions associated with material or component replacement and periodic maintenance during the building's lifespan can be up to $32 \%$ of the initial embodied energy or emissions. Treloar, Fay, Love, \& Iyer-Raniga, (2000) 


\subsection{3. - Embodied $\mathrm{CO}_{2}$ emissions}

This table shows the amount of major building materials which results in the energy consumption and $\mathrm{CO}_{2}$ emission. The raw materials in different categories were calculated by using input-output analysis. However, energy resources used for the production of these kinds of materials have been calculated and added to each category, the most common fossil fuels here are: coal, oil, and gas. ${ }^{14}$

Table $\mathrm{N}^{\circ} 5$ Major resources required for house construction per $\mathrm{m}^{2}$

\begin{tabular}{|c|c|c|c|c|c|c|c|c|}
\hline & \multicolumn{2}{|c|}{$\begin{array}{l}\text { Concrete } \\
\text { houses }\end{array}$} & \multicolumn{3}{|c|}{$\begin{array}{l}\text { Wooden single-family } \\
\text { house }\end{array}$} & & \multicolumn{2}{|c|}{ Lightweight steel structure } \\
\hline & & & & & & & \multicolumn{2}{|c|}{$\begin{array}{l}\text { single-family } \\
\text { house }\end{array}$} \\
\hline & $\begin{array}{l}\text { House } \\
\text { N1 }\end{array}$ & $\begin{array}{c}\text { House } \\
\text { N2 }\end{array}$ & $\begin{array}{l}\text { House } \\
\text { N1 }\end{array}$ & $\begin{array}{l}\text { House } \\
\text { N2 }\end{array}$ & $\begin{array}{c}\text { House } \\
\text { N3 }\end{array}$ & $\begin{array}{l}\text { House } \\
\text { N4 }\end{array}$ & $\begin{array}{c}\text { House } \\
\text { N1 }\end{array}$ & $\begin{array}{l}\text { House } \\
\text { N2 }\end{array}$ \\
\hline Lime stone (kg) & 365 & 543 & 160 & 100 & 246 & 143 & 268 & 384 \\
\hline Coal (kg) & 132 & 183 & 30 & 34 & 34 & 33 & 69 & 62 \\
\hline Oil (I) & 71 & 99 & 37 & 32 & 35 & 32 & 59 & 46 \\
\hline LPG (kg) & 19 & 16 & 6 & 7 & 7 & 6 & 15 & 9 \\
\hline Coke (kg) & 4 & 10 & 2 & 2 & 3 & 2 & 4 & 5 \\
\hline Iron ore (kg) & 354 & 500 & 48 & 53 & 52 & 64 & 158 & 125 \\
\hline Other metal (kg) & 4 & 4 & 2 & 2 & 1 & 1 & 2 & 2 \\
\hline Electric power (kWh) & 1 & 1 & 1 & 1 & & 1 & & 1 \\
\hline City gas (m3) & 232 & 299 & 102 & 88 & 99 & 96 & 205 & 152 \\
\hline
\end{tabular}

The disagreement in the magnitude of primary energy use and $\mathrm{CO}_{2}$ emissions of using Input-output analysis in LCA assessments shown by Nassen, Holmberg, Wadeskog, \& Madeleine, (2006, p. 1593) is about $90 \%$ higher specific energy use $\mathrm{GJ} / \mathrm{m}^{2}$ and $20 \%$ for the share coupled to production and processing of building materials. Possible reasons for that is the definition of the system boundaries plus the apparent underestimation of energy use for transport, services, etc. ${ }^{15}$

\footnotetext{
${ }^{14}$ Suzuki, Oka, \& Okada, (1994, p. 167)

${ }^{15}$ Nassen, Holmberg, Wadeskog, \& Madeleine, (2006, p. 1593)
} 


\subsection{4. - $\mathrm{CO}_{2}$ emissions for steel structures}

In the Japanese context Suzuki, Oka, \& Okada, (1994, p. 168) found that for lightweight steel-framed single family houses $\mathrm{CO}_{2}$ emissions account for $400 \mathrm{~kg} / \mathrm{m}^{2}$ for the embodied energy. On the other hand, in New Zealand, Buchanan \& Levine, (1999, p. 433) found a value of $351 \mathrm{~kg} / \mathrm{m}^{2}$ for the closest example of a steel house for the embodied energy. Such differences may be explained by the way the calculations are made or how primary energy is produced in every project. Suzuki, Oka, \& Okada, (1994, p. 165), an input output table is used for the calculation of the total domestic product. Buchanan \& Levine, $(1999$, p. 433) used a carbon coefficient of $20 \mathrm{~kg}$ of carbon emission per GJ of total embodied energy.

\subsection{5. - $\mathrm{CO}_{2}$ emissions for concrete structures}

Suzuki, Oka, \& Okada, (1994, p. 168) found that for concrete multifamily houses in Japan $\mathrm{CO}_{2}$ emissions are $850 \mathrm{~kg} / \mathrm{m}^{2}$. A New Zealand study Buchanan \& Levine, $(1999$, p. 433) found a value of $344 \mathrm{~kg} / \mathrm{m}^{2}$ for the closest example of a concrete house for the embodied energy. The causes of this disagreement are unknown. Possible reasons could be that the New Zealand research used a carbon coefficient rather than made the appraisal of $\mathrm{CO}_{2}$ emissions for separate components. Differing carbon emissions for primary energy may also play a role.

\subsection{6. - for wooden structures}

Suzuki, Oka, \& Okada, (1994, p. 168) found that for wooden houses with single family in Japan $\mathrm{CO}_{2}$ emissions account $250 \mathrm{~kg} / \mathrm{m}^{2}$. A New Zealand study Buchanan \& Levine, (1999, p. 433) found a value of $78 \mathrm{~kg} / \mathrm{m}^{2}$ for a typical house made of timber for the embodied energy. In terms of energy use in the embodied energy of a building Buchanan \& Levine, (1999), Mithraratne \& Vale,(2003), both New Zealand studies and Suzuki, Oka, \& Okada, (1994) agree in the relationship between houses and building materials. This means, that these studies found that houses constructed by using concrete and steel are more likely to have higher values in contrast with wooden houses. However, Adalberth, K. (2000) and Nassen, Holmberg, Wadeskog, \& Madeleine, (2006) differs this relationship of energy use and building material. The first, a Swedish research finding, claims that the wooden house seems to have the highest value between steel and concrete houses. The second study is a Danish investigation which disagrees in the amount of energy per square metre for every project rather than the relationship of houses - building materials. However, it is unclear why these studies disagree largely. In terms of $\mathrm{CO}_{2}$ emissions the New Zealand study Buchanan \& Levine, (1999) differs largely in contrast with the concrete figure from the Japanese study Suzuki, Oka, \& Okada, (1994). Again, the reasons for these divergences are unknown and could be partially explained in the way the calculations are made plus the difference of the values of the primary energy generation for every country. 
6.17. - Comparison of steel, concrete and wooden $\mathrm{CO}_{2}$ emissions

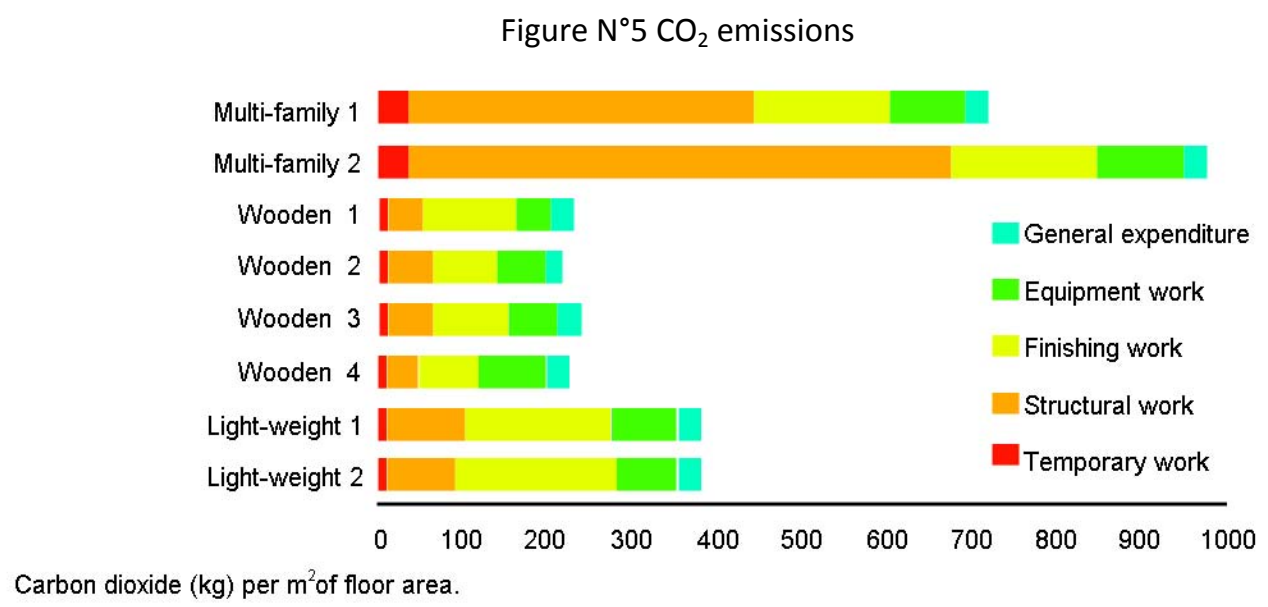

The same Japanese study Suzuki, Oka, \& Okada, (1994) shown before suggests that the lowest $\mathrm{CO}_{2}$ emissions are achieved by the usage of timber structures, followed by lightweight houses, which is the closest to the shipping container house and finally the highest figure is presented by the multi-family concrete houses.

The same United Kingdom study Eaton \& Amato, (1998, p. vii) shown before, which compared steel, composite, reinforced and precast concrete options for the structure of a commercial building, found that there is not a significant difference between various types of construction with regard to:

- the embodied $\mathrm{CO}_{2}$ emission values

- operational $\mathrm{CO}_{2}$ emission values

- $\mathrm{CO}_{2}$ emission values

The key results of Eaton \& Amato, (1998) potentially would apply to a wider range of building forms, but care should be done when these results are extrapoled to other climate conditions and/ or services systems, such is the case of this research.

For New Zealand studies, Buchanan \& Levine, (1999) found an analysis of typical forms of building construction shows that timber buildings require much lower process energy and result in lower carbon emissions than buildings of other materials such as brick, aluminium, steel and concrete. However, the increment in the usage of wood can only be justified if there is a corresponding increase in the area of forest available for long term sustainable management. ${ }^{16}$

\footnotetext{
${ }^{16}$ Buchanan \& Levine, (1999, p. 436)
} 


\subsection{8. - Summary of the chapter}

- In comparison with recent years the amount of energy needed in order to manufacture products and services may have decreased in some areas taking advantage of the continuous development of technologies in making more efficient production processes.

- The Life-cycle Assessment is a process to evaluate the environmental burdens associated with a product, process or activity by identifying and quantifying energy and materials used and wastes released to the environment. ${ }^{17}$

- The Life Cycle Assessment can be divided into four main stages: Initial embodied energy, Operating energy, Recurrent embodied energy, and Demolition energy.

- Life cycle energy analyses: there are a series of analyses according to the boundary-systems: Statistical analysis, Process analysis, Input-output analysis and Hybrid analysis.

- Through the phase of use, energy is divided into embodied energy for the replacement of materials and components (this stage is also called recurrent embodied energy) and the use of energy in order to run the building, space heating, space cooling, water heating, lighting and so on.

- For major refurbishment embodied energy increases (or recurrent energy) because new processes are required such as the extraction of new materials.

- The energy used in demolition process and transport of rubble matches with the embodied energy process and this means the end of the life of the building.

- Operating energy is an important issue because is the highest energy figure and is related to the energy end-uses, which for residential structures tend to have a consistent use pattern. ${ }^{18}$

- One of the disadvantages of steel in comparison with other building materials is that in order to produce it a large amount of energy is required.

- In terms of energy used-square meter, steel and concrete houses in New Zealand are more likely to have higher values in contrast with timber-based structures.

- In terms of $\mathrm{CO}_{2}$ emissions, again, steel and concrete houses in New Zealand are more likely to have higher values in contrast with timber-based structures.

\footnotetext{
${ }^{17}$ Eaton \& Amato, (1998, p. 5)

${ }^{18}$ Isaacs, Lee, \& Donn, (1995, p. vii)
} 


\section{Chapter VII - Life cycle energy for houses in New Zealand}

This chapter aims to explain and discuss the energy end-use patterns of residential buildings in New Zealand, selecting a suitable study area in Wellington for future case studies. The discussion will be focussed on physical issues linked to climate-geographic conditions of the country, heating patterns (for space and water), types of fuels used for heating and so on.

\section{1. - Background}

New Zealand is a long and narrow country encompassing two main land masses, the North Island, the South island and a group of small islands. It extends approximately $1,600 \mathrm{~km}$ in length, with a land area of $270,000 \mathrm{~km}^{2}$, ranging from latitude $37^{\circ} \mathrm{S}$ to $46^{\circ} \mathrm{S}^{1}$

In the residential sector, around one-third of the current housing stock -by the year of 2009- has been constructed since insulation standards were introduced in $1978 .^{2}$ This means, around $60-70 \%$ of total dwellings were built before that date. In terms of heating patterns, New Zealand households commonly heat only one room -usually the living room or the living room and sometimes one or two bedrooms are heated. In comparison with other OECD countries (see chapter V) New Zealand has the lowest space heating intensity of all the countries studied (Australia, Canada, Japan, UK, USA). This can be corroborated with an International Energy Agency report done in Australia, which investigated the relationship between energy efficiencies or energy intensities; suggesting that New Zealand had the lowest space heating requirement for all the nations assessed. ${ }^{3}$ In addition, the report found that New Zealanders on higher incomes do not heat their homes to a significantly warmer temperature than those of lower incomes. ${ }^{4}$

Howden-Chapman, Viggers, Chapman, \& O' Dea, (2009) discuss the problems of poorly constructed and inadequately heated houses in relation to OECD standards. Those problems are attributed to house age and climate conditions.

\footnotetext{
${ }^{1}$ French, Camilleri, Isaacs, \& Pollard, (2007, p. 771)

${ }^{2}$ Howden-Chapman, Viggers, Chapman, \& O' Dea, (2009, p. 3388)

${ }^{3}$ Ibid

${ }^{4}$ Ibid
} 
Electricity in New Zealand is highly used in most areas in contrast to solar energy which is uncommon for heating homes. The burning of coal is used more often on the West Coast and the Southern parts of the South Island where it is produced. Wood is the most common fuel of the rural areas, but is less common in the main cities, where restrictions related to air quality apply. Reticulated natural gas usage is limited to the North Island, but not exclusively to main cities; it is used in Auckland, Taranaki and Wellington. Electricity, wood and bottled gas are the major available fuels for domestic heating nationwide. In contrast with commercial and industrial electricity -in the residential sector- the price of electricity has increased faster over 30 years. In addition, about $2 \%$ of New Zealand households do not heat their dwellings. ${ }^{5}$

On average, the warmest houses are those heated by solid fuels. Usually the living room is the warmest room. Post-1978 new houses are warmer in summer and winter than those houses built before 1978. Since $1^{\text {st }}$ April 1978, New Zealand new houses have required thermal insulation. This thermal insulation requirement is not retroactive and only applies for new dwellings. Traditional houses in New Zealand are timber-based structures with weather board cladding; floors are made of timber or concrete and roofs are of long run steel. New houses ground floors are often made of concrete. Houses are conventionally placed alone with one or two storeys, because of New Zealand being an earthquake zone. ${ }^{6}$

Space heating

The most common heated room is the living room. The coldest times are mornings in an average New Zealand house and the coldest time outside is during the night. On the other hand, evenings are the warmest but the most common heating time. Other rooms such as bedrooms on average are slightly colder than living rooms. A typically New Zealand dwelling is considered to be low thermal mass. In addition, houses made of concrete or double-wall brick which are high thermal mass would be expected to have a lower temperature range compared with those built by using wood-based materials. $^{7}$

There are a series of key factors that can be crucial for achieving higher indoor temperatures like the climate, the fuel and the heater type used in the dwelling, the age of the house and the level of thermal insulation.

\footnotetext{
${ }^{5}$ Howden-Chapman, Viggers, Chapman, \& O' Dea, (2009, pp. 3389-3391)

${ }^{6}$ French, Camilleri, Isaacs, \& Pollard, (2007, p. 771)

${ }^{7}$ French, Camilleri, Isaacs, \& Pollard, (2007, p. 772)
} 


\section{2. - Climate}

Northland has a sub-tropical climate. Houses located in the North Island are heated for a much shorter time than their counterparts from the South Island. Heating patterns vary by location. In addition, houses located in colder climates tend to use more energy. The winter season in New Zealand (a southern hemisphere country) is during the months of June, July and August. The summer months are December, January and February. The majority of homes are in a coastal climate, but the central areas of both islands are more continental. The far south is cooler than the far north. For example, the daily mean winter temperature in Invercargill (in the far south) is $6.2^{\circ} \mathrm{C}$ compared to $11.9^{\circ} \mathrm{C}$ in Kaikohe (in the far north). Average summer ambient daily temperature in Kaikohe is $18.8^{\circ} \mathrm{C}$, but in Invercargill only $13.3^{\circ} \mathrm{C}$ a difference of $5.5^{\circ} \mathrm{C}$. The annual range of monthly mean temperature (difference between the mean temperature of the warmest and coldest months) is relatively small. In the top of the North Island and in western districts of both islands it is about $8^{\circ} \mathrm{C}$, while for the remainder of the North Island and east cost districts of the South Island it is $9-10^{\circ} .8$

New Zealand has required thermal insulation in new houses since 1 April $1978 .{ }^{9}$ These modest requirements were increased slightly for houses in the central North Island and all the South Island (Zone 3) in 2000. The other two climate zones cover the remaining area of the North Island (Zones 1 and 2 ) forming the official climate zones in New Zealand. ${ }^{10}$

Climate and regional differences

The main key factors of summer living room daytime temperature have been found to be the climate and the house age.

\footnotetext{
${ }^{8}$ French, Camilleri, Isaacs, \& Pollard, (2007)

${ }^{9}$ French, Camilleri, Isaacs, \& Pollard, (2007, p. 771)

${ }^{10}$ French, Camilleri, Isaacs, \& Pollard, (2007)
} 
Figure $N^{\circ} 1$ : Climate zones for New Zealand

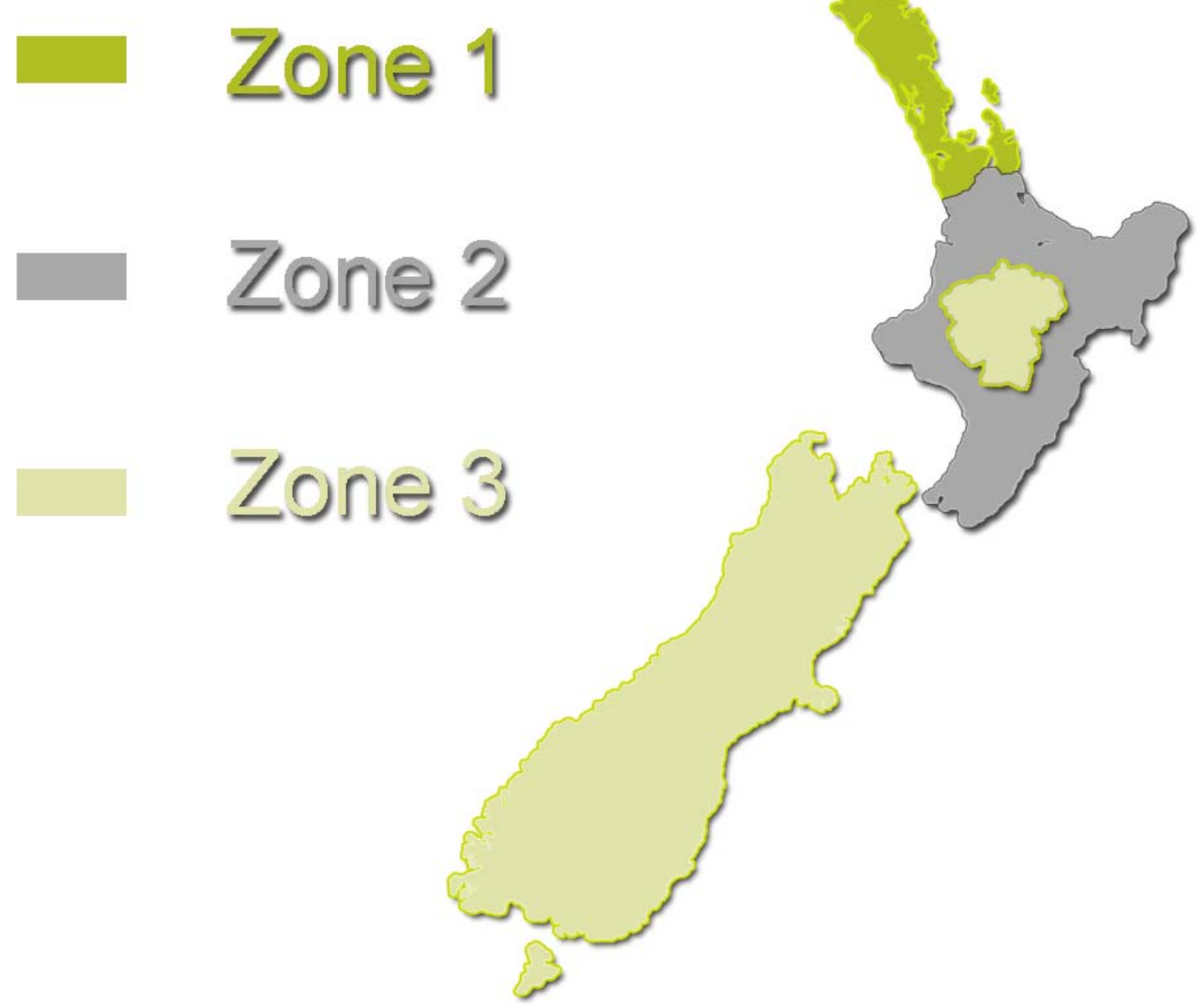

Image source: www.dbh.govt.nz/codewords-26-8 


\section{3. - Heating patterns: fuel and heater type}

New Zealand houses are heated for about half of the year, with little heating or cooling in the summer months. French, Camilleri, Isaacs, \& Pollard, (2007) Therefore the heating schedule has an influence on temperatures in winter, while the ambient temperature and climate have the largest influence in summer. ${ }^{11}$

In 2006 electric heating was the most common form of heating, reaching $75 \%$ of homes. $^{12}$

Figure $\mathrm{N}^{\circ} 2$ : Heating fuels

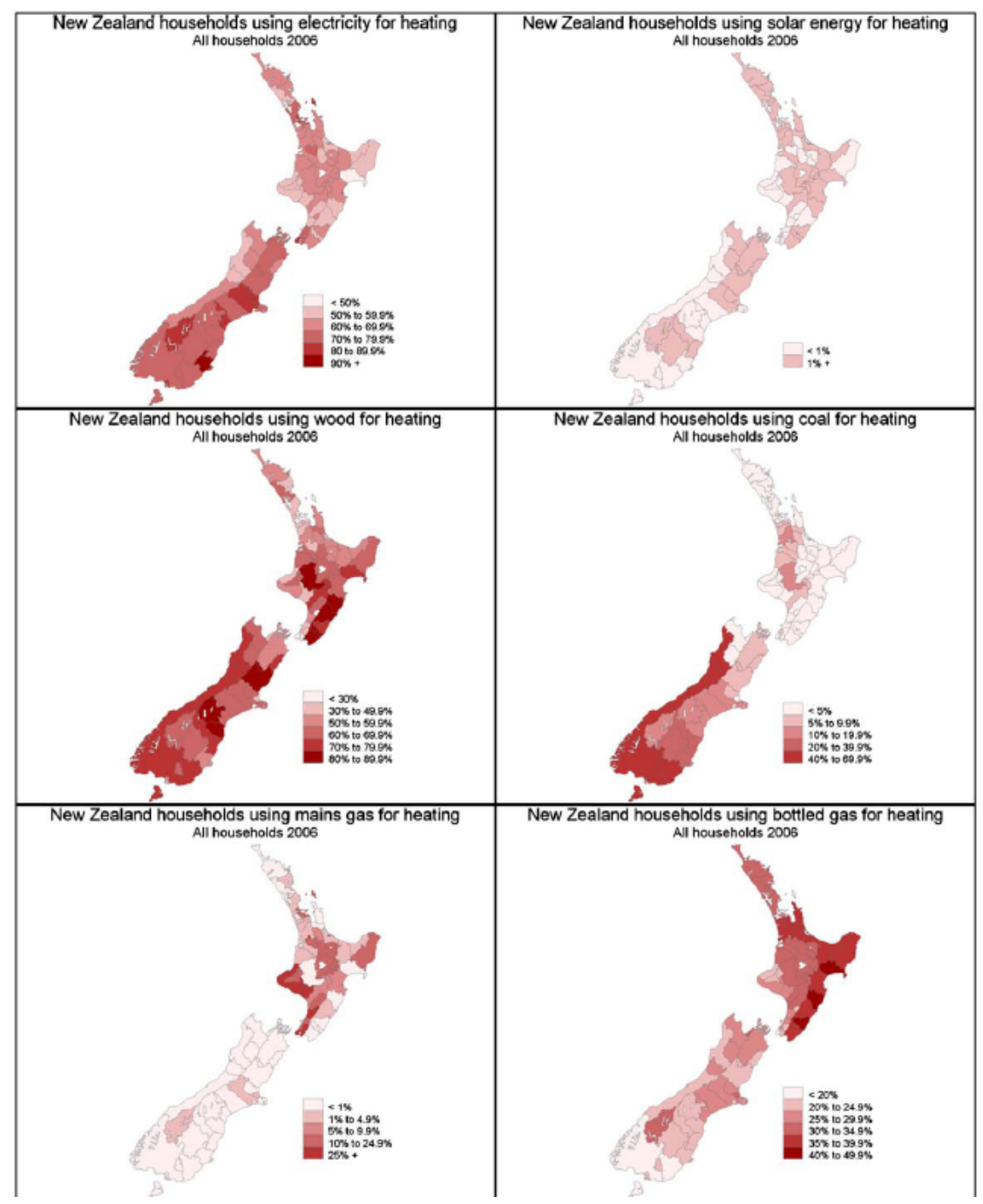

Source: (Howden-Chapman, Viggers, Chapman, \& O' Dea, 2009, p. 3390)

\footnotetext{
${ }^{11}$ French, Camilleri, Isaacs, \& Pollard, (2007, p. 771)

12 Howden-Chapman, Viggers, Chapman, \& O' Dea, (2009, p. 3388)
} 
The major driver of the average living-room evening temperature in winter is the type of heating system. The warmest dwellings are those heated by enclosed solid fuel burners. The coldest are those houses that use open fires, portable LPG (Liquefied Petroleum Gas) heaters or portable electric heaters. In addition, the cost of providing heat varies depending on the fuel and appliance chosen by the householder and the cost of different fuels might be relevant. ${ }^{13}$

Studies have found a strong relationship between the heater type and the winter temperatures. In New Zealand, gas central heating is restricted to the North Island. All of those houses that warm their living rooms by using inefficient open solid fuel burners are cooler in comparison with those residences which use more efficient enclosed solid fuel burners to heat their living rooms being in consequence the warmest. $^{14}$

Table $\mathrm{N}^{\circ} 1$ Winter living room evening temperatures and heating energy by heater type

\begin{tabular}{ccc}
\hline Main heater type & Mean evening temperature $\left(^{\circ} \mathbf{C}\right)$ & Net energy (kWh) \\
\hline Open solid fuel & & \\
\hline Electric & 16 & 973 \\
\hline LPG & 16.9 & 2,175 \\
\hline Fixed electric & 17 & 1,640 \\
\hline Heat pump & 17.8 & 3,563 \\
\hline Gas & 18 & 2,057 \\
\hline Gas Central & 18.1 & 3,836 \\
\hline Solid or liquid central & 18.3 & 6,727 \\
\hline Enclosed solid fuel & 18.5 & 2,908 \\
\hline
\end{tabular}

Source: Table modified from French, Camilleri, Isaacs, \& Pollard, (2007, p. 777)

As can be seen Table $\mathrm{N}^{\circ} 1$ shows the winter living room evening temperatures and heating energy by heater type. Extremes: Living rooms heated by open solid fuel burners are the coldest from the list. Not surprisingly -they use at the same time- less net heating energy or only $973 \mathrm{kWh}$. On the other hand, the warmest living rooms are those heated by using enclosed solid fuel burners. Not surprisingly more energy is required $(3,803 \mathrm{kWh}$ are provided by these types of heaters). LPG represents the average of temperature and net energy required. The usage of Gas central heating seems to be the worst in relation to the energy needed and the temperature performance of the heater.

\footnotetext{
${ }^{13}$ French, Camilleri, Isaacs, \& Pollard, 2007, (2007, p. 775)

${ }^{14}$ French, Camilleri, Isaacs, \& Pollard, 2007, (2007, p. 776)
} 
House Age

House age and the living room winter evening temperature are strongly related. New heating systems and thermal insulation have been added in many older houses throughout the country. Temperature comfort range is about 20 to $25^{\circ} \mathrm{C}$. A few pre1910 houses are still in original condition. Houses built after 1990 on average have a daytime living room summer temperature of above $20^{\circ} \mathrm{C}$. As factor, the house age alone, without the mean outdoor temperature explains $14 \%$ of the variation in daytime living room temperatures. In addition, house age and climate are independent variables. In comparison with older houses, newer residences tend to be warmer. Possible reasons for that can be explained by ${ }^{15}$ :

- Higher thermal performance: since 1978 all New Zealand houses had have to be insulated.

- Air-tightness: Newer houses tend to be less leaky due to tighter construction and better building materials for example.

- Increased glazing area: A tendency to increase glazing areas resulting in greater solar gain and the same time higher winter heat losses.

- Possible better orientation of windows for passive solar heating.

- Lower ceiling heights that can potentially lead to lower room volumes.

- The reduction or no employment of eaves.

Impact of thermal insulation

Houses built after 1 April 1978 were required to include a minimum level of insulation. In theory, Post-1978 houses are likely to have a higher thermal performance than Pre1978 dwellings. New Zealand is considered by its inhabitants as a temperate climate country in which requires certain level of heating during winter seasons and little or no summer cooling ${ }^{16}$.

\section{Summer}

- Few houses use air conditioning in New Zealand.

- Ventilation is controlled by occupants.

- Most living rooms are between $20^{\circ} \mathrm{C}$ and $25^{\circ} \mathrm{C}$ most of the time.

- On average, bedroom temperatures are lower than living room temperatures.

- Few New Zealand houses have high thermal mass.

\footnotetext{
${ }^{15}$ French, Camilleri, Isaacs, \& Pollard, (2007, pp. 777-778)

${ }^{16}$ French, Camilleri, Isaacs, \& Pollard, (2007, p. 779)
} 
The largest impacts on the summer daytime living room temperatures are defined by the house age (related to the decade of construction) and the local climate conditions (the average outdoor temperature over summer). During summer seasons newer houses tend to be warmer than old homes with the mean living room temperature increasing by $0.25^{\circ} \mathrm{C}$ per decade. In addition, houses built at the present time are likely to be $2.5^{\circ} \mathrm{C}$ warmer than those constructed 100 years ago in the same climate. However, no obvious link has been found between large areas of solar gain: West, North and East facing glazing and indoor high temperatures. ${ }^{17}$

\section{Winter}

The average traditional New Zealand house has a mean living room temperature below that which is recommended for comfort. Moreover, only 5\% of New Zealand dwellings have incorporated central heating systems. The living room is the most common heated room and the most common heating time is on winter evenings. One of the advantages of the usage of solid fuel burners is that they heat houses well. On the other hand, the problem is that with little control they can reach very high temperatures.

Houses heated by open fires (solid fuels) and portable electric heaters are the coolest and all those houses heated by enclosed solid fuel burners are the warmest. New houses are warmer during winter seasons than older houses. Possible reasons for that may include higher levels of thermal insulation, increased air-tightness and heating systems more efficient and more powerful. In contrast with those houses built before 1978 , the winter evening living room temperatures in new residences are on average $1^{\circ} \mathrm{C}$ warmer. ${ }^{18}$

\footnotetext{
${ }^{17}$ French, Camilleri, Isaacs, \& Pollard, (2007, p. 780)

${ }^{18}$ French, Camilleri, Isaacs, \& Pollard, $(2007$, p. 781)
} 


\section{4. - Energy use in residential buildings in New Zealand}

The residential sector consumes 13\% (60PJ) of New Zealand's energy, and one-third or $33 \%$ of all electricity; this includes the growth in consumption of over $2 \%$ per year. In addition, the domestic sector accounts for $10 \%$ of national $\mathrm{CO}_{2}$ emissions. As energy consumption grows, the negative economic, social and environmental effects increase. ${ }^{19}$ HEEP or the Household Energy End-use Project was a long term (10 years) research project established in late 1995 in order to create a scientifically and technically accurate base of energy use and end-uses for New Zealand houses.

Pie charts $\mathrm{N}^{\circ} 1$ and $\mathrm{N}^{\circ} 2$ preliminary results of HEEP based on types of fuels and energy end-use
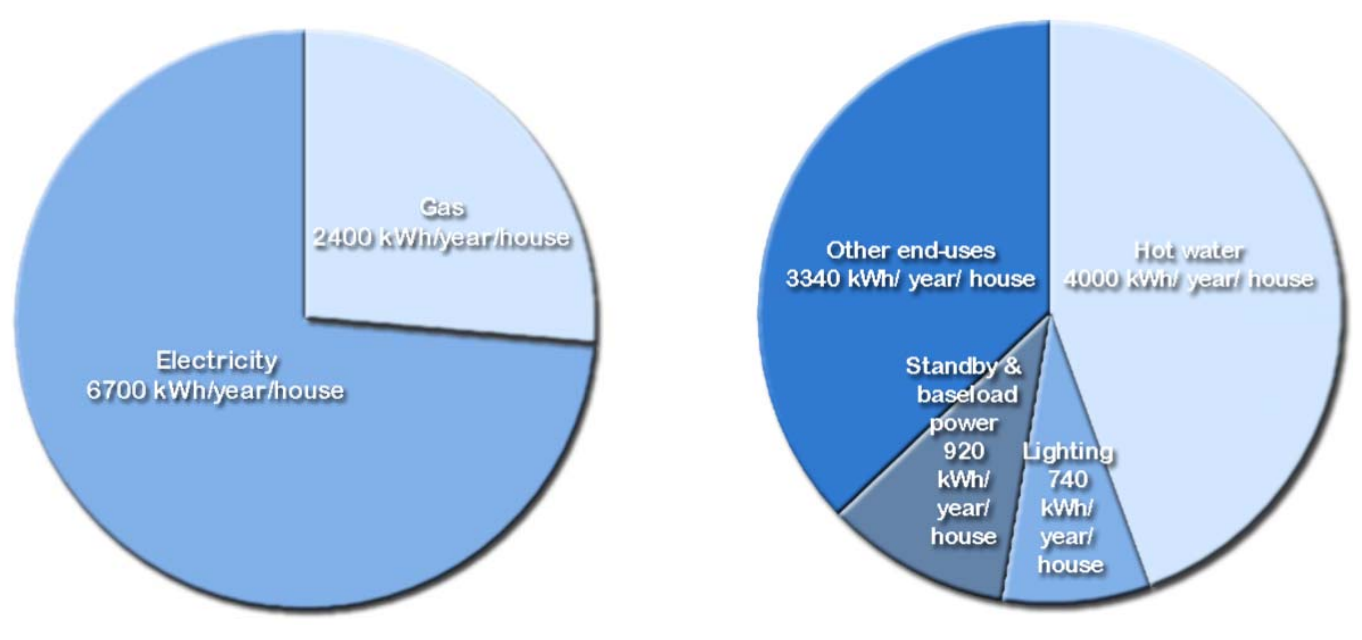

Source: information from (BRANZ, 2001, p. ii)

The 1971-1972 electricity survey generated a set of data which was not questioned since that time. These two pie charts show the preliminary results of HEEP monitored houses for the $5^{\text {th }}$ year report. As can be seen from the charts $N^{\circ} 1$ shows the total energy on average excluding LPG, is around 9,000 kWh/year/ house. In addition, almost one-quarter of the total energy consumed was gas and the remaining threequarters of the energy consumed was electricity. Water heating-energy compared with the total energy used by households is an important component of the whole figure. However, New Zealand lacks efficient hot water cylinders. Only 5\% of them have got " $A$ " grade specifications (that will be discussed in more detail later). ${ }^{20}$

\footnotetext{
${ }^{19}$ BRANZ, (2003, p. i)

${ }^{20}$ BRANZ, (2001, p. ii)
} 
New performance requirements under NZBC Clause $\mathrm{H} 1$ were set up for new dwellings. This became compulsory on $29^{\text {th }}$ December 2000 and its main purpose is to improve the performance of electric hot water cylinders. In addition, the HEEP assessment shows that about $20 \%$ of New Zealand houses sometimes run out of hot water. Possible reasons for that may include small cylinder size for the household hot water requirement. $^{21}$

Standby power and losses

Even those appliances that are waiting connected to be used consume a considerable amount of energy. Standby power is the power consumed by an appliance when it is connected to the mains but is not in operation. Depending on appliance type this may range from nil to as much as $20 \mathrm{~W}$ or more. International studies have shown that at least $10 \%$ of domestic electricity is from standby power consumption.

The main five contributors to the residential electricity end-use in the form of baseload power are: listed below from the highest to the lowest. ${ }^{22}$ Modern appliances consume less energy related to standby power than older units. The refrigeration appliances contribute both, to the base load (because they switch on and off) and the standby power, all the other appliances in the list below are there because of their standby power.

- Fridge or fridge freezer

- Television

- Video

- Washing machine

- Microwave

Indoor Temperatures

Research outcomes indicate that about one half of New Zealand households achieve comfortable indoor temperatures in winter seasons. The average indoor temperature in dwellings- which were reported always as comfortable was about $19^{\circ} \mathrm{C}^{23}$

\footnotetext{
${ }^{21}$ BRANZ, (2001, p. iii)

22 BRANZ, (2001, p. iv)

${ }^{23}$ BRANZ, (2001, p. iv)
} 
Solar Gains

Space heating in winter seasons is a large component of the energy-end used in New Zealand residences. Local climate conditions are determinant in energy requirements of a house, plus the physical characteristics of a building and the comfort of the occupants. In addition, indoor temperatures within buildings are dynamic and solar gains increase temperature within the living room on the afternoon produced due to radiant effect. $^{24}$

7.5. - Life cycle analysis for houses in New Zealand

Houses in New Zealand tend to last a life cycle of 100 years.

7.6. - Embodied energy

House construction types of walls

New Zealand houses are generally timber-based structures. However, there is a wide diversity of cladding types.

- Concrete masonry

- Tilt up slab wall

- Polystyrene block

- Solid timber

- Light steel frame

- Wood based panels

${ }^{24}$ BRANZ, (2001, p. iv) 


\section{7. - Operating energy}

2002 HEEP Annual Report

Since 1990 the average energy-use per family unit has grown by about $2 \%$ and the total household energy-use has increased by $16 \%$; the number of households has increased too. ${ }^{25}$

Pie chart $N^{\circ} 3$ Energy end use per household in New Zealand in 2002

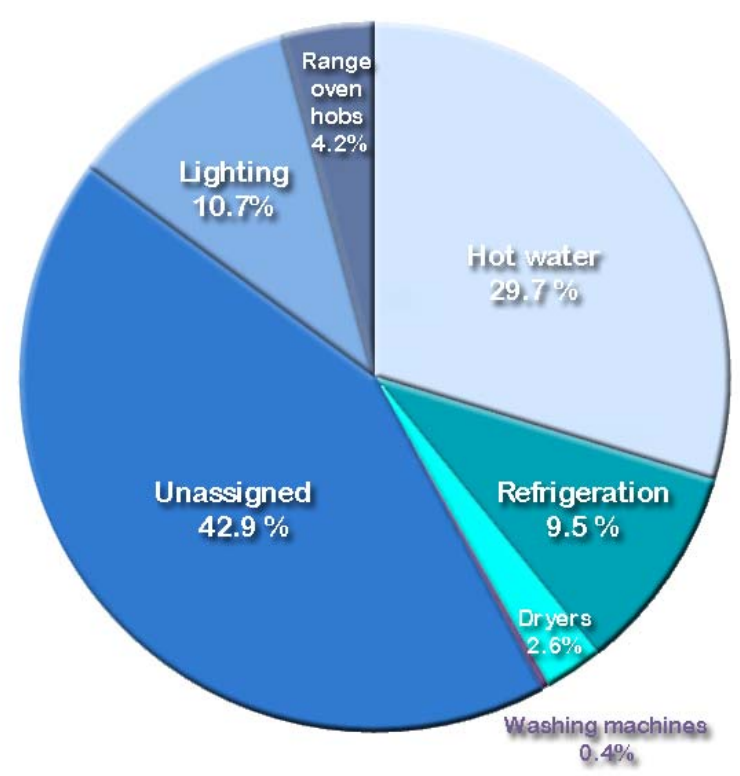

Source: BRANZ, (2002, p. i)

The pie chart shows the distribution of energy end uses in households of New Zealand in 2002, with a more detailed breakdown than given earlier in pie chart $N^{\circ} 2$. Energy consumption in New Zealand is dynamic. Energy used in hot water is an important driver. The unassigned figure may contain the proportion of space heating, which remains unknown in this stage of HEEP.

${ }^{25}$ BRANZ, (2002, p. i) 
The average energy-use per family unit is $10,500 \mathrm{kWh} / \mathrm{year}$, including the most common types of fuels, meaning electricity, natural gas and LPG in Auckland, Wellington and Hamilton. At the same time, there is not a significant difference in the average energy consumption of houses from the main cities in the North Island such as Auckland, Hamilton and Wellington. ${ }^{26}$

In all locations water heating is about one-third of the total energy consumption. Meanwhile lighting is around $10 \%$ of the total similar to refrigeration, cooking reaches $4 \%$ and clothes washing and drying account for about $3 \%$. In addition, annual energy use per New Zealand household has increased from $40 \mathrm{GJ}$ in the 1980 s to $42 \mathrm{GJ}$ in 2000. Conversely, there is no evidence that internal temperatures in New Zealand residences have risen. In comparison with other OECD countries New Zealand consumes less energy per household. ${ }^{27}$ (See Chapter 5)

Heating time

Table $\mathrm{N}^{\circ} 2$ Heating time in different North Island cities

\begin{tabular}{cccc}
\hline City & Start heating & Peak temperature & Heating period \\
\hline Auckland & 5:45 p.m. & $8: 30$ p.m. & 4.5 hours \\
Hamilton & 4:30 p.m. & 7:00 p.m. & 4.75 hours \\
Wellington & 5:00 p.m. & $9: 30$ p.m. & 7 hours \\
\hline \multicolumn{4}{c}{} \\
\hline
\end{tabular}

Table $\mathrm{N}^{\circ} 2$ shows the heating schedule in different cities of the North Island. Among the examples Wellington appears to be the city which spends more time heating residences -7 hours in total- in comparison with Auckland -4.5 hours- and Hamilton almost 5 hours. In addition, household heating is strongly zoned and at least- 50 per cent of households heat bedrooms. There is no correlation between household income or house floor area and winter evening temperatures. High-income houses are no warmer than those of low-income residents.

\footnotetext{
${ }^{26}$ BRANZ, (2002, p. ii)

${ }^{27}$ BRANZ, (2002, p. ii)
} 
Winter temperatures

Table $\mathrm{N}^{\circ} 3$ Average winter evening temperature

\begin{tabular}{ccc}
\hline Insulation group & $\begin{array}{c}\text { Average winter } \\
\text { evening temperature }\end{array}$ & $\begin{array}{c}\text { Winter evening } \\
\text { energy use }\end{array}$ \\
\hline & & \\
Pre-1978 & $17.0+-0.2^{\circ} \mathrm{C}$ & $1070+-280 \mathrm{~W}$ \\
Post- 1978 & $18.4+-0.4^{\circ} \mathrm{C}$ & $1130+-150 \mathrm{~W}$ \\
\hline
\end{tabular}

Source: (BRANZ, 2002, p. iv)

There is a significant connection between the age of the house and indoor temperatures. In addition, houses built after the 1978 insulation requirement are on average $1.4^{\circ} \mathrm{C}$ warmer than those units built before 1978 . However, this does not represent a significant difference among them. ${ }^{28}$

LPG (Liquid Petroleum Gas) Heaters

In 2002 the number of households with portable gas heaters has increased from $2 \%$ in comparison with households in 1984 to $33 \%$. The increment of the usage of portable gas heaters is correlated to the reduction in the use of the other two types of portable heaters assessed: Portable electric heaters and portable kerosene heaters. ${ }^{29}$

Hot water

Hot water has a significant impact in the energy-use of the average New Zealand house. Hot water energy-use was about $4,000 \mathrm{kWh} /$ year/house or close to $44 \%$ of total energy. The average hot water standing loss is $1,000 \mathrm{kWh} /$ system/year, or about $11-12 \%$ of total energy use. ${ }^{30}$

\footnotetext{
${ }^{28}$ BRANZ, (2002, p. iv)

${ }^{29} \mathrm{Ibid}$

${ }^{30}$ Ibid
} 


\section{Saving energy}

Each $1 \%$ of improvement in the efficiency of energy use in New Zealand dwellings would result in a benefit of $\$ 17$ million and the reduction of the national $\mathrm{CO}_{2}$ emissions by $0.1 \% .^{31}$

Major changes in the way New Zealand houses are built and used.

- Materials

- Building Code (thermal insulation required from 1978)

- Appliances

- Consumer expectations

- Work practices

- The characteristics, size, age, configuration and cultural diversity of households.

Household energy-use

Table $\mathrm{N}^{\circ} 4$ and pie chart $\mathrm{N}^{\circ} 4$ Energy end use in New Zealand houses in 2003

\begin{tabular}{|cc|}
\hline Energy use & $\%$ \\
\hline Hot water & 29 \\
\hline Space heating & 22 \\
\hline Lighting & 11 \\
\hline Refrigeration & 10 \\
\hline Cooking (inc. range) & 8 \\
\hline Large Misc. & 3 \\
\hline Entertainment & 3 \\
\hline Other & 5 \\
\hline Unassigned & 9 \\
\hline
\end{tabular}

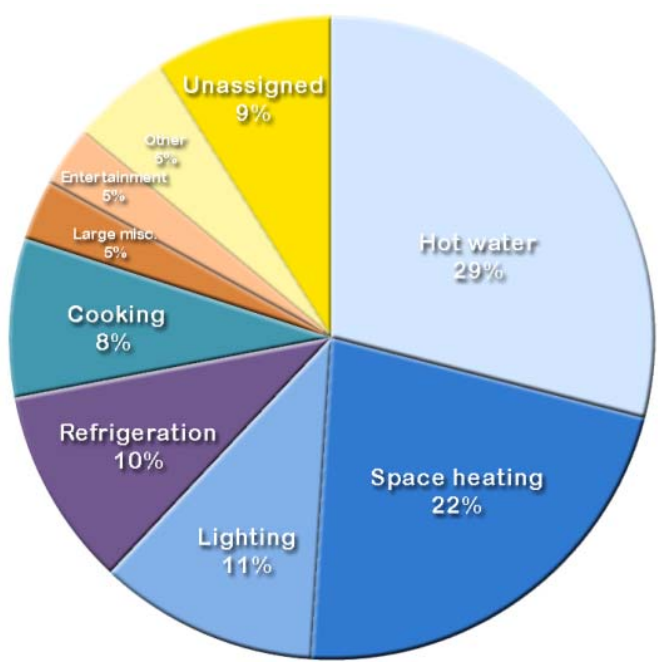

Source: BRANZ, (2003, p. ii)

Both, table $\mathrm{N}^{\circ} 4$ and pie chart $\mathrm{N}^{\circ} 4$ shows the average energy end-use of a household of New Zealand in 2003. Almost one-third of the total is destined to hygiene, being hot water forming $29 \%$ of the consumption. Space heating requires about $22 \%$; meanwhile lighting requires half of the power for space heating with $11 \%$, followed by refrigeration with $10 \%$ and the rest of the items are divided in similar proportions.

${ }^{31}$ BRANZ, (2003, p. i) 


\subsection{1. - Space heating}

Table $\mathrm{N}^{\circ} 5$ Average winter evening temperatures for living and bedrooms

\begin{tabular}{cccc}
\hline Insulation group & Average winter evening & Average winter evening & Winter evening \\
\hline & living room temperature & bedroom temperature & energy use \\
Pre-1978 & $17.0+-0.2^{\circ} \mathrm{C}$ & $13.8+-0.2^{\circ} \mathrm{C}$ & $1680+-114 \mathrm{~W}$ \\
Post- 1978 & $18.0+-0.3^{\circ} \mathrm{C}$ & $14.9+-0.3^{\circ} \mathrm{C}$ & $1590+-1210 \mathrm{~W}$ \\
\hline
\end{tabular}

Source: BRANZ, (2003, p. iii)

New Zealand houses are considered low thermal mass. Only 5\% of New Zealand houses have central heating ${ }^{32}$ with most houses only heating one or two rooms. Occupants tend to turn a heater on when they arrive, and off when they leave, or when the room is considered to be warm enough. As a result, temperatures that would be considered comfortable elsewhere in the temperate world are often not achieved. French, Camilleri, Isaacs, \& Pollard, (2007, p. 771)

The most commonly heated room is the living room which is heated in the evenings in $90 \%$ of houses during weekdays and in $87 \%$ of houses during the weekends. Only $6 \%$ of houses have no heating in the living room. On the other hand in $50 \%$ of houses the bedroom is never heated, and $68 \%$ of houses do not heat utility areas (laundry, bathroom, and corridor). French, Camilleri, Isaacs, \& Pollard,(2007, p. 772)

The mornings are the coldest time inside the average New Zealand house, although the coldest time outside is overnight. French, Camilleri, Isaacs, \& Pollard, (2007, p. 773)

The average space heating energy use is 3,650 $\mathrm{kWh} / \mathrm{year}$, the extremes are: a minimum of $253 \mathrm{kWh} /$ year and a maximum 14,120 kWh/year. Normalised to floor area, heating energy-use ranges from the lowest worth of $0.8 \mathrm{kWh} / \mathrm{m}^{2} / \mathrm{year}$ to a highest value of $42.9 \mathrm{kWh} / \mathrm{m}^{2} /$ year with an average of $13.5 \mathrm{kWh} / \mathrm{m}^{2} /$ year. $^{33}$

\footnotetext{
${ }^{32}$ French, Camilleri, Isaacs, \& Pollard, (2007, p. 771)

33 BRANZ, (2003, p. iii)
} 


\subsection{2. - Water heating (Hot Water)}

The provision of hot water in New Zealand is divided into two categories.

- Batch production: often based around carrying cold water to a pan or other container or receptacle above a fire and.

- Continuous production: with piped water flowing into a device heated by electricity, gas or fuel.

Historically, in $194527 \%$ of national households lacked a hot water service. By the early 1950 s $11.6 \%$ of families lacked a hot water service. The proportion fell to $5.9 \%$ to 1961 and $1.1 \%$ by 1966 . By the mid 1960s the hot water service became completely wide-used and extensive to the whole territory of New Zealand. By the year of 2007, $88 \%$ of the total amount of hot water systems was electric and most of them were low pressure. In addition, $81 \%$ of these cylinders delivered water over a safe temperature of $55^{\circ} \mathrm{C}^{34}$

Solid fuels

In New Zealand centrally-provided and treated piped water became common not until the first years of the twentieth century. The provision of hot water remains a batch process based on a kerosene tin on the coal or wood stove. Copper containers were common. $^{35}$

Gas

Town-gas produced by the destructive usage of coal was available in Auckland in 1862 . The town -gas "geyser" or "califont" followed the approach of the solid fuel chipheaters, with the gas burning inside a water jacket. ${ }^{36}$ After that, gas storage based water heaters followed. With the wide introduction of hydro-electricity in the 1950s coal and other fuels declined. Meanwhile electricity rapidly became the dominant fuel due to its affordability in comparison with other sources of energy.

\section{Electricity}

In New Zealand electricity was available and widely used since the early years of the twentieth century. The hot water heating service dates back to 1915 when Lloyd Mandeno, a Tauranga borough engineer developed one of the first electric storage systems of hot water for use in the world. ${ }^{37}$

\footnotetext{
${ }^{34}$ Isaacs, Camilleri, \& French (2007)

${ }^{35} \mathrm{Ibid}$

${ }^{36} \mathrm{Ibid}$

${ }^{37}$ Ibid
} 
The impact of the electric hot water cylinder on the electricity system was important. 34 years after the first one, $32 \%$ of the total energy end-use of the nation was destined to the domestic hot water use. Since then, small cylinder volumes and heating elements may have been suitable for one bath a day, but nowadays it is difficult that those elements can meet modern household needs. At the present day $88 \%$ of New Zealand dwellings have at least one electric hot water cylinder. By 2007 residential hot water used $31 \%$ of total energy end use and $8 \%$ of all electricity of the country. ${ }^{38}$

Hot water today

Table $N^{\circ} 6$, Domestic hot water fuel comparison

\begin{tabular}{cccccc}
\hline Domestic Hot Water Fuel & Australia & Canada & USA & England & NZ \\
\hline Source & ABS 2005 & NRC 2005 & EIA 2004 & $\begin{array}{c}\text { ODPM } \\
2003\end{array}$ & $\begin{array}{c}\text { Census } \\
1996\end{array}$ \\
& & & & & \\
Electric & $51 \%$ & $51 \%$ & $38 \%$ & $12 \%$ & $88 \%$ \\
Natural gas & $36 \%$ & $44 \%$ & $54 \%$ & $76 \%$ & $8 \%$ \\
Fuel oil & & $4 \%$ & $4 \%$ & & \\
LPG & $3 \%$ & & $3 \%$ & & $12 \%$ \\
\hline Other & $12 \%$ & & $1 \%$ & & $12 \%$ \\
\hline
\end{tabular}

Source: (Isaacs, Camilleri, \& French, Hot Water Over Time: The New Zealand Experience, 2007)

Table $\mathrm{N}^{\circ} 6$ compares domestic hot water fuel for different countries including New Zealand. In addition, columns do not match necessarily $100 \%$. In comparison with other OECD countries, New Zealand has the highest proportion of electric hot water systems. On the other hand, England has the highest proportion of natural gas for hot water systems and the lowest proportion for electric $\mathrm{DHW}^{39}$ systems.

\section{Water pressure}

The conventional New Zealand electric-based hot water system is "low pressure". 79\% of electric storage systems are low pressure. As low pressure, electric hot water cylinders tend to fail more often.

\footnotetext{
${ }^{38}$ Isaacs, Camilleri, \& French, (2007)

${ }^{39}$ DHW: Domestic Hot Water
} 
When cylinders have to be replaced there are two implications:

- Copper low pressure cylinders have a longer life than glass-lined steel.

- Low pressure systems have lower shower flow rates. ${ }^{40}$

Water temperature

New Zealand Building Code, Clause G12: Water Supplies effectively requires the use of a tempering valve to permit storage to be above $60^{\circ} \mathrm{C}$ and delivery to be below $55^{\circ} \mathrm{C}$ in new buildings and installations. ${ }^{41}$

More than $40 \%$ of the cylinders have unsafe delivered water temperature levels. In addition, one-third of the cylinders have problems with imprecision of thermostat control. Even when the thermostats are fixed by the user one third of them still have problems in delivering water at safe temperatures. ${ }^{42}$

\section{Discussion}

- Hot water supply has changed in the last 100 years.

- Methods used in the past in order to provide hot water for households are still in use in New Zealand today.

- The burning of coal in order to produce "Town-gas" has been replaced by the usage of natural gas. In addition, small electric storage elements and tanks have been replaced by larger systems. Solid fuel systems have been redesigned and fixed but continue to be used.

- Hot water energy end-use reflects the historical market development in New Zealand.

- The shift from low pressure hot water systems to higher pressure systems will have significant implication for future water and electricity demands due to higher flow rates that will be needed.

- New Zealand households have unacceptable high temperature hot water delivered.

\footnotetext{
${ }^{40}$ Isaacs, Camilleri, \& French, (2007)

${ }^{41}$ Ibid

42 BRANZ, (2003, p. v)
} 

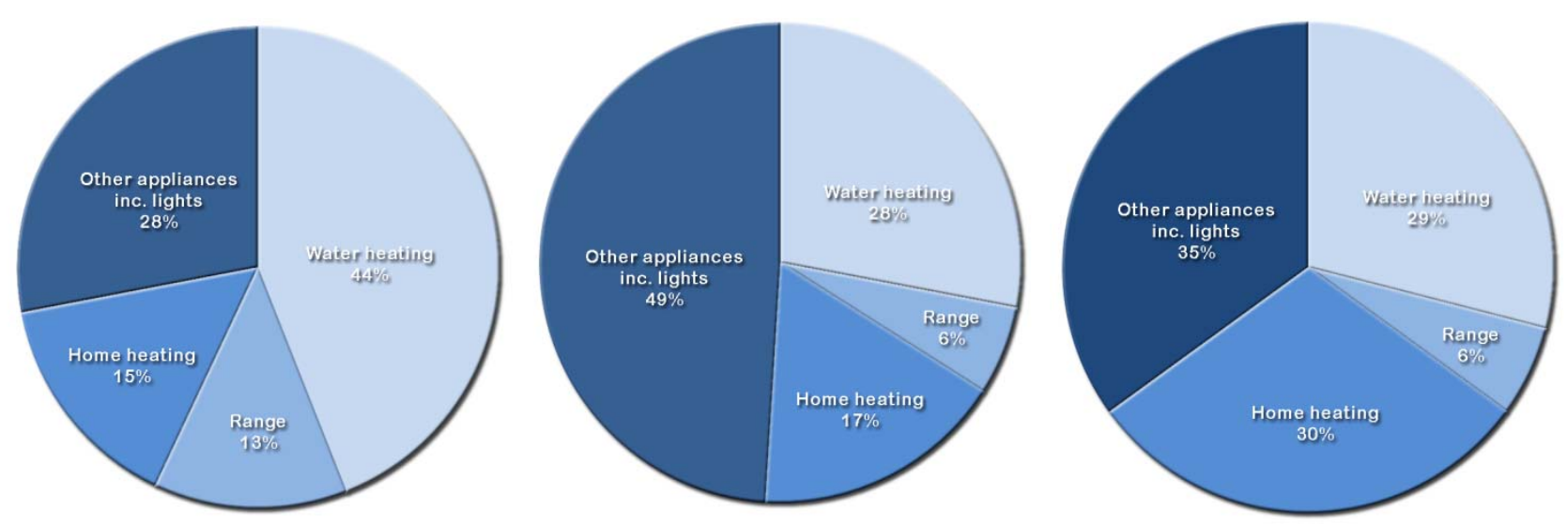

Source: BRANZ, (2004, p. ii)

The first pie chart represents the energy end-uses found in 1971-1972 patterns. The second pie chart corresponds to HEEP houses in Auckland electricity end-uses. The third pie chart shows the residential energy end use for Auckland, Wellington, Christchurch, Dunedin, Invercargill, Whangarei and Tauranga, including all types of fuels in 2004.

1971-1972 average energy consumption was 8,400 kWh/year in comparison with 7,900 kWh/year for the Auckland HEEP sample houses. ${ }^{43}$ In terms of energy consumption over the years there is not a significant variation, but in terms of energyend use 1971-1972 national patterns and 2004 Auckland patterns are dissimilar. In addition, compared with the first and the second, the third pie chart is different too. This shows that energy end uses over time are dynamic.

\subsection{3. - Cooking}

Cooking seems to be a minor driver among energy end-use in New Zealand dwellings. However, energy use for cooking is about $4-6 \%$ of the total figure.

\subsection{4. - Lighting and peak power}

Lighting has a noticeable use in dwellings and forms a significant part of peak power demand. Some HEEP studies suggest that peak lighting load was about $200 \mathrm{~W}$ per family unit. In addition, on average, all of those houses monitored by HEEP have 20 incandescent lamps, one compact fluorescent lamp or CFL and one halogen lamp. ${ }^{44}$

\footnotetext{
${ }^{43}$ BRANZ, (2004, p. ii)

${ }^{44}$ BRANZ, (2004, p. iii)
} 


\subsection{5. - Refrigerators and freezers}

Refrigeration equipment (refrigerators, freezers, or combination of freezers) has varied over time and uses about $10-12 \%$ of household electricity. ${ }^{45}$

7.7.6. - Domestic appliances and equipment

Standby and base load

Pie charts $\mathrm{N}^{\circ} 8$ Standby and base load

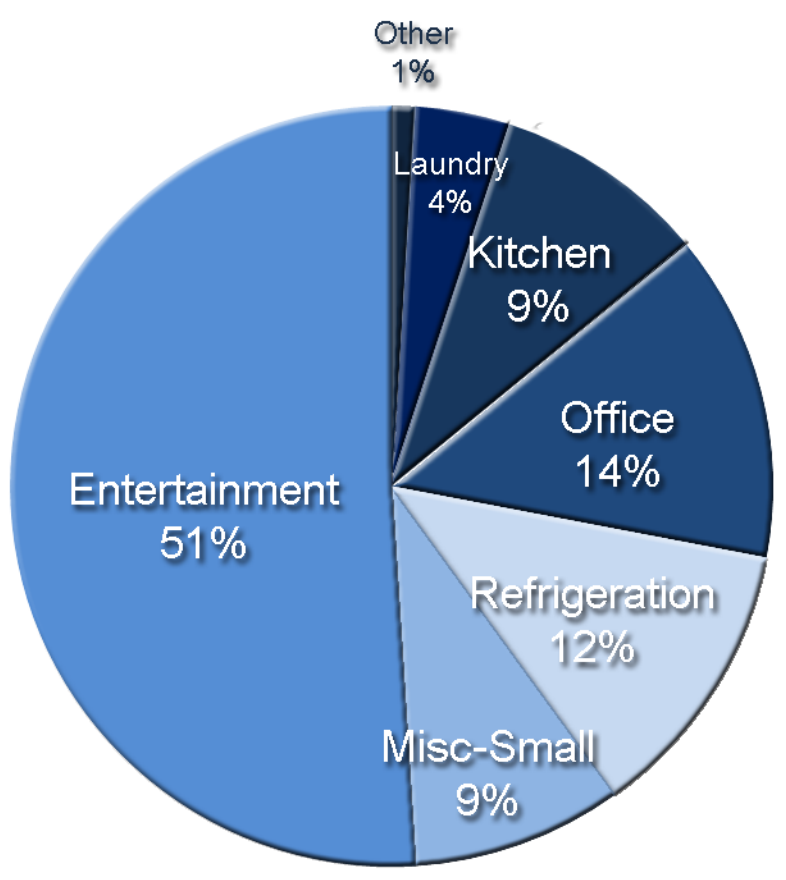

Source: BRANZ, (2005, p. iii)

As can be seen from the pie chart all of those appliances related to entertainment consume half of the total standby and base load power, followed by all those appliances related to office $14 \%$, refrigeration $12 \%$, kitchen $9 \%$ and others.

${ }^{45}$ BRANZ, (2004, p. iii) 


\section{8. - Life cycle energy}

The total life cycle energy could be defined by the sum of the energy used in every stage of a house through its lifespan. It is the sum of the energy used in the construction stage, the energy used to operate it, the energy used to refurbish it and the energy used in the waste and disposal or the demolition stage depending on the boundaries traced in the Life Cycle Analysis methodology. However, the operational stage is the phase with the highest consumption of energy in contrast with the energy used to build, maintain or demolish a house, because when this energy is divided in time becomes minor compared to the operation stage. ${ }^{46}$

\section{9. - Recurrent embodied energy}

According to New Zealand study Johnstone, (1999, p. 34)

..."the sum of maintenance costs totals 0.14 per cent of the costs to construct a new dwelling. The energy requirement of annual maintenance is estimated at $357 \mathrm{MJ} /$ year based on the average energy intensity per dollar to construct a new dwelling."

\subsection{0. - Recurrent $\mathrm{CO}_{2}$ emissions}

The recurrent $\mathrm{CO}_{2}$ emissions are strongly related to the recurrent embodied energy. Both, recurrent $\mathrm{CO}_{2}$ emissions and recurrent embodied energy seem to be dependent variables.

\subsection{1. - Demolition and recycling}

The results presented by Adalberth, K. (1996, pp. 324-326) show that location of waste disposal plant is a key factor. In addition, the study suggests that possible discrepancies in energy calculation values could occur due to the differences of the quantity of materials transported and the relative locations for waste disposal.

In terms of proportion, the same study Adalberth, K. (1996, p. 327) proves that the amount of energy needed for demolition in comparison with the total figure over the years is small.

\footnotetext{
${ }^{46}$ Mithraratne, Vale, \& Vale, (2007)
} 
7.12. - Summary of the chapter

- Residential and commercial buildings consume $22 \%$ of the energy use in New Zealand. ${ }^{47}$

- $56 \%$ of electricity used in New Zealand is used in Buildings (residential, commercial and others). ${ }^{48}$

- The annual cost of electricity and gas consumed in residential buildings is about $\$ 2.3$ billion. $^{49}$

- About one third of total energy consumed in residential buildings is used to heat water, one third to heat space and a third to power household appliances and lights. ${ }^{50}$

Social data

The predominant HEEP household is the classic family institution. This means, a couple with children which make up $35.5 \%$ of the total, followed by couples only which consist of $31 \%$ and one-person households account for $13.1 \%$.

Indoor temperatures

Studies carried out in the past (1971-1972) related to temperature found a strong variation between indoor and outside temperatures. In the Northern North Island this variation is around $4.6^{\circ} \mathrm{C}$ and in the Southern South Island this difference is $7.4^{\circ} \mathrm{C}$ between outside and inside. Average temperatures have increased and this growth may be explained due to the rising use of solid fuel burners in the current monitoring. Heating schedules have not changed over time independent of the introduction of the thermal insulation requirement in 1978. The type of fuel plays an important role in establishing house temperatures. ${ }^{51}$

Table $\mathrm{N}^{\circ} 7$ Type of fuel and indoor temperature

\begin{tabular}{cc}
\hline Fuel & Temperature \\
\hline LPG & $17.1+-0.2^{\circ} \mathrm{C}$ \\
\hline Electricity & $17.2+-0.2^{\circ} \mathrm{C}$ \\
\hline Gas & $18.0+-0.4^{\circ} \mathrm{C}$ \\
\hline Solid fuel & $18.7+-0.2^{\circ} \mathrm{C}$ \\
\hline
\end{tabular}

Source: (BRANZ, 2004, p. v)

\footnotetext{
${ }^{47}$ Department of Building and Housing,(2007, p. 12)

${ }^{48} \mathrm{Ibid}$

${ }^{49} \mathrm{Ibid}$

${ }^{50} \mathrm{Ibid}$

${ }^{51}$ BRANZ, (2004, p. v)
} 
ALF 3 and HEEP household space heating energy use

ALF 3 or Annual Loss Factor third edition, estimates the annual heating energy needed for a residential building based on the physical location of the house, construction type and a specific heating schedule. ${ }^{52}$

Energy end-uses

On average, across all fuel types, space heating is the largest single end-use $34 \%$, followed by hot water $29 \%$, appliances $13 \%$, refrigeration $10-15 \%$ and cooking $6 \%$. The most important fuel source is electricity, while the most important space heating fuel is solid fuel, wood and coal Isaacs, et al. (2006, p. ii)

Low temperature heat is the main (63\%) use of household energy, providing space heat (34\%) and water heat (29\%) Isaacs, et al. (2006, p. ii)

Electricity provides three-quarters (75\%) of energy use for hot water, with gas (20\%) and wetback $5 \%$ providing almost all the rest. Seventy-seven percent of household water cylinders are electric -the highest proportion for any country. This is combined with the high proportion of low pressure systems (72\%) Isaacs, et al. (2006, p. ii)

Solid fuel with $56 \%$ and electricity with $24 \%$ are the main space heating fuels. Wood has increased from $5 \%$ to $14 \%$ of the residential energy share, while electricity has reduced from $82 \%$ to $69 \% .{ }^{53}$

Houses heated by LPG heaters or electric heaters tend to be the coolest, those heated by using enclosed solid fuel burners are the warmest.

Total energy and electricity use per family unit appears to vary slightly by region, although, the end-uses and energy consumption per occupant differs.

Faulty Refrigeration appliances

On average, refrigeration appliances use approximately $15 \%$ of total household electricity. In the past they used to consume only $10 \%$ of the energy but this figure has changed over time.

Pre and Post 1978 heating energy use

Since 1978 all new houses are required to be insulated. New houses compared to those built before 1978 are bigger, more likely to be in warmer places and on average they use less solid fuels and tend to be occupied by higher-income households. ${ }^{54}$

\footnotetext{
52 BRANZ, (2004, p. v)

${ }^{53}$ Isaacs, et al., (2006, p. iii)

${ }^{54}$ Isaacs, et al., (2006, p. v)
} 
For pre-1978 houses insulation level varies because most of them were built without insulation. However, many of these residences have added some kind of insulation to provide a degree of protection against the outdoor temperatures.

The HEEP analysis found that in all cases mandatory insulation was associated with less energy use.

Improvements

Most of the energy reductions have come from non-electric fuels. The total energy savings for all fuels in the $27 \%$ of Post- 1978 houses would be about $2-3 \%$ of total energy consumption of all fuels. In this line of action, the results suggest that large energy savings cannot be expected from insulation retrofit of houses in New Zealand, perhaps $5 \%$ reductions are feasible with most of the saving in non-electric fuels Isaacs, et al. $(2006$, p. ii)

Potential savings are minimum, still around $1 \%$. However, in comparison with other OECD countries where insulation in the residential sector has been used successfully New Zealand houses and people appear to be very different.

Solid fuels

The usage of solid fuels has a long tradition in New Zealand homes. Solid fuel heating was used in a significant proportion in the past (59\% in 1971-1972). In 1976 solid fuel burned in homes reached almost half of the family units or $49 \%$ of the total, raising to $67 \%$ for 1986 and then failing to $54 \%$ in $2001 .^{55}$

Maori households

The number of Maori monitored is small and no general results can be expected. However, there is a difference in the average annual gross heating energy use which is $3,827 \mathrm{kWh} /$ year compared to 3,001 kWh / year for Maori HEEP households. ${ }^{56}$

\footnotetext{
${ }^{55}$ Isaacs, et al., (2006, p. v)

${ }^{56}$ Ibid
} 


\section{Chapter VIII - Environmental control of ISO containers}

This chapter aims to study the energy used for space heating when shipping containers are transformed into buildings. Calculations are made by using ALF 3 or Annual Loss Factor third edition. This section compares ordinary 20-foot and 40-foot containers with two different cladding conditions: insulated and non insulated container.

Key parameters are:

- Orientation

- Number of occupants

- Location

- Different building materials

- Number of containers

There are two elements (containers) with two different features (with and without insulation) and five key parameters to compare them. This drives twenty possible combinations. Unfortunately analysing one type of feature or one element will not allow the drawing of any conclusive conclusion. On the other hand, this talks about the complexity of a design when -even a simple cargo-container- is modified and becomes habitable.

\section{ALF 3 Assumptions}

Calculations here are strongly related to the physical conditions of the Stevens House which is the first future case study (it will be assessed in the next chapter). This comparative exercise takes advantage of the same characteristics of the current house, by meaning that the containers to be simulated are located in Wellington, the heating schedule is in the evening only (from 17:00 to 23:00), the heating level has been chosen as $18^{\circ} \mathrm{C}$, the floor is suspended, for walls, the R-values range from 0 (no insulation) to 1.2 which is the value of a FRP (Fiberglass Reinforced Panel), windows are composed of single clear glass encompassed by an aluminum frame with no thermal break. The roof has an $R$ value of 3 according to the minimum required by the Building Code, for air-tightness parameters: airtight was selected and for site exposure the option of sheltered has been chosen. 


\section{1. - Environmental control}

The family of ISO Containers is not small; there are a wide range of them according to their size, material-make up, type of load, and so on. However, according to their cladding conditions, in the current market there are two types of steel boxes: With and without insulation.

External insulation

Figure $\mathrm{N}^{\circ} 1$ Types of claddings in containers
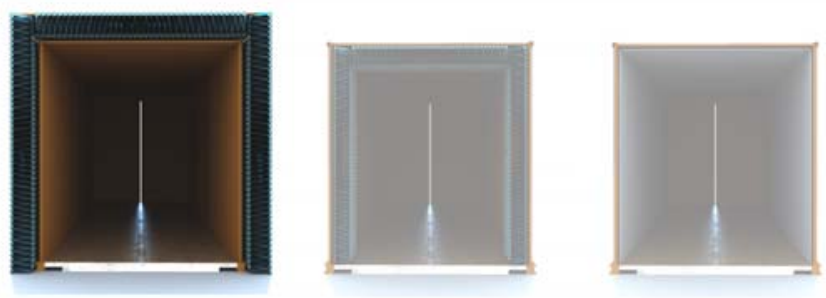

Internal insulation
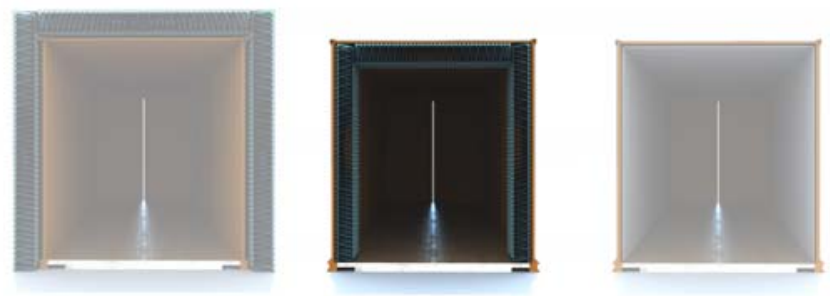

Insulated container
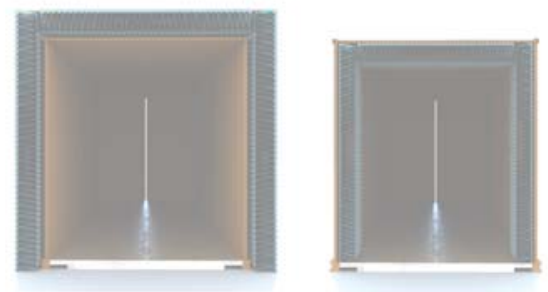

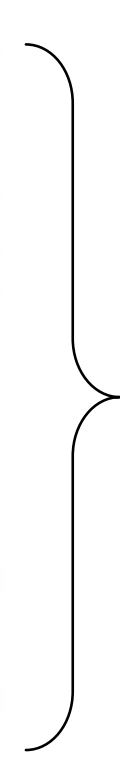

When containers without insulation are turned into architectural forms there are two possible operations:

The corrugated steel walls could be hidden and an external skin placed outside the structure. The benefits of doing this are associated with a relative gain of inner space and the enclosure's shape.

Secondly, internal insulation could be placed inside the structure with the consequent loss of inner space.

The advantage of a refrigerated container is that they are already insulated. They are made up of FRP or Fibreglass Reinforced Panels, of which the insulation Rvalue commonly reaches a minimum of 1.2 depending on their thickness. 


\section{2. - Orientation}

Table $\mathrm{N}^{\circ} 1$, Space heating by orientation for a 20 -foot shipping container with insulation

Figure $\mathrm{N}^{\circ} 220$-foot containers

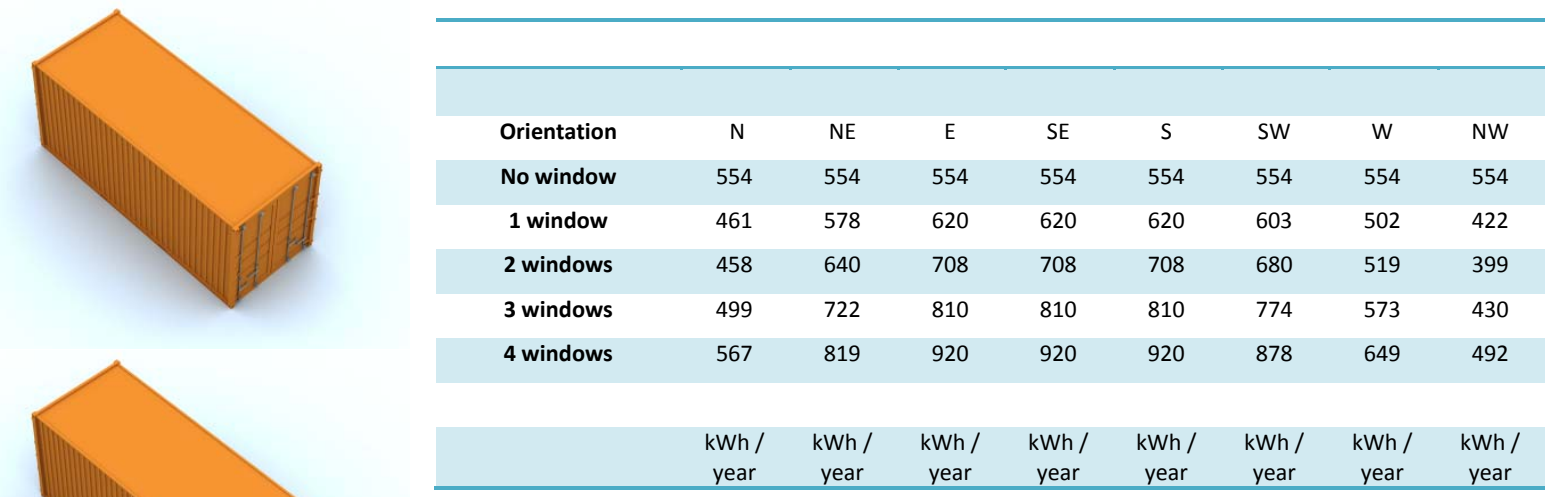

Vertical images present a theoretical modification of a 20 -foot shipping container in which cuts in the walls are linked to the total length of this metal box in proportions of $1 / 4,1 / 2,3 / 4$ and one entire wall of the longest façade. Table $\mathrm{N}^{\circ} 1$ shows the energy required for heating a single container depending on its glazing area for different orientations.

Results explain that when no windows are placed, heating energy remains constant for all the orientations. But, no window or windows means that the container has not been modified yet. The first simulation with one window shows that North and North West façades are more likely to use less heating energy than those oriented for South and South East walls.

Table $\mathrm{N}^{\circ} 2$, Space heating by orientation for a 20-foot shipping container without insulation

\begin{tabular}{|c|c|c|c|c|c|c|c|c|}
\hline Orientation & $\mathrm{N}$ & $\mathrm{NE}$ & $\mathrm{E}$ & SE & $S$ & SW & W & NW \\
\hline No window & 1,289 & 1,289 & 1,289 & 1,289 & 1,289 & 1,289 & 1,289 & 1,289 \\
\hline 1 window & 1,204 & 1,285 & 1,313 & 1,313 & 1,313 & 1,301 & 1,232 & 1,176 \\
\hline 2 windows & 1,155 & 1,294 & 1,344 & 1,344 & 1,344 & 1,324 & 1,203 & 1,108 \\
\hline 3 windows & 1,131 & 1,314 & 1,382 & 1,382 & 1,382 & 1,354 & 1,192 & 1,071 \\
\hline \multirow[t]{2}{*}{4 windows } & 1,124 & 1,342 & 1,425 & 1,425 & 1,425 & 1,391 & 1,197 & 1,055 \\
\hline & $\begin{array}{c}\text { kWh / } \\
\text { year }\end{array}$ & $\begin{array}{c}\text { kWh / } \\
\text { year }\end{array}$ & $\begin{array}{c}\text { kWh / } \\
\text { year }\end{array}$ & $\begin{array}{c}\text { kWh / } \\
\text { year }\end{array}$ & $\begin{array}{c}\text { kWh / } \\
\text { year }\end{array}$ & $\begin{array}{c}\text { kWh / } \\
\text { year }\end{array}$ & $\begin{array}{c}\text { kWh / } \\
\text { year }\end{array}$ & $\begin{array}{c}\text { kWh / } \\
\text { year }\end{array}$ \\
\hline
\end{tabular}


Table $\mathrm{N}^{\circ} 3$, Space heating by orientation for a 40 -foot shipping container with insulation

Figure $\mathrm{N}^{\circ} 340$-foot containers

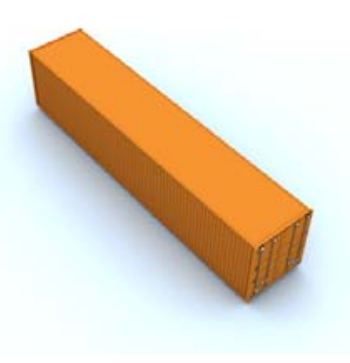

\begin{tabular}{|c|c|c|c|c|c|c|c|c|}
\hline Orientation & $\mathrm{N}$ & $\mathrm{NE}$ & $E$ & SE & $S$ & SW & W & NW \\
\hline No window & 1,118 & 1,118 & 1,118 & 1,118 & 1,118 & 1,118 & 1,118 & 1,118 \\
\hline 1 window & 892 & 1,140 & 1,230 & 1,230 & 1,230 & 1,194 & 977 & 808 \\
\hline 2 windows & 869 & 1,252 & 1,397 & 1,397 & 1,397 & 1,338 & 997 & 747 \\
\hline 3 windows & 947 & 1,413 & 1,596 & 1,596 & 1,596 & 1,521 & 1,100 & 804 \\
\hline \multirow[t]{2}{*}{4 windows } & 1,082 & 1,604 & 1,815 & 1,815 & 1,815 & 1,728 & 1,251 & 928 \\
\hline & $\begin{array}{c}\text { kWh / } \\
\text { year }\end{array}$ & $\begin{array}{l}\text { kWh / } \\
\text { year }\end{array}$ & $\begin{array}{l}\text { kWh / } \\
\text { year }\end{array}$ & $\begin{array}{l}\text { kWh / } \\
\text { year }\end{array}$ & $\begin{array}{c}\text { kWh / } \\
\text { year }\end{array}$ & $\begin{array}{l}\text { kWh / } \\
\text { year }\end{array}$ & $\begin{array}{l}\text { kWh / } \\
\text { year }\end{array}$ & $\begin{array}{c}\text { kWh / } \\
\text { year }\end{array}$ \\
\hline
\end{tabular}

This second container has the same wall modifications in comparison with its predecessor. Table $\mathrm{N}^{\circ} 3$ shows an insulated 40-foot freight container with one occupant, located in Wellington and following the same site conditions of the Stevens house despite the diversity of orientations. In contrast with Table $\mathrm{N}^{\circ} 4$, or its non-insulated counterpart, Table $\mathrm{N}^{\circ} 3$ demonstrates that insulation is a key driver for achieving less energy consumption for space heating. In addition, less than one-half of the total amount of energy is required for heating an insulated unit in comparison with a non-insulated container.

Table $\mathrm{N}^{\circ} 4$, Space heating by orientation for a 40-foot shipping container without insulation

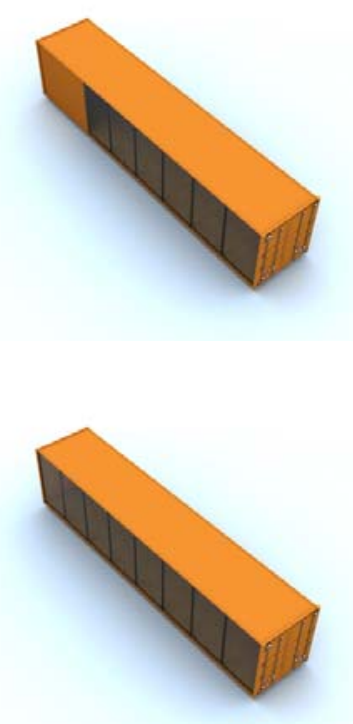

\begin{tabular}{lcccccccc}
\hline & & & & & & & & \\
\hline
\end{tabular}


Graph $\mathrm{N}^{\circ} 1$ shows an insulated 20 -foot cargo container located in Wellington including one occupant. As can be seen from graph $\mathrm{N}^{\circ} 1$, Northern facades are more likely to use less energy in contrast with those oriented to South and East façades.

Graph $N^{\circ} 1$, 20-foot shipping container with insulation

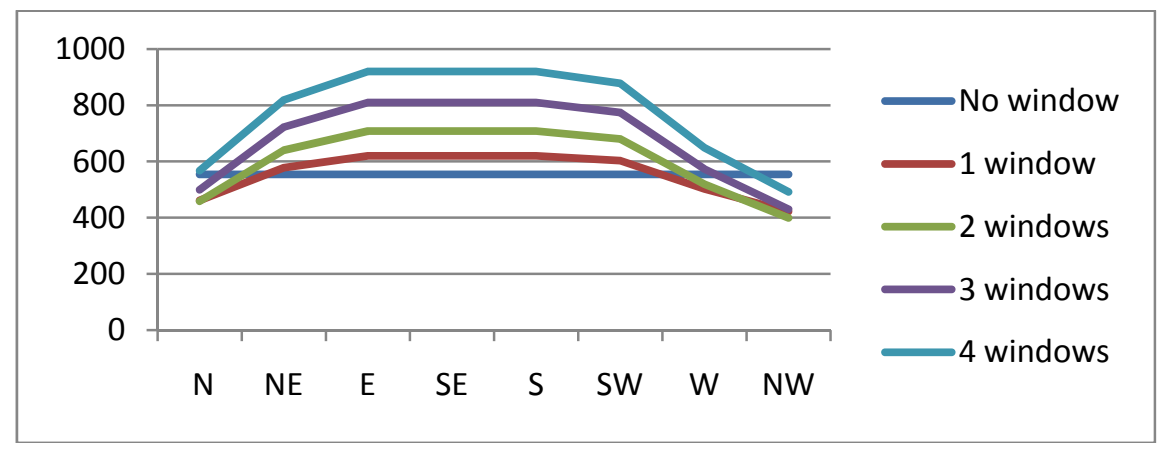

Graphs $\mathrm{N}^{\circ} 1$ and $\mathrm{N}^{\circ} 2$ conserve the same site conditions, number of occupants, same heating schedules and so on. The energy-use pattern is similar for both graphs, regardless of the increment of the square meters. Possible reasons for this can be that the increment of space and glazing areas are dependent variables. However, the gap between the options of windows increases when floor space and percentage of glazing area increase.

Graph $N^{\circ} 2$, 40-foot shipping container with insulation

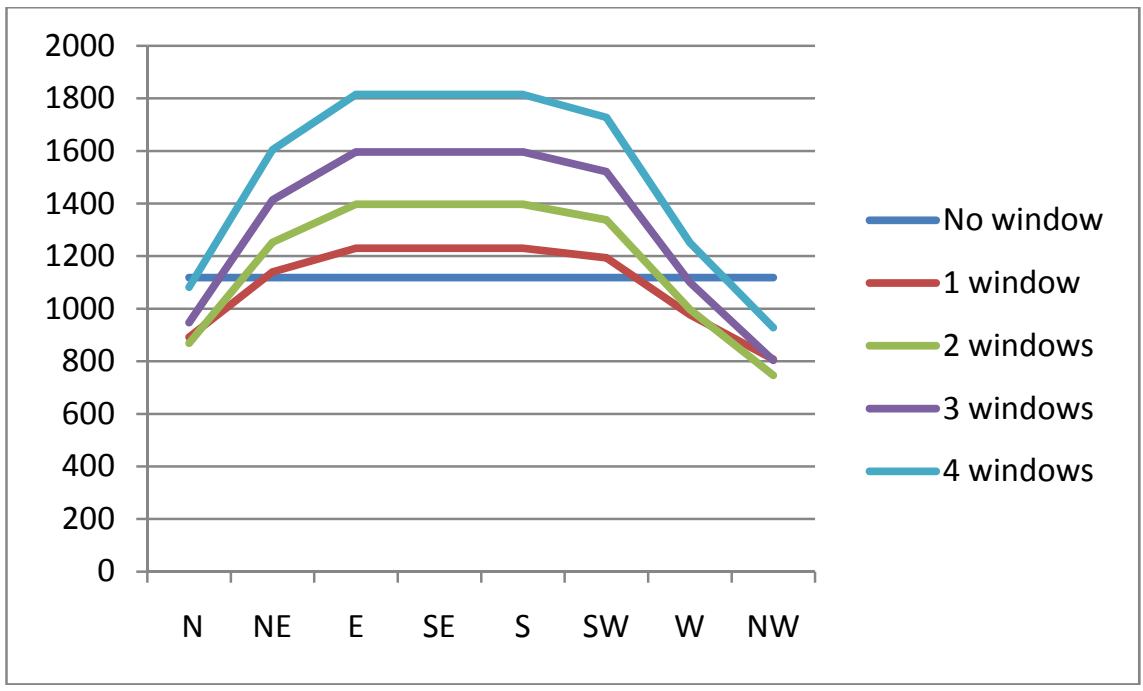


Graph $\mathrm{N}^{\circ} 3$ shows a 20 -foot shipping container with no-insulation. Most of these trade boxes are made of aluminum or steel, the advantages of the first are that aluminum offers less dead-weight because of its lightness and it also shows great capacity against corrosion in contrast with steel. However, both of them have a practically nil R-value. The gap between different orientations and the number of windows are minimum in comparison with the insulated containers shown in graphs $\mathrm{N}^{\circ} 1$ and $\mathrm{N}^{\circ} 2$.

Graph $N^{\circ} 3,20-$ foot shipping container without insulation

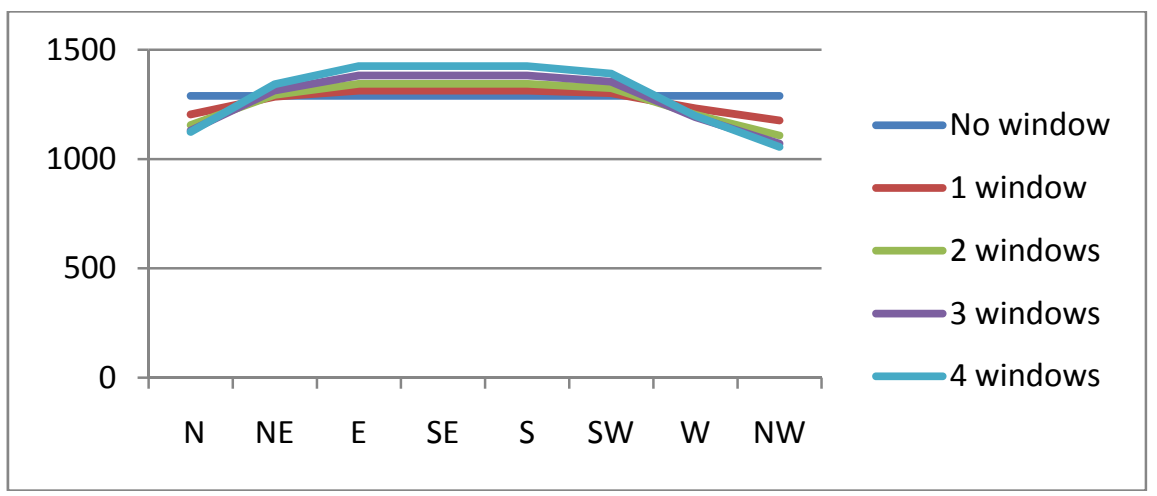

Energy requirement for heating space in both graphs show a consistent similarity. North and Northwest façades are more likely to use less energy in comparison with East and South walls. East, Southeast and South façades report linear energy consumption.

Graph $N^{\circ} 4,40$-foot shipping container without insulation

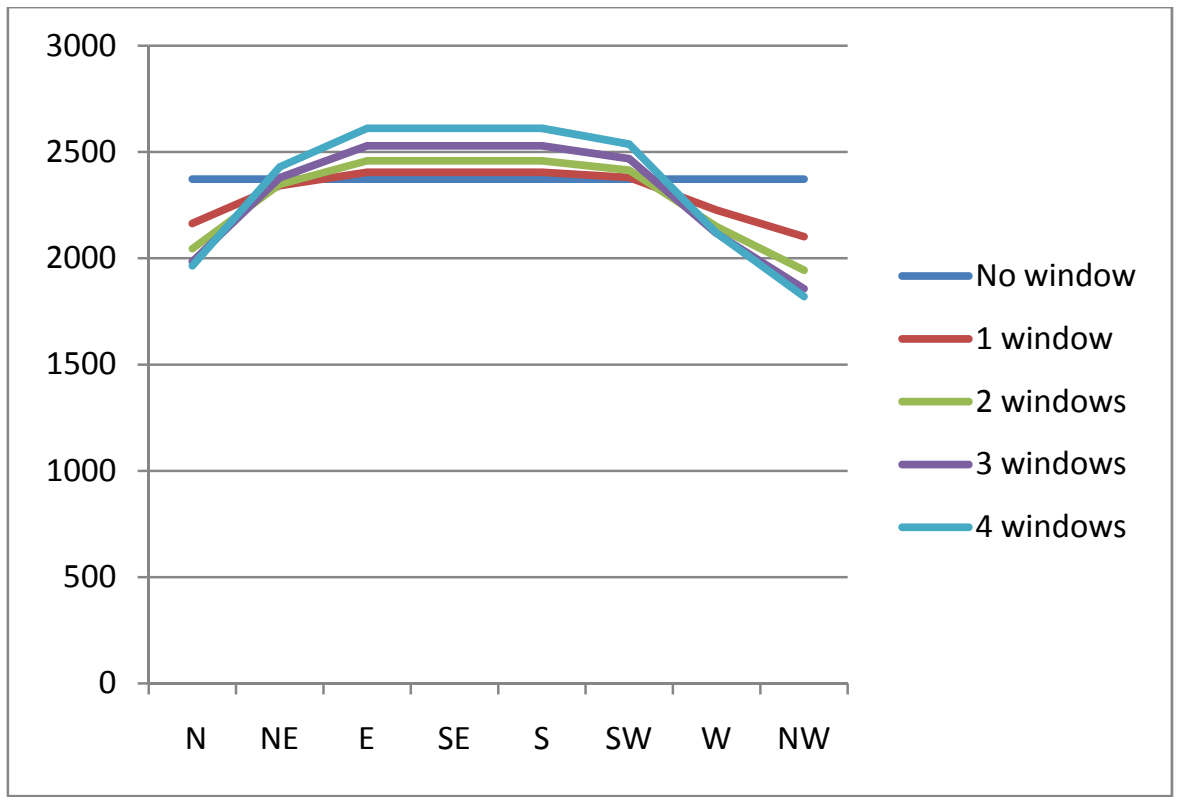

As can be seen in graph $\mathrm{N}^{\circ} 4$, there is a similar trend in energy consumption in comparison with graph $\mathrm{N}^{\circ} 3$, with an increment of the gap for different windows. 
Graph N5, 20-foot shipping container with insulation

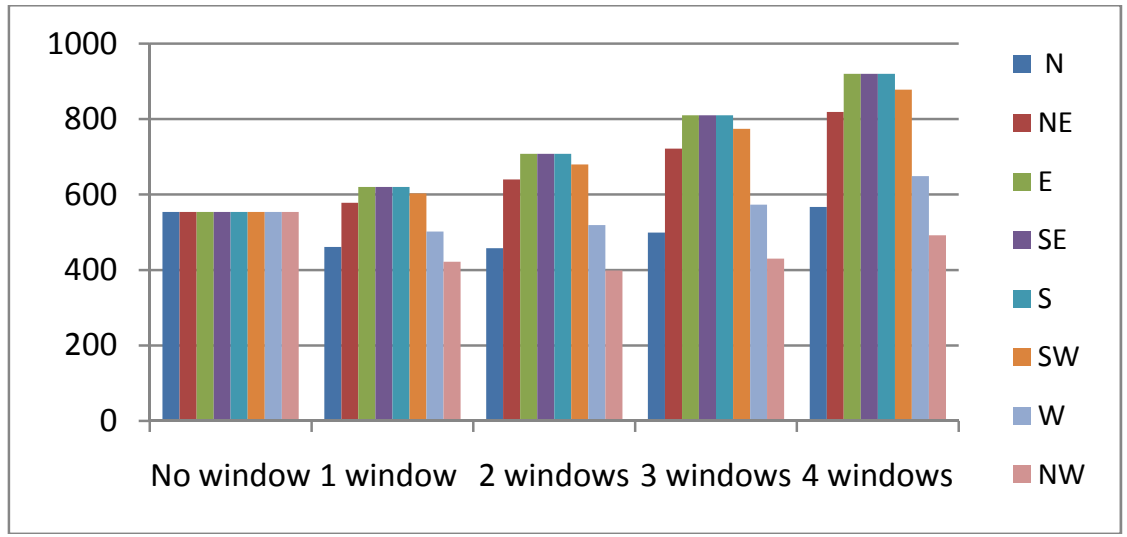

As can be seen from graph $\mathrm{N}^{\circ} 5$ there is a strong relationship between the increment of glazing area and the increment of energy use in all orientations. North and Northwest façades tend to be more linear in contrast with others which tend to rise exponentially.

Graph N6, 40-foot shipping container with insulation

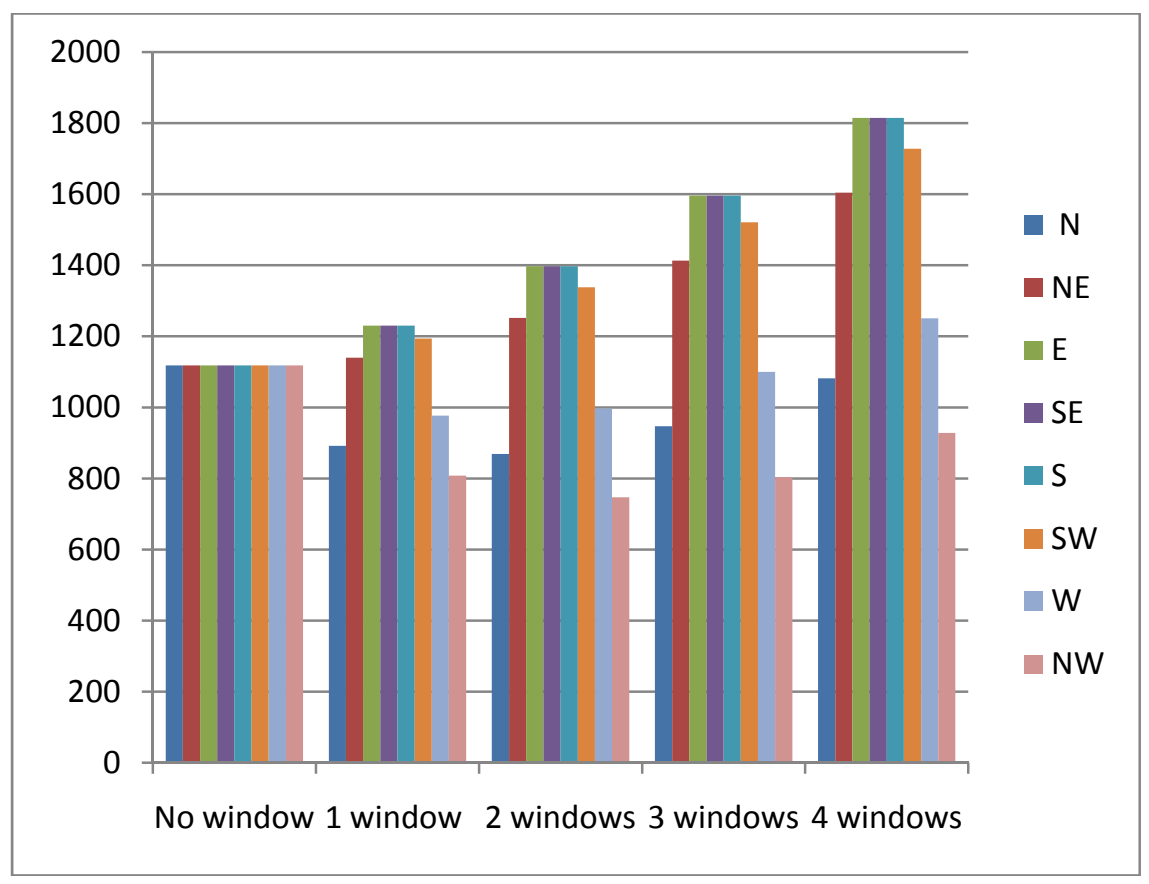

Graph $N^{\circ} 6$ shows a 40 -foot shipping container with insulation. Compared with a 20 -foot cargo container, a 40-foot steel box tends to have similar heating patterns. There is less evidence of linear performance for North and Northwest façades. In addition, most other orientations grow rapidly. This suggests that generally when glazing area increases, energy use rises, although some glazing areas and orientations show lower energy use than a container without glazing. 
Graph $N^{\circ} 7,20$-foot shipping container without insulation

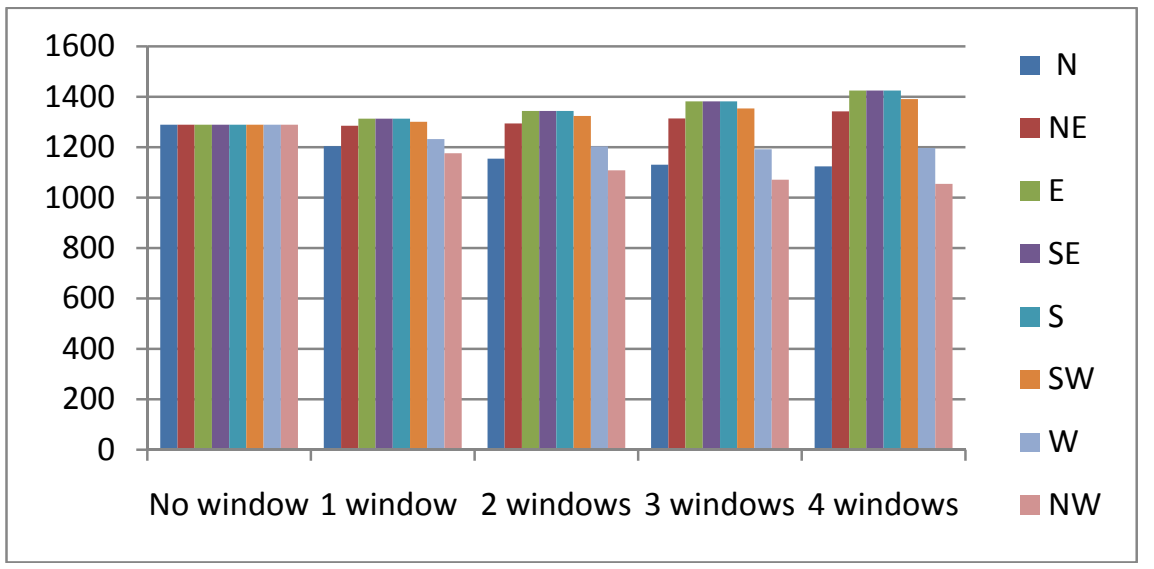

Graph $\mathrm{N}^{\circ} 7$ shows a 20 -foot shipping container without insulation. The trend shows a growth when the façade is open to East, Southeast and South orientations and a reduction when windows are placed in North, Northwest and West façades. Possible reasons for that can be some savings in energy due to the solar gain.

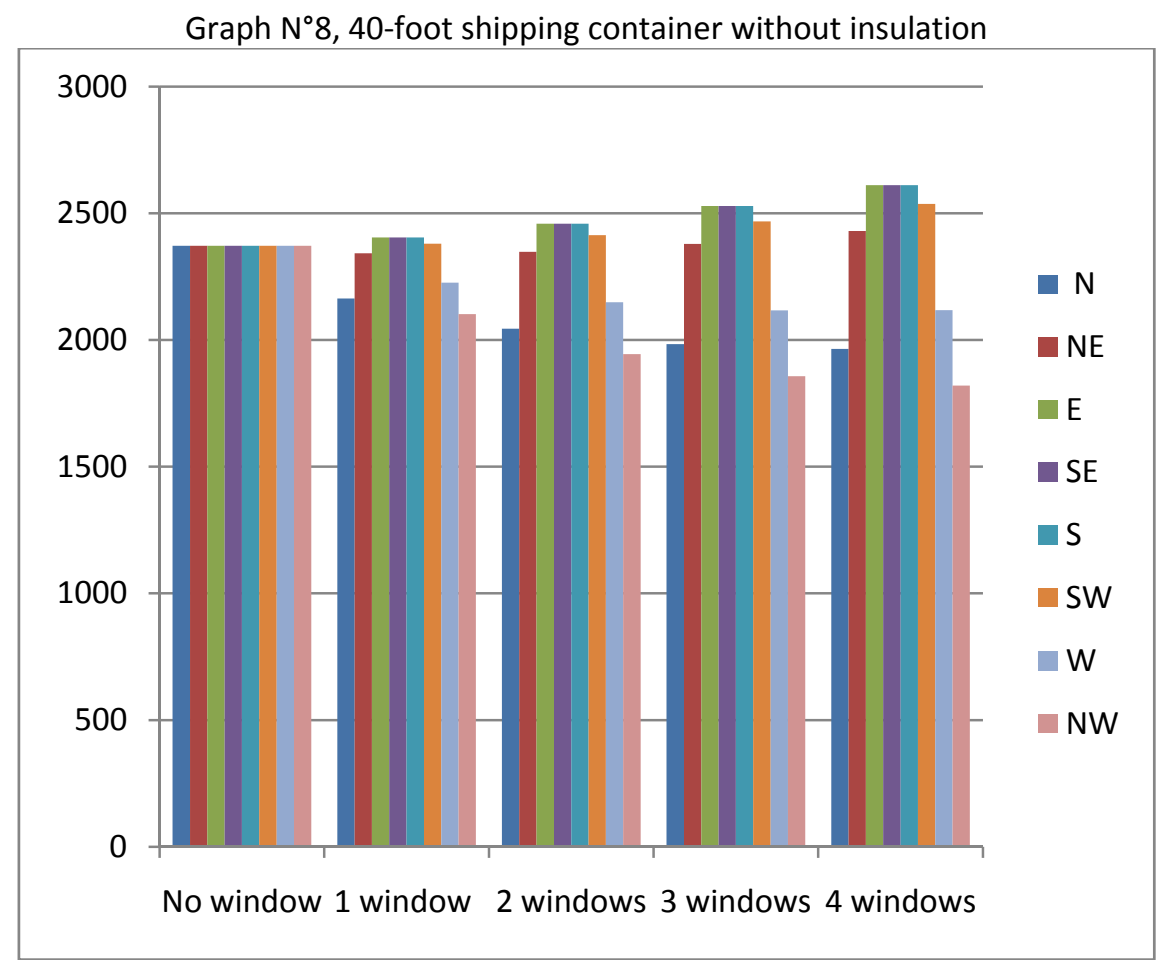

In comparison with graph $\mathrm{N}^{\circ} 7$, a 40 -foot freight container without insulation has similar energy-use pattern. Again, all of those with walls oriented to the East, Southeast and South, are likely to use more energy that those façades which are oriented to West, Northwest and North. 


\section{3. - Number of occupants}

Graph $N^{\circ} 9,20$-foot shipping container with insulation 1 and 2 occupants

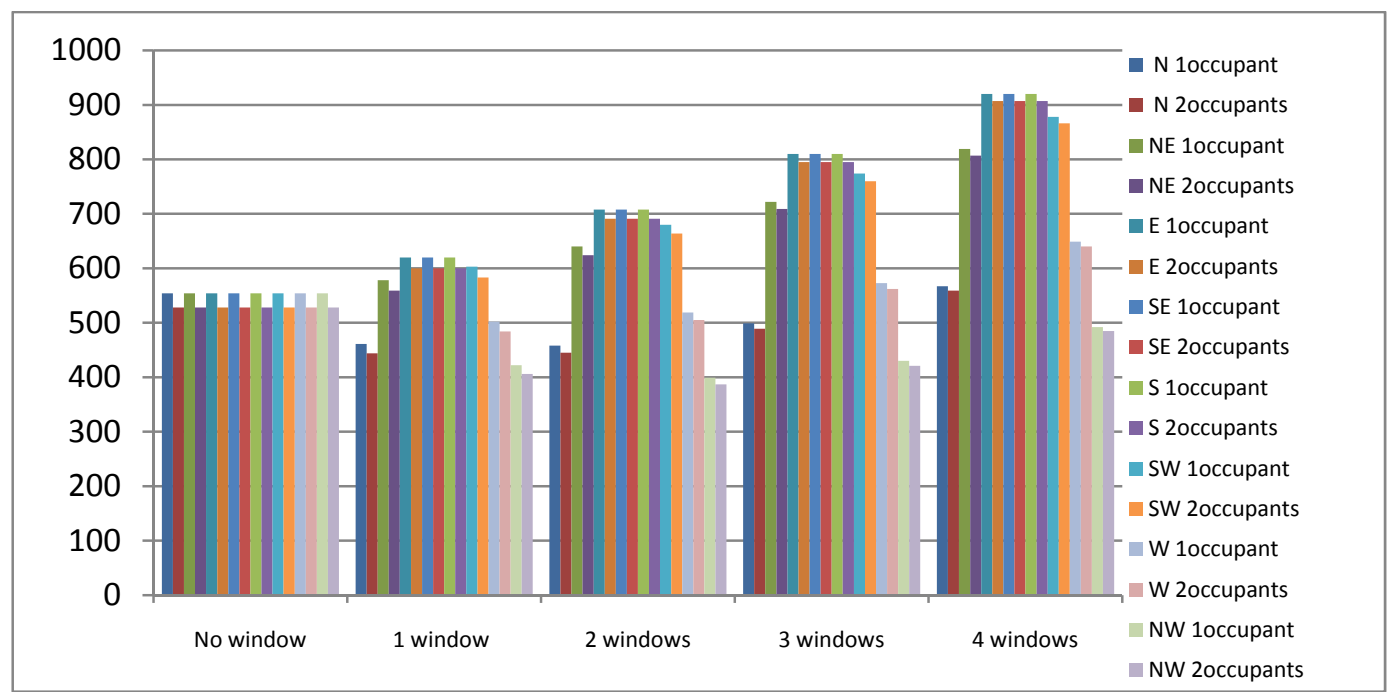

Graph $N^{\circ} 10$, 40-foot shipping container with insulation 1 and 2 occupants

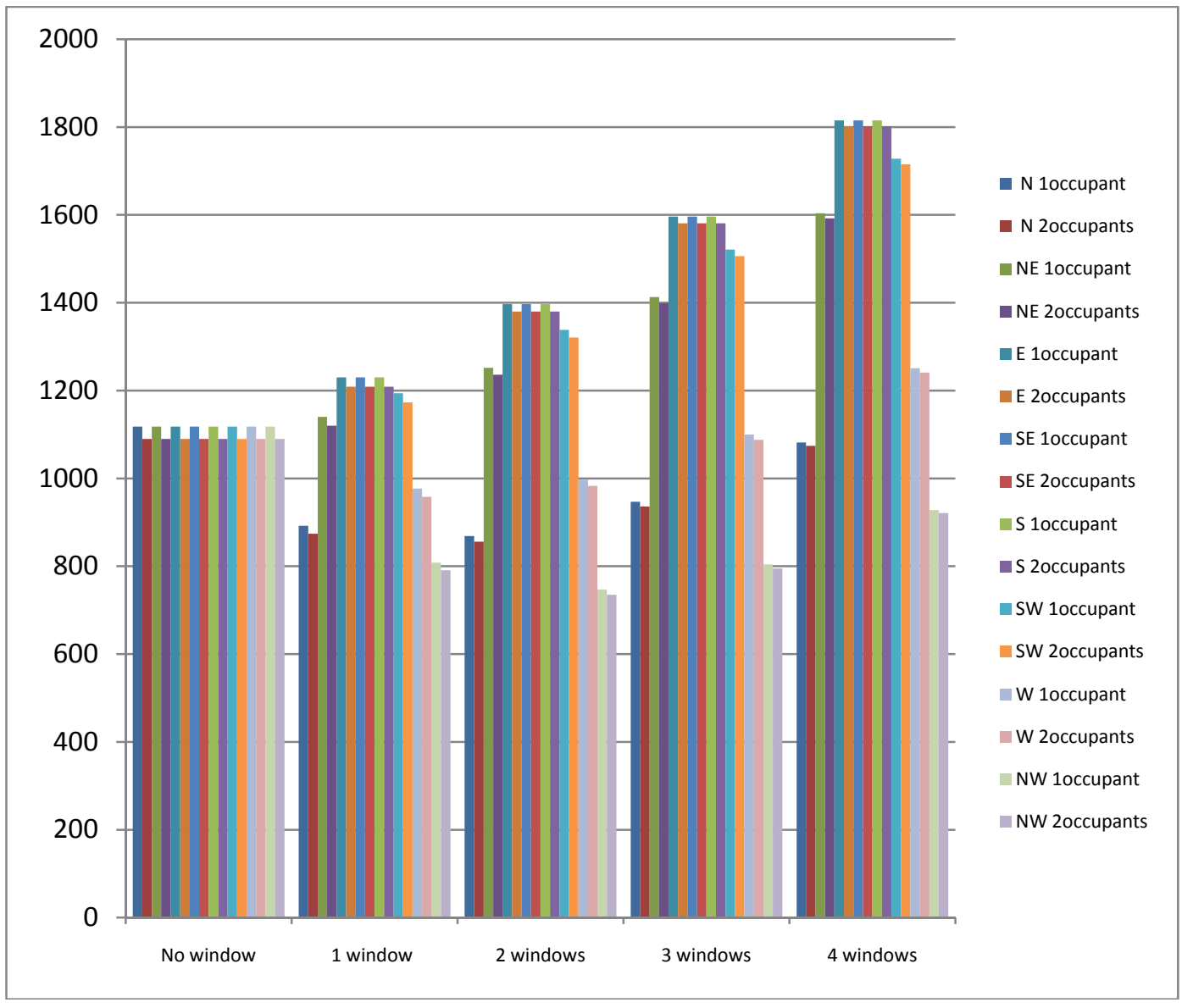


Graphs $\mathrm{N}^{\circ} 9$ and $\mathrm{N}^{\circ} 10$ show both, a 20 and a 40-foot shipping container, located in Wellington, both with insulation (1.2 R-value), with one and two occupants.

Graphs $\mathrm{N}^{\circ} 9$ and $\mathrm{N}^{\circ} 10$ show both a slight reduction in space heating energy use when two people live together.

\subsection{Location}

For this exercise two different locations have been chosen in the North Island of New Zealand. This is to explore the impact of climate. Only general considerations have been taken into account, such as that Auckland is placed in the Northern part of the North Island, so it is warmer than Wellington, it is the largest of cities of New Zealand and energy-use data is available for this area.

Graph $N^{\circ} 11,20$-foot shipping container with insulation 1 occupant located in Auckland and Wellington

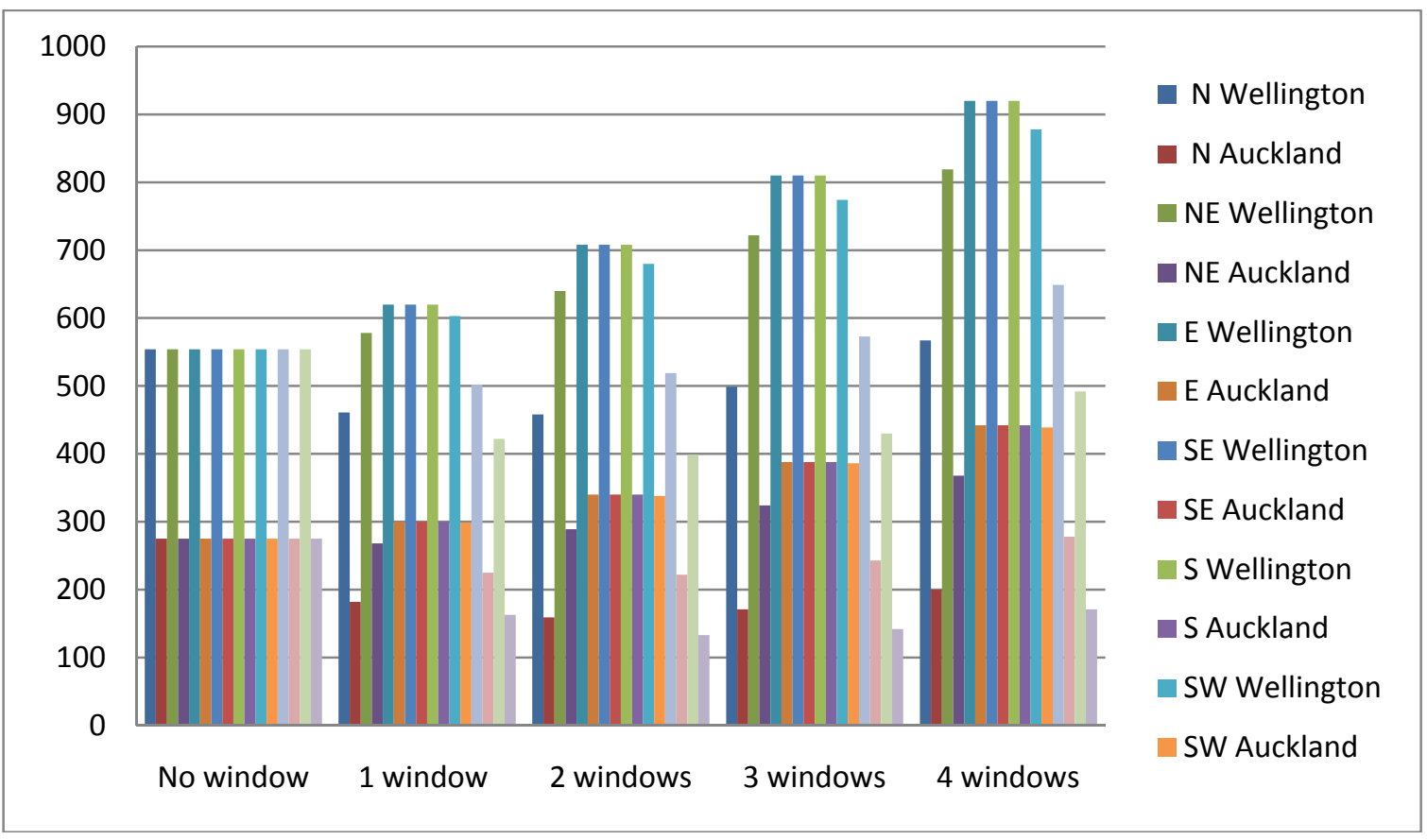

As can be seen from graph $\mathrm{N}^{\circ} 11$, a 20-foot shipping container located in Auckland consumes practically one-half of the energy required in Wellington with the same conditions of orientations, occupants, level of insulation and so on. This suggests that climate may play a significant role in the performance of container architecture. 
Graph $\mathrm{N}^{\circ} 12,40$-foot shipping container with insulation 1 occupant located in Auckland and Wellington

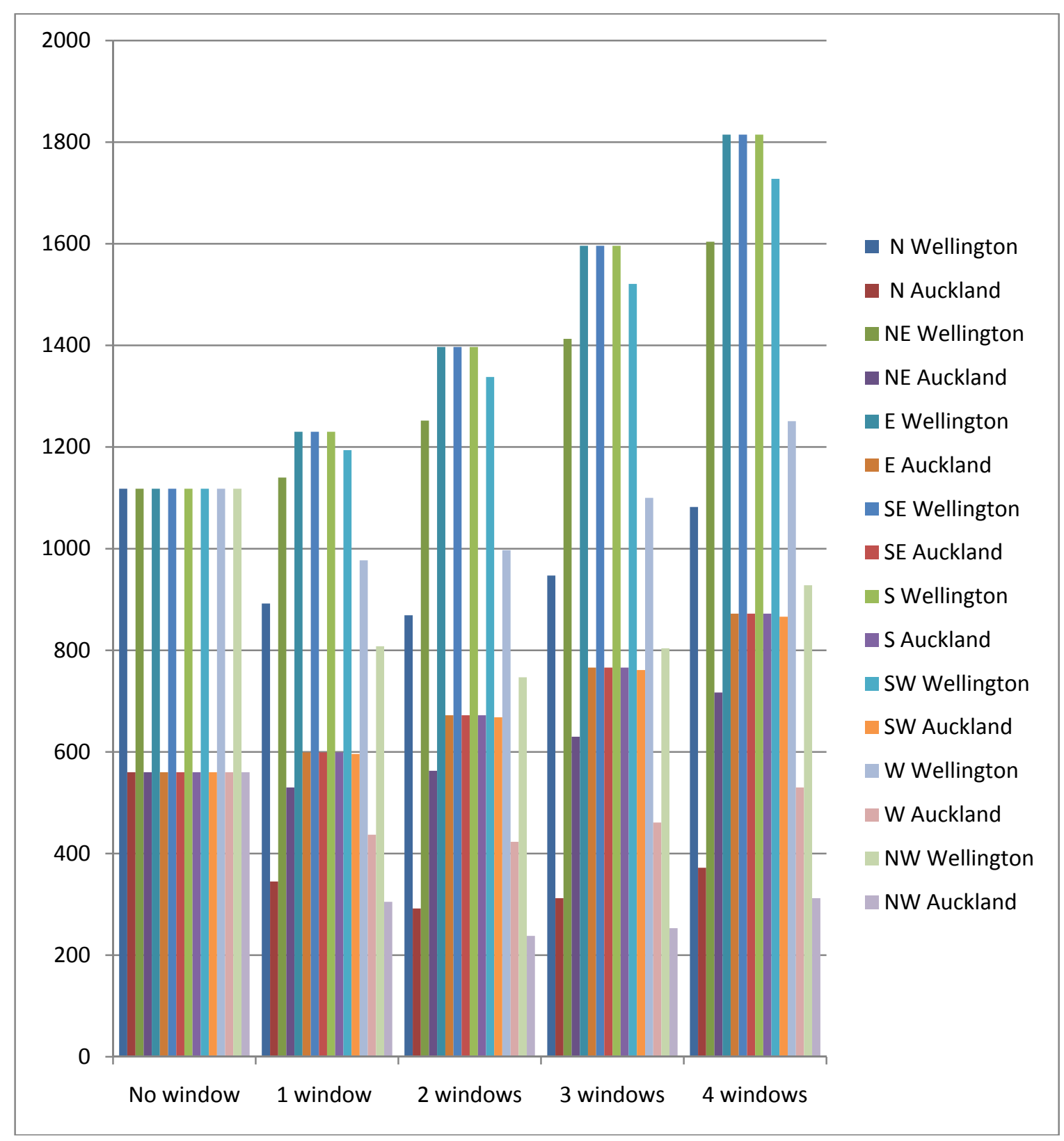

As can be seen from graph $\mathrm{N}^{\circ} 12$, a 40 -foot shipping container located in Auckland consumes practically one-half of the energy required in Wellington. Moreover, in comparison with graph $\mathrm{N}^{\circ} 11$, graph $\mathrm{N}^{\circ} 12$ shows consistently similar patterns in energy consumption (space heating).

Another comparison that can be assumed is that one 40-foot shipping container located in Auckland consumes virtually the same amount of energy as a 20-foot cargo container located in Wellington. 


\section{5. - Different building materials}

The next stage of the simulation is to compare the performance of the container against a range of conventional building options. ALF 3 gives a series of wall options, and out of these three building materials have been chosen for comparison: steel, concrete and timber based structures. For steel, the shipping container which is not a classical structure has been selected; the corrugated steel walls are lined with FRP Fiberglass Reinforced Panels, which have a nominal R-value of 1.2 and $25 \mathrm{~mm}$ thickness (custom option in ALF 3). For concrete, a typical construction $200 \mathrm{~mm}$ concrete block is assumed, fully grouted with rigid and semi-rigid insulation on the internal side of the wall. The timber-based wall is made up by bevel-backed weatherboard with timber framing and internal lining. All types of walls have the same R-value: 1.2

In Graph $\mathrm{N}^{\circ} 13$ below the horizontal axis is orientation organised in groups of three, for different materials. The vertical axis is energy use for space heating in $\mathrm{kWh} /$ year.

Graph $N^{\circ} 13,20$-foot shipping container with insulation 1 occupant located in Wellington

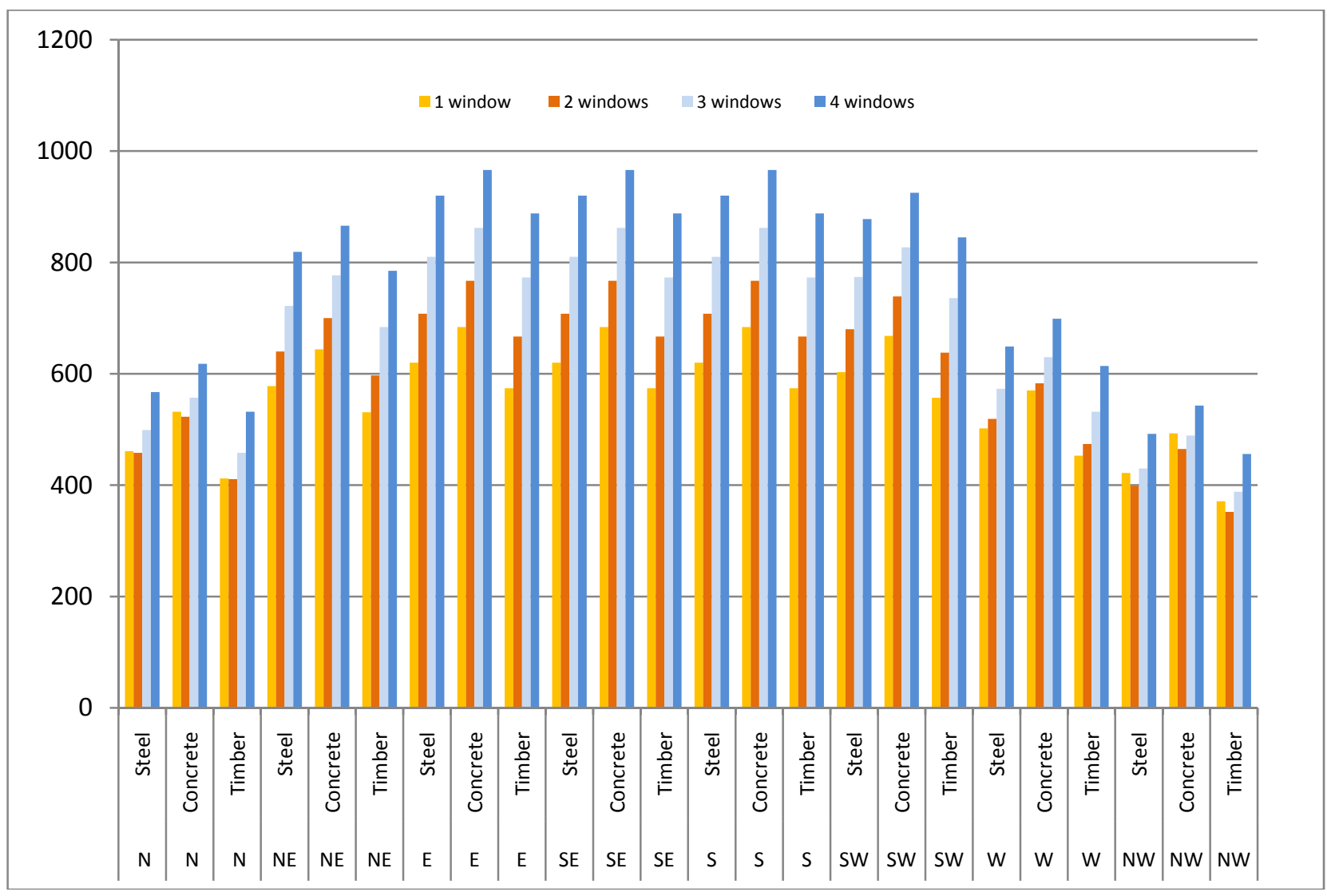

Graph $\mathrm{N}^{\circ} 13$ shows a 20 -foot shipping container with insulation, one occupant and located in Wellington. For all types of walls and materials used, orientation seems to be a key driver in energy consumption. Concrete walls are more likely to use additional energy than other materials among the claddings. In contrast, timber based walls seem to use slightly less energy than steel framed walls, being the most efficient of the list. 
It is likely that placing the insulation on the external face of the concrete structure would give a different thermal performance, because of the availability of increased thermal mass. However, this is probably not relevant for this analysis, because the heating schedule is evening only, meaning that heating would have to raise the temperature of the mass.

Graph N¹4, 40-foot shipping container with insulation 1 occupant located in Wellington

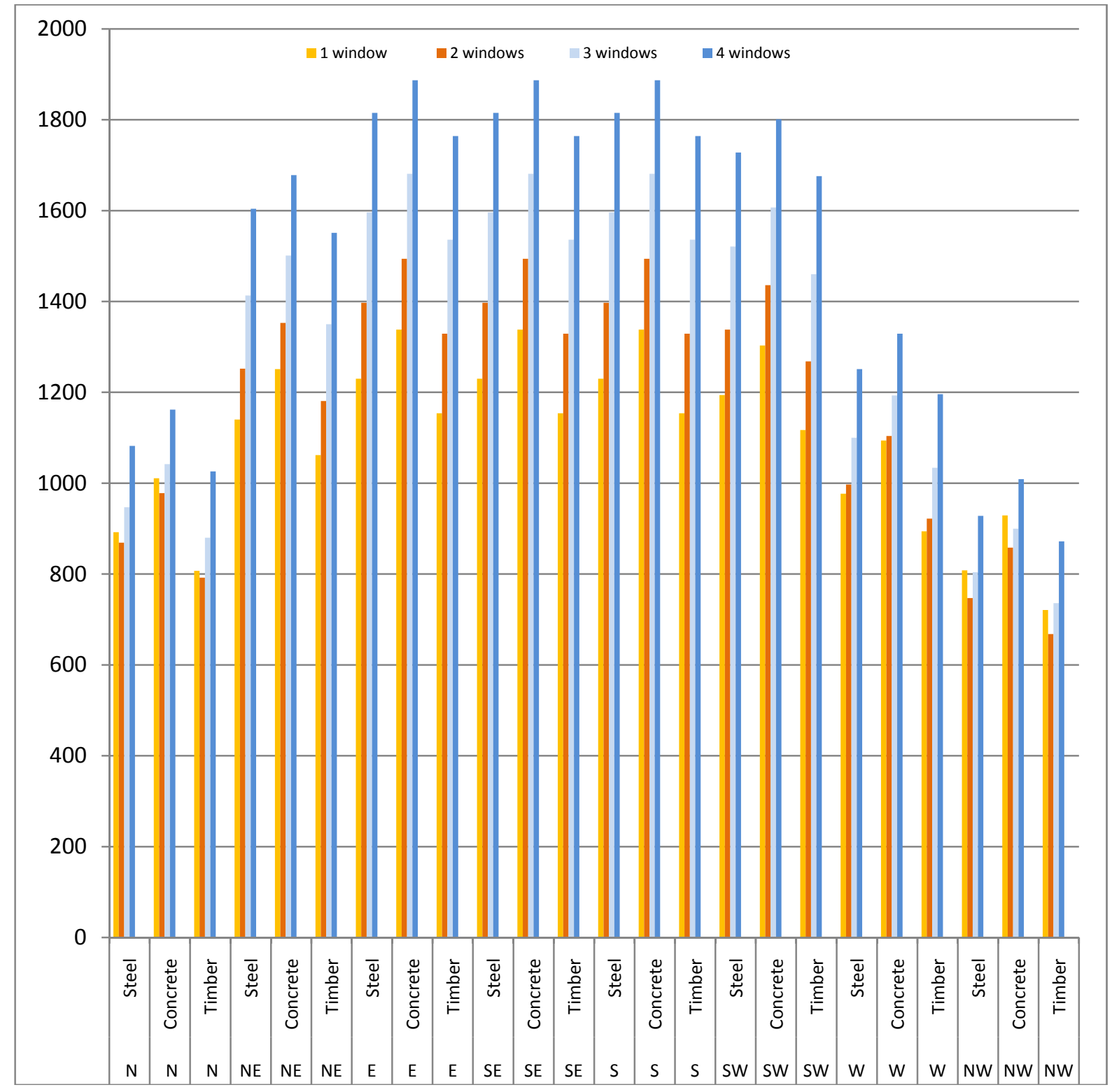

Graph $\mathrm{N}^{\circ} 14$, in comparison with graph $\mathrm{N}^{\circ} 13$ shows that a 40 -foot container is likely to have twice the energy consumption per orientation and wall material. For the fourwindow option, timber-based structures use in all orientations less energy in comparison with the same number of windows but different wall materials. It is the same for three, two and one windows if timber is used as main component of the walls. 


\section{6. - Connectivity and number of containers}

This section aims to discuss the way how shipping containers should be connected with each other. Windows are placed in the same wall, which means, when walls are rotated always only one façade receives solar gains. Once more, windows are composed of a single clear glass encompassed by an aluminum frame with no thermal break.

Figure $\mathrm{N}^{\circ} 4,40$-foot containers horizontal connectivity Figure $\mathrm{N}^{\circ} 540$-foot containers vertical connectivity
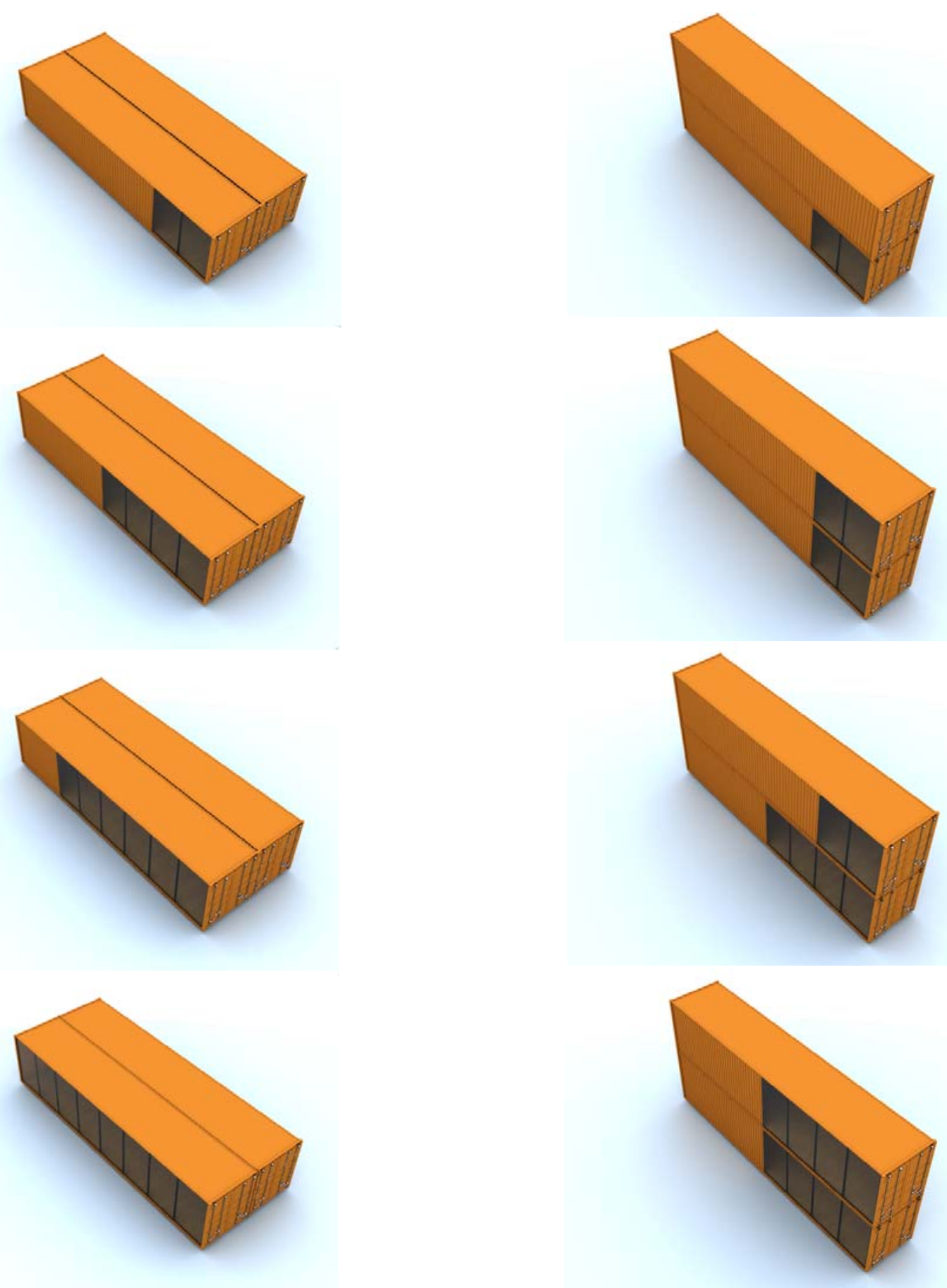
Graph $N^{\circ} 15$, Two 40-foot shipping container 1 level with insulation 1 occupant located in Wellington

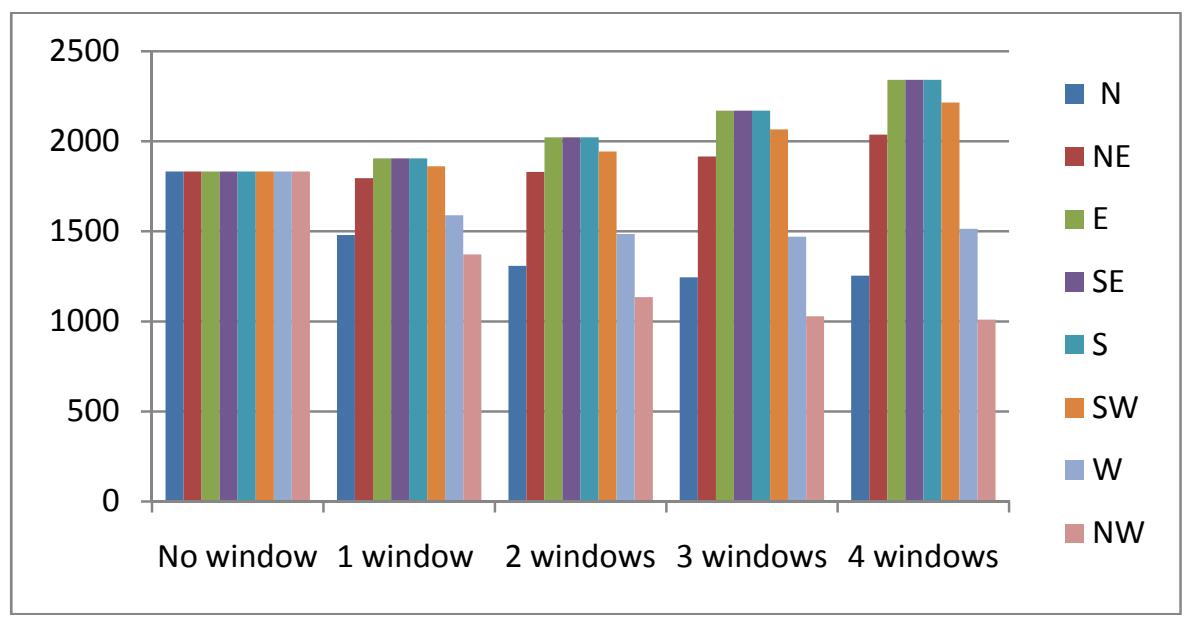

Graph №16, Two 40-foot shipping container 2 levels with insulation 1 occupant located in Wellington

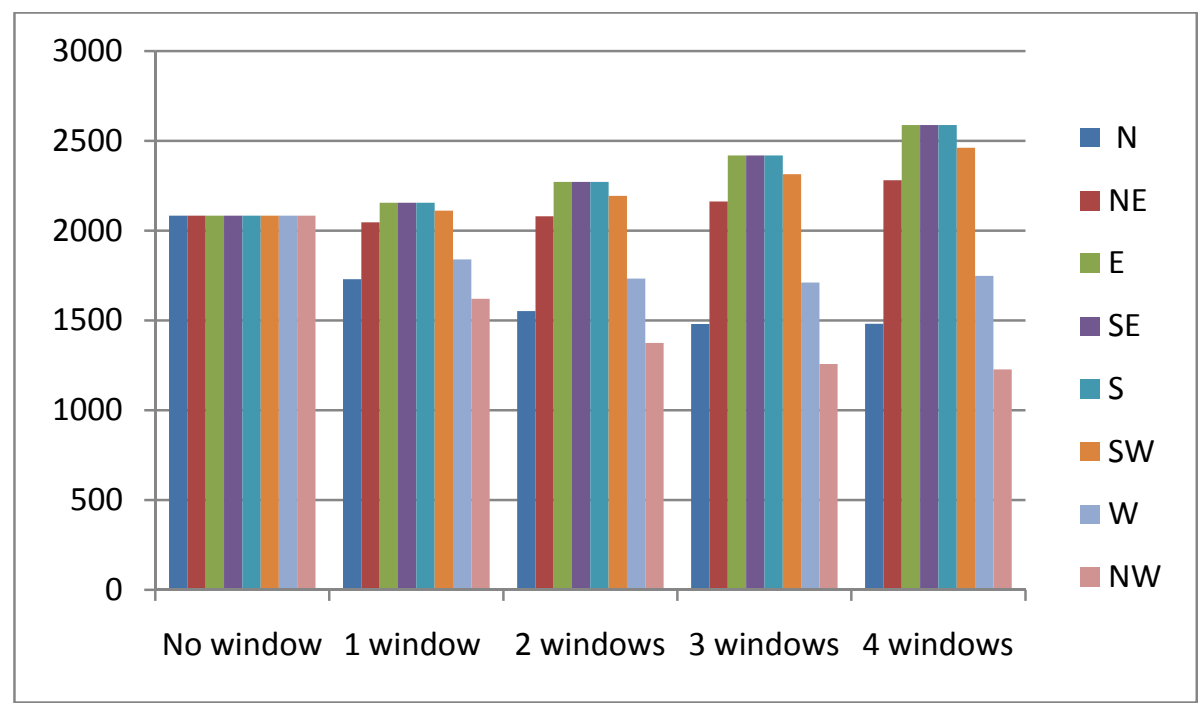

Graph $\mathrm{N}^{\circ} 16$ shows that vertical connectivity has a slightly higher consumption of energy than its horizontal counterpart. No major differences can be drawn between these two types of connections. 
For the next two graphs windows are placed in two opposite long walls, meaning, when walls are rotated always two façades receive solar gains.

Graphs $\mathrm{N}^{\circ} 17$ and $\mathrm{N}^{\circ} 18$ shows an interesting change in energy-use patterns when windows are placed in different walls.

Graph N ${ }^{\circ} 17$, Two 40-foot shipping containers 1 level with insulation 1 occupant located in Wellington and windows in both sides

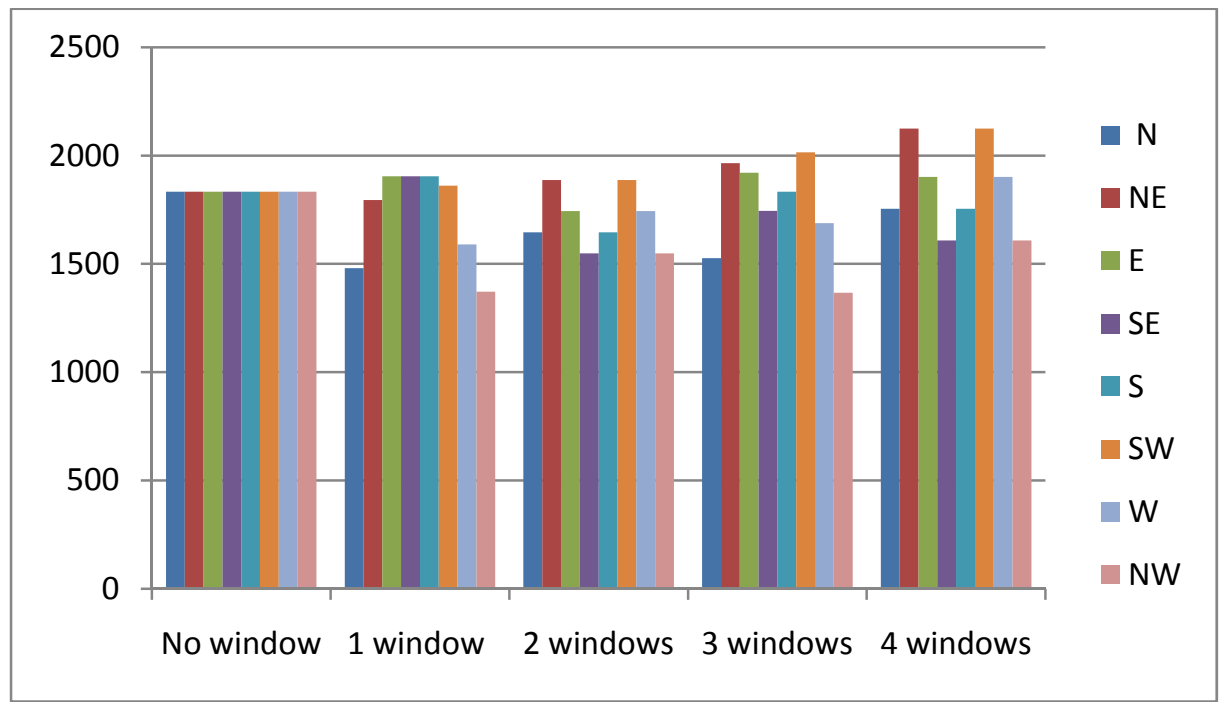

Graph N ${ }^{\circ} 18$, Two 40-foot shipping containers 2 levels with insulation 1 occupant located in Wellington and windows in both sides

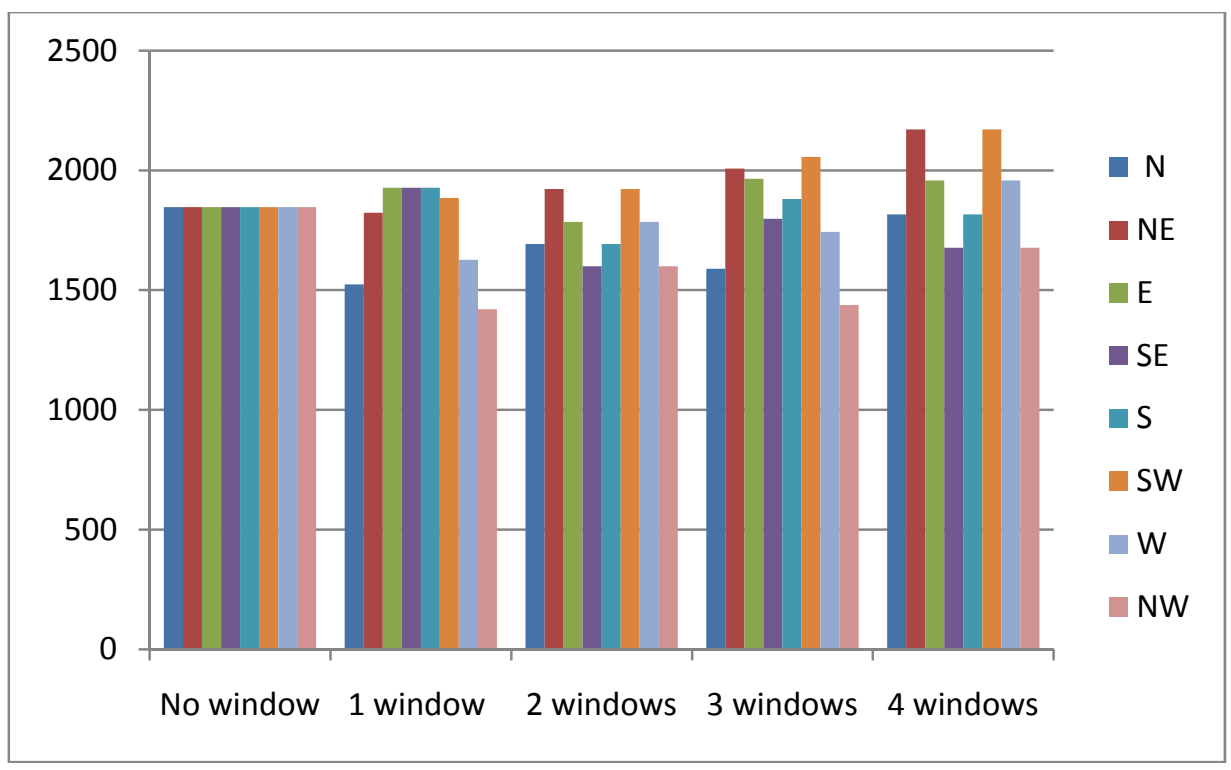


8.7. - Energy required per square metre (windows in one elevation and average orientation values)

The breakdowns into categories are explained below. However, table $\mathrm{N}^{\circ} 5$ shows the four categories set up by the size of the containers, from the lowest to the highest values.

- 20 foot shipping container with insulation with one occupant in Wellington

- 40 foot shipping container with insulation with one occupant in Wellington

- 20 foot shipping container without insulation with one occupant in Wellington

- 40 foot shipping container without insulation with one occupant in Wellington

- 20 foot shipping container with insulation with two occupants in Wellington

- 40 foot shipping container with insulation with two occupants in Wellington

- 20 foot shipping container with insulation with one occupant in Auckland

- 40 foot shipping container with insulation with one occupant in Auckland

\begin{tabular}{|c|c|c|c|c|c|c|c|c|}
\hline & 20 foot & 20 foot & 20 foot & 20 foot & 40 foot & 40 foot & 40 foot & 40 foot \\
\hline & $\begin{array}{c}\text { with } \\
\text { insulation }\end{array}$ & $\begin{array}{c}\text { with } \\
\text { insulation }\end{array}$ & $\begin{array}{c}\text { with } \\
\text { insulation }\end{array}$ & $\begin{array}{l}\text { without } \\
\text { insulation }\end{array}$ & $\begin{array}{c}\text { with } \\
\text { insulation }\end{array}$ & $\begin{array}{c}\text { with } \\
\text { insulation }\end{array}$ & $\begin{array}{c}\text { with } \\
\text { insulation }\end{array}$ & $\begin{array}{l}\text { without } \\
\text { insulation }\end{array}$ \\
\hline & Auckland & Wellington & Wellington & Wellington & Auckland & Wellington & Wellington & Wellington \\
\hline & square metre & square metre & square metre & square metre & square metre & square metre & square metre & square metre \\
\hline & 1 occupant & 2 occupants & 1 occupant & 1 occupant & 1 occupant & 2 occupants & 1 occupant & 1 occupant \\
\hline No window & 20.3 & 39.0 & 40.9 & 95.1 & 19.8 & 38.5 & 39.5 & 83.8 \\
\hline 1 window & 18.8 & 39.4 & 40.8 & 93.5 & 17.7 & 37.7 & 38.4 & 81.4 \\
\hline 2 windows & 19.9 & 43.3 & 44.5 & 93.3 & 18.6 & 40.9 & 41.5 & 80.7 \\
\hline 3 windows & 22.4 & 49.1 & 50.1 & 94.2 & 20.8 & 46.2 & 46.7 & 81.2 \\
\hline 4 windows & 25.7 & 56.1 & 56.9 & 95.8 & 23.9 & 52.8 & 53.2 & 82.6 \\
\hline
\end{tabular}

Table $\mathrm{N}^{\circ} 5$, Energy use per square meter in 20 and 40 -foot shipping containers $\mathrm{n} \mathrm{kWh} / \mathrm{m}^{2}$

The values of the table $\mathrm{N}^{\circ} 5$ show the average energy consumed (for space heating only) in every orientation. This has been normalised into square metres. 
Graph $N^{\circ} 19$, Energy use per square metre in 20 and 40 -foot shipping containers

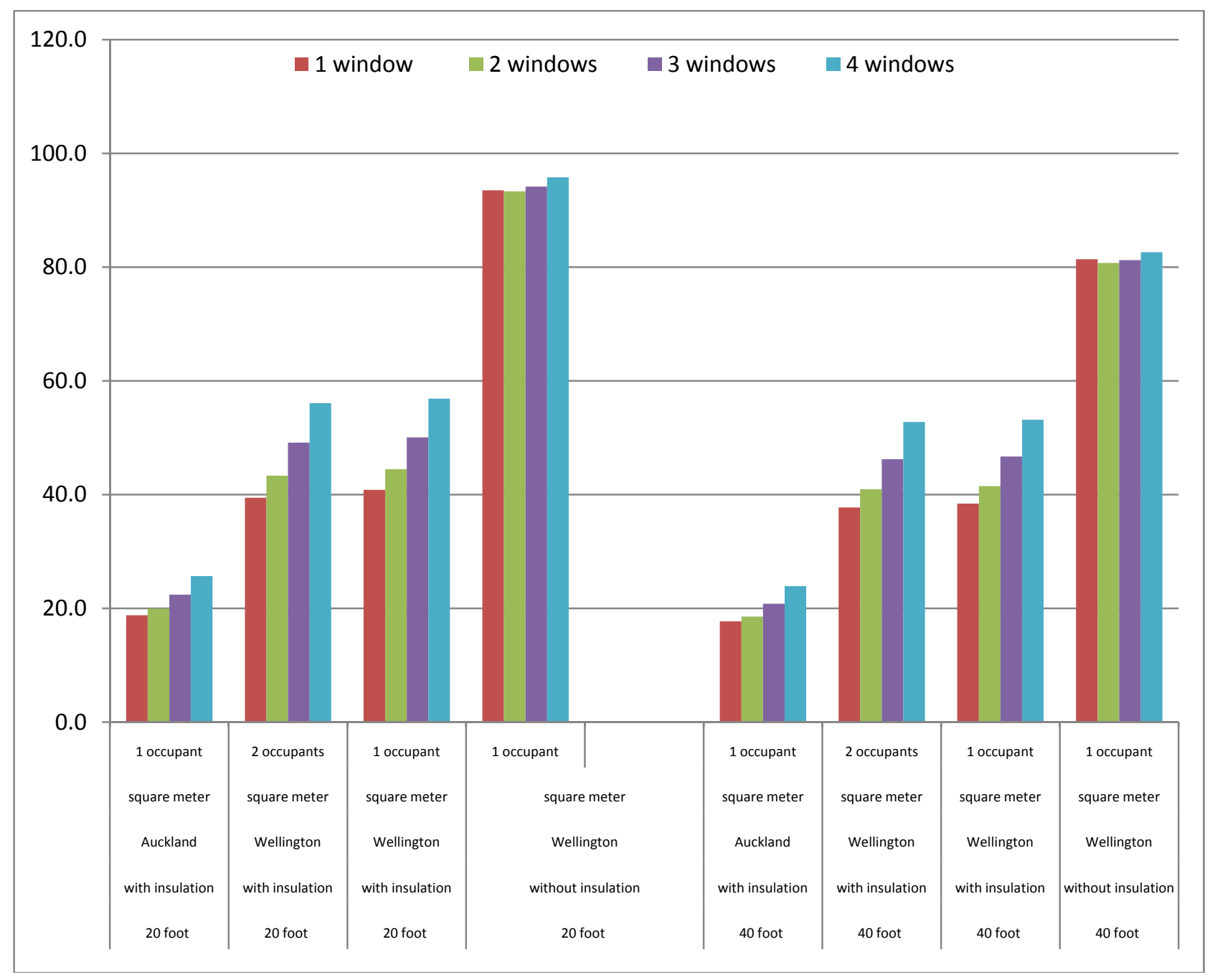

Graph $\mathrm{N}^{\circ} 19$ shows that 40 -foot shipping containers are more likely to use less energy per square metre in contrast with their 20 -foot counterpart.

When shipping container units are located in Auckland all use less energy than in Wellington per square metre in the case, of both 20 and 40 -foot freight containers. The number of occupants -whether one or two- seems to be insignificant. 
Table $\mathrm{N}^{\circ} 6$, Two 40-foot shipping containers 1 and 2 levels with insulation 1 occupant located in Wellington and windows in both sides and average orientation values

\begin{tabular}{ccc}
\hline & horizontal & vertical \\
\hline & 1 level & 2 levels \\
\hline No window & & \\
\hline 1 window & 64.8 & 65.3 \\
\hline 2 windows & 61.0 & 62.1 \\
\hline 3 windows & 60.3 & 61.8 \\
\hline 4 windows & 62.1 & 63.9 \\
\hline
\end{tabular}

Graph $N^{\circ} 20$, Two 40 -foot shipping containers 1 and 2 levels with insulation 1 occupant located in Wellington and windows in both sides

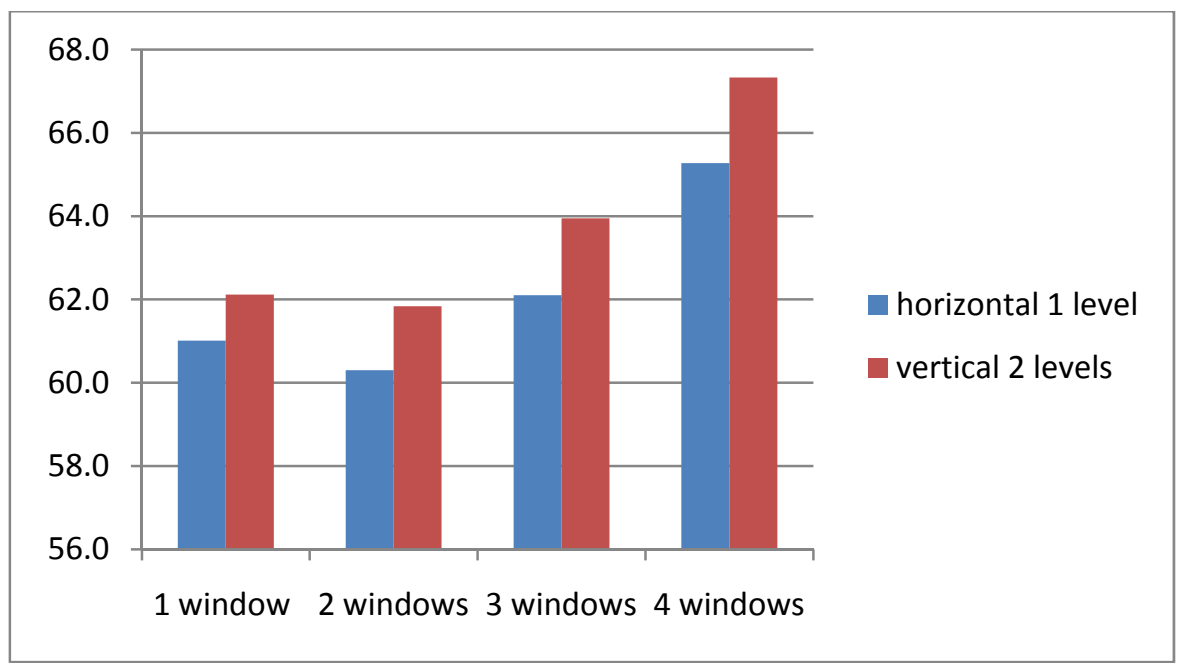

Graph $\mathrm{N}^{\circ} 20$ shows two 40 -foot shipping containers placed on one and two levels with insulation and one occupant located in Wellington and with windows placed in both sides. Energy normalised into square metres demonstrates that a vertical organisation of containers is likely to use more energy for space heating than the horizontal equivalent. The logic of this is that the roof has to be more highly insulated than the walls, in order to meet the requirements of the Building Code. The vertically stacked containers have more wall area relative to roof area than the horizontally placed containers. 
8.8. - Summary of the chapter

- ISO Containers can be classified according to their cladding in two categories: with and without insulation.

- The energy required for heating a single container depending on its glazing area for different orientations.

- Insulation of a container is a key driver for achieving less energy consumption for space heating.

- Less than one-half of the total amount of energy is required for heating an insulated unit (40-foot container) in comparison with a non-insulated container (40-foot as well).

- There is a strong relationship between the increment of glazing area and the increment of energy use in all orientations.

- North and Northwest façades tend to be more linear in contrast with others which tend to rise exponentially.

- Most orientations grow exponentially. This suggests that generally when glazing area increases, energy use rises, although some glazing areas and orientations show lower energy use than a container without glazing.

- A 20-foot shipping container located in Auckland consumes practically one-half of the energy required in Wellington with the same conditions of orientations, occupants, level of insulation and so on.

- Vertical connectivity has a slightly higher consumption of energy than its horizontal counterpart.

- When shipping container units are located in Auckland all use less energy than in Wellington per square metre in the case, of both 20 and 40 -foot freight containers. The number of occupants -whether one or two- seems to be insignificant.

- Energy normalised into square metres demonstrates that a vertical organisation of containers is likely to use more energy for space heating than the horizontal equivalent. 


\section{Chapter IX - Case studies}

A comparative life cycle analysis for three different buildings in the residential sector of New Zealand will be carried out in this research. The advantages and disadvantages in the usage of shipping containers in architecture were discussed in earlier chapters. Selection criteria are based upon relationships between container-architecture's main features that match with some ideals of the Modern Movement in Architecture: the construction of prefabricated and mass produced elements, modularity and formal simplicity. Emphasis is put on numerical relationships related to shipping steel-boxes, size and form, scale, material properties, density, site location and climatic conditions. The assessment includes examples with low, medium and high thermal mass.

The three case studies are: for steel, the Stevens house, which is the first container house constructed in Wellington, for concrete, a single dwelling unit of the Jellicoe Towers, a post-WWII model of Modern Architecture in New Zealand built in the late 1960s and for timber, the Firth house, a wooden-based house designed by Cedric Firth which was inspired by the works of Walter Gropius and Konrad Wachsmann, German figures of the Modern Movement in Architecture.

All buildings are located in Wellington city, New Zealand. The first case study, designed by Ross Stevens, was built in 2006 using shipping containers. The Jellicoe Towers was built in the 1960's and the oldest project is the Firth house built in 1945 and expanded in 1964. In addition, for this study the total square metres of the case studies' basement areas will not be taken into account. However, the ALF 3 modeling program calculates and includes these spaces in order to determine the amount of energy lost or gained for each individual case study. One floor of the 16 storeys Jellicoe Towers, corresponding to one apartment,

will be evaluated in this research. For convention, the $8^{\text {th }}$ floor, which is located in the middle of the total height of the building, has been chosen because the higher floors are likely to be more exposed to the wind and the lowest floors are likely to be more protected from the wind.

The order, in which the case studies are organised, will be related to the expected outcome of energy consumption and $\mathrm{CO}_{2}$ emissions. First is the Stevens house that uses mainly steel, with an almost nil $R$-Value and potentially would have more insulation problems in comparison with the Jellicoe Towers' $8^{\text {th }}$ floor and finally the Firth house, which is expected to have the least environmental impact of the three. 
Figure $\mathrm{N}^{\circ} 1$ : Case studies
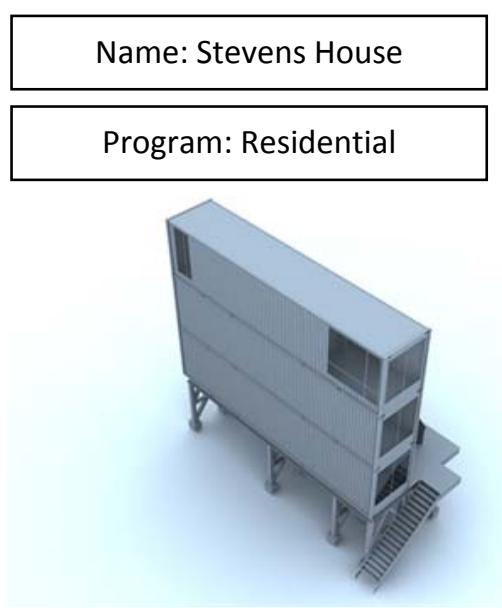

Name: Jellicoe Towers

Program: Residential

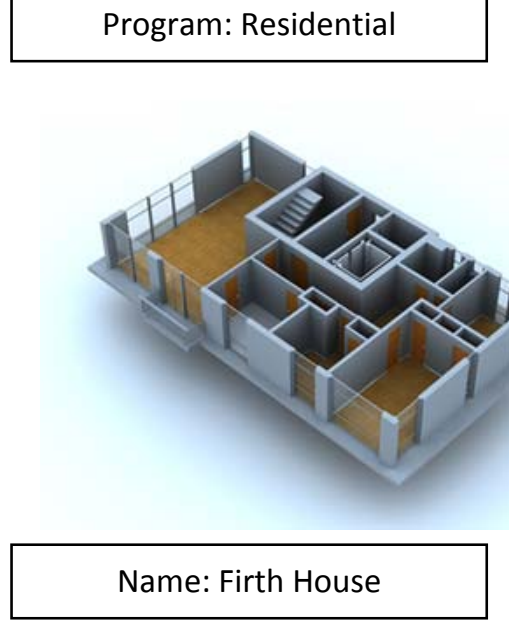

Program: Residential
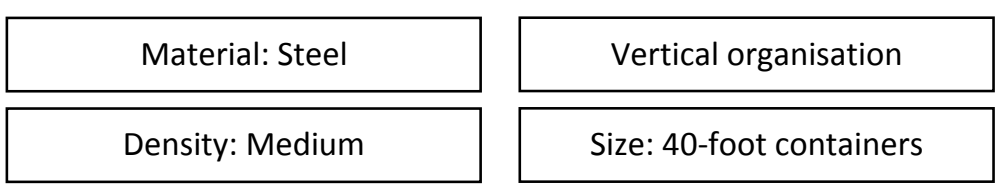

Images in the left side show the case studies meanwhile images in the right side of the page show a basic design of how the case studies should look like if they are made of shipping containers.

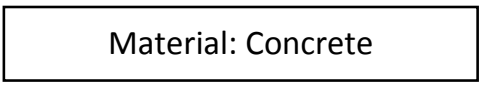

Density: High (building)
Horizontal organisation

Size: 40-foot containers

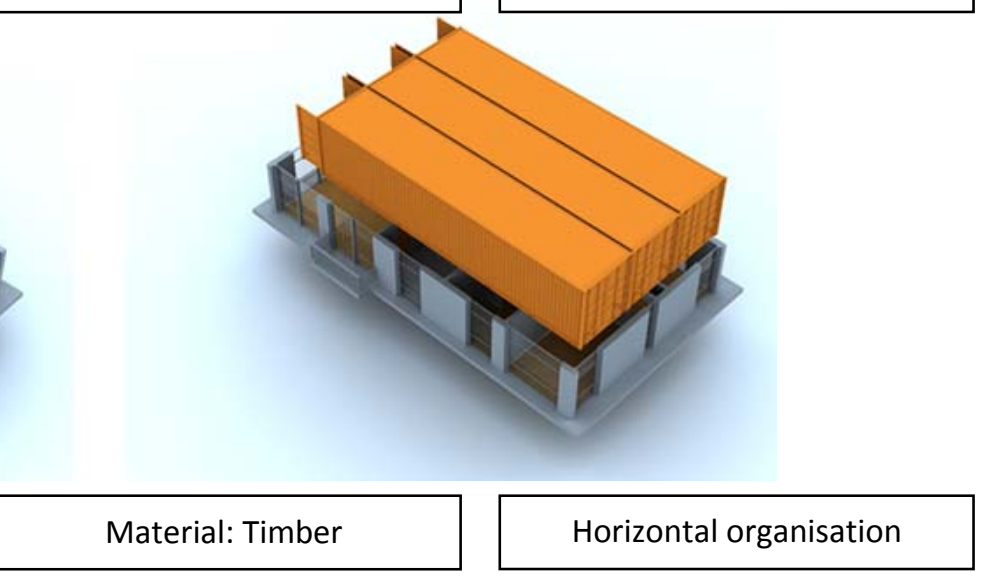

Density: Low

Size: 20 and 30 -foot containers
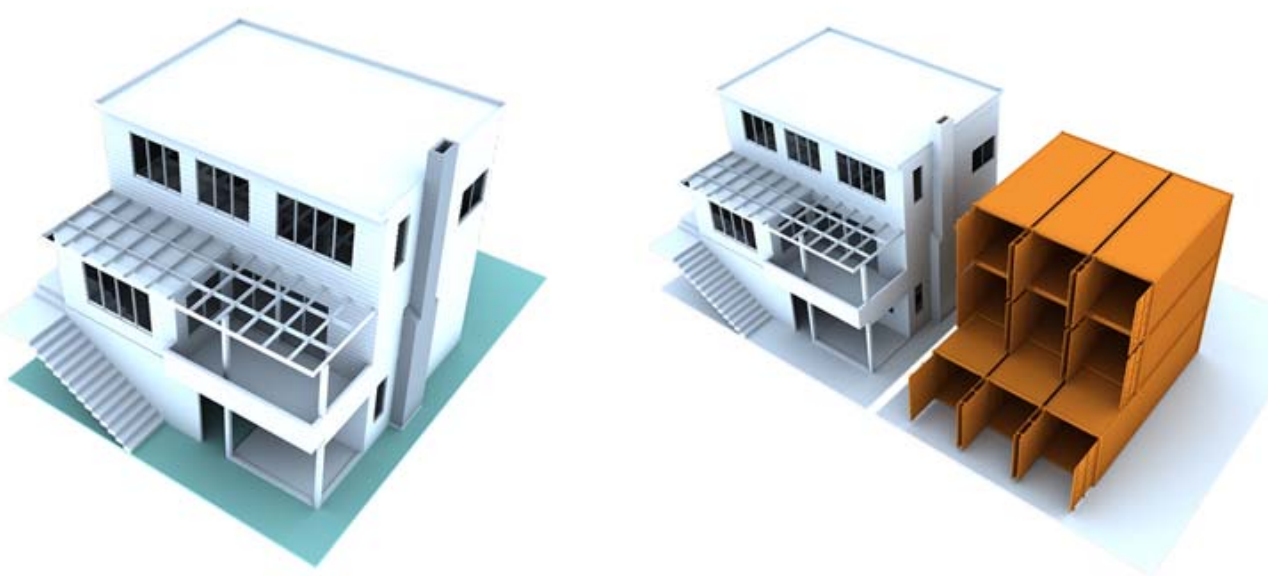


\section{1. - Site and structure}

All projects have different site conditions which should be considered.

Figure $N^{\circ} 2$ : Stevens house Jellicoe Towers Firth house

\subsection{1. - Stevens house}

In contrast with the other two examples the Stevens house remains sheltered and at the same time exposed in one of its sides. This is because the dwelling is placed in front of a geographic accident of the hill in which a big barrier of naked rock encompasses the entire structure.

\subsection{2. - Jellicoe Towers}

The Jellicoe Towers building is located in the middle of The Terrace, in downtown Wellington. This case study is therefore completely exposed to weather conditions.

\subsection{3. - Firth house}

The timber based counterpart is placed in a regular and steeply sloping plot in Karori and it is medium exposed.
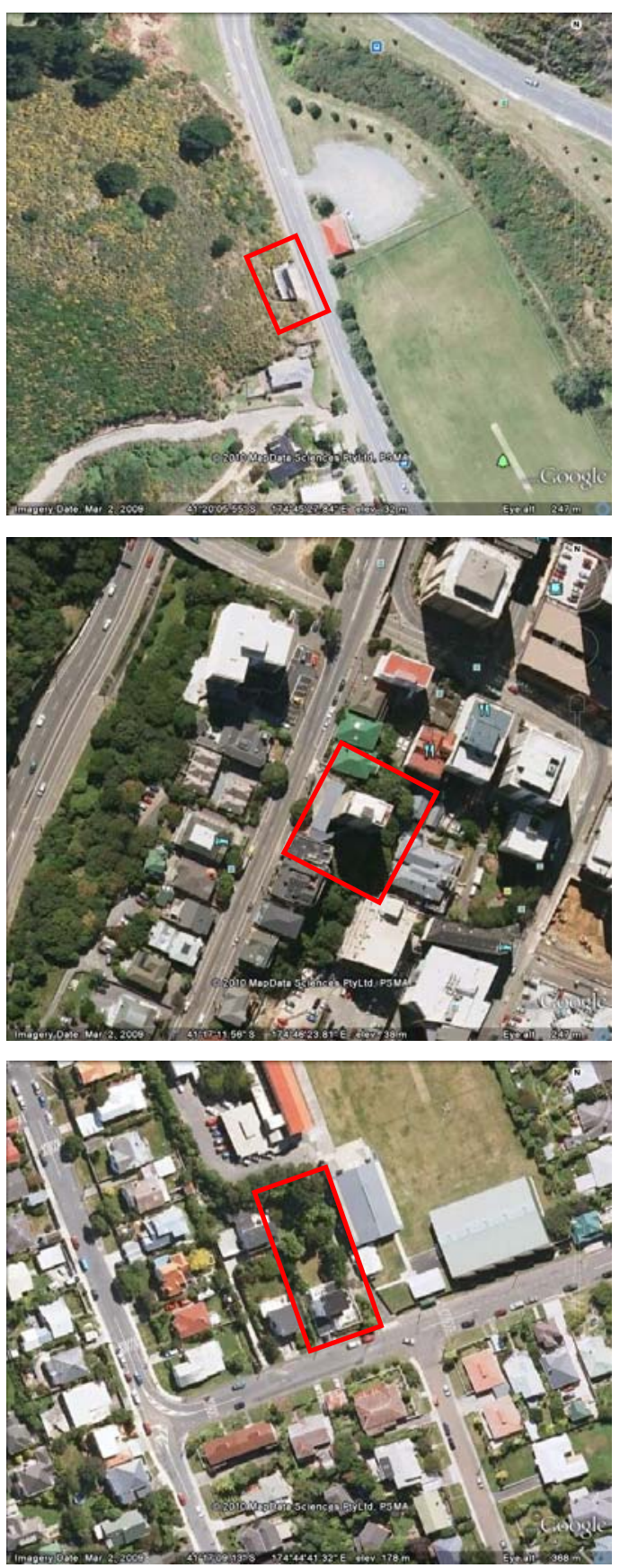

Image source: Google Earth 


\section{2. - Case studies background}

\subsection{1. - Stevens house}

The Stevens house is probably one of the first examples of container architecture in Wellington and New Zealand, a simple, modular and narrow dwelling unit. Located near the Wellington Landfill, the house takes advantage of a geographic accident and settles its structure into a hillside fulfilling the emptiness of the place.

Figure $\mathrm{N}^{\circ} 3$ : Basement and first floor Stevens house

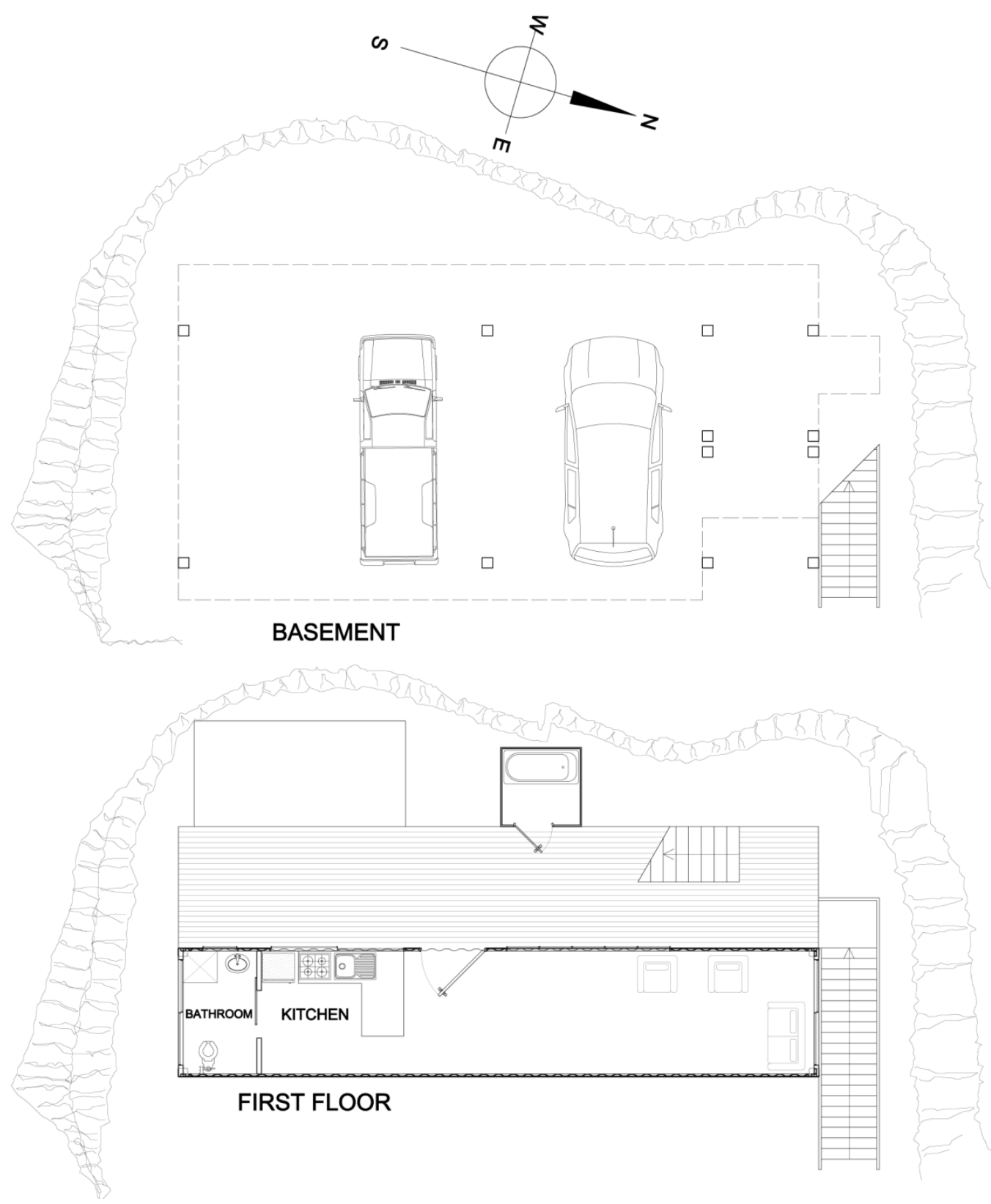

Image source: Own drawing based on plans of Container Architecture by (Kotnik, 2008, p. 151) 
The building is composed of the basement: a steel structure with a concrete slab of 100 $\mathrm{mm}$ thick and three forty foot steel shipping containers stacked vertically upon each other. The building itself can be split into two parts, inner and outer space. The natural mass of rock outside acts as a big wall and limits the first floor. This brings natural lighting disadvantages and means a loss of solar energy to the house.

Figure $\mathrm{N}^{\circ} 4$ : Second and third floors Stevens house

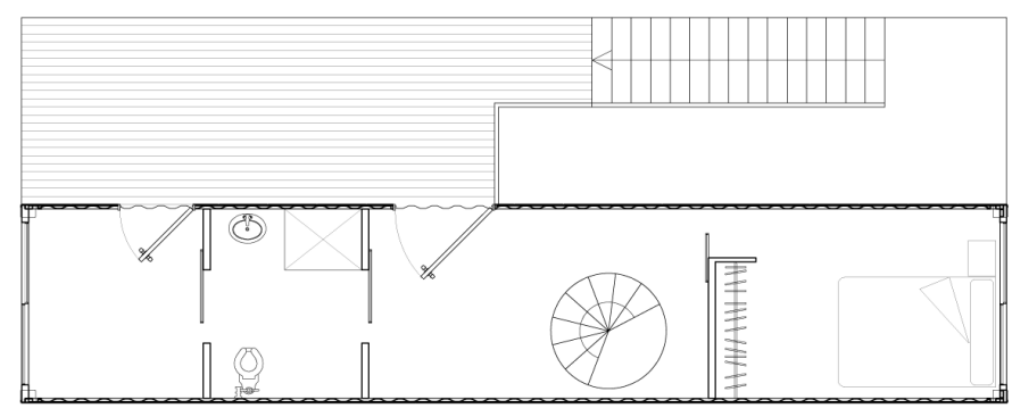

SECOND FLOOR

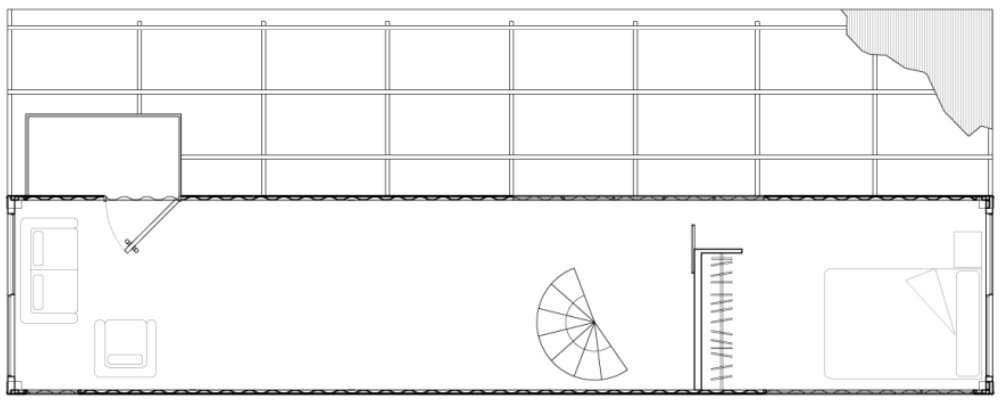

THIRD FLOOR

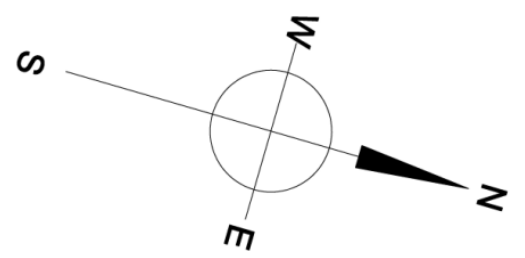


The program is divided into four different levels; the first one is the basement which provides parking and the base for the containers. The first floor contains the program in which public activities are developed such as the living room, a small kitchen, an exterior dining area, an internal bathroom and an external shower. An external staircase connects the first with the second floor. The second floor holds two bedrooms placed in each opposite corner of the shipping container. In the middle of the container a spiral stair connects this level with the last one, which is a large living area.

This spatial diversity also brings some functional problems. Wellington is a cold city, with harsh weather condition and a cold summer, so in this context, a shower outside of the shipping containers may be hard to use and can potentially bring health problems, especially in winter time.

Figure $\mathrm{N}^{\circ} 5$ : Stevens house west elevation

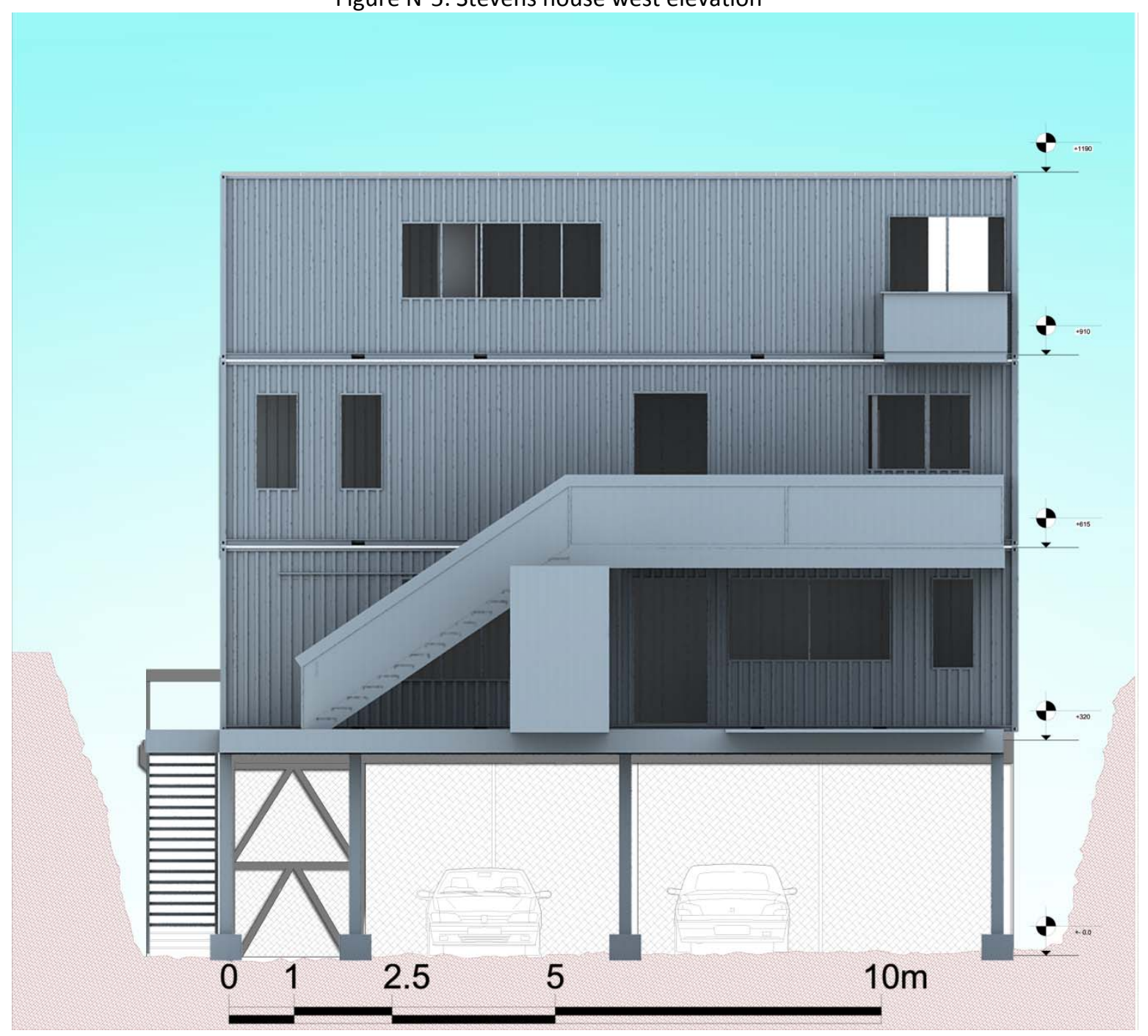

Image source: Own drawing based on plans of Container Architecture by (Kotnik, 2008, p. 150) 
Figure $\mathrm{N}^{\circ} 6$ : Stevens house east elevation

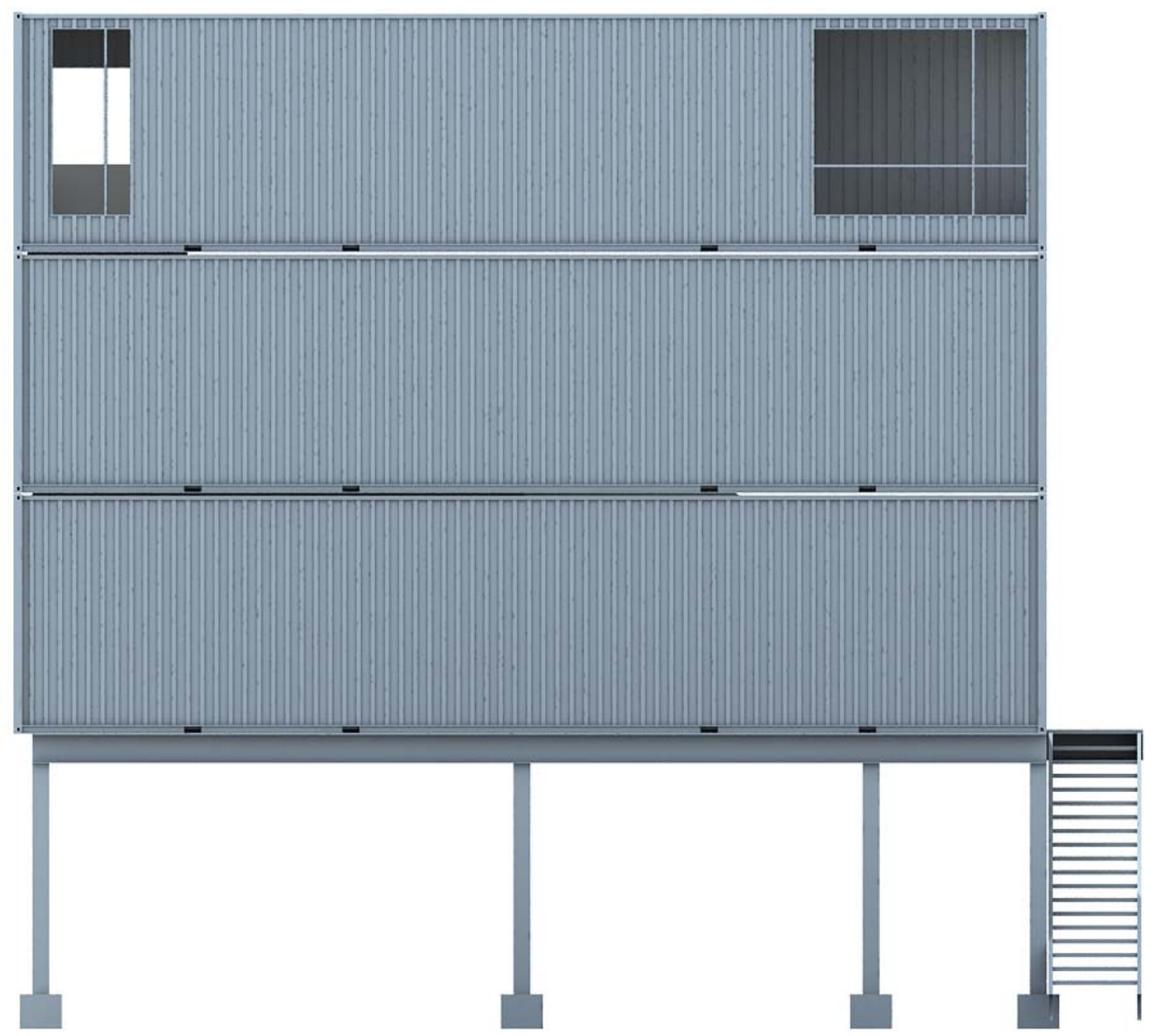

Image source: Own drawing based on plans of Container Architecture by (Kotnik, 2008, p. 150)

This image shows the east elevation and main façade of the Stevens house. As can be seen from the picture, the building is made up of three 40-foot high-cube shipping containers which have an external height of $9^{\prime} 6^{\prime \prime}$ or $2.90 \mathrm{~m}$ each. 
Figure $\mathrm{N}^{\circ} 7$ : Stevens house north and south elevations

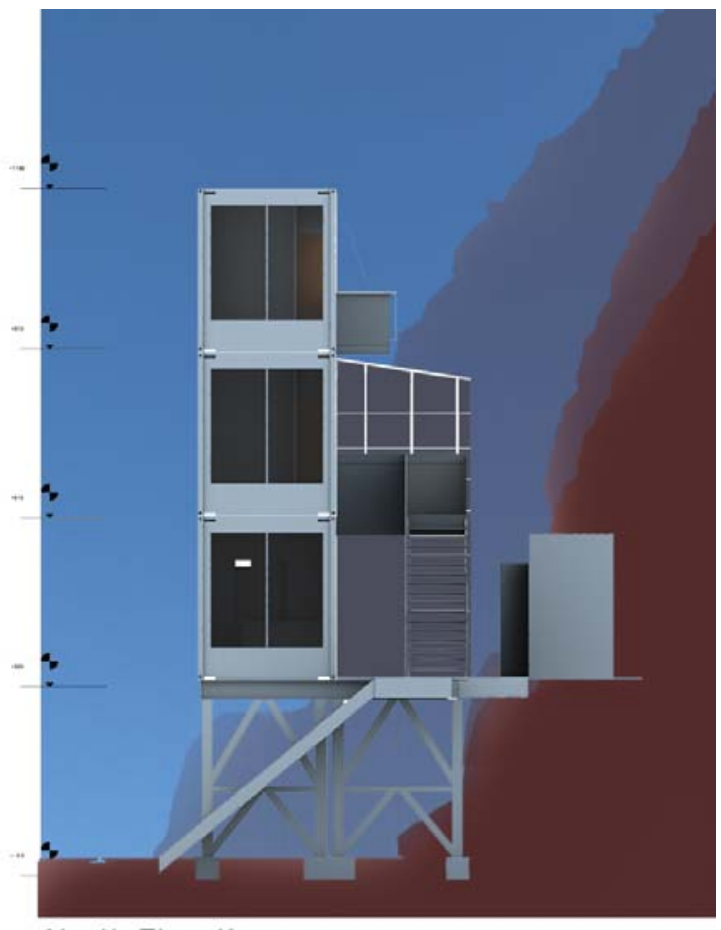

North Elevation

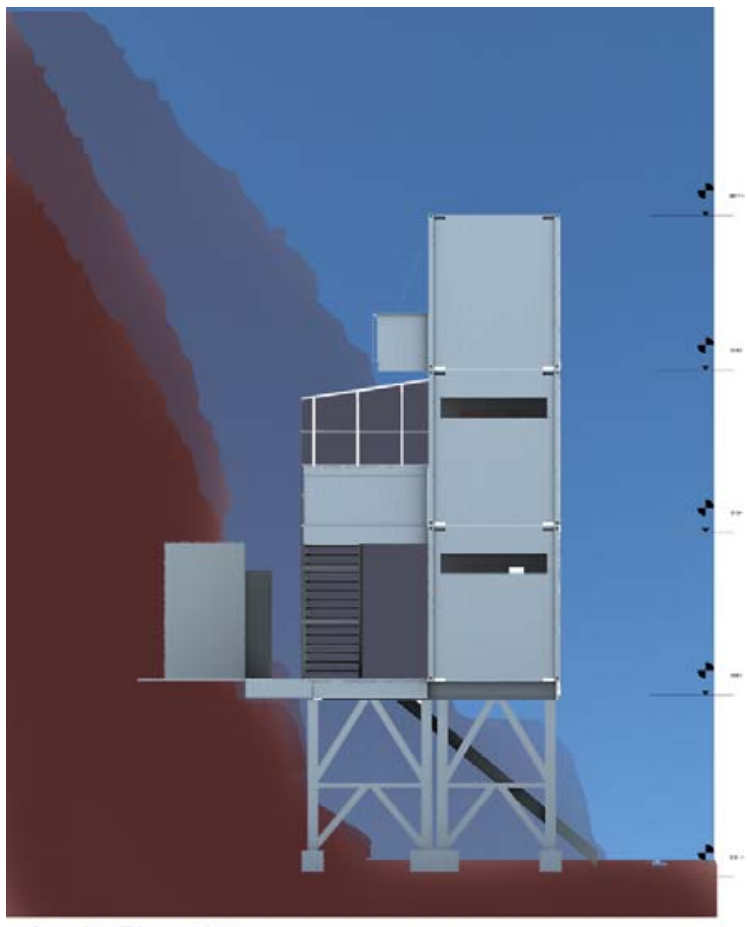

South Elevation

Image source: Own drawing based on plans of Container Architecture by (Kotnik, 2008, p. 150)

The above images show North and South elevations. On the North elevation, the glazing area covers almost the entire face where doors of containers are usually placed. Conversely, very little of the walls have been modified in the South façade.

Figure $\mathrm{N}^{\circ} 8$ : Stevens house section

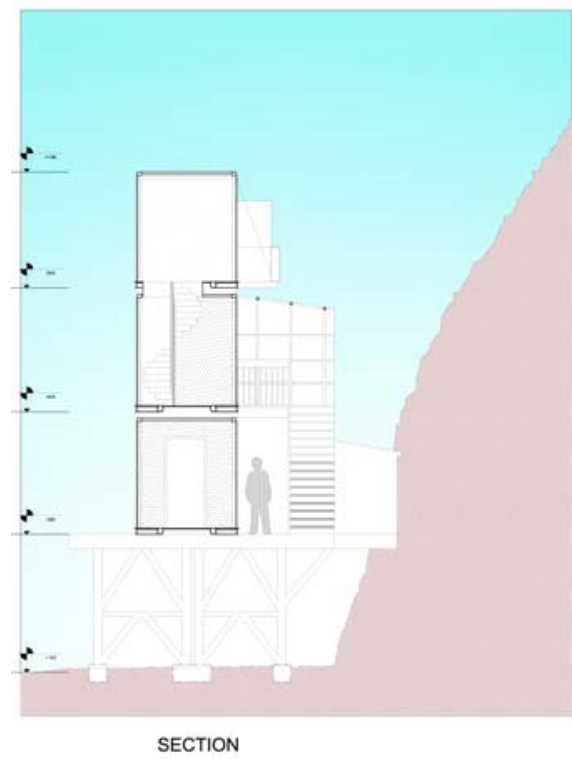

Image source: Own drawing based on plans of Container Architecture by (Kotnik, 2008, p. 150) 
Figure $\mathrm{N}^{\circ} 9$ : Stevens house axonometric
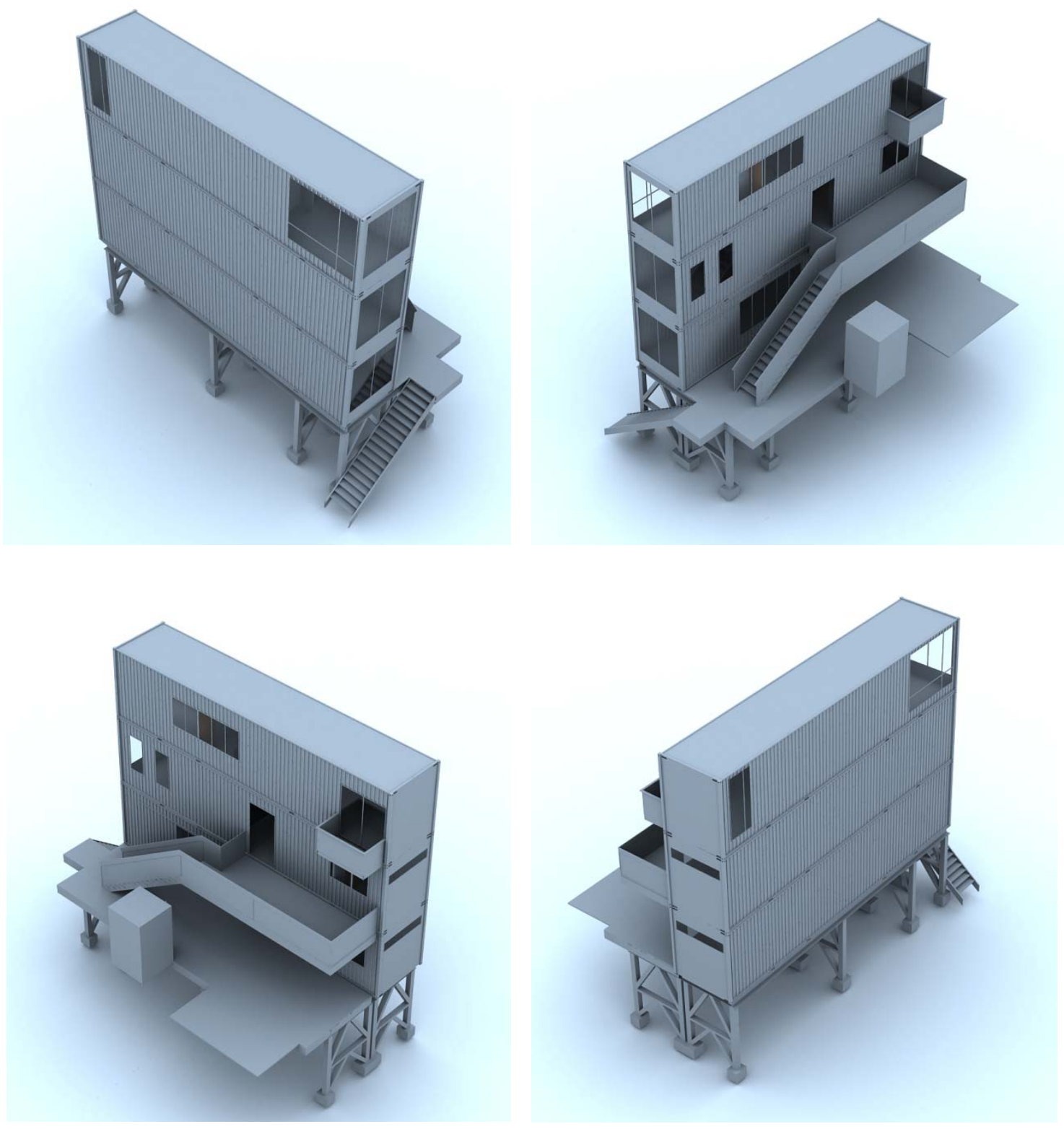

Image source: Own drawing based on plans of Container Architecture by (Kotnik, 2008, p. 150)

Note: these three dimensional drawings do not show an existent little greenhouse structure which covers the deck of the second floor in where circulation is placed. 


\subsection{2. - Jellicoe Towers}

The second case study corresponds to a concrete structure, the Jellicoe Towers apartment building. However, for this research only one single dwelling will be assessed in order to make a fair comparison within the other projects. Perhaps, the plural in the name refers that in the original project two or more towers might be built.

This building is located in the core of Wellington's downtown; in its sixteen floors there is only one apartment per level that includes a typical residential structure meaning three bedrooms, a little kitchen, bathroom and an extensive and large living area.

Figure $\mathrm{N}^{\circ} 10$ : Jellicoe Towers

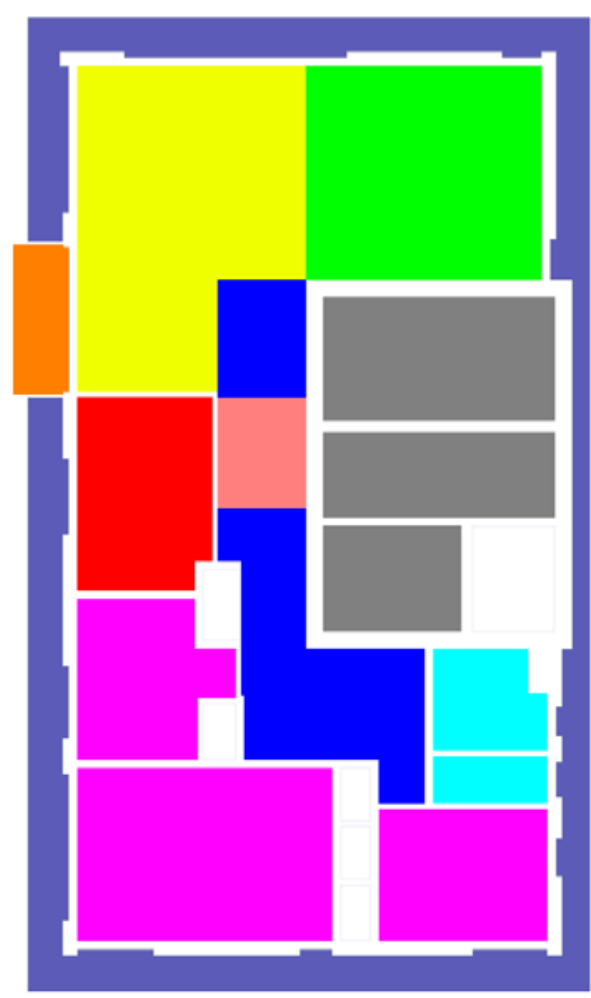

Dining room

Living room

Inner circulation

Kitchen

Hall
Outer circulation

Bathroom

Bedroom

Concrete structure

Balcony
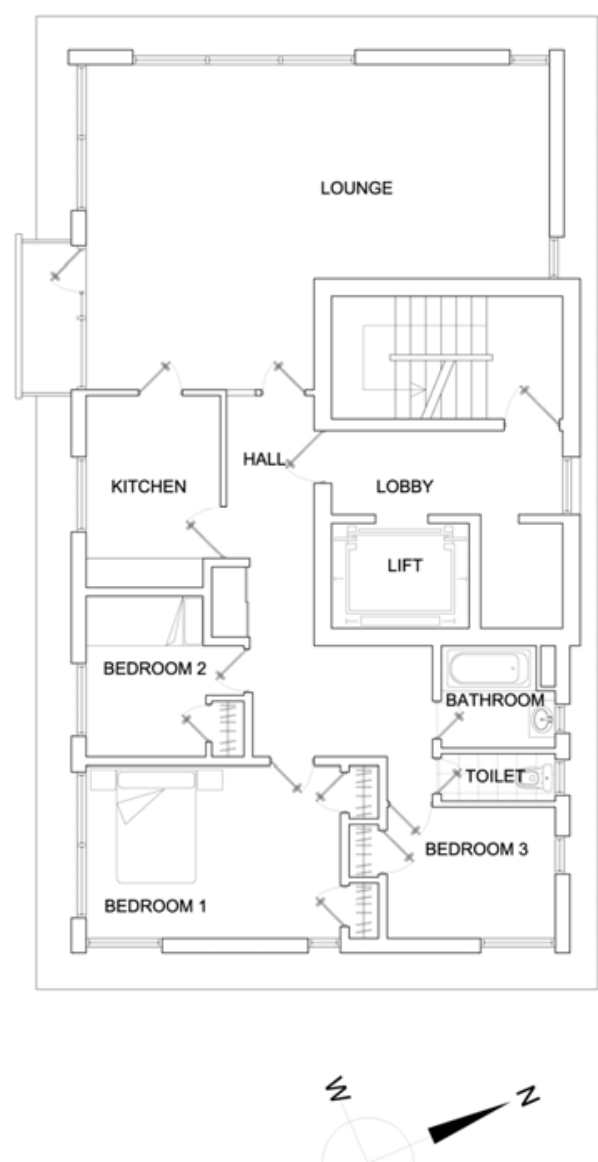

$\infty$

$m$ 
Architect Daniele Abreu e Lima says: "The individual apartments can be described as both, luxurious and relatively modest. ${ }^{11}$

This is explained: luxury because the great views that the city offers with the harbor, the green belt and relatively modest due to the compact layout of the internal space. Figures $\mathrm{N}^{\circ} 11$ shows different areas including inner and outer circulations, cupboards and storage cabinets which have been taken into account in table $\mathrm{N}^{\circ} 1$.

Figures $N^{\circ} 11$ : Jellicoe Towers (one dwelling) elevations
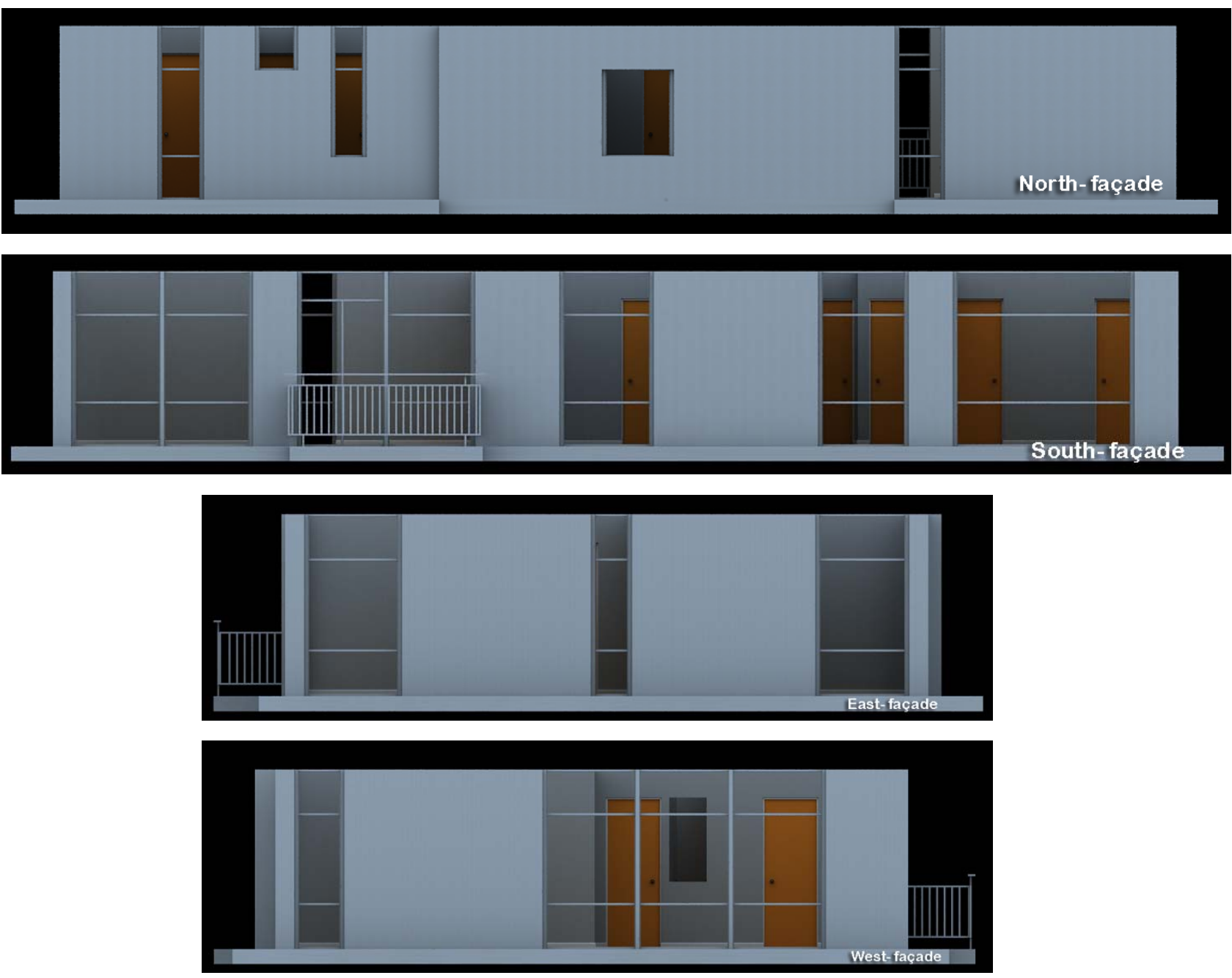

Image source: Own drawing based on plans and own pictures taken from the street

\footnotetext{
${ }^{1}$ Gatley, J. (2008, p. 147)
} 
Figures $N^{\circ} 12$ : Jellicoe Towers (one dwelling) axonometric
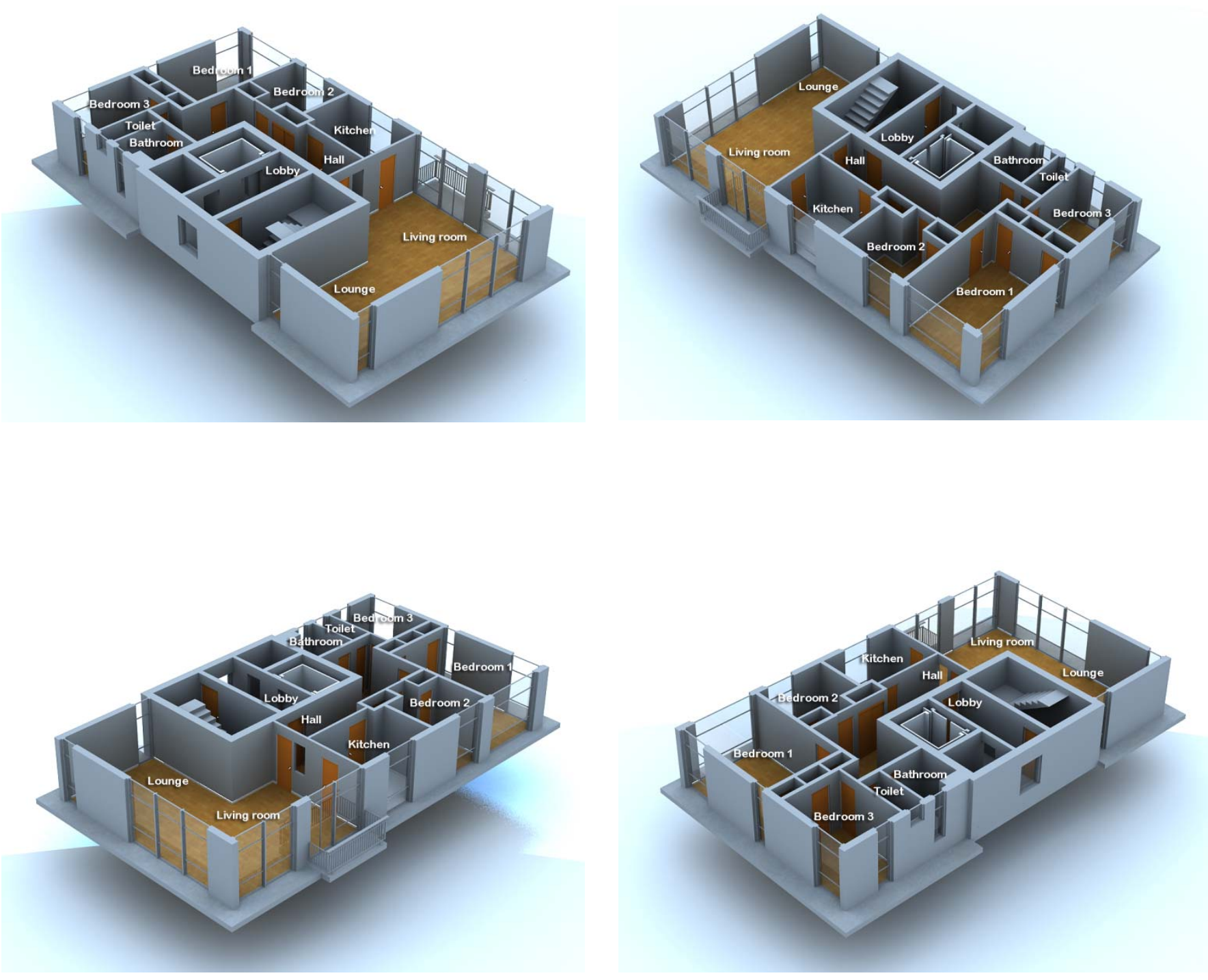

Image source: Own drawing based on plans and own pictures taken from the street 


\subsection{3. - Firth house}

The last house is a timber-based structure. It is the oldest building of the three projects assessed here. Designed and built in 1941 by Cedric Firth, the Firth house had a low footprint impact. ${ }^{2}$ The dwelling is made up of a basement and two storeys in a rectangular and sloped plot. The designer discussed the advantages of a twenty foot wide house and suggested that, following German precedents, even narrower houses could be explored in New Zealand. ${ }^{3}$ The home design may be explained due to the strong influence of the works of German architects such as Walter Gropius and Konrad Wachsmann. Cedric Firth was particularly interested in the arithmetic and numeric relationships between the materials and the structure, similar to Wachsmann. In addition, this European influence makes this case study unique and remarkably interesting to analyze due to theoretical similarities that ignore other average wooden houses and because of the proximity to the concepts associated with container architecture explained in chapter one.

Moreover, the residence has a traditional residential program and is divided into three levels, the basement, the first and the second floors. On the first floor are located the living room, a wide dining room, which later was modified and extended (1964), ${ }^{4}$ the kitchen and the laundry. For Cedric Firth, the fireplace was the most important place of a New Zealand house because it was "the focal point for more than a half of the year". ${ }^{5}$ This might be seen as something trivial, but its importance will be discussed further.

The second level contains the rest of the program, the three bedrooms with their respective cabinets and the bathroom for the family.

\footnotetext{
${ }^{2}$ Gatley, J. (2008, p. 37)

${ }^{3}$ Ibid

${ }^{4}$ Ibid

${ }^{5}$ Ibid
} 


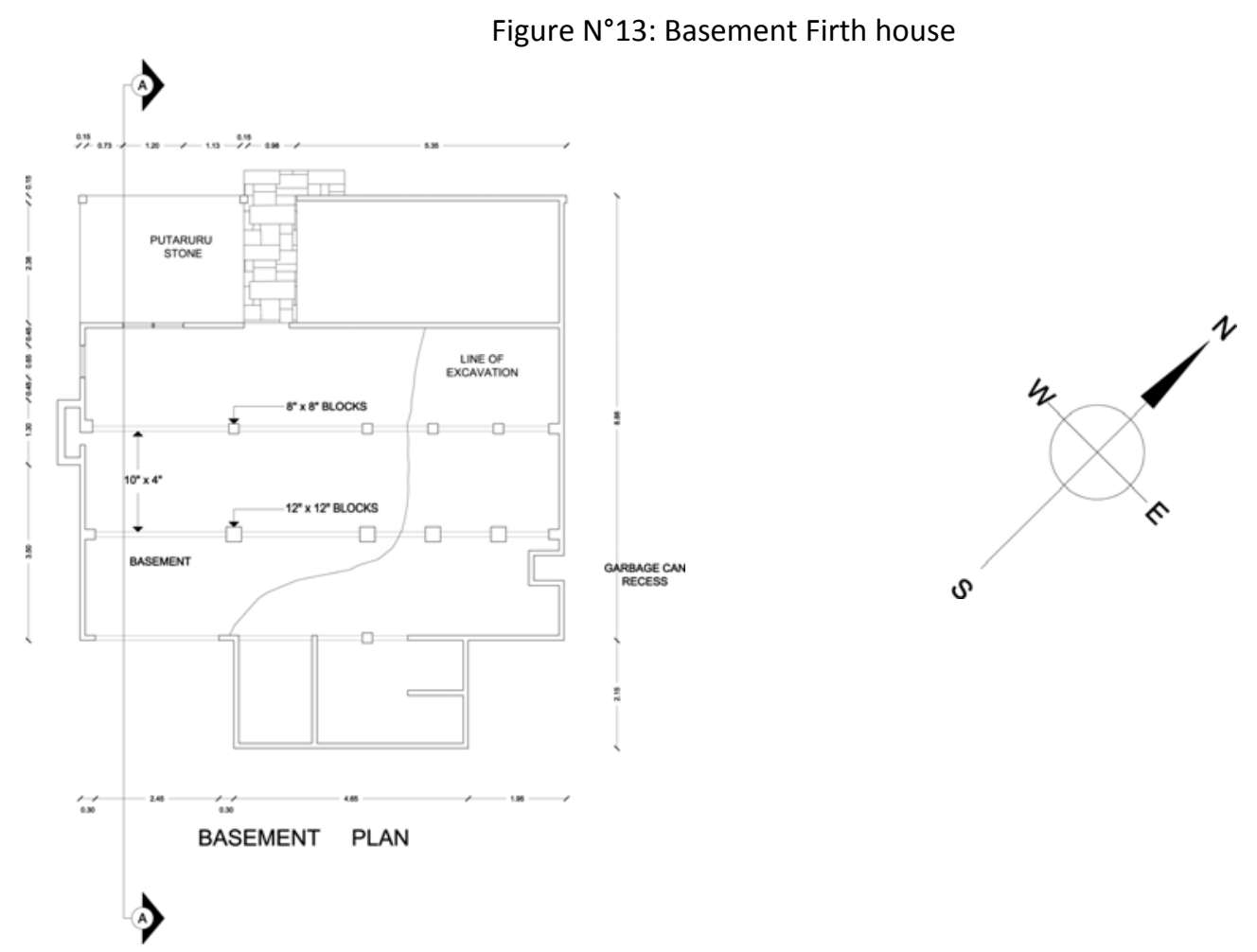

Figure $N^{\circ} 14$ : First floor Firth house

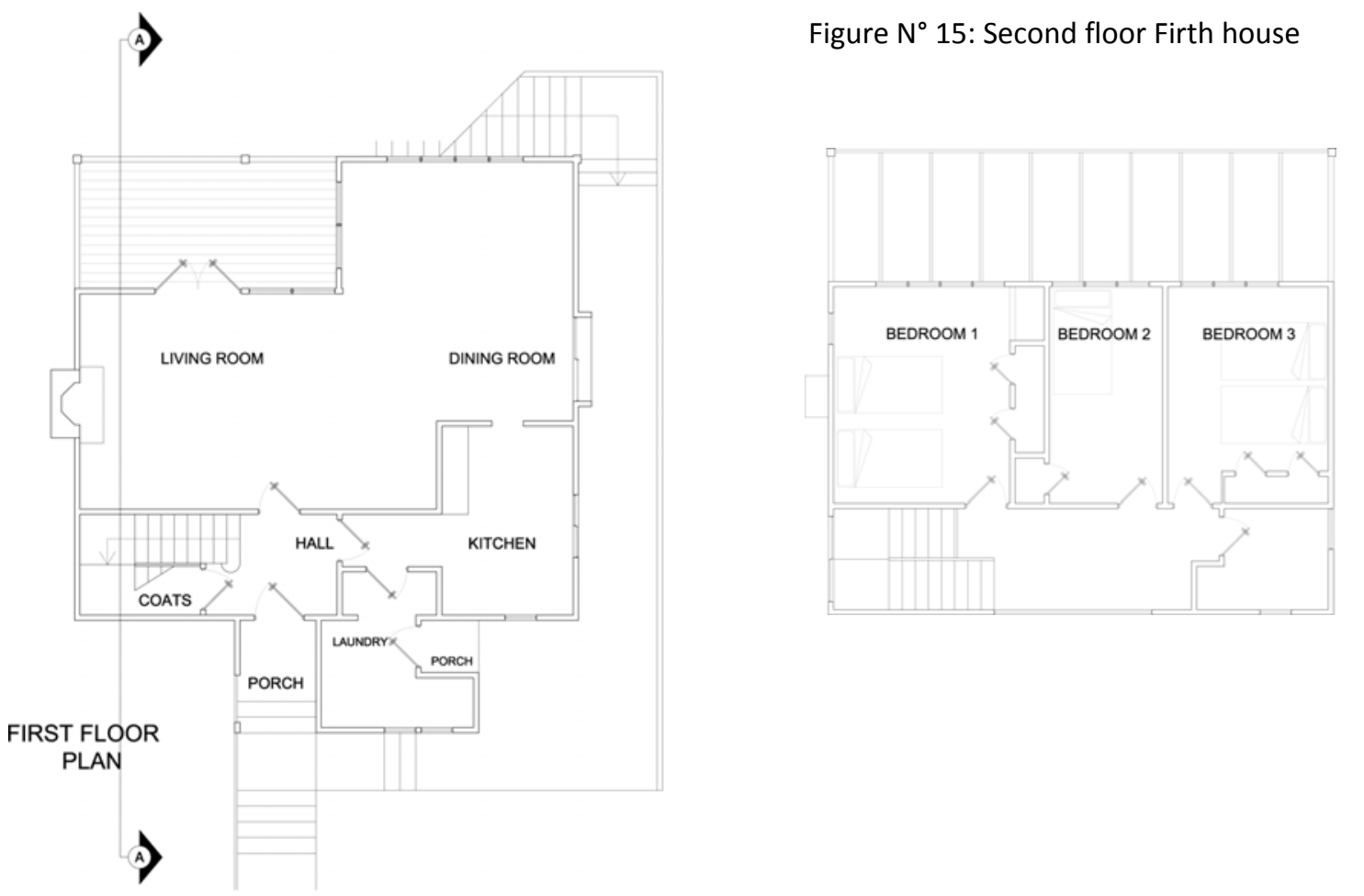

Image source: Own drawing based on plans and pictures taken from The Cedric Firth Collection, Alexander Turnbull Library 
Figure $N^{\circ} 16$ : Facades Firth house
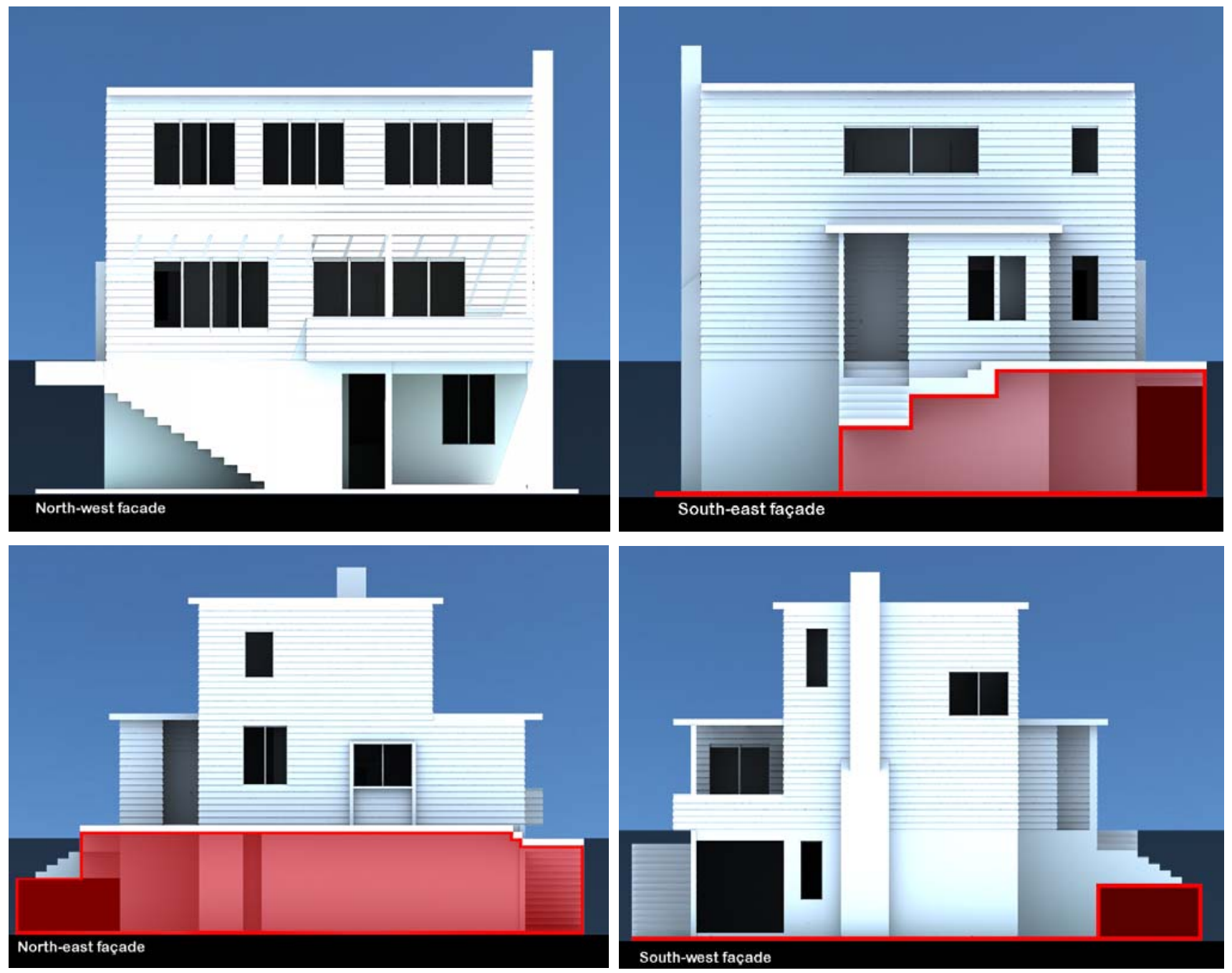

Image source: Own drawing based on plans and pictures taken from The Cedric Firth Collection, Alexander Turnbull Library 
Figure $N^{\circ} 17$ : Facades Firth house axonometric

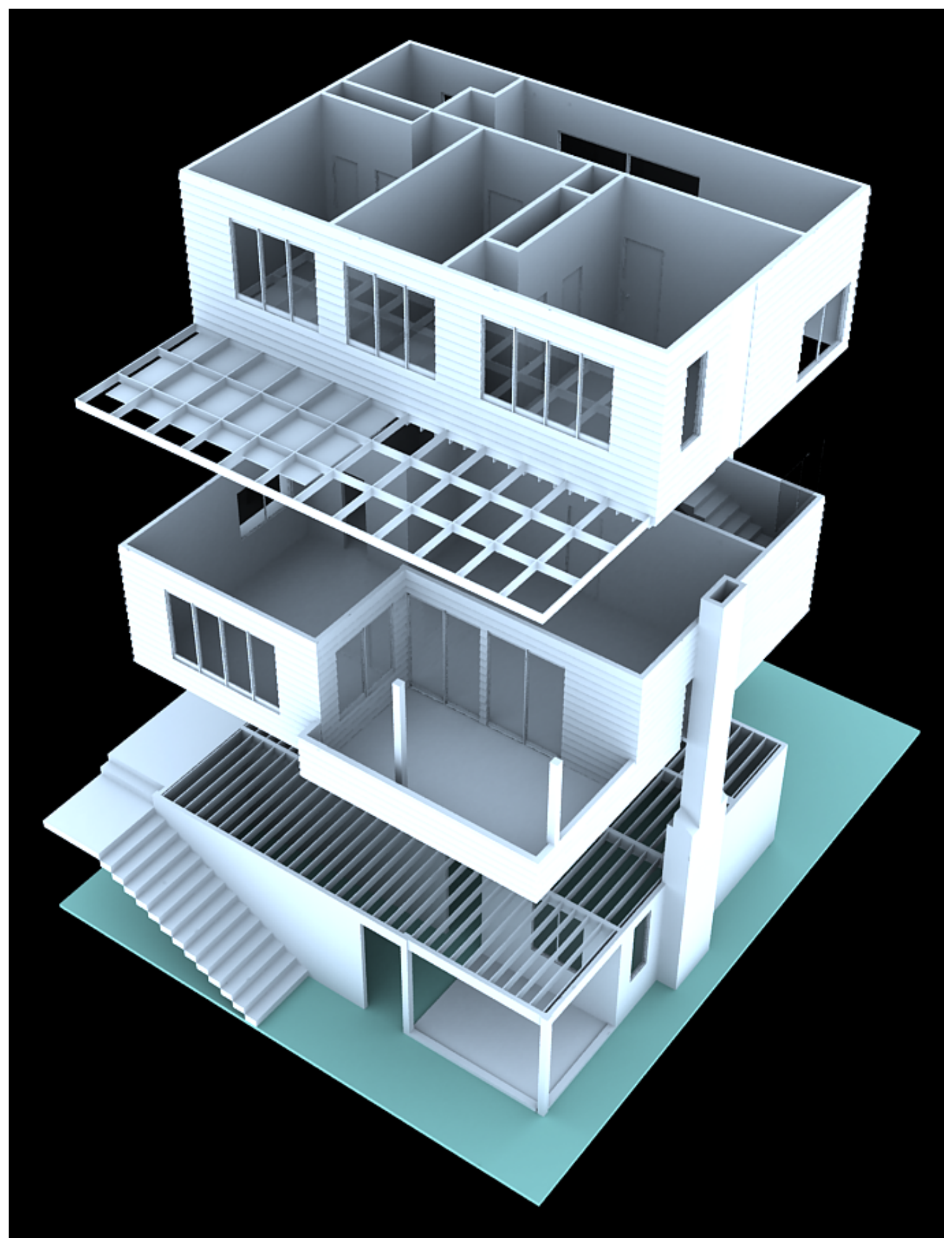

Image source: Own drawing based on plans and pictures taken from The Cedric Firth Collection, Alexander Turnbull Library 
Figure $N^{\circ} 18$ : Facades Firth house axonometric
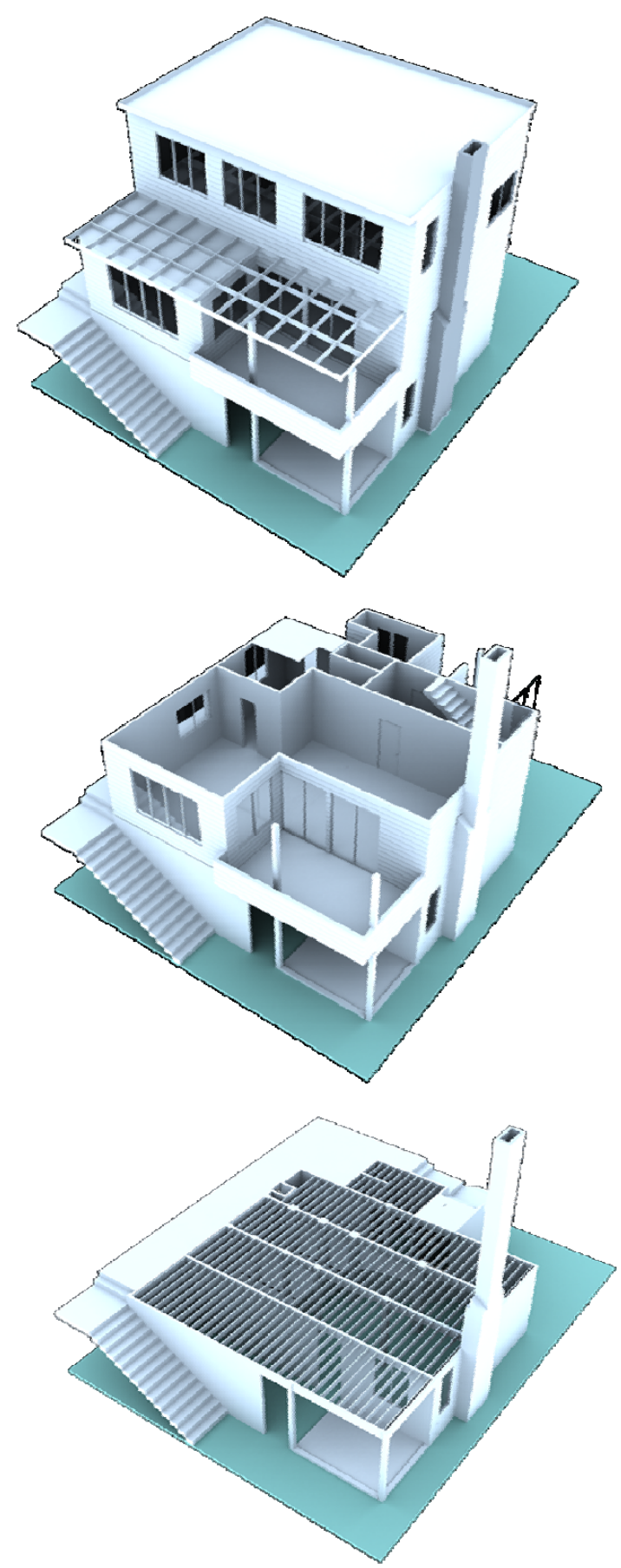

Image source: Own drawing based on plans and pictures taken from The Cedric Firth Collection, Alexander Turnbull Library 
Table $N^{\circ} 1$ Case studies make up

\begin{tabular}{ccccc}
\hline & Location & Stevens house & Jellicoe Towers & Firth house \\
\hline & & $\mathrm{m}^{2}$ & $\mathrm{~m}^{2}$ & $\mathrm{~m}^{2}$ \\
\hline $\mathbf{1}$ & & & \\
\hline $\mathbf{2}$ & Hall & 3.45 & 2.85 & 3.56 \\
$\mathbf{3}$ & Living room area & 14.5 & 14.7 & 23.65 \\
$\mathbf{4}$ & Kitchen area & 9.8 & 18.8 & 21.7 \\
$\mathbf{5}$ & Bathroom 1 & 4.4 & 7.4 & 9 \\
$\mathbf{6}$ & Laundry & 8.2 & 4.7 & 4.2 \\
$\mathbf{7}$ & Bedroom 1 & 7 & 2.5 & 4.7 \\
$\mathbf{8}$ & Bedroom 2 & 7 & 12.8 & 13.8 \\
\hline $\mathbf{9}$ & Bedroom 3 & 5 & 6.4 & 11.3 \\
\hline $\mathbf{1 0}$ & Closets / cabinets & 1.7 & 6.1 & 8.8 \\
\hline $\mathbf{1 1}$ & Bathroom 2 & 4.3 & 2.67 & 3.1 \\
\hline $\mathbf{1 2}$ & Shower & 2.1 & 0 & 0 \\
$\mathbf{1 3}$ & Terrace & 14.6 & 0 & 0 \\
\hline $\mathbf{1 4}$ & Balcony & 1.8 & 0 & 0 \\
\hline $\mathbf{1 5}$ & Others / structure & 19.2 & 2.4 & 0 \\
$\mathbf{1 6}$ & Inner circulation & 13.4 & 27.5 & 14.8 \\
$\mathbf{1 7}$ & Outer circulation & 19.76 & 12.4 & 0 \\
\hline $\mathbf{1 8}$ & Walls (thickness) & 8.3 & 18 & 22.7 \\
\hline $\mathbf{1 9}$ & Wasted space & 1.1 & 20.6 & 0 \\
& & & 0 & 153.5 \\
\hline & Total gross area(*) & 148.75 & & \\
\hline & (*) excluding basement & area & 160.5 & \\
\hline
\end{tabular}

As can be seen, table $\mathrm{N}^{\circ} 1$ shows the case studies' composition. The most important feature demonstrates that spatial structure patterns in all the cases show a wide diversity in house distribution. The graph $\mathrm{N}^{\circ} 1$ shows the case studies' make up. Despite their differences in square meter values, case studies retain the same design pattern for the group of rooms used for public activities, such as the hall, the living room, dining room and kitchen areas in each project. The same occurs with those places destined for sleep. 
Graph $N^{\circ} 1$ Case studies make up

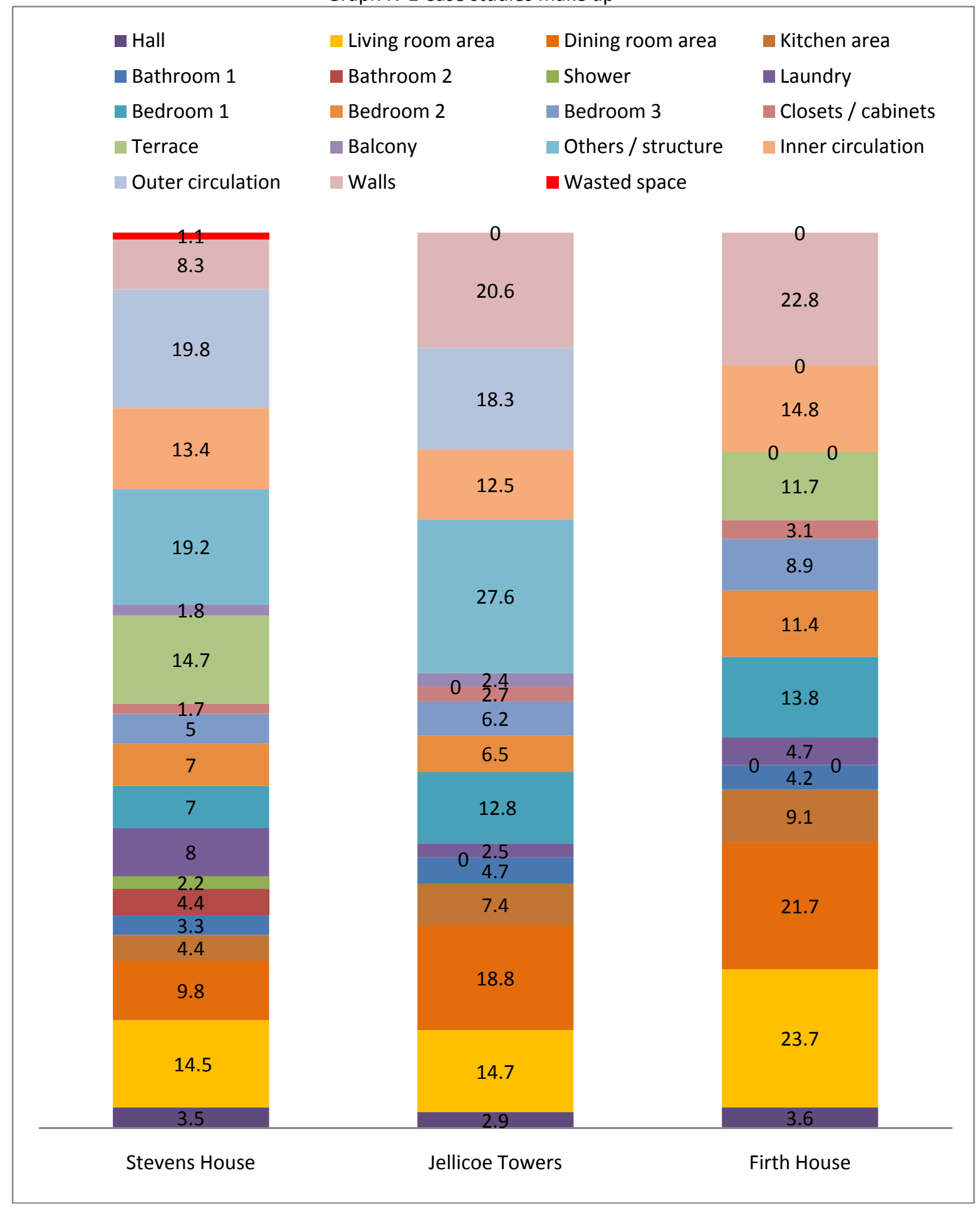




\section{3. - Modeling ALF3 (Annual Loss Factor)}

In order to calculate the energy required for space heating for all these projects, which make up the case studies, the modeling program ALF 3 (or Annual Loss Factor 3) developed under BRANZ (Building Research Association of New Zealand) has been used. In New Zealand homes the most commonly heated room is the living room, which is heated in the evenings in $90 \%$ of houses during weekdays and in $87 \%$ of houses during the weekends of the winter season. ${ }^{6}$ (Discussed in chapter VII)

Most New Zealand households do not heat the house uniformly. However, this constitutes a relevant issue that should be discussed because ALF 3 is a zone model (i.e. treats the entire house as one single heating zone) and as few New Zealand houses are heated uniformly. ${ }^{7}$ As a modeling program, the ALF 3 is a method which considers the effects of insulation, thermal mass and solar overheating. The annual loss factor accounts for the effects of temperature, solar radiation and other climatic parameters. Moreover, climate information of building location is a key parameter of this program. The calculations of floor R-values are separated by construction, as suspended timber floors and slab on grounds have very different thermal characteristics. For roof heat losses, ceiling area will usually be the same as the (internal) floor area. ${ }^{8}$

\subsection{1. - Stevens house}

ALF 3 Model assumptions for the Stevens house: It is located in Wellington city, New Zealand. The total floor area is $89 \mathrm{~m}^{2}$. Internal room height is $2.4 \mathrm{~m}$ and the number of the occupants is estimated as four. The heating schedule has been chosen to be evening heating only between $(17: 00-23: 00 \mathrm{hrs})$ and the heating level is about $18^{\circ} \mathrm{C}$. For floor options, the house has a suspended floor area of $29.5 \mathrm{~m}^{2}$, the perimeter length is $29.1 \mathrm{~m}$, perimeter height is $3.3 \mathrm{~m}^{2}$ and perimeter area is established to be $96 \mathrm{~m}$. The exposed floor (Pole house) option was entered. Floor insulation R- value is 1.3 . Floor covering Rvalue is 0.4 (carpet and underlay). So the total slab floor R-value is 1.7 . For walls, a steel frame has been selected with an insulation R-value of 1.2 and a construction R-value of 1.2. The windows have a single clear glass with aluminum frame (no thermal break). For the roof: a net area of $29 \mathrm{~m}^{2}$ is analyzed. Insulation and construction R-values are set up to give a total of 3.0 which is necessary to achieve the permitted minimum level of overall performance (NZS 4218 schedule method). ${ }^{9}$ For Air Leakage, the option of airtight was chosen and for site exposure, sheltered was selected. For thermal mass in floors an area of $29.5 \mathrm{~m}^{2}$ was entered for all of them and for exterior and interior walls areas of $197.8 \mathrm{~m}^{2}$ were set up.

\footnotetext{
6 French, Camilleri, Isaacs, \& Pollard,(2007, p. 772)

${ }^{7}$ Isaacs, Camilleri, French, \& Pollard, (2005, p. 61)

${ }^{8}$ BRANZ, (1990, pp. 6,8)

${ }^{9}$ BRANZ, (2005, p. 12)
} 


\subsection{2. - Jellicoe Towers}

ALF 3 Model assumptions for the Jellicoe Towers: Jellicoe Towers is located in downtown Wellington city, New Zealand. The total floor area is $118.5 \mathrm{~m}^{2}$. Internal room height is 2.4 $\mathrm{m}$ and the number of the occupants is estimated as four. The heating schedule has been chosen to be evening heating only between (17:00 - 23:00 hrs) and the heating level is about $18^{\circ} \mathrm{C}$. For floor options, and to give comparability with the other case studies, the dwelling is assumed to have a slab on ground floor area of $160.5 \mathrm{~m}^{2}$, (to take account of the circulation space), the perimeter length is $45.9 \mathrm{~m}$, an external wall thickness $0.25 \mathrm{~m}$ and soil conductivity $\left(\mathrm{W} / \mathrm{m}^{\circ} \mathrm{C}\right)$ of 1.2 . Slab and ground R-value of 2.1 is given. Floor covering R-value is $\mathbf{0 . 4}$. So the total slab floor R-value is 2.5 . For walls, a concrete block wall, strapped and lined and internally insulated has been selected with an insulation Rvalue of 0.7 and a construction $R$-value of 0.75 . The windows have a single clear glass with aluminum frame (no thermal break). For the roof: a net area of $160.5 \mathrm{~m}^{2}$ is analyzed, taking account of the circulation space. Insulation and construction R-values are set up to be a total of 3.0 which is necessary to achieve the permitted minimum level of overall performance (NZS 4218 schedule method). ${ }^{10}$ For Air Leakage, the option of average was chosen and for site exposure exposed was selected. For thermal mass in floors an area of $118.5 \mathrm{~m}^{2}$, (area which excludes the circulation space) was entered and for exterior and interior walls areas of $69.6 \mathrm{~m}^{2}$ were set up.

\subsection{3. - Firth house}

ALF 3 Model assumptions for the Firth house: It is located in Wellington city, New Zealand. The total floor area is $128 \mathrm{~m}^{2}$. Internal room height is $2.4 \mathrm{~m}$ and the number of the occupants is estimated to be four. The heating schedule has been chosen to be evening heating only between $(17: 00-23: 00 \mathrm{hrs})$ and the heating level is about $18^{\circ} \mathrm{C}$. For floor options, the house has a suspended floor area of $92.5 \mathrm{~m}^{2}$, the perimeter length is $84.5 \mathrm{~m}$, perimeter height is $2.4 \mathrm{~m}^{2}$ and perimeter area is established to be $203.3 \mathrm{~m}$. The continuous perimeter wall (sheltered) option was entered. Floor insulation R-value is 1.3. Floor covering R-value is 0.4 . So the total suspended floor R-value is 1.75 . (Plus sub Rvalue of 0.05 ). For the timber-based wall, bevel-backed weatherboard with timber framing and internal lining has been selected with an insulation R-value of 1.5 and a construction R-value of 1.68 . The windows have a single clear glass with aluminum frame (no thermal break). For the roof: a net area of $95.1 \mathrm{~m}^{2}$ is analyzed. Insulation and construction Rvalues are set up to be 3.0 which is necessary to achieve the permitted minimum level of overall performance (NZS 4218 schedule method). ${ }^{11}$ For Air Leakage, the option of leaky was chosen (because of timber window frames) and for site exposure medium exposed was selected. For thermal mass in floors an area of $128 \mathrm{~m}^{2}$ was entered and for exterior and interior walls areas of $165.5 \mathrm{~m}^{2}$ were set up.

\footnotetext{
${ }^{10}$ BRANZ, (2005, p. 12)

${ }^{11}$ BRANZ, (2005, p. 12)
} 


\section{4. - House size}

Buildings are classified as being small or large. The definition of a small building is any structure or building with a net lettable area (NLA can be defined as the area for which a tenant could be charged for occupancy under a lease $)^{12}$, no greater than $300 \mathrm{~m}^{2}$. All case studies are considered small buildings, including the Jellicoe Towers, which is in terms of this analysis is considered as only one floor-unit dwelling.

According to (www.demographia.com) compared with international new houses, a New Zealand house averages around 176 square metres, more than two times the space of a new house in England and exactly a third more than a Japanese new home, United States and Australia lead the figure with 203 and 206 square metres for each case. (Discussed in chapter VII)

Figure $N^{\circ} 19$ Comparisons of House Sizes
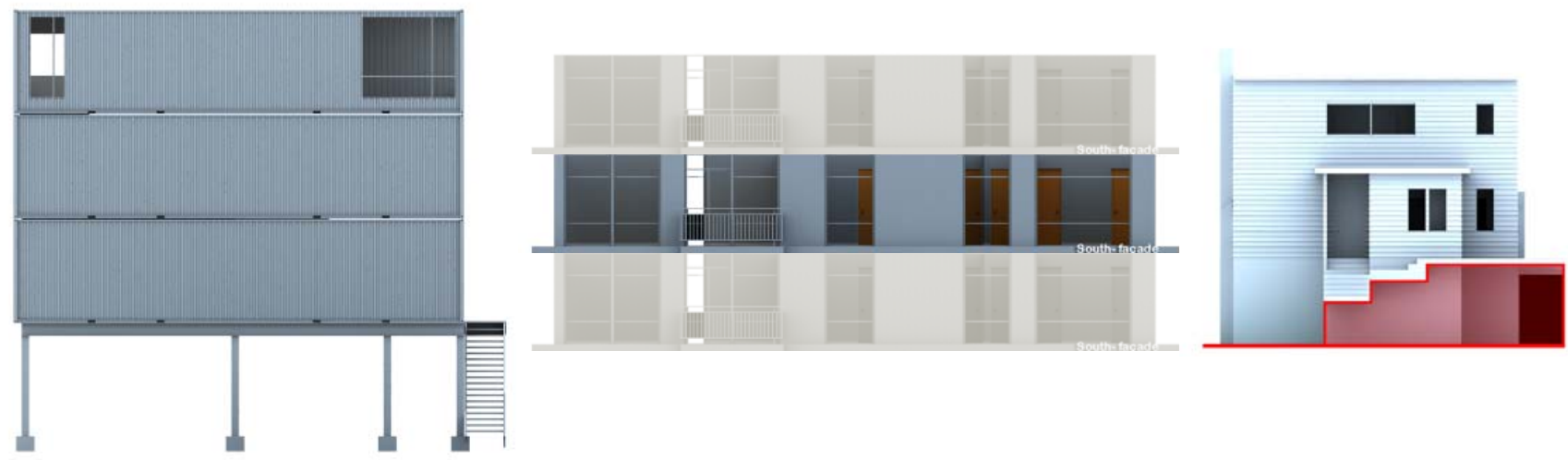

Table $\mathrm{N}^{\circ} 2$ Total and interior useful areas per project

\begin{tabular}{ccccc}
\hline & Location & Stevens house & Jellicoe Towers & Firth house \\
\hline & & $\mathrm{m} 2$ & $\mathrm{~m} 2$ & $\mathrm{~m} 2$ \\
\hline $\mathbf{1}$ & Total gross area & 148.75 & 160.5 & 153.5 \\
$\mathbf{2}$ & Internal useful area & 89 & 118.5 & 128 \\
\hline
\end{tabular}

${ }^{12}$ (www.tefma.com) 
Graph $\mathrm{N}^{\circ} 2$ Total and interior useful areas per project

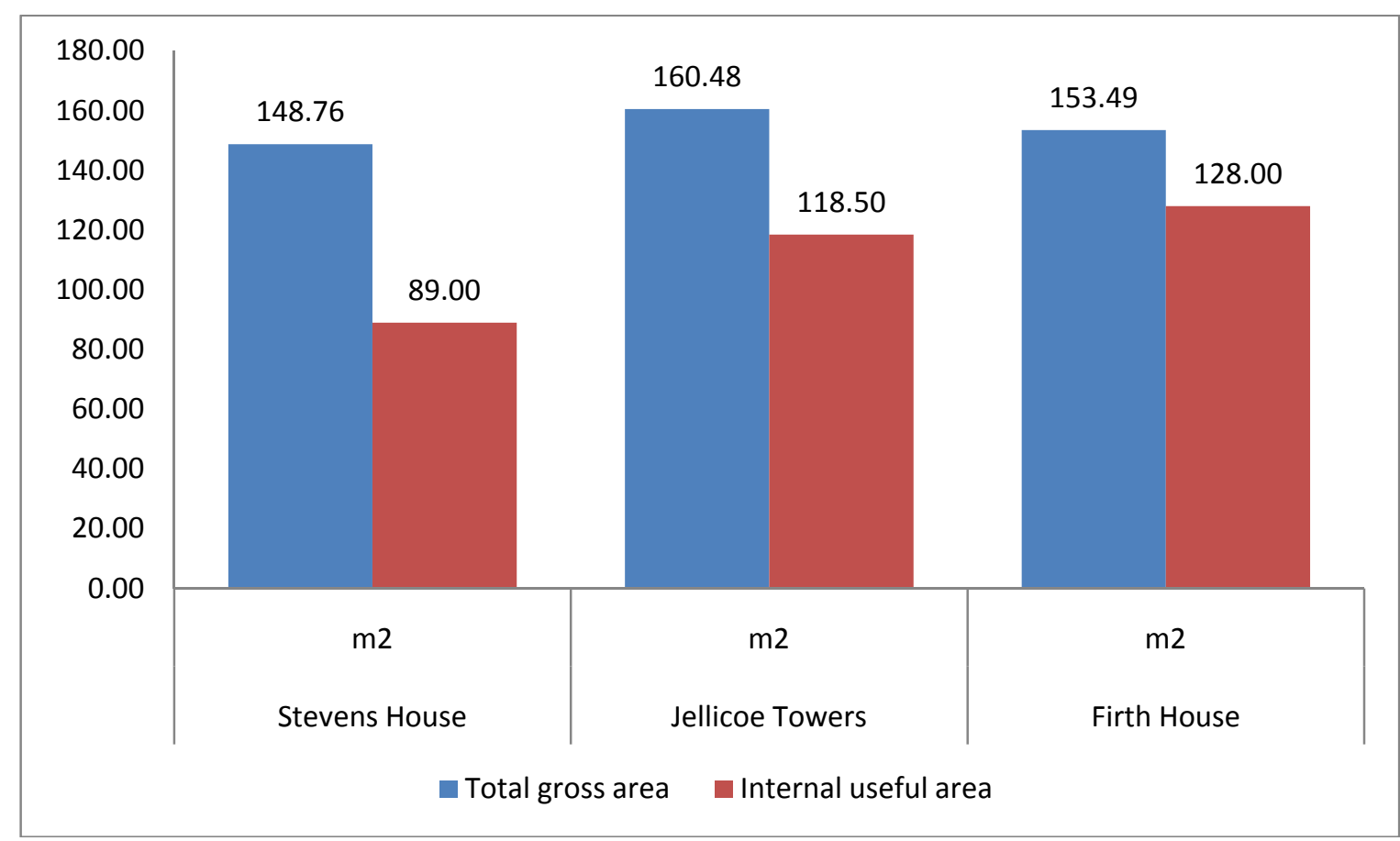

As can be seen in graph $\mathrm{N}^{\circ} 2$, the relationship between the total and internal useful area, in two out of three examples, remain the same pattern. From this graph can be deduced that red columns represent useful floor area and the gap of every house represents external and internal circulations. It can be seen that, with the values given in the case of the Firth house, circulation is relatively small in comparison with the other two samples. However, Stevens house and Jellicoe Towers provide a considerable percentage of their square metres to circulation. Preliminary suggestion that could be drawn is that, on the one hand, Firth house might be spatially more efficient than its compared counterparts. More space destined to circulation means more volume of air and might also mean more loss of energy.

\subsection{1. - Stevens house}

The Stevens house is the smallest among the three examples studied here in both, total gross area and internal useful area.

\subsection{2. - Jellicoe Towers}

One single unit of the Jellicoe Towers is the biggest in terms of total gross area and the second example behind the Firth house related to inner space.

\subsection{3. - Firth house}

The Firth house is the second example in terms of total gross area in square metres and the biggest in internal useful area. 


\section{5. - Exterior envelope and thermal mass}

This topic discusses the diversity of the exterior envelope and thermal mass for the different samples shown here.

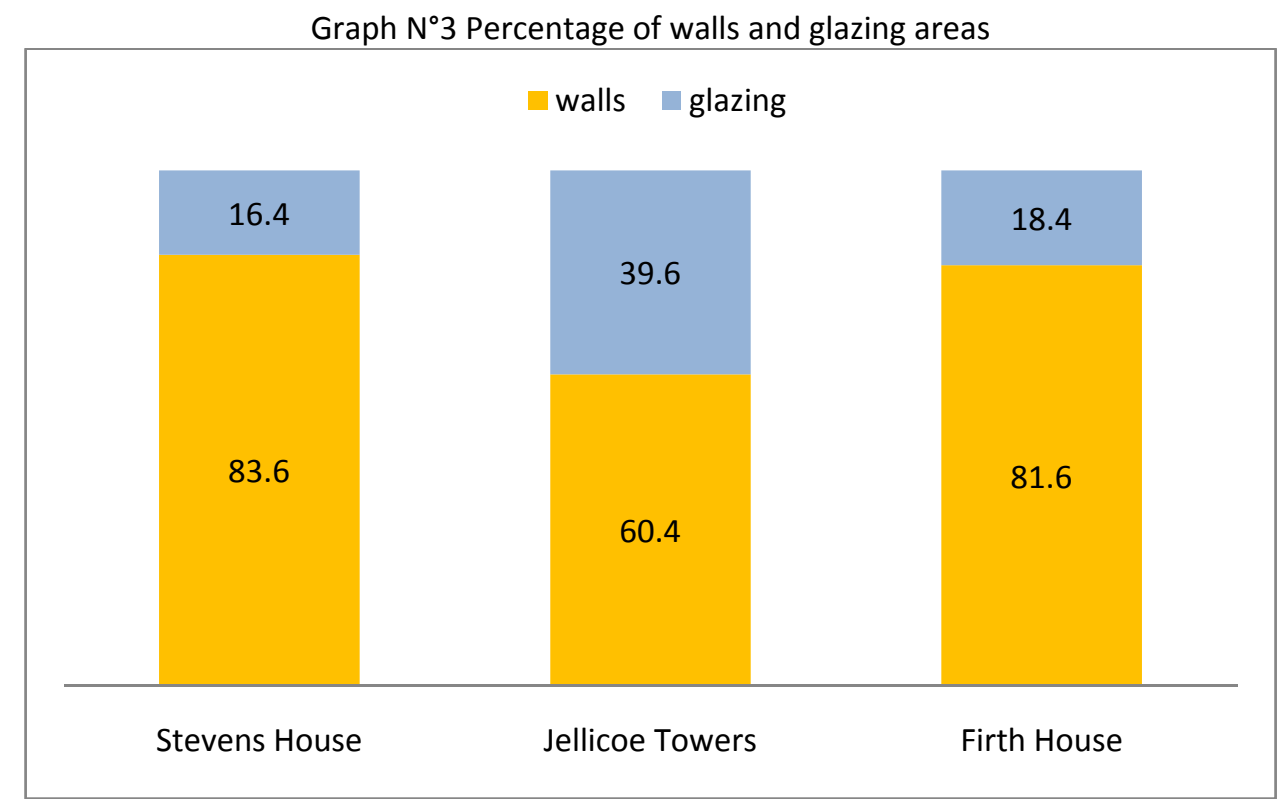

Graph $\mathrm{N}^{\circ} 3$, illustrates the relative percentage of walls and glazing areas. In two, out of the three cases walls overwhelm considerably the space used for windows and glazing areas. The most important feature is that in the cases of the Stevens and the Firth houses glazing percentages do not exceed 20 per cent of the total surface. However, in the case of the Jellicoe Towers (a single unit is taken into account), the glazing area exceeds the $30 \%$ recommended for the Clause $\mathrm{H} 1$ of energy efficiency in the Building Code of New Zealand, reaching $39.2 \%$ of the total surface of the façade.

According to the Department of Building and Housing, (2007, p. 20) table for solid construction (excluding solid timber) note 3 states, "if the sum of the area of glazing on the East, South and West facing walls (see Appendix H of NZS 4218) is more than $30 \%$ of the total area of all of these walls, then the calculation or modelling method shall be used. The verification method $\mathrm{H} 1 / \mathrm{VM} 1$ can be used in a wide range of buildings such is the case of housing, communal residential, communal non residential and commercial structures in order to determine the insulation requirements of the building envelope. ${ }^{13}$

\footnotetext{
${ }^{13}$ Department of Building and Housing, (2007, p. 17)
} 
The remarkable differences within the case studies may be explained by a wide diversity of factors, one of those issues might be a house's major elements and material uses. According to (Mithraratne \& Vale, 2003) for all the construction types, the major elements (floor, walls and roof) collectively represent the bulk of the life cycle energy (34\%, 43\% and $38 \%$ ) of the New Zealand house. On the other hand, for ISO shipping containers, only in terms of surface, the walls represent $50 \%$ of the whole structure. (Discussed in chapter three)

\subsection{1. - Stevens house}

Stevens house is made up by three 40 -foot high cube shipping containers; only walls correspond to $83.6 \%$ of the total surface of the house, (see graph $\mathrm{N}^{\circ} 3$ ). Moreover, steel is a poor material in terms of R-Value. With walls with a limited amount of insulation the loss and gain of heat and consequently energy end use may be great.

\subsection{2. - Jellicoe towers}

The Jellicoe Towers apartments are made of reinforced concrete and glass, a mixture of high and low thermal mass material. Probably due to its high percentage of glazing areas (more than 30\%), heating energy-is likely to be relatively high.

\subsection{3. - Firth house}

In terms of heating energy consumption the Firth house is the most similar to standard New Zealand construction and may therefore be the most efficient house of the group of examples.

Table $\mathrm{N}^{\circ} 3$ Walls and glazing areas per project

\begin{tabular}{cccc}
\hline $\mathbf{m}^{\mathbf{2}}$ & Stevens house & Jellicoe Towers & Firth house \\
\hline walls & 197.8 & 69.6 & \\
glazing & 38.9 & 45.7 & 165.9 \\
\hline
\end{tabular}

Table $\mathrm{N}^{\circ} 3$ shows the walls and glazing areas make up of all case studies. 
Graph $\mathrm{N}^{\circ} 4$ Walls and glazing areas per project in square metres.

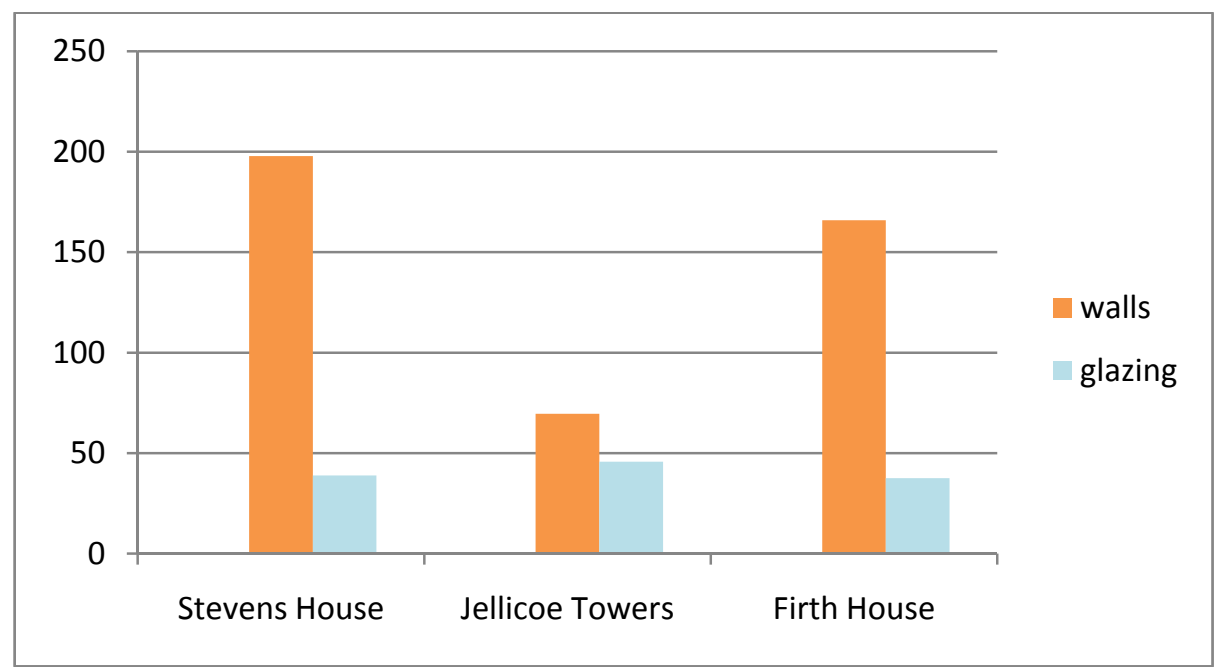

Graph $N^{\circ} 4$, shows the relationship of wall surface versus glazing area surface. The sums of these two elements -walls and glazing areas- compose the total vertical surface areas of the case studies (not the roof and floor though, which are also surface areas). The most important feature is the strong difference between the projects. The Stevens and the Firth Houses have similar wall and glazing composition patterns. On the other hand, Jellicoe Towers has completely different features.

\section{6. - Thermal insulation of the envelope}

These three case studies are made of three different building materials. These materials have different thermal masses, with different physical features to protect them against weather conditions and solar overheating. The consequences of these factors produce strong differences in the consumption of energy in each building. It is possible that Jellicoe Towers has only a solid $200 \mathrm{~mm}$ concrete wall and no insulation, and it is also possible that Firth House has no insulation, as both these projects were constructed before the Building Code required insulation. It has been assumed, to allow a comparison between buildings constructed at different dates that all three case studies have been insulated in accordance with the current requirements of the Building Code. 


\subsection{1. - Stevens house}

Figure $\mathrm{N}^{\circ} 20$ Thermal insulation of the envelope

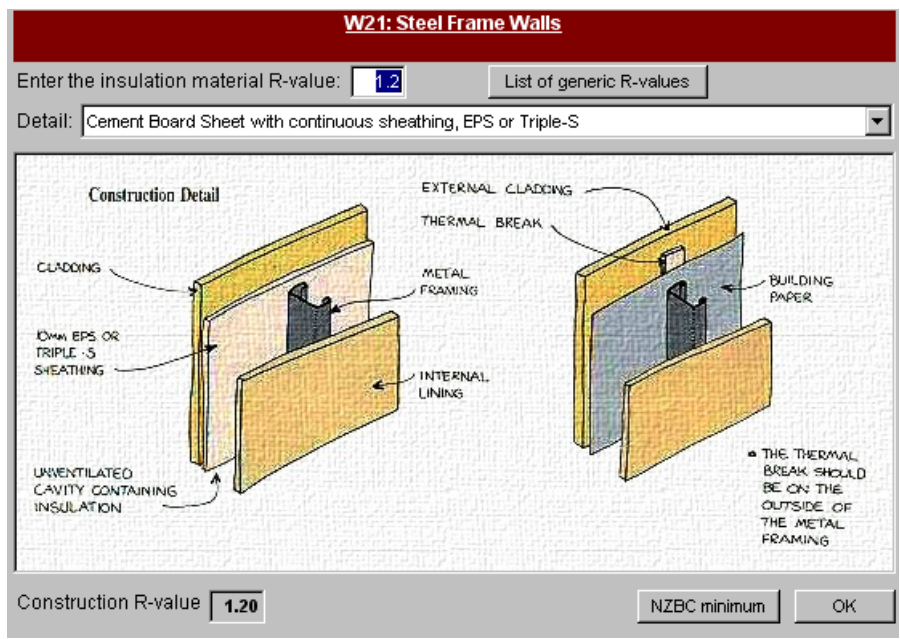

9.6.2. - Jellicoe towers

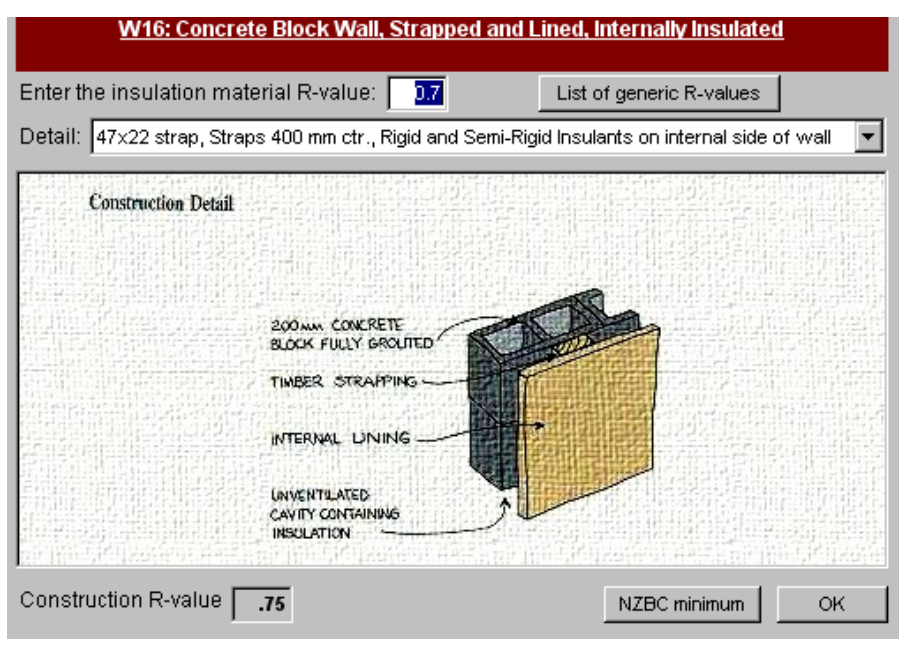

9.6.3. - Firth house

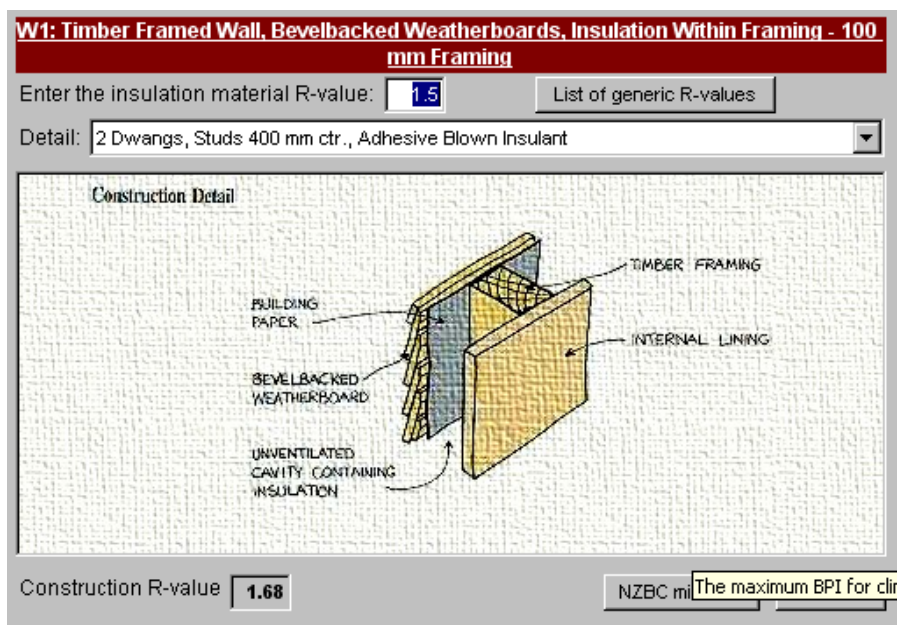

Even though the ALF 3 program lacks the option of steel corrugated walls, there is the possibility to customise it. Again, the main insulation component of the steel walls in the container house is a FRP, or Fiberglass Reinforced Panel, which covers the walls and the ceiling of these trade boxes. Its $\mathrm{R}$ value is 1.2 ( 7 in American units).

The Jellicoe Towers project may represent one of the Modern Movement iconic buildings in Wellington. Like most of its counterparts of this period of time in the architectural history structures were made by using reinforced concrete, steel and glass. The assumption of the ALF 3 program is the option of $200 \mathrm{~mm}$ concrete fully grouted with internal lining with an unventilated cavity containing the insulation.

The Firth House represents the most common type of timber-based structures among the case studies for New Zealand. The program gives the option -for at least- fifteen different wooden based cladding alternatives. It was chosen as timber framing with internal lining, bevelbacked weatherboard and an unventilated cavity which contains the insulation. 


\section{7. - Embodied energy}

9.7.1. - Stevens house

9.7.2. - Jellicoe towers

9.7.3. - Firth house

Table $\mathrm{N}^{\circ} 4$ Construction materials used in different case studies

\begin{tabular}{|c|c|c|c|c|}
\hline & $\begin{array}{c}170 \mathrm{~m} 2 \text { average } \\
\text { house }\end{array}$ & Stevens house & Jellicoe Towers & Firth house \\
\hline Floor area $\mathrm{m} 2$ & 170 & 89 & 119 & 128 \\
\hline Stories & 1 & 3 & 1 & 2 \\
\hline Lifetime & 100 years & 100 years & 100 years & 100 years \\
\hline Average electricity & $8,000 \mathrm{kWh} /$ year & $8,000 \mathrm{kWh} /$ year & $8,000 \mathrm{kWh} /$ year & $8,000 \mathrm{kWh} /$ year \\
\hline Location & Wellington & Wellington & Wellington & Wellington \\
\hline \multicolumn{5}{|l|}{ Foundation } \\
\hline Concrete & $40,000 \mathrm{~kg}$ & $4,600 \mathrm{~kg}\left({ }^{* *}\right)$ & $28,000 \mathrm{~kg}\left({ }^{*}\right)$ & $30,117 \mathrm{~kg}\left({ }^{*}\right)$ \\
\hline Steel wire & $800 \mathrm{~kg}$ & $92 \mathrm{~kg}\left({ }^{*}\right)$ & $560 \mathrm{~kg}\left({ }^{*}\right)$ & $602 \mathrm{~kg}\left({ }^{*}\right)$ \\
\hline \multicolumn{5}{|l|}{ Floors } \\
\hline Concrete & 0 & 0 & $96,300 \mathrm{~kg}$ & 0 \\
\hline Epoxy resin & $50 \mathrm{~kg}$ & $26.2 \mathrm{~kg}\left({ }^{*}\right)$ & $35 \mathrm{~kg}\left({ }^{*}\right)$ & $38 \mathrm{~kg}\left({ }^{*}\right)$ \\
\hline Carpet & $250 \mathrm{~kg}$ & $131 \mathrm{~kg}\left({ }^{*}\right)$ & $175 \mathrm{~kg}\left({ }^{*}\right)$ & $188 \mathrm{~kg}\left({ }^{*}\right)$ \\
\hline \multicolumn{5}{|l|}{ Walls } \\
\hline Steel & 0 & $11,700 \mathrm{~kg}$ & 0 & 0 \\
\hline Concrete Block & 0 & 0 & $92,160 \mathrm{~kg}(* * * *)$ & 0 \\
\hline Timber cladding & $1,300 \mathrm{~kg}$ & 0 & 0 & $979 \mathrm{~kg}\left({ }^{*}\right)$ \\
\hline Timber framing & $200 \mathrm{~kg}$ & 0 & 0 & $150.5 \mathrm{~kg}\left({ }^{*}\right)$ \\
\hline Glass fibre insulation & $200 \mathrm{~kg}$ & 0 & $140 \mathrm{~kg}(*)$ & $150.5 \mathrm{~kg}\left({ }^{*}\right)$ \\
\hline Gypsum board & $850 \mathrm{~kg}$ & 0 & $595 \mathrm{~kg}\left({ }^{*}\right)$ & $640 \mathrm{~kg}\left({ }^{*}\right)$ \\
\hline Paint & $90 \mathrm{~L}$ & $47 L^{(*)}$ & $63 L\left(^{*}\right)$ & $68 \mathrm{~L}\left(^{*}\right)$ \\
\hline FRP & 0 & $2,890 \mathrm{~kg}\left(\left(^{*}\right)\right)$ & 0 & 0 \\
\hline \multicolumn{5}{|l|}{ Windows } \\
\hline Glass & $400 \mathrm{~kg}$ & $583.5 \mathrm{~kg}(* * * * *)$ & $685.5 \mathrm{~kg}(* * * * *)$ & $562.5 \mathrm{~kg}(* * * *)$ \\
\hline Aluminium framing & $100 \mathrm{~kg}$ & $133.9 \mathrm{~kg}\left({ }^{*}\right)$ & $171 \mathrm{~kg}\left({ }^{*}\right)$ & $140 \mathrm{~kg}\left({ }^{*}\right)$ \\
\hline \multicolumn{5}{|l|}{ Ceiling and roof } \\
\hline Timber framing & $300 \mathrm{~kg}$ & 0 & 0 & $226 \mathrm{~kg}\left({ }^{*}\right)$ \\
\hline Glass fibre insulation & $150 \mathrm{~kg}$ & 0 & 0 & $113 \mathrm{~kg}\left({ }^{*}\right)$ \\
\hline Gypsum board & $1,000 \mathrm{~kg}$ & 0 & 0 & $753 \mathrm{~kg}\left({ }^{*}\right)$ \\
\hline Paint & $40 \mathrm{~L}$ & $21 L^{(*)}$ & $28 L^{(*)}$ & $30 \mathrm{~L}(*)$ \\
\hline Concrete roof tiles & $5,000 \mathrm{~kg}$ & 0 & 0 & $3,765 \mathrm{~kg}\left({ }^{*}\right)$ \\
\hline FRP & 0 & $395 \mathrm{~kg}\left(\left(^{*}\right)\right)$ & 0 & 0 \\
\hline
\end{tabular}


Table $\mathrm{N}^{\circ} 4$ construction materials used in different case studies (continuation)

\begin{tabular}{ll}
\hline$(*)$ & $\begin{array}{l}\text { proportional to the Gabi } \\
\text { house }\end{array}$ \\
\hline$(* *)$ & $\begin{array}{l}2,300 \mathrm{~kg} / \mathrm{m} 3 \text { conventional concrete density for } \\
\text { foundations }\end{array}$ \\
$(* * *)$ & $\begin{array}{l}3,900 \mathrm{~kg} \text { each empty } 40 \text {-foot } \\
\text { container }\end{array}$ \\
$(* * * *)$ & $\begin{array}{l}2,400 \mathrm{~kg} / \mathrm{m} 3 \text { conventional } \\
\text { concrete density }\end{array}$ \\
$(* * * * *)$ & $\begin{array}{l}2,500 \mathrm{~kg} / \mathrm{m} 3 \text { conventional } \\
\text { glass density }\end{array}$ \\
$(* * * * *)$ & $\begin{array}{l}\text { the roof of any } 40-\text { foot container represents } 23 \% \text { of area it is assumed that this percentage is } 23 \% \text { of } \\
\text { the weight of the container due to its uniformity }\end{array}$ \\
$((*))$ & $\begin{array}{l}\text { FRP is defined by a density of greater or equal to } \\
1,850 \mathrm{~kg} / \mathrm{m} 3 .\end{array}$ \\
\hline
\end{tabular}

In order to calculate the total energy consumption (embodied, maintenance, operating, demolition) and the total $\mathrm{CO}_{2}$ emissions for the cases studies Gabi software will be used. For the calculation of space heating ALF 3 will be used (explained before see page 201). A Gabi example house has been introduced to set up a benchmark within the rest of the dwellings assessed here to make a fair and more accurate comparison. However, Gabi is a software which uses a European database for its calculations. In contrast to ALF 3 this program at first sight seems to be much more complex. The calculations in Gabi are related to "flows" of inputs/outputs that are tracked by the program automatically and providing the energy consumed in all processes involved for a specific product or service. This means that for an LCA of a house, energy consumption, emissions of $\mathrm{CO}_{2}$, monetary values, working times and many other data can be assessed by using this platform. On the other hand, Gabi does not evaluate location of projects. Likewise, houses are assessed for a lifespan of 100 years. The assumed average electricity use per year is 8,000 kWh (discussed in chapter seven).

As can be seen Table $\mathrm{N}^{\circ} 4$ shows a series of building materials used for the foundations, floors, walls, windows and roofs/ceilings in four constructions. The Gabi house is an example of the program in which inputs like the primary energy used in the elaboration of a specific material and outputs like the $\mathrm{CO}_{2}$ emissions produced in the process are given. (This example is a model too and is not based on a real house). For foundations, the amount of material used in the Stevens house was directly calculated. For the Jellicoe Towers unit and the Firth house foundations were calculated in proportion to the Gabi house example. It was the same for floors. For the walls, the Stevens house and the Jellicoe Towers dwelling were calculated directly from the 3D models made in AutoCAD ${ }^{\mathrm{TM}}$ before. The timber cladding and the timber framing of The Firth house were estimated in proportion to the Gabi house. The Stevens house does not use glass fibre insulation (it uses FRP). The other two case studies which use glass fibre insulation were estimated according to the Gabi house again. 
For the calculations of the amount of FRP within the containers, some proportions studied in chapter three were used. The Gabi program does not have information related to FRP. The density of this material was found on the internet. This website: http://www.freepatentsonline.com/4082882.pdf provides some information about the composition of a typical FRP sandwich wall. This second website: http://www.boedeker.com/durost p.htm sets up the density of a Fiberglass Reinforced Plastic, similar material to the FRP. The density given is $1.85 \mathrm{~g} / \mathrm{cm}^{3}$ or $1,850 \mathrm{~kg} / \mathrm{m}^{3}$ and the standard thickness are 0.118", 0.157", 0.197", 0.236", 0.315", 0.394" and 0.472". However, the lack of reliable data potentially could bring some errors in the final assessment. This particular issue may not have any major incidence in the final outcome of the research.

..."The conventional FRP fiberglass reinforced plastic plywood sandwich consists essentially of a layer of gel coat, a standard generally white pigmented composition comprised of polyester-orthophthalic polymer resin comprised of a polymer of propylene glycol, maleic anhydride and phthalic anhydride and additives, a layer of fiberglass on the resin, the entire unit becoming, in the processing thereof, an integrated composite unit."14

9.8. - Total embodied and operating energy consumption

9.8.1. - Stevens house

9.8.2. - Jellicoe towers

9.8.3. - Firth house

Table $\mathrm{N}^{\circ} 5$ Total energy consumption

\begin{tabular}{ccc}
\hline & Energy (net calorific value) & Energy per square meter \\
\hline Gabi Example house & GJ & $\mathrm{GJ} / \mathrm{m}^{2}$ \\
\hline Stevens house & 3,372 & 19.8 \\
& & 37.6 \\
\hline Jellicoe Towers & 3,345 & 29.4 \\
\hline Firth house & 3,495 & \\
\hline
\end{tabular}

Table $\mathrm{N}^{\circ} 5$ shows the Total consumption of energy per project. The highest figure corresponds to the Jellicoe Towers apartment with 3,495 GJ, followed by the Stevens house with 3,345 GJ and the Firth house with 3,362 GJ.

\footnotetext{
${ }^{14}$ http://www.freepatentsonline.com/4082882.pdf
} 
9.9. - Space heating

Graph $\mathrm{N}^{\circ} 5$ Case studies space heating energy required in kWh/year

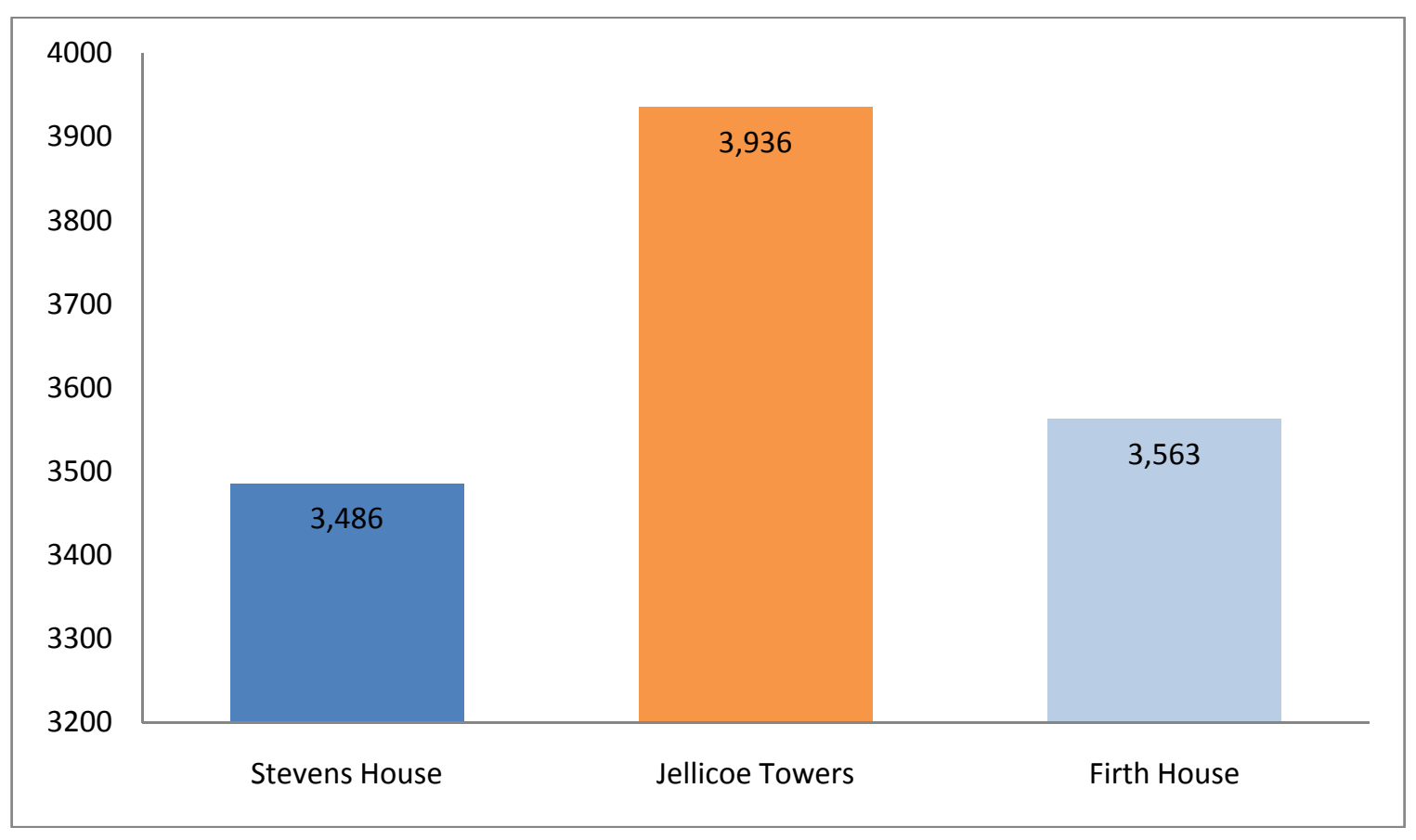

About a third of total energy consumed in New Zealand residential buildings is used to heat space. ${ }^{15}$ In addition, the case study houses were calculated for an internal temperature of $18^{\circ} \mathrm{C}$, which is recommended by the World Health Organisation. ${ }^{16}$ Graph $\mathrm{N}^{\circ} 5$ shows the case studies' energy required for space heating. The first case, the container house requires less energy in order to heat its space in contrast with the Jellicoe Towers and uses less energy in comparison with the Firth house as well. Its energy consumption represents the lowest figure among the examples reaching 3,486 kWh/year, which is less than a Jellicoe Towers' single dwelling unit, which uses 3,936 kWh/year. Finally, the second most efficient project is the Firth house, which consumes 3,563 kWh/year. The result showed by ALF 3 was calculated for a life cycle expectancy of the project for 30 years.

\footnotetext{
${ }^{15}$ Department of Building and Housing, (2007, p. 12)

${ }^{16}$ French, Camilleri, Isaacs, \& Pollard, (2007)
} 
Graph $N^{\circ} 6$ Case studies space heating energy required per square meter

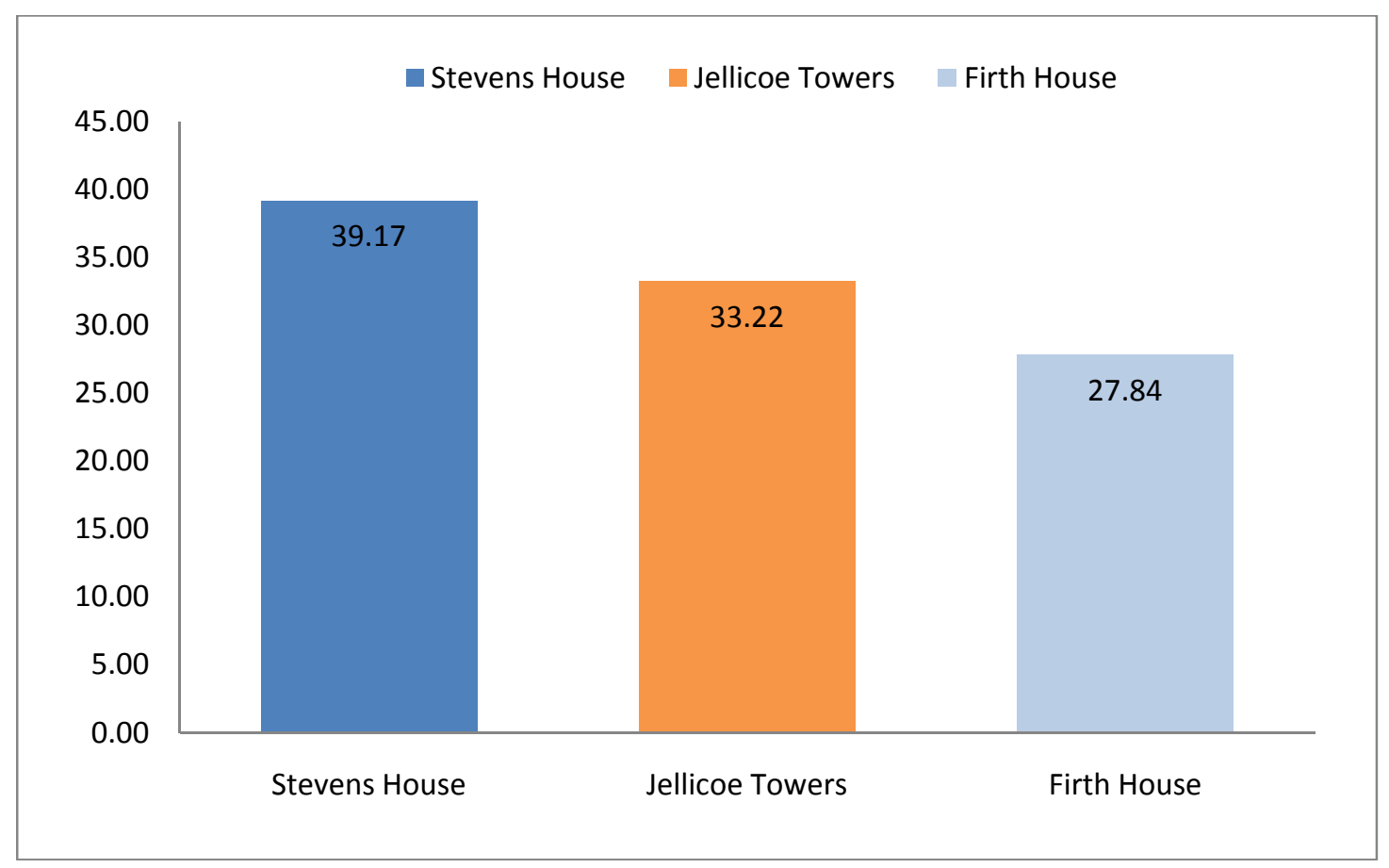

Table $N^{\circ} 6$ Case studies space heating energy required per square meter

\begin{tabular}{cccc}
\hline & Stevens house & Jellicoe Towers & Firth house \\
\hline Required Energy Heating $(\mathbf{k W h} /$ year $)$ & & & \\
Internal useful area $\left(\mathbf{m}^{2}\right)$ & 3,486 & 3,936 & 3,563 \\
& 89 & 118.5 & 128 \\
\hline Total Energy Heating divided per square meter & 39.17 & 33.22 & 27.84 \\
\hline$\left(\mathbf{k W h} / \mathrm{m}^{2} /\right.$ year) & $\left(\mathrm{kWh} / \mathrm{m}^{2} /\right.$ year $)$ & $\left(\mathrm{kWh} / \mathrm{m}^{2} /\right.$ year $)$ & $\left(\mathrm{kWh} / \mathrm{m}^{2} /\right.$ year $)$ \\
\hline
\end{tabular}

As can be seen in graph $\mathrm{N}^{\circ} 6$ which shows the energy required per square metre related to the space heating among the examples, the Stevens house has the biggest consumption of energy with $39.17 \mathrm{kWh} /$ year $/ \mathrm{m}^{2}$, followed by the Jellicoe Towers with $33.22 \mathrm{kWh} / \mathrm{m}^{2} /$ year and finally the Firth house with $27.84 \mathrm{kWh} / \mathrm{m}^{2} /$ year.

9.9.1. - Stevens house has $39.17 \mathrm{kWh} / \mathrm{m}^{2} /$ year and 3,486 $\mathrm{kWh} /$ year.

9.9.2. - Jellicoe Towers unit has $33.22 \mathrm{kWh} / \mathrm{m}^{2} /$ year and 3,936 $\mathrm{kWh} /$ year the highest energy consumption among the three case studies.

9.9.3. - Firth house has $27.84 \mathrm{kWh} / \mathrm{m}^{2} /$ year and 3,563 $\mathrm{kWh} /$ year. The lowest figure total energy consumption per square metre. 


\subsection{0. - Energy end use}

The biggest figure of the energy end-use in average New Zealand houses is associated with hot water representing one of the main drivers of the total consumption of power. The second largest is space heating, consuming around $22 \%$ of the total energy used in households. The rest of the energy can be divided among other uses, this mean, the energy use for cooking, for lighting, for equipment and appliances.

9.10.1 - Water heating

9.10.2 - Cooking energy

9.10.3 - Lighting energy

9.10.4 - Refrigerators and freezers energy use

9.10.5 - Domestic appliance energy use

The discussion of the energy consumed in a specific space can be centered under physical and objective approaches. But it is not the aim and scope of this research to discuss about behaviors of the people and this is why the rest of energy end-use will be estimated at the same level for the three case studies.

Table $\mathrm{N}^{\circ} 7$ and pie chart $\mathrm{N}^{\circ} 1$ Energy end use in New Zealand houses in 2003

\begin{tabular}{|cc|}
\hline Energy use & $\%$ \\
\hline Hot water & 29 \\
\hline Space heating & 22 \\
\hline Lighting & 11 \\
\hline Refrigeration & 10 \\
\hline Cooking (inc. range) & 8 \\
\hline Large Misc. & 3 \\
\hline Entertainment & 3 \\
\hline Other & 5 \\
\hline Unassigned & 9 \\
\hline
\end{tabular}

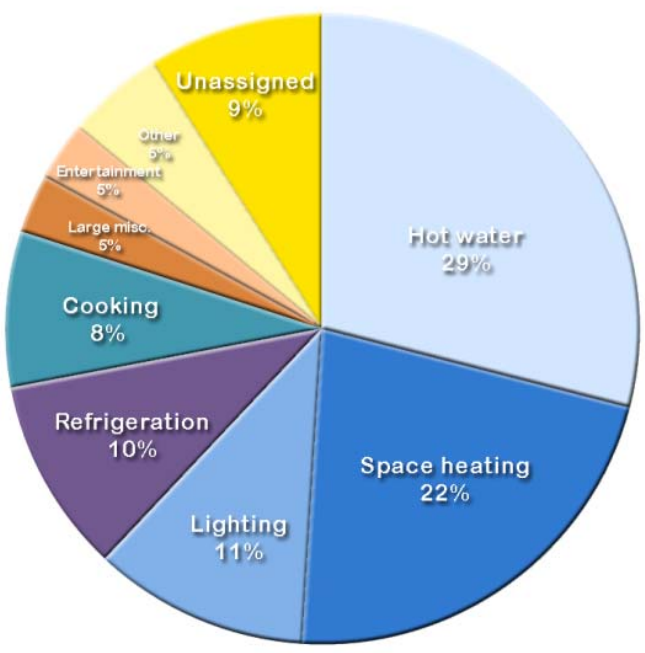

Source BRANZ: (2003, p. ii) 


\subsection{1. - Recurrent embodied energy}

9.11.1. - Stevens house

9.11.2. - Jellicoe towers

9.11.3. - Firth house

Table $\mathrm{N}^{\circ} 8$ below shows the amount of building materials used in the maintenance of every case study. The values in the first column were given through the Gabi house example, the conditions are: a $170 \mathrm{~m}^{2}$ wooden house with concrete slab foundation with timber cladding and concrete roof tiles. Life cycle of the house has been set up at 100 years. The replacement time and the amount of each material are dissimilar. For example, in the construction stage of the Gabi house $5,000 \mathrm{~kg}$ of concrete roof tiles were used and its replacement time is around 50 years, this means, one replacement of another $5,000 \mathrm{~kg}$ of this element through the 100 years lifespan of the house. The Stevens house and the Jellicoe Towers unit do not use concrete roof tiles. The symbol (*) means that materials used in the maintenance are in proportion to the Gabi house example. The symbol $(* * * * * *)$ means that the amount of material calculated is related to the proportion of the roof of any 40 -foot container, which represents $23 \%$ (discussed in chapter three) of area and it is assumed that this percentage is $23 \%$ of the weight of the container due to its uniformity in the constitution of the steel box.

Table $N^{\circ} 8$ Maintenance stage of case studies

\begin{tabular}{|c|c|c|c|c|}
\hline Maintenance & $\begin{array}{c}170 \mathrm{~m}^{2} \text { average } \\
\text { house }\end{array}$ & Stevens house & Jellicoe Towers & Firth house \\
\hline \multicolumn{5}{|l|}{ Floors } \\
\hline Epoxy resin & $500 \mathrm{~kg}$ & $268 \mathrm{~kg}\left({ }^{*}\right)$ & $350 \mathrm{~kg}(*)$ & $376 \mathrm{~kg}(*)$ \\
\hline Carpet & $1,250 \mathrm{~kg}$ & $654 \mathrm{~kg}\left({ }^{*}\right)$ & $875 \mathrm{~kg}(*)$ & $941 \mathrm{~kg}\left({ }^{*}\right)$ \\
\hline \multicolumn{5}{|l|}{ Walls (exterior) } \\
\hline Paint & $450 \mathrm{~L}$ & $236 L(*)$ & $315 L(*)$ & 339 L (*) \\
\hline \multicolumn{5}{|l|}{ Ceiling and roof } \\
\hline $\begin{array}{c}\text { Concrete roof } \\
\text { tiles }\end{array}$ & $5,000 \mathrm{~kg}$ & 0 & 0 & $3,765 \mathrm{~kg}(*)$ \\
\hline Steel roof & 0 & $897 \mathrm{~kg}(* * * * * *)$ & 0 & 0 \\
\hline
\end{tabular}


9.12. - $\mathrm{CO}_{2}$ emissions

9.12.1. - Stevens house

9.12.2. - Jellicoe towers

9.12.3. - Firth house

Table $\mathrm{N}^{\circ} 9$ Life cycle analysis in the operation stage $\%$ of $\mathrm{CO}_{2}$ emissions to air

\begin{tabular}{ccccc}
\hline$\%$ of $\mathrm{CO}_{2}$ & Gabi example house & Stevens house & Jellicoe Towers & Firth house \\
\hline emissions to air & house life cycle & house life cycle & house life cycle & house life cycle \\
operation & operation & operation & operation \\
& 75.9 & 52.4 & 50.4 & 80.0 \\
\hline
\end{tabular}

As can be seen, table $\mathrm{N}^{\circ} 9$ shows the life cycle analysis in the operation stage for all case studies. The Gabi example is the benchmark between the modelling program and the case studies. The most important feature is that -in terms of $\mathrm{CO}_{2}$ emissions- the Gabi example and the Firth house produce near to $75-80 \%$ of the total amount of carbon dioxide release to the atmosphere in the operation stage. On the other hand, the container house and the Jellicoe Towers single unit dwelling produce slightly less than half of the total amount of carbon dioxide in the operation stage of the LCA through its lifespan.

Graph $\mathrm{N}^{\circ} 7$ Case studies: $\mathrm{CO}_{2}$ produced in operation and other stages

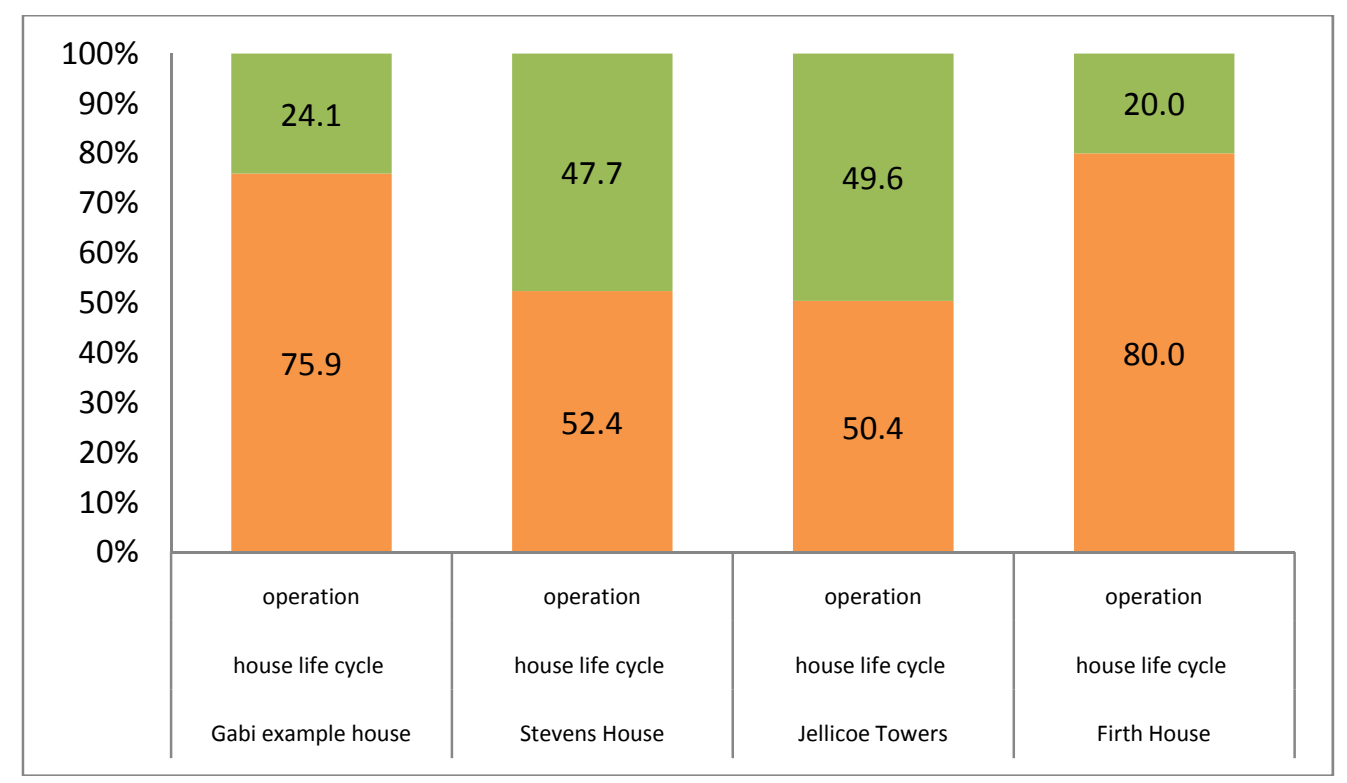

Graph $\mathrm{N}^{\circ} 7$ shows the Case studies and the percentage of $\mathrm{CO}_{2}$ produced in operation and other stages. In the case of the Stevens house, this is an unexpected outcome in contrast 
with the other timber houses that show a consistent pattern of carbon dioxide production. Possible reasons for this may be the high amount of $\mathrm{CO}_{2}$ emissions in the production of steel and cement.

According to (Mithraratne \& Vale, 2003) Virgin Aluminium has $35943 \mathrm{~kg} / \mathrm{m}^{3}$, virgin and general steel has $3790 \mathrm{~kg} / \mathrm{m}^{3}$, concrete block has about $486 \mathrm{~kg} / \mathrm{m}^{3}$ and most of the timber has negative values.

Table $\mathrm{N}^{\circ} 10$ Life cycle analysis broken down in the construction stage in $\mathrm{kg}$ of $\mathrm{CO}_{2}$

\begin{tabular}{|c|c|c|c|c|c|c|c|c|c|}
\hline & & & $\begin{array}{l}\text { house life } \\
\text { cycle }\end{array}$ & $\begin{array}{l}\text { house life } \\
\text { cycle }\end{array}$ & $\begin{array}{l}\text { house life } \\
\text { cycle }\end{array}$ & $\begin{array}{l}\text { house life } \\
\text { cycle }\end{array}$ & $\begin{array}{l}\text { house life } \\
\text { cycle }\end{array}$ & $\begin{array}{l}\text { house life } \\
\text { cycle }\end{array}$ & $\begin{array}{l}\text { house life } \\
\text { cycle }\end{array}$ \\
\hline & & & Total & construction & construction & construction & construction & construction & construction \\
\hline & & & & & $\begin{array}{l}\text { ceiling and } \\
\text { roof }\end{array}$ & floors & foundation & walls & windows \\
\hline $\begin{array}{l}\text { Gabi Example } \\
\text { house }\end{array}$ & Flows & $\begin{array}{l}\text { Emissions to } \\
\text { air }\end{array}$ & 299,571 & 12,958 & 718 & 3,074 & 6,680 & 1,039 & 1,447 \\
\hline $\begin{array}{l}\text { Stevens } \\
\text { house }\end{array}$ & Flows & $\begin{array}{l}\text { Emissions to } \\
\text { air }\end{array}$ & 435,108 & 173,976 & 45,289 & 1,611 & 768 & 124,322 & 1,975 \\
\hline $\begin{array}{l}\text { Jellicoe } \\
\text { Towers }\end{array}$ & Flows & $\begin{array}{c}\text { Emissions to } \\
\text { air }\end{array}$ & 451,798 & 39,704 & 58 & 17,367 & 4,676 & 15,127 & 2,476 \\
\hline Firth house & Flows & $\begin{array}{l}\text { Emissions to } \\
\text { air }\end{array}$ & 284,743 & 10,696 & 541 & 2,315 & 5,029 & 783 & 2,028 \\
\hline
\end{tabular}

Table $\mathrm{N}^{\circ} 10$ shows the Life cycle analysis broken down into the construction stage. Again, the values shown in the first column represent the total amount of $\mathrm{CO}_{2}$ emissions. The second column represents the construction stage of all case studies. These values have been calculated by using Gabi software. The Gabi house is the benchmark. The Stevens house has the highest production of carbon dioxide among the all cases, especially in the construction of the walls. For the foundations, all samples have a linear performance. For the floors, case studies in contrast with the Gabi example show a significant reduction of $\mathrm{CO}_{2}$ produced. 
Table $\mathrm{N}^{\circ} 11$ Life cycle analyses broken down into the maintenance stages in $\mathrm{kg}$ of $\mathrm{CO}_{2}$

\begin{tabular}{|c|c|c|c|c|c|c|}
\hline & & & $\begin{array}{c}\text { house life } \\
\text { cycle }\end{array}$ & house life cycle & house life cycle & house life cycle \\
\hline & & & maintenance & maintenance & maintenance & maintenance \\
\hline & & & & $\begin{array}{c}\text { floor } \\
\text { maintenance }\end{array}$ & $\begin{array}{c}\text { roof } \\
\text { maintenance }\end{array}$ & $\begin{array}{c}\text { wall } \\
\text { maintenance }\end{array}$ \\
\hline $\begin{array}{c}\text { Gabi Example } \\
\text { house }\end{array}$ & Flows & Emissions to air & 19,811 & 17,560 & 1,315 & 936 \\
\hline Stevens house & Flows & Emissions to air & 17,846 & 7,210 & 10,145 & 491 \\
\hline Jellicoe Towers & Flows & Emissions to air & 23,092 & 12,292 & 10,145 & 655 \\
\hline Firth house & Flows & Emissions to air & 14,911 & 13,216 & 990 & 705 \\
\hline
\end{tabular}

Graph $\mathrm{N}^{\circ} 8$ Life cycle analysis broken down into the maintenance stages in $\mathrm{kg}$ of $\mathrm{CO}_{2}$

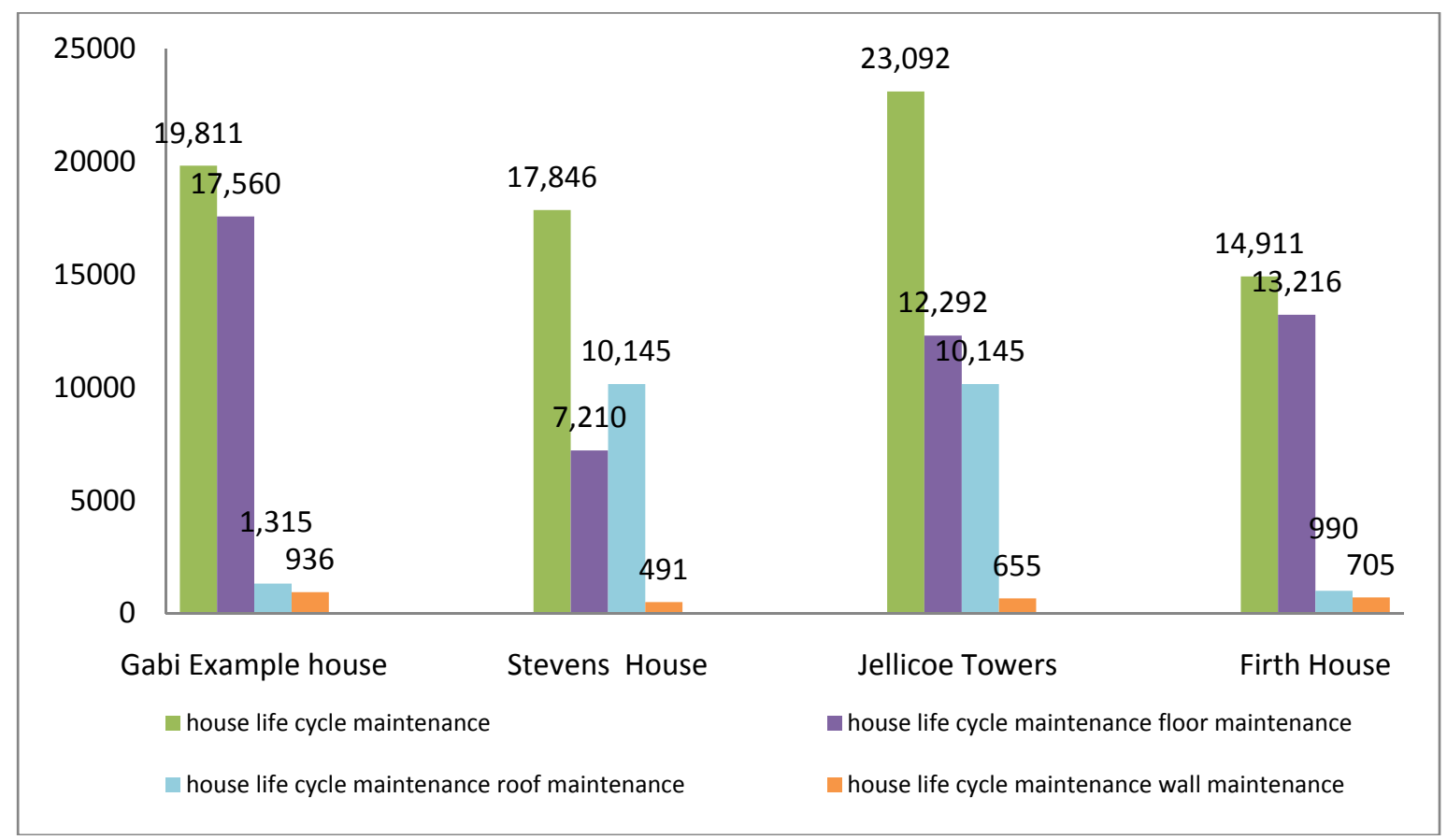

Graph $\mathrm{N}^{\circ} 8$ shows the life cycle analysis broken down in the maintenance stage. The amount of $\mathrm{CO}_{2}$ emissions released into the atmosphere in the maintenance stage of every project present inconsistent patterns among their constitutive elements. The Gabi house, the Stevens house and the Firth house show low figures in contrast to the Jellicoe Towers unit. 
9.13. - Demolition and recycling

9.13.1. - Stevens house

9.13.2. - Jellicoe towers

9.13.3. - Firth house

Table $\mathrm{N}^{\circ} 12$ Demolition and waste treatment in $\mathrm{kg}$

\begin{tabular}{|c|c|c|c|c|}
\hline Waste treatment & $170 \mathrm{~m}^{2}$ average house & $\begin{array}{c}\text { Stevens house } \\
89 \mathrm{~m}^{2}\end{array}$ & $\begin{array}{c}\text { Jellicoe Towers } \\
119 \mathrm{~m}^{2}\end{array}$ & $\begin{array}{c}\text { Firth house } \\
128 \mathrm{~m}^{2}\end{array}$ \\
\hline Timber & $1,800 \mathrm{~kg}$ & 0 & 0 & $1,355 \mathrm{~kg}(*)$ \\
\hline Concrete roof tiles & $10,000 \mathrm{~kg}$ & 0 & 0 & $7,530 \mathrm{~kg}\left({ }^{*}\right)$ \\
\hline Carpet & $1,500 \mathrm{~kg}$ & $785 \mathrm{~kg}\left({ }^{*}\right)$ & $1,050 \mathrm{~kg}\left({ }^{*}\right)$ & $1,129 \mathrm{~kg}\left({ }^{*}\right)$ \\
\hline Gypsum board & $1,850 \mathrm{~kg}$ & 0 & $1,295 \mathrm{~kg}(*)$ & $1,393 \mathrm{~kg}\left({ }^{*}\right)$ \\
\hline Glass & $400 \mathrm{~kg}$ & $583.5 \mathrm{~kg}(* * * * *)$ & $685.5 \mathrm{~kg}(* * * * *)$ & $562.5 \mathrm{~kg}(* * * *)$ \\
\hline Aluminium & $100 \mathrm{~kg}$ & $133.9 \mathrm{~kg}$ & $171 \mathrm{~kg}$ & $140 \mathrm{~kg}$ \\
\hline Concrete & $40,000 \mathrm{~kg}$ & $4600 \mathrm{~kg}$ & $216,460 \mathrm{~kg}$ & $30,117 \mathrm{~kg}(*)$ \\
\hline Steel & $800 \mathrm{~kg}$ & $11700 \mathrm{~kg}(* * *)$ & 0 & 0 \\
\hline Steel wire & 0 & $92 \mathrm{~kg}(*)$ & $560 \mathrm{~kg}\left({ }^{*}\right)$ & $602 \mathrm{~kg}(*)$ \\
\hline FRP & 0 & $3285 \mathrm{~kg}\left(\left(^{*}\right)\right)$ & 0 & 0 \\
\hline TOTAL (kg) & 56,450 & 21,179 & 220,222 & 42,829 \\
\hline$(*)$ & \multicolumn{4}{|c|}{ proportional to the first house } \\
\hline$(* *)$ & \multicolumn{4}{|c|}{$2,300 \mathrm{~kg} / \mathrm{m} 3$ conventional concrete density for foundations } \\
\hline$(* * *)$ & \multicolumn{4}{|c|}{$3,900 \mathrm{~kg}$ each empty 40 -foot container } \\
\hline$(* * *)$ & \multicolumn{4}{|c|}{$2,400 \mathrm{~kg} / \mathrm{m} 3$ conventional concrete density } \\
\hline$(* * * *)$ & \multicolumn{4}{|c|}{$2,500 \mathrm{~kg} / \mathrm{m} 3$ conventional glass density } \\
\hline \multirow[t]{2}{*}{$(* * * * *)$} & \multicolumn{4}{|c|}{ the roof of any 40 -foot container represents $23 \%$ of area it is assumed } \\
\hline & \multicolumn{4}{|c|}{ that this percentage is $23 \%$ of the weight of the container due to its uniformity } \\
\hline$((*))$ & \multicolumn{4}{|c|}{$\mathrm{FRP}$ is defined by a density of greater or equal to $0.941 \mathrm{~g} / \mathrm{cm} 3$. } \\
\hline
\end{tabular}

Table $\mathrm{N}^{\circ} 12$ shows the demolition and waste treatment stage. The amounts of materials involved in this process are given in the first column. The amount of some materials in the Stevens house, the Jellicoe Towers and the Firth house are proportional per square metre to the Gabi house. The amount of kilograms of steel used in the Stevens house is known. Every empty 40-foot high-cube shipping container masses (in correct physical language) $3,900 \mathrm{~kg}$. In addition, the amount of FRP is the sum of 2,890 kg that corresponds to the insulation of the walls plus $285 \mathrm{~kg}$ from the roof. (These results are the product of an average thickness of approximately $6 \mathrm{~mm}$ multiplied by the internal area of 40 -foot shipping containers in walls and roof. See page 62 of chapter 3 ). 
Table $\mathrm{N}^{\circ} 13$ Demolition and waste treatment in $\mathrm{kg}$ of $\mathrm{CO}_{2}$

\begin{tabular}{|c|c|}
\hline & house life cycle \\
\hline & waste treatment and disposal \\
\hline $\begin{array}{l}\text { Gabi Example } \\
\text { house }\end{array}$ & 39,310 \\
\hline Stevens house & 15,505 \\
\hline Jellicoe Towers & 161,220 \\
\hline Firth house & 31,354 \\
\hline
\end{tabular}

Table $\mathrm{N}^{\circ} 13$ shows the amount of $\mathrm{CO} 2$ in kilograms released into the atmosphere during the demolition and waste treatment process. The highest value of the case studies corresponds to the Jellicoe Towers single unit, followed by the Firth house. The lowest figure is for the container house. The Gabi example house is the benchmark.

\subsection{4. - Total energy consumption}

9.14.1. - Stevens house

9.14.2. - Jellicoe towers

9.14.3. - Firth house

Table $N^{\circ} 14$ Total energy consumption

\begin{tabular}{|c|c|c|}
\hline & Energy (net calorific value) & $\mathrm{MJ} / \mathrm{m} 2$ \\
\hline \multicolumn{3}{|c|}{ MJ } \\
\hline $\begin{array}{l}\text { Gabi Example } \\
\text { house }\end{array}$ & $3,371,857$ & 19,835 \\
\hline Stevens house & $3,345,405$ & 37,589 \\
\hline Jellicoe Towers & $3,494,680$ & 29,367 \\
\hline Firth house & $3,361,642$ & 26,263 \\
\hline
\end{tabular}


Table $\mathrm{N}^{\circ} 14$ and graph $\mathrm{N}^{\circ} 9$ show the total energy consumption in energy net calorific values. The container house is the highest figure among the rest of the examples when normalised into square metres. The amount of energy per square metre is the following:

- The Stevens house $37,589 \mathrm{MJ} / \mathrm{m}^{2}$

- Jellicoe Towers single unit: $29,367 \mathrm{MJ} / \mathrm{m}^{2}$

- The Firth house $26,263 \mathrm{MJ} / \mathrm{m}^{2}$

Graph $\mathrm{N}^{\circ} 9$ Energy net calorific value (MJ) per square metres

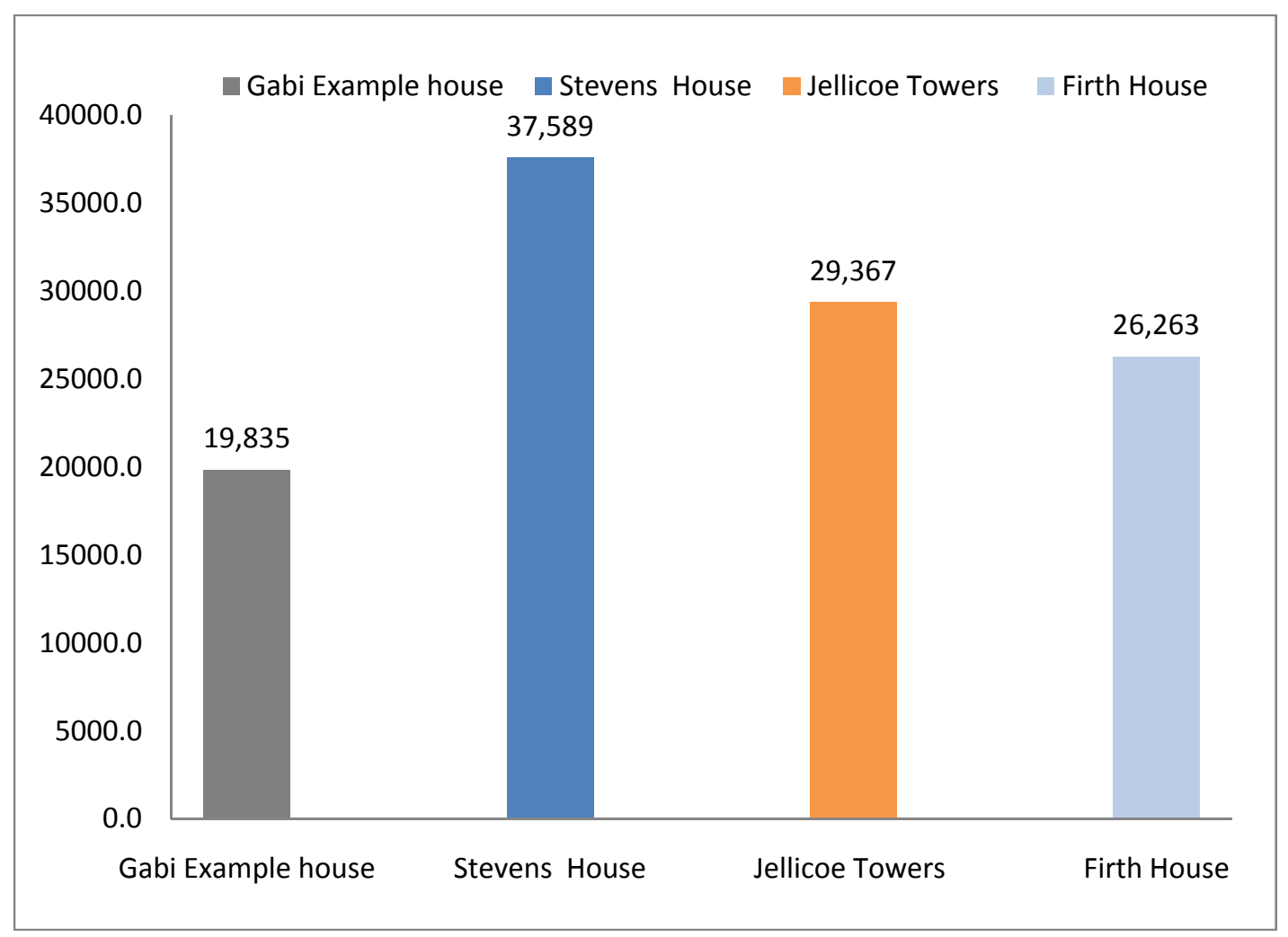




\subsection{5 - Total $\mathrm{CO}_{2}$ emissions}

9.15.1. - Stevens house

9.15.2. - Jellicoe towers

9.15.3. - Firth house

Table $\mathrm{N}^{\circ} 15$ Total $\mathrm{CO}_{2}$ emissions in percentages

\begin{tabular}{|c|c|c|c|c|c|c|c|}
\hline & & Percentage of & $\begin{array}{c}\text { house life } \\
\text { cycle }\end{array}$ & $\begin{array}{l}\text { house life } \\
\text { cycle }\end{array}$ & $\begin{array}{l}\text { house life } \\
\text { cycle }\end{array}$ & $\begin{array}{l}\text { house life } \\
\text { cycle }\end{array}$ & house life cycle \\
\hline & & $\mathrm{CO}_{2}$ emissions & & construction & maintenance & operation & $\begin{array}{l}\text { waste treatment and } \\
\text { disposal }\end{array}$ \\
\hline $\begin{array}{l}\text { Gabi Example } \\
\text { house }\end{array}$ & Flows & $\begin{array}{l}\text { Emissions to } \\
\text { air }\end{array}$ & 100.0 & 4.3 & 6.6 & 75.9 & 13.1 \\
\hline $\begin{array}{l}\text { Stevens } \\
\text { house }\end{array}$ & Flows & $\begin{array}{l}\text { Emissions to } \\
\text { air }\end{array}$ & 100.0 & 40.0 & 4.1 & 52.4 & 3.6 \\
\hline $\begin{array}{l}\text { Jellicoe } \\
\text { Towers }\end{array}$ & Flows & $\begin{array}{l}\text { Emissions to } \\
\text { air }\end{array}$ & 100.0 & 8.8 & 5.1 & 50.4 & 35.7 \\
\hline Firth house & Flows & $\begin{array}{l}\text { Emissions to } \\
\text { air }\end{array}$ & 100.0 & 3.8 & 5.2 & 80.0 & 11.0 \\
\hline
\end{tabular}

Table $\mathrm{N}^{\circ} 16$ Total $\mathrm{CO}_{2}$ emissions in absolute values in kilograms

\begin{tabular}{|c|c|c|c|c|c|c|c|}
\hline & & $\begin{array}{l}\text { Absolute } \\
\text { values of }\end{array}$ & $\begin{array}{c}\text { house life } \\
\text { cycle }\end{array}$ & $\begin{array}{c}\text { house life } \\
\text { cycle }\end{array}$ & $\begin{array}{c}\text { house life } \\
\text { cycle }\end{array}$ & $\begin{array}{l}\text { house life } \\
\text { cycle }\end{array}$ & house life cycle \\
\hline & & $\begin{array}{c}\mathrm{CO2} \\
\text { emissions }\end{array}$ & & construction & maintenance & operation & $\begin{array}{l}\text { waste treatment and } \\
\text { disposal }\end{array}$ \\
\hline $\begin{array}{c}\text { Gabi Example } \\
\text { house }\end{array}$ & Flows & $\begin{array}{l}\text { Emissions to } \\
\text { air }\end{array}$ & 299,571 & 12,958 & 19,811 & 227,493 & 39,309 \\
\hline $\begin{array}{l}\text { Stevens } \\
\text { house }\end{array}$ & Flows & $\begin{array}{l}\text { Emissions to } \\
\text { air }\end{array}$ & 435,108 & 173,976 & 17,846 & 227,782 & 15,505 \\
\hline $\begin{array}{l}\text { Jellicoe } \\
\text { Towers }\end{array}$ & Flows & $\begin{array}{l}\text { Emissions to } \\
\text { air }\end{array}$ & 451,798 & 39,704 & 23,092 & 227,782 & 161,220 \\
\hline Firth house & Flows & $\begin{array}{l}\text { Emissions to } \\
\text { air }\end{array}$ & 284,743 & 10,696 & 14,911 & 227,782 & 31,354 \\
\hline
\end{tabular}

Table $\mathrm{N}^{\circ} 15$ presents the percentages in the emissions of $\mathrm{CO}_{2}$ thought the life cycle of the different houses assessed in this chapter and $\mathrm{N}^{\circ} 16$ shows the same stages with their absolute values. 
Graph $\mathrm{N}^{\circ} 10$ Total $\mathrm{CO}_{2}$ emissions in percentages

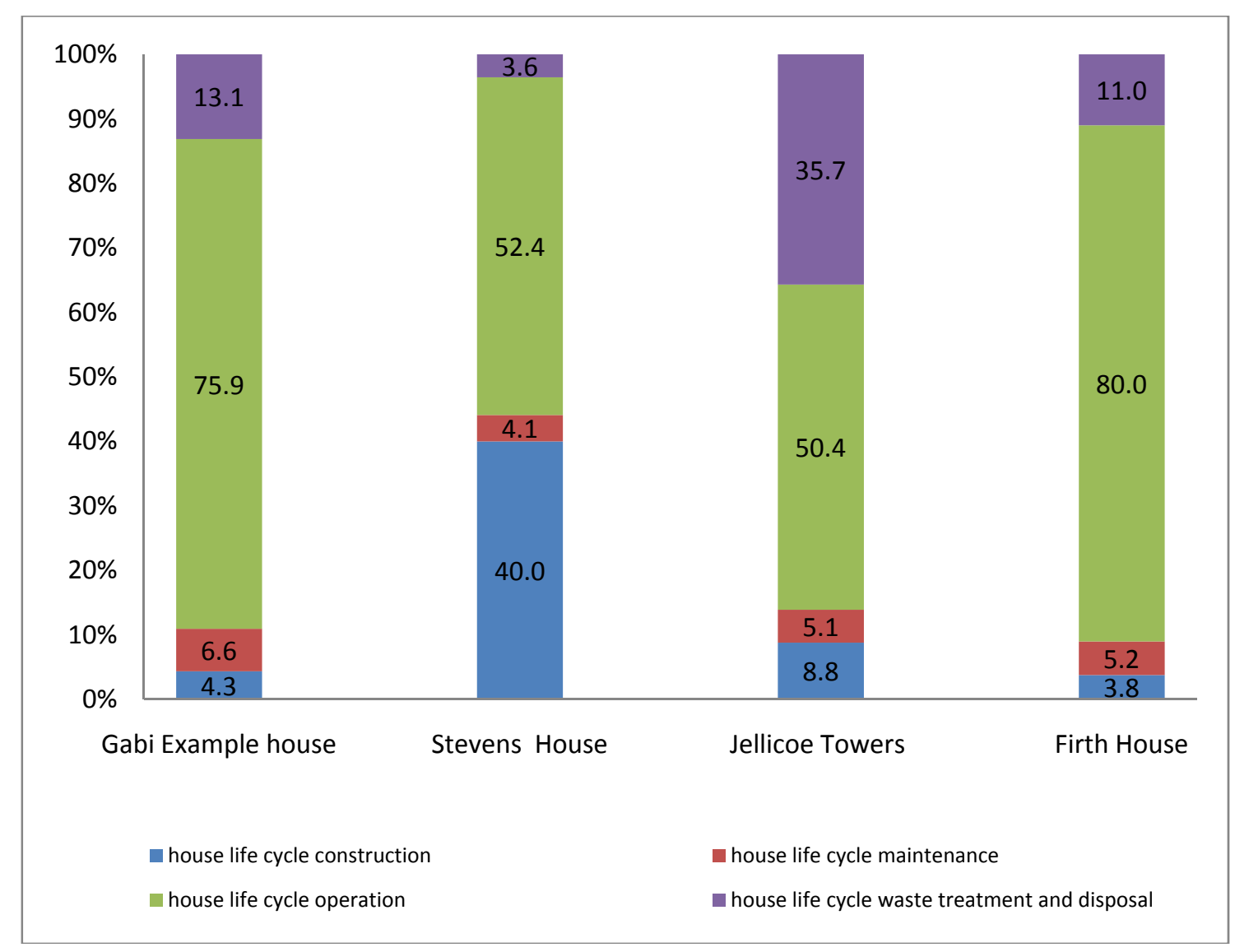

As can be seen graph $\mathrm{N}^{\circ} 10$ shows the total $\mathrm{CO}_{2}$ emissions in percentages. The Gabi house and the Firth house show similar consistent patterns of $\mathrm{CO}_{2}$ emissions. On the other hand, the Stevens house and Jellicoe Towers unit show a dissimilar concentration of $\mathrm{CO}_{2}$ emissions through the different stages of its lifespan. 
Graph $\mathrm{N}^{\circ} 11$ Total $\mathrm{CO}_{2}$ emissions in absolute values in kilograms

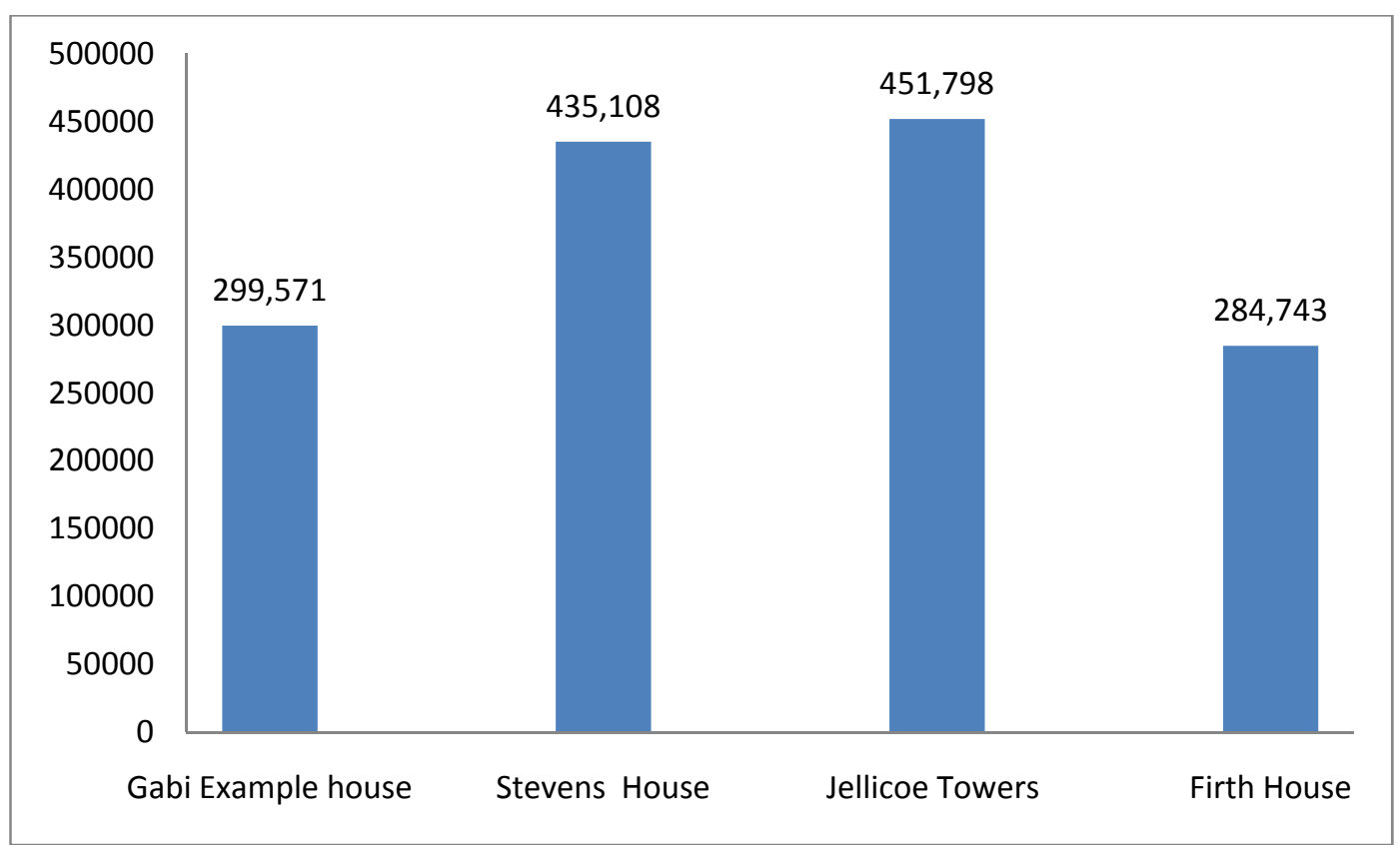

Graph $\mathrm{N}^{\circ} 11$ shows the total $\mathrm{CO}_{2}$ emissions in absolute values. The Jellicoe Towers produces more $\mathrm{CO}_{2}$ emissions in contrast to The Stevens house made of three 40 -foot high-cube shipping containers, the Gabi example house and the Firth house.

One early conclusion that may be drawn here is that when second hand shipping containers are used as main components for building, $\mathrm{CO}_{2}$ emissions in the construction stage can be saved because the containers have been used before. 
Graph $\mathrm{N}^{\circ} 12$ Total $\mathrm{CO}_{2}$ emissions in absolute values in all stages in kilograms

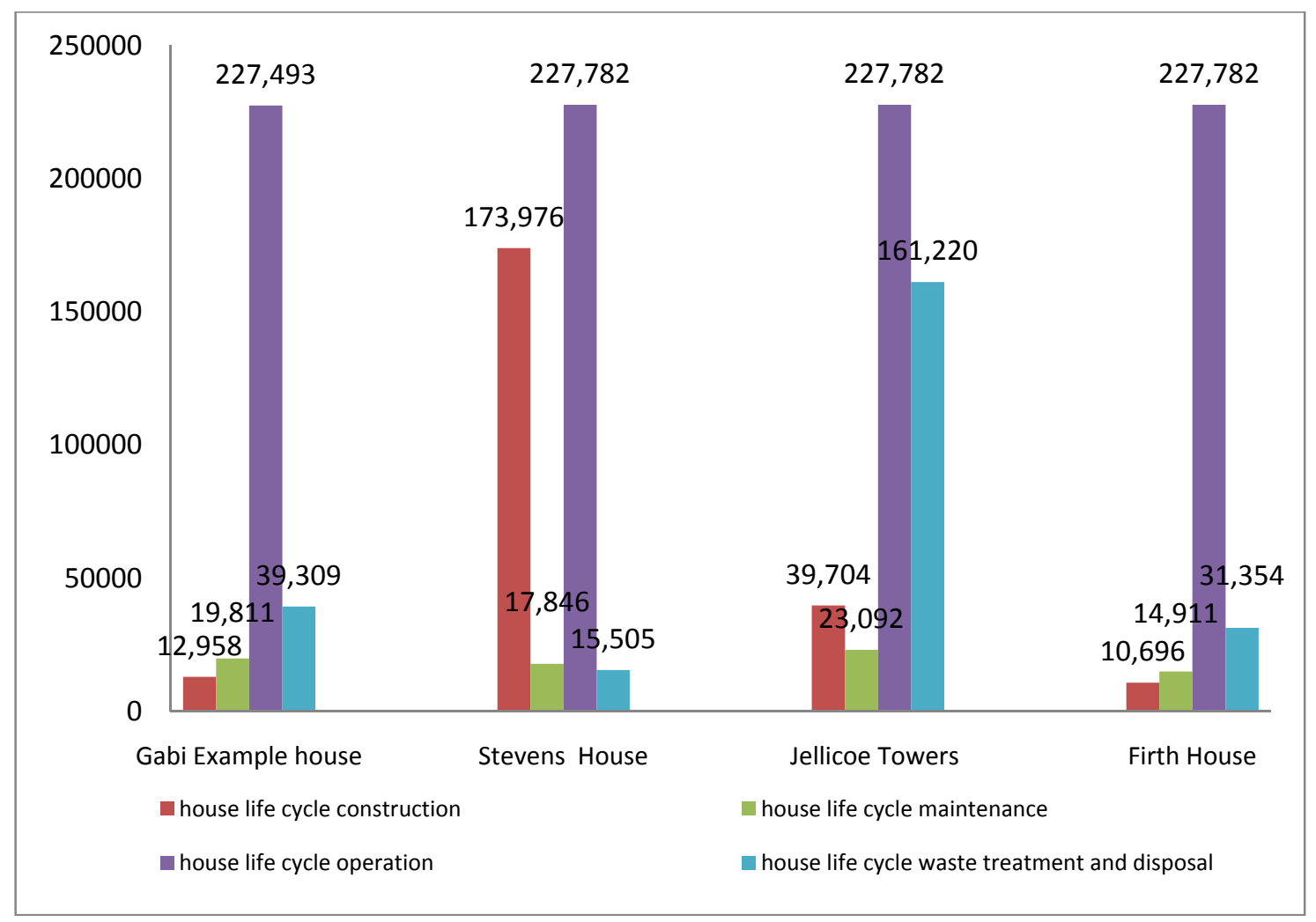

Graph $\mathrm{N}^{\circ} 12$ presents the total amount of $\mathrm{CO}_{2}$ emissions in absolute values in all stages. For all case studies the highest figure is associated with the operation stage.

Table $\mathrm{N}^{\circ} 17$ Total $\mathrm{CO}_{2}$ emissions kilograms per square meters

\begin{tabular}{|c|c|c|c|c|c|c|c|c|c|c|c|}
\hline & $\begin{array}{l}\text { Absolute } \\
\text { values of }\end{array}$ & $\begin{array}{c}\text { house life } \\
\text { cycle }\end{array}$ & $\begin{array}{l}\mathrm{kg} / \\
\mathrm{m} 2\end{array}$ & $\begin{array}{c}\text { house life } \\
\text { cycle }\end{array}$ & $\begin{array}{l}\mathrm{kg} / \\
\mathrm{m} 2\end{array}$ & $\begin{array}{c}\text { house life } \\
\text { cycle }\end{array}$ & $\begin{array}{l}\mathrm{kg} / \\
\mathrm{m} 2\end{array}$ & $\begin{array}{c}\text { house life } \\
\text { cycle }\end{array}$ & $\begin{array}{l}\mathrm{kg} / \\
\mathrm{m} 2\end{array}$ & house life cycle & $\begin{array}{l}\mathrm{kg} / \\
\mathrm{m} 2\end{array}$ \\
\hline $\begin{array}{l}\text { Gabi Example } \\
\text { house }\end{array}$ & $\begin{array}{l}\text { Emissions to } \\
\text { air }\end{array}$ & 299,571 & 1,762 & 12,958 & 76 & 19,811 & 117 & 227,493 & 1,338 & 39,309 & 231 \\
\hline $\begin{array}{l}\text { Jellicoe } \\
\text { Towers }\end{array}$ & $\begin{array}{l}\text { Emissions to } \\
\text { air }\end{array}$ & 451,798 & 3,797 & 39,704 & 334 & 23,092 & 194 & 227,782 & 1,914 & 161,220 & 1,355 \\
\hline Firth house & $\begin{array}{l}\text { Emissions to } \\
\text { air }\end{array}$ & 284,743 & 2,225 & 10,696 & 84 & 14,911 & 116 & 227,782 & 1,780 & 31,354 & 245 \\
\hline
\end{tabular}


Graph $\mathrm{N}^{\circ} 13$ Total $\mathrm{CO}_{2}$ emissions per square meters

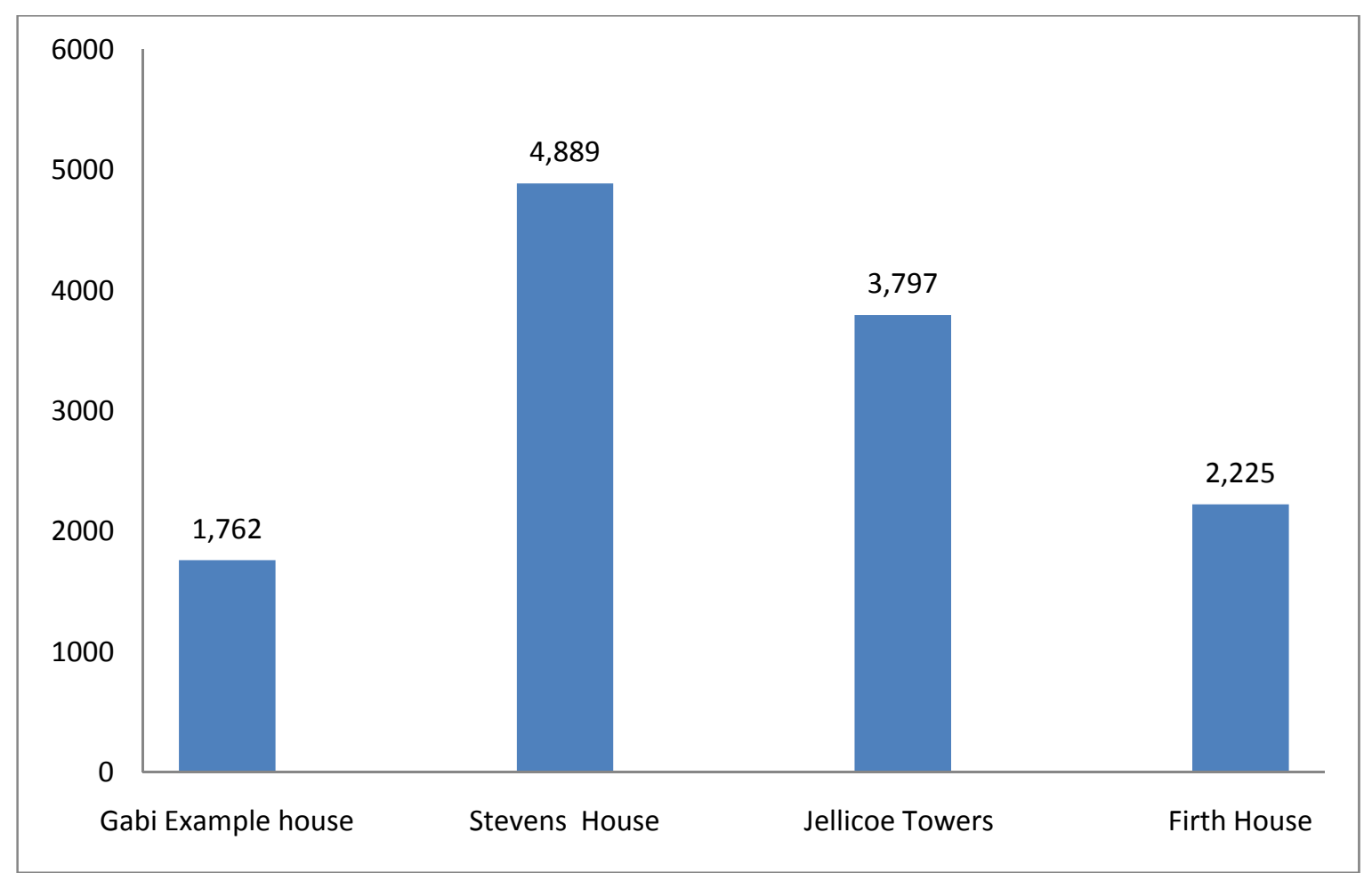

Graph $\mathrm{N}^{\circ} 13$ shows the amount of $\mathrm{CO}_{2}$ emitted in terms of kilograms per square metre. According to the calculations given by Gabi software, the Stevens house has the highest production of $\mathrm{CO}_{2}$ in contrast with the rest of the examples. Its $\mathrm{CO}_{2}$ emissions resulting from its life cycle are about $4,889 \mathrm{~kg} / \mathrm{m}^{2}$, which is more than two times the average $\mathrm{CO}_{2}$ emissions of the Firth house. It is followed by the Jellicoe Towers unit with $3,797 \mathrm{~kg} / \mathrm{m}^{2}$ and the Firth house with $2,225 \mathrm{~kg} / \mathrm{m}^{2}$. The Gabi house is just a benchmark with 1,762 $\mathrm{kg} / \mathrm{m}^{2}$. 


\section{Conclusions}

\section{1. - Results}

This study has examined -through the life cycle analysis methodology- the importance of the energy-end use and its consequences in the residential sector of New Zealand for three different constructions which use three different building materials. Mainly physical rather than historical (or non-physical) approaches rule this research. This investigation was focused on sustainability in prefabricated architecture. However, prefabricated homes in New Zealand are uncommon and houses made of shipping containers are rare exceptions as well.

The outcomes are eloquent. A shipping container dwelling potentially could use more energy and produce more $\mathrm{CO}_{2}$ emissions in its lifespan that an average or traditional house does. These outcomes are the result of an intensive investigation based on modelling and by using different software to make a fair analysis. Comparisons have been made between OECD countries and New Zealand standards of energy use and consumption. How energy is produced and how energy is consumed have been studied too. Data has been corroborated with international studies, most of them following the same line of analysis. Disagreements with this methodology (LCA) are also considered. Socio-economic, climate conditions and locations, number of occupants, orientation and a series of other factors have been assessed in depth. This study has the capability to become a forerunner of studies based on sustainable design in order to enhance energy efficiency in the residential sector if shipping containers are planned to be used as main or partial components in buildings in New Zealand or somewhere else. Energy consumption and $\mathrm{CO}_{2}$ emissions seem to be dependent variables and should be studied together. Emissions of $\mathrm{CO}_{2}$ also depend on the way primary energy is generated, hydroelectricity, fossil fuels, and so on.

\section{2. - Life cycle energy consumption}

The life cycle energy consumption is given by using two different software packages. The first is known as Gabi, which has a European database. It is useful to calculate the total amount of energy used and the amount of $\mathrm{CO}_{2}$ released into the atmosphere by the different projects through their lifespan. The second program is New Zealand software known as ALF 3 (Annual Loss Factor), which is useful to calculate space heating energy.

The calculated energy is given in two different ways by the programs. However, this has been normalised into energy use per square meter per year. ${ }^{1}$

- energy net calorific: in MJ through the lifespan (Gabi) then normalised into $\mathrm{MJ} / \mathrm{m}^{2} /$ year

- space heating: in kWh / year (ALF 3) then normalised into $\mathrm{MJ} / \mathrm{m}^{2} /$ year (will be used for space heating so that it allows an easy comparison with the Gabi data)

\footnotetext{
${ }^{1}$ Note: MJ rather than GJ will be used due to the scale of the energy consumption values.
} 
10.3. - Life cycle operating energy consumption

All projects including the Gabi example house (discussed in case studies) share similar values in the total operational energy consumption. The Stevens House consumes 3,371,857 MJ for energy net calorific value. The Jellicoe Towers single unit consumes 3,494,680 MJ for energy net calorific value, which is the highest figure among the case studies. The Firth House consumes 3,361,642 MJ for energy net calorific value. This normalised into square meters give the following values:

- The Stevens House consumes $37,588 \mathrm{MJ} / \mathrm{m}^{2}$

- The Jellicoe Towers single unit consumes $29,367 \mathrm{MJ} / \mathrm{m}^{2}$

- The Firth House consumes $26,367 \mathrm{MJ} / \mathrm{m}^{2}$

Space heating requires one third of the total energy end-used in New Zealand. In terms of space heating the Stevens House uses $141 \mathrm{MJ} / \mathrm{m}^{2} /$ year, followed by the Jellicoe Towers single unit with $120 \mathrm{MJ} / \mathrm{m}^{2} /$ year and finally the Firth House with $100 \mathrm{MJ} / \mathrm{m}^{2} /$ year

\section{4. - Life cycle $\mathrm{CO}_{2}$ emissions}

Life cycle $\mathrm{CO}_{2}$ emissions can be divided into four main stages: Construction, maintenance, operation and waste treatment and disposal. The operation life cycle stage seems to be the most important phase of all. In terms of $\mathrm{CO}_{2}$ emissions the modeling of the Jellicoe Towers dwelling unit shows the highest figure among the examples, reaching 451 tons of $\mathrm{CO}_{2}$ released to the atmosphere in its 100 years of lifespan or more than two times the amount of carbon dioxide of its counterpart built of wood. In contrast the Stevens House produces 435 tons and the Firth House 284 tons of $\mathrm{CO}_{2}$ approximately.

Thus, normalised into square metres these give the following values: $4,889 \mathrm{~kg} / \mathrm{m}^{2}$ for the container house, $3,797 \mathrm{~kg} / \mathrm{m}^{2}$ for the concrete house and $2,259 \mathrm{~kg} / \mathrm{m}^{2}$ for the timber-based dwelling. 
10.5. - $\mathrm{CO}_{2}$ emissions for the steel structure

The Stevens House: The $\mathrm{CO}_{2}$ emissions are divided into four stages: Construction $40 \%$, maintenance $4.1 \%$, operation $52.4 \%$ and waste treatment and disposal $3.6 \%$. The values of the $\mathrm{CO}_{2}$ emissions in the construction phase of the Stevens House are, $1,955 \mathrm{~kg} / \mathrm{m}^{2}$, for the maintenance are $201 \mathrm{~kg} / \mathrm{m}^{2}, 2,259 \mathrm{~kg} / \mathrm{m}^{2}$ in the operation phase and waste treatment and disposal are $174 \mathrm{~kg} / \mathrm{m}^{2}$.

10.6. $-\mathrm{CO}_{2}$ emissions for the concrete structure

The Jellicoe Towers single unit: The $\mathrm{CO}_{2}$ emissions are divided into four stages: Construction $8.8 \%$, maintenance $5.1 \%$, operation $50.4 \%$ and waste treatment and disposal $37.7 \%$. The values of the $\mathrm{CO}_{2}$ emissions in the construction phase of the Jellicoe Towers single unit are, $334 \mathrm{~kg} / \mathrm{m}^{2}$, for the maintenance are $194 \mathrm{~kg} / \mathrm{m}^{2}, 1,914 \mathrm{~kg} / \mathrm{m}^{2}$ in the operation phase and waste treatment and disposal are $1,355 \mathrm{~kg} / \mathrm{m}^{2}$.

10.7. - $\mathrm{CO}_{2}$ emissions for the timber structure

The Firth House: The $\mathrm{CO}_{2}$ emissions are divided into four stages: Construction $3.8 \%$, maintenance $5.2 \%$, operation $80 \%$ and waste treatment and disposal $11 \%$. The values of the $\mathrm{CO}_{2}$ emissions in the construction phase of the Firth House are, $84 \mathrm{~kg} / \mathrm{m}^{2}$, for the maintenance are $116 \mathrm{~kg} / \mathrm{m}^{2}, 1,780 \mathrm{~kg} / \mathrm{m}^{2}$ in the operation phase and waste treatment and disposal are $245 \mathrm{~kg} / \mathrm{m}^{2}$.

\section{Discussion}

10.8. - Life cycle energy consumption

The energy consumed through the life cycle of a house can be divided into four stages: Construction, operation, maintenance and demolition or "Cradle to grave analysis". ${ }^{2}$

Most of the examples of shipping container buildings shown in Chapter 1 are located in countries with cold and hard weather conditions. At the same time, OECD countries such as the United States, Canada and The United Kingdom and so on consume much more energy per household than do family-units in New Zealand. Energy consumption in the residential sector of some OECD countries assessed in this research is strongly related to location and climate conditions.

In terms of the structure, 20-foot cargo containers are stronger than their 40-foot counterparts. In terms of costs, -in the construction stage of container houses- containers (different size and type) of 20, 40 and 40 foot high-cube have a noticeable difference in the prices normalised into square meters.

\footnotetext{
${ }^{2}$ Mithraratne, Vale, \& Vale, (2007, p. 23)
} 
In terms of the performance in the construction phase, a 40-foot high-cube container is more useful than the others because it is easier to install services and still leave adequate headroom, due to their greater height (Interior height $2.65 \mathrm{~m}$ ). On the other hand, they are more expensive and more difficult to find in contrast with 20 or 40 -foot typical containers.

The energy used and the subsequent emissions of carbon dioxide in the embodied energy stage or construction phase of a house is usually a quite minor component in contrast with the total amount of energy used in the operational stage. The container house assessed in the case study shows a great amount of $\mathrm{CO}_{2}$ emissions in the construction phase. This can be crucial. When new shipping containers are used in new houses the amount of energy and the amount of $\mathrm{CO}_{2}$ released into the atmosphere is added into the life cycle of the house. This occurs because the container has not been used yet. Ninety percent of shipping containers of the world are produced in China. In 2007 China consumed 15.2\% of world total energy consumption ${ }^{3}$ in all fuels (coal, gas, oil, electricity and so on) and released $21 \%$ of world total $\mathrm{CO}_{2}$ emissions for the same year. ${ }^{4}$ In addition, China's primary energy generation is related to the burning of fossil fuels mainly. ${ }^{5}$ Another possible scenario is that second-hand containers can be used in buildings. The problem is that, according to (www.zen.co.uk) the lifespan of a container house is estimated to be fifty years. This means the average lifespan of a New Zealand house (100 years) is halved.

Operational energy consumption is usually the largest driver of emissions in the life cycle of a house. (It will be assessed separately) Heating schedule is a main driver in the energy consumption of a house. In the simulation process (chapter 8 using ALF 3) containers oriented with the principal façade facing North or Northwest are more likely to use less energy in comparison with East and South placed walls for 20 and 40-foot insulated containers. Benefits in the energy use are achieved when containers are insulated.

The numbers of the occupants are also important. In the simulation process, two occupants use slightly less energy in comparison with one inhabitant. This may have a lesser importance in traditional buildings but, container architecture structures -in the residential sector- use most of the time a single shipping container as a single unit with one dweller.

10.9. - Life cycle operating energy consumption

For traditional constructions at present used in New Zealand houses, operating energy is a significant component of the life cycle energy. The sizes of the house and energy consumption do not necessarily have a proportional relationship. Some OECD countries have different square meter values for average houses. In the operational energy consumption stage of a house, the increment of square metres does not always mean an increment of the energy consumed, depending on how the house is designed and the climate in which is located.

\footnotetext{
${ }^{3}$ See chapter 4 page 84

${ }^{4}$ See chapter 4 page 97

${ }^{5}$ See chapter 4
} 
10.10. - Life cycle energy consumption for steel structures

Another comparative life cycle analysis Suzuki, Oka, \& Okada, (1994, p. 167) found a value of $4.5 \mathrm{GJ} / \mathrm{m}^{2}$ in the construction stage for lightweight steel-structure single family houses in Japan. This represents the second highest value among concrete, steel and timber-based dwellings. Yohanis \& Norton, $\left(2002\right.$, p. 83) found a value of $6.6 \mathrm{GJ} / \mathrm{m}^{2}$ for steel buildings in New Zealand in the construction phase.

The making of a metal shipping container, either: aluminum or steel, requires a high and intensive use of primary energy with the subsequent $\mathrm{CO}_{2}$ emissions. $90 \%$ of shipping containers of the world are produced in China, at the same time China's primary energy is provided mainly by using fossil fuels (discussed in chapter four).

\subsection{1. - Life cycle energy consumption for concrete structures}

The extraction, refinery and other processes associated with the production of concrete make this material energy intensive. A Japanese comparative life cycle analysis Suzuki, Oka, \& Okada, $\left(1994\right.$, p. 167) found a value of $8-10 \mathrm{GJ} / \mathrm{m}^{2}$ in the construction stage for a concrete multi-family house. This represents the highest value among concrete, steel and timberbased dwellings. Yohanis \& Norton, (2002, p. 83) found a value of $5.6 \mathrm{GJ} / \mathrm{m}^{2}$ for concrete buildings in New Zealand in the construction phase, making concrete lower than steel.

\subsection{2. - Life cycle energy consumption for wooden structures}

International studies agree largely. Timber structures seem to have less environmental impact in contrast with other materials. The same Japanese comparative life cycle analysis Suzuki, Oka, \& Okada,(1994, p. 167) found a value of $3 \mathrm{GJ} / \mathrm{m}^{2}$ in the construction stage for a wooden single-family house. This represents the lowest value among concrete, steel and timber-based dwellings. Adalberth, K. (1996) analyzed three different wooden prefabricated houses. The difference of each example relies upon the difference in the percentage of concrete versus wood. The values were $3.24,3.1$ and $2.6 \mathrm{GJ} / \mathrm{m}^{2}$ in the construction stage. Buchanan \& Levine, (1999) found that wood used in buildings require much lower process energy and has consequently lower carbon emissions than buildings of other materials such as brick, aluminium, steel and concrete. The first value was $2.5 \mathrm{GJ} / \mathrm{m}^{2}(1983)$ and the second more recent value was, $1.7 \mathrm{GJ} / \mathrm{m}^{2}$ (1996) in the construction stage of a wooden based house.

10.13. - Life cycle $\mathrm{CO}_{2}$ emissions

There are substantial differences in the amount of $\mathrm{CO}_{2}$ emissions shown in several studies. 


\subsection{4. - $\mathrm{CO}_{2}$ emissions for steel structures}

When old or second hand shipping containers are used in buildings the high amount of primary energy used and $\mathrm{CO}_{2}$ emitted in all the processes involved (embodied energy) can be discounted from the global figure because it is assumed that this energy is related to the first life of the container as an instrument of trade. However, old freight containers are more likely to last less time. The lifespan of the container as a building could be reduced. No studies of this particular issue have been assessed yet. But it estimated that a second hand container could last around fifty years, half of the life cycle of an ordinary wooden house in New Zealand.

In terms of $\mathrm{CO}_{2}$ emissions a comparative life cycle analysis Suzuki, Oka, \& Okada,(1994, p. 168) found a value of $400 \mathrm{~kg} / \mathrm{m}^{2}$ in the construction stage for lightweight steel-structure single family houses in Japan. This represents the second highest value among concrete, steel and timber-based dwellings.

10.15. - $\mathrm{CO}_{2}$ emissions for concrete structures

The same Japanese comparative life cycle analysis Suzuki, Oka, \& Okada, (1994, p. 168) found a value of $850 \mathrm{~kg} / \mathrm{m}^{2}$ in the construction stage for a concrete multi-family house. This represents the highest value among concrete, steel and timber-based dwellings.

\subsection{6. - $\mathrm{CO}_{2}$ emissions for timber structures}

Wood as a building material seems to have less impact on the environment. In terms of $\mathrm{CO}_{2}$ emissions, timber is a good building material compared with more energy intensive materials such as bricks, concrete blocks, aluminium or steel. This Japanese comparative life cycle analysis Suzuki, Oka, \& Okada, (1994, p. 168) found a value of $250 \mathrm{~kg} / \mathrm{m}^{2}$ in the construction stage for a wooden single-family house. This represents the lowest value among concrete, steel and timber-based dwellings.

\subsection{7. - Predictions}

The temptation of using cargo containers for making buildings would increase in the future. Projects which use shipping containers as main or partial components of their structures would follow appearing in websites on the internet, magazines and books. Future research in this topic could explore the real cost of these buildings in contrast with traditional ones.

\subsection{8. - Conclusions}

The construction of new houses requires a huge amount of primary energy and accounts for a considerable portion of the total national's energy use in New Zealand. In the residential sector of New Zealand prefabricated houses and especially shipping container dwellings are likely to consume more energy than those built by traditional means. 
Adalberth, K. (1996, p. 329) found when dwellings are prefabricated in factories for further transportation to the building site. The "extra" transportation requirement compared with the traditional situation where a house is erected on site, so not result in any significantly increased use of energy compared to the total energy requirement. Thus, in those places with harsh weather conditions, the advantages of prefabrication outweigh the disadvantages, because construction materials are protected from wind and weather in contrast with traditional constructions which take place on site.

Some research questions have been tested. The first three opening questions have being answered through the whole thesis implicitly. The concept of "sustainability" related to the prefabricated house has been discussed holistically. It was not the aim of this study to discuss the concept of sustainability in architecture in general terms.

Again, the concept of "sustainability" underlies among the chapters. First, by analysing and by defining -through worldwide examples- the background and the physical features of container architecture. Second, by exploring and by understanding the constitutive elements of container architecture through the discussion on energy generation and energy consumption of different types of fuels, different countries, different sectors and different building materials and their impact into the environment and third, by gathering and by analysing the information obtained into the case studies by using the life cycle assessment as a methodology.

The history of the prefabricated house has shown both successes and failures. However, in light of these outcomes shown earlier, container houses in the residential sector of New Zealand difficultly could be named as "low-energy houses" ${ }^{6}$ in terms of energy consumption and in terms of emissions of carbon dioxide released into the atmosphere. The way how container architecture should be manipulated by architects, engineers, designer or anyone interested -in order to enhance energy efficiency- has been tested in Chapter eight. The disadvantages in the usage of shipping containers for residential structures in New Zealand outweigh the advantages. Container architecture hardly could become a source of low income houses. Finally, in terms of energy consumption and $\mathrm{CO}_{2}$ emissions per square metres container architecture projects in comparison with other buildings constructed with concrete or wood located in Wellington New Zealand hardly could be called the new environmental living box.

\footnotetext{
${ }^{6}$ http://www.epa.gov/greenbuilding/pubs/about.htm
} 


\section{References}

\section{Introductory Chapter}

Grant, A. (2008, October 11). The rise of CARGOtecture; One of the biggest trends in green building makes use of the many shipping containers just sitting around, and the result can be spectacular. The Gazette , p. 1.

Kotnik, J. (2008). Container Architecture: This Book Contains 6441 Containers. Barcelona: Links International.

Levinson, M. (2006). The box : how the shipping container made the world smaller and the world economy bigger. Princeton: Princeton : Princeton University Press.

Williamson, T. J. (2002). Understanding Sustainable Architecture. New York : Spon Press.

\section{Chapter I Container Architecture}

Adalberth, K. (1996). Energy use during the Life Cycle of Buildings: a Method. Elsevier Ltd. , 317-320.

BRANZ . (2005). House Insulation Guide. Wellington: BRANZ Ltd.

Burg, G. V. (1975). Containerisation and other unit transport . London : London : Hutchinson, 1975.

Corbusier, L. (1927). Towards A New Architecture. London: London Architectural Press.

Davies, C. (2005). The Prefabricated Home. London: Reaktion Book Ltd.

Eaton, K. J., \& Amato, A. (1998). A comparative Environmental Life Cycle Assessment of Modern Office Buildings. Berkshire: The Steel Construction Institute, Silwood Park.

Grant, A. (2008, October 11). The rise of CARGOtecture; One of the biggest trends in green building makes use of the many shipping containers just sitting around, and the result can be spectacular. The Gazette, p. 1.

Gray. (1945). 61.

Gropius, W. (1956). Scope of Total Architecture. London: Allen \& Unwin.

Isaacs, N., Lee, J., \& Donn, M. (1995). Energy Efficiency In The New Zealand Building Code. Wellington: Centre for Building Performance Research.

Kotnik, J. (2008). Container Architecture: This Book Contains 6441 Containers. Barcelona: Links International.

Levinson, M. (2006). The box : how the shipping container made the world smaller and the world economy bigger. Princeton: Princeton : Princeton University Press.

Mithraratne, N., Vale, B. V., \& Vale, R. (2007). Sustainable Living: the Role of Whole Life Costs and Values. London: Elsevier Limited.

Schneider, T. (2007). Flexible Housing. London: Elsevier Inc.

Scoates, C., Tolla, A., \& Lignano, G. (2003). Lot - E: Mobile Dwelling Unit. New York: Art Publishers.

Stevenson, G. (2003). Palaces for the people: Prefabs in Post-war Britain . London: BT Bastford.

Teige, K. (. (2002). The Minimum Dwelling. Massachusetts: Massachusetts Institute of Technology. 
Towne. (1942). TVA Prefab houses. 55.

Towne, \& Purnel. (1946). Prefabricated houses. 57.

Vale, B. (1995). Prefabs a history of the UK temporary housing programme. London: Spon.

Williamson, T. J. (2002). Understanding Sustainable Architecture. New York : Spon Press.

www.archmedia.com.au. (n.d.). Retrieved April 11, 2010, from

http://www.archmedia.com.au/aa/aaissue.php?issueid=200109\&article=11\&typeon=2

www.boqueteweather.com. (n.d.). Retrieved April 11, 2010, from

www.boqueteweather.com/.../world_climate_map.jpg

www.containercity.com. (n.d.). Retrieved April 09, 2010, from http://www.containercity.com/container-citytwo.html

www.containercity.com. (n.d.). Retrieved April 09, 2010, from http://www.containercity.com/riversidebuilding.html

www.geobytes.com. (n.d.). Retrieved April 08, 2010, from

http://www.geobytes.com/CityDistanceTool.htm?loadpage

www.gliving.com. (n.d.). Retrieved April 11, 2010, from http://gliving.com/puma-city/

www.inhabitat.com. (n.d.). Retrieved April 09, 2010, from http://www.inhabitat.com/2008/08/22/travelodgeshipping-container-hotel/

www.mimoa.eu. (n.d.). Retrieved April 09, 2010, from

http://www.mimoa.eu/projects/Netherlands/Amsterdam/Qubic

www.openarchitecturenetwork.org. (n.d.). Retrieved April 08, 2010, from

http://openarchitecturenetwork.org/projects/6633

www.openarchitecturenetwork.org. (n.d.). Retrieved April 08, 2010, from

http://openarchitecturenetwork.org/projects/6625

www.openarchitecturenetwork.org. (n.d.). Retrieved April 09, 2010, from

http://openarchitecturenetwork.org/projects/6372

www.shippingcontainerarchitecture.com. (n.d.). Retrieved April 09, 2010, from

http://shippingcontainerarchitecture.com/node/50

www.verbussystems.com. (n.d.). Retrieved April 09, 2010, from http://www.verbussystems.com/

www.youtube.com. (n.d.). Shipping Containers Recycled as Homes . Retrieved April 08, 2010, from

http://www.youtube.com/watch?v=UvcUe_yPHdg

www.zen.co.uk. (n.d.). Retrieved April 09, 2010, from

http://www.zen17279.zen.co.uk/images/CCFREQUENTLY\%20ASKED\%20QUESTIONS.pdf

www.zigloo.ca. (n.d.). Retrieved April 08, 2010, from

http://www.zigloo.ca/index/projects/zigloo_domestique_gallery\#top 


\section{Chapter II General Background}

Davies, C. (2005). The Prefabricated Home. London: Reaktion Book Ltd.

Levinson, M. (2006). The Box: How Shipping Container Made the World Smaller and the World Economy Bigger. New Jersey: Princeton University Press.

O'Sullivan, A., \& Sheffrin, S. M. (2006). Economics: Principles in Action. Pearson Prentice Hall.

\section{Chapter III-Physical characteristics of ISO containers}

Burg, G. V. (1975). Containerisation and other unit transport . London : London : Hutchinson, 1975.

Containerisation International. (2008). World Container Census 2008. London: Unwin Brothers Ltd, Old Woking.

Ebeling, C. E. (2009). "Evolution of a Box",. Invention and Technology , 23 (4): 8-9.

International, B. M. (2009). China Freight Transport Report. London: Business Monitor International.

United Nations. (2008). Review of Maritime Transport. New York: United Nations, New York.

Vale, B. a. (2009). Time to eat the dog? London: Thames \& Hudson Ltd.

Freightraders. (n.d.). www.freightraders.co.nz. Retrieved October 13, 2009, from

http://www.freightraders.co.nz/containerspecs.html

Gordon, J. S. (2007, April 20). www.americanheritage.com. Retrieved April 20, 2010, from http://www.americanheritage.com/events/articles/web/20070426-cargo-container-international-tradeshipping-malcom-mclean-longshoremen-inventions.shtml

History Channel. (n.d.). www.youtube.com. Retrieved October 13, 2009, from http://www.youtube.com/watch?v=QmJvhBfoJGE

http://www.runkleconsulting.com. (n.d.). Retrieved March 23, 2010, from http://www.runkleconsulting.com/contact/contact.htm

Runkle, G. (n.d.). www.runkleconsulting.com. Retrieved March 23, 2010, from http://www.runkleconsulting.com/Shipping\%20Container\%20Houses/shipping_container_building_design_an d_construction.html

www.zen.co.uk. (n.d.). Retrieved April 09, 2010, from http://www.zen17279.zen.co.uk/images/CCFREQUENTLY\%20ASKED\%20QUESTIONS.pdf 
Chapter IV Energy Generation, energy consumption and environmental issues in the construction sector

Alcorn, A. (2003). Embodied Energy and CO2 Coefficients For New Zealand Building Materials. Wellington: Centre for Building Performance Research.

Fulton, L., Unarder, F., Schipper, L., \& Difiglio, C. (2000). CO2 Emission Trends and Reduction Opportunities in Transport, Households and Commercial Sectors. Copenhagen: UNFCCC Workshop on Policies and Measures.

International Energy Agency. (2009 ). Key World Energy Statistics. Paris: 9, rue de la Fédération.

Isaacs, N., Lee, J., \& Donn, M. (1995). Energy Efficiency In The New Zealand Building Code A New Structure. Wellington: Centre for Building Performance Research.

United Nations . (2008). CCCC Kick the Habit: A UN guide to climate neutrality. Malta: Progress press Itd.

United Nations. (2008). Review of Maritime Transport. New York: United Nations, New York.

United Nations. (2004). World Population to 2300. New York: United Nations, New York.

www.aboutnuclear.org. (n.d.). Retrieved April 14, 2010, from

http://www.aboutnuclear.org/view.cgi?fC=Electricity,Benefits_\%5E_Effects

www.ipcc.ch. (n.d.). Retrieved April 14, 2010, from http://www.ipcc.ch/pdf/assessment-

report/ar4/syr/ar4_syr_appendix.pdf

www.oecd.org. (n.d.). Retrieved April 12, 2010, from

http://www.oecd.org/home/0,2987,en_2649_201185_1_1_1_1_1,00.html

\section{Chapter V Energy use in residential buildings}

BRANZ. (2002). Energy use in New Zealand Households -Executive Summary Year 6. Wellington: BRANZ.

Department of Building and Housing . (2007). Building for the 21st Century Report on the Review of the Building Code. Wellington: Department of Building and Housing.

Department of Building and Housing. (2007). Energy efficiency of buildings (domestic hot water and commercial heating, ventilating and air-conditioning systems). Wellington, New Zealand: Department of Building and Housing.

Department of Trade and Industry. (2001). Enegy Consumption in the United Kingdom. London: Department of Trade and Industry.

Dzioubinski, O., \& Chipman, R. (1999). Trends in consumption and production: Household Energy Consumption. New York: United Nations.

Gustavsson, L., \& Joelsson, A. (2009). Life cycle primary energy analysis of residential buildings. Elsevier Ltd. , 210-220.

Hacker, J. N., De Saulles, T. P., Minson, A. J., \& Holmes, M. J. (2006). Embodied and operational carbon dioxide emissions from housing: A case study on the effects of thermal mass and climate change. Elsevier Ltd. , 375384. 
Isaacs, N., \& Donn, M. (1994). Effect of thermal mass on house and internal temperatures. Wellington: Centre for Building Performance Research, Victoria University of Wellington.

Isaacs, N., Lee, J., \& Donn, M. (1995). Energy Efficiency In The New Zealand Building Code A New Structure. Wellington: Centre for Building Performance Research.

Isham, M., \& Lakewood, W. (2004, March). A quantification of minimum floor space requirements. Retrieved April 26, 2010, from www.springerlink.com: http://www.springerlink.com/content/e4jw6w8273164g55/

Metz, B., Davidson, O. R., Bosch, P. R., Dave, R., \& Meyer, L. A. (2007). Contribution of Working Group III to the Fourth Assessment Report of the Intergovernmental Panel on Climate Change, 2007. Cambridge, United Kingdom and New York, NY, USA.: Cambridge University Press.

Peeters, L., de Dear, R., Hensen, J., \& D'haeseleer, W. (2008). Thermal comfort in residential buildings: Comfort values and scales for building energy simulation. Elsevier Ltd.

Tamborini, S. (1999). Living in a small space: Experimental projects from four continents . London: Edition Axel Menges, Stuttgart / London.

United Nations . (2008). CCCC Kick the Habit: A UN guide to climate neutrality. Malta: Progress press Itd.

United Nations Environment Programme. (2008). CCCC Kick the habit: A UN guide to climate neutrality. New York: United Nations.

United Nations. (2004). World Population to 2300. New York: United Nations, New York.

Upton, B., Miner, R., Spinney, M., \& Heath, L. (2007). The greenhouse gas and energy impacts of using wood instead of alternatives in residential construction in the United States. Elsevier Ltd , 1-10.

Zhang, Q. (2004). Residential energy consumption in China and its comparison with Japan, Canada and USA. Elsevier Ltd.

www.demographia.com. (n.d.). www.demographia.com. Retrieved January 29, 2010, from http://www.demographia.com/db-intlhouse.htm

www.need.org. (n.d.). www.need.org. Retrieved March 19, 2010, from http://www.need.org/needpdf/infobook_activities/IntInfo/Consl.pdf

\section{Chapter VI Life cycle assessment}

Alcorn, A. (1996). Embodied energy coefficients of building materials. Wellington: Centre for Building Performance Research.

Baird, G., Alcorn, P., \& Haslam, P. (1997). The energy embodied in building materials-updated New Zealand coefficients and their significance. Elsevier Ltd. , 46-54.

Buchanan, A. H., \& Levine, B. S. (1999). Wood-based building materials and atmospheric carbon emissions . Elsevier Ltd. , 427-437.

Burg, G. V. (1975). Containerisation and other unit transport . London : London : Hutchinson, 1975.

Cole, R. J., \& Kernan, P. C. (1996). Life-Cycle Energy Use in Office Buildings. Elsevier Ltd , 307-317. 
Eaton, K. J., \& Amato, A. (1998). A comparative Environmental Life Cycle Assessment of Modern Office Buildings. Berkshire: The Steel Construction Institute, Silwood Park.

Isaacs, N., \& Donn, M. (1994). Effect of thermal mass on house and internal temperatures. Wellington: Centre for Building Performance Research, Victoria University of Wellington.

Isaacs, N., Lee, J., \& Donn, M. (1995). Energy Efficiency In The New Zealand Building Code A New Structure. Wellington: Centre for Building Performance Research.

Kernan, P. C. (1996). Life Cycle Energy Analysis of an Office Building. Vancouver: The University of British Columbia.

Metz, B., Davidson, O. R., Bosch, P. R., Dave, R., \& Meyer, L. A. (2007). Contribution of Working Group III to the Fourth Assessment Report of the Intergovernmental Panel on Climate Change, 2007. Cambridge, United Kingdom and New York, NY, USA.: Cambridge University Press.

Mithraratne, N., \& Vale, B. (2003). Life cycle analysis model for New Zealand houses. Elsevier Ltd. , 483-492.

Mithraratne, N., Vale, B. V., \& Vale, R. (2007). Sustainable Living: the Role of Whole Life Costs and Values. London: Elsevier Limited.

Nassen, J., Holmberg, J., Wadeskog, A., \& Madeleine, N. (2006). Direct and indirect energy use and carbon emissions in the production phase of building: An input-output analysis. Elsevier Ltd. , 1593-1602.

Suzuki, M., Oka, T., \& Okada, K. (1994). The estimation of energy consumption and CO2 emission due to housing construction in Japan. Elsevier Ltd. , 165-169.

Treloar, G. J., Fay, R., Love, P. E., \& Iyer-Raniga. (2000). Analysing the Life Cycle Energy of an Australian Residential Building and its Householders. Building Research and Information.

Yohanis, Y. G., \& Norton, B. (2002). Life-cycle operational and embodied energy for a generic single-storey office building in the UK. Elsevier Ltd. , 77-92.

www.bcmgrc.com. (n.d.). http://www.bcmgrc.com/. Retrieved April 30, 2010, from http://www.bcmgrc.com/

www.convertunits.com. (n.d.). http://www.convertunits.com/info/megapascal. Retrieved April 30, 2010, from http://www.convertunits.com/info/megapascal

www.gzbirch.com. (n.d.). Retrieved December 16, 2009, from

www.gzbirch.com:http://www.gzbirch.com/hot/en/products.asp?action=show\&id=850

\section{Chapter VII Life cycle energy for houses in New Zealand}

Adalberth, K. (1996). Energy use during the life cycle of single-unit dwellings: Examples. Lund, Sweden: Department of Buildings Physics, Lund University.

BRANZ. (2001). Energy Use in New Zealand Households: Report on the year 5. Wellington: BRANZ.

BRANZ. (2002). Energy Use in New Zealand Households: Report on the year 6. Wellington: BRANZ .

BRANZ. (2003). Energy Use in New Zealand Households: Report on the year 7. Wellington: BRANZ.

BRANZ. (2004). Energy Use in New Zealand Households: Report on the year 8. Wellington: BRANZ.

BRANZ. (2005). Energy Use in New Zealand Households: Report on the year 9. Wellington: BRANZ. 
Department of Building and Housing. (2007). Energy efficiency of buildings (domestic hot water and commercial heating, ventilating and air-conditioning systems). Wellington: Department of Building and Housing.

French, L., Camilleri, M., Isaacs, N., \& Pollard, A. (2007). Temperatures and heating energy in New Zealand houses from a nationally representative study HEEP. BRANZ Ltd. , 770-780.

Howden-Chapman, P., Viggers, H., Chapman, R., \& O' Dea, D. (2009). Warm homes: Drivers of the demand for heating in the residential sector of New Zealand. Elsevier Ltd , 3387-3399.

Isaacs, N., Camilleri, M., \& French, L. (2007). Hot Water Over Time: The New Zealand Experience. Presented at the XXXVth International Association of Housing Science (IAHS) World Congress on Housing Science. Melbourne: BRANZ.

Isaacs, N., Camilleri, M., French, L., Pollard, A., Saville-Smith, K., Fraser, R., et al. (2006). Energy Use in New Zealand Households: Report on the Year 10 Analysis for the Household Energy End-use Project HEEP. Wellington: BRANZ.

Johnstone, I. M. (1999). Energy and mass flows of housing. a model and example. Auckland, New Zealand: Department of Property, The University of Auckland .

Mithraratne, N., \& Vale, B. (2003). Life cycle analysis model for New Zealand houses. Auckland, New Zealand: School of Architecture, The University of Auckland.

\section{Chapter IX Case studies}

BRANZ. (1990). ALF Manual. Wellington: BRANZ.

BRANZ. (2003). Energy Use in New Zealand Households: Report on the year 7. Wellington: BRANZ.

BRANZ. (2005). House Insulation Guide. Wellington: BRANZ Ltd.

Department of Building and Housing. (2007). Compliance Document for New Zealand Building Code Clause H1 Energy Efficiency- Third Edition. Wellington, New Zealand.: Department of Building and Housing.

Department of Building and Housing. (2007). Energy efficiency of buildings (domestic hot water and commercial heating, ventilating and air-conditioning systems). Wellington, New Zealand: Department of Building and Housing.

French, L., Camilleri, M., Isaacs, N., \& Pollard, A. (2007). Temperatures and heating energy in New Zealand houses from a nationally representative study HEEP. BRANZ Ltd. , 770-780.

Gatley, J. (2008). Long Live the Modern: New Zealand's New Architecture, 1904-1984. Auckland, N.Z.: Auckland University Press.

Isaacs, N., Camilleri, M., French, L., \& Pollard, A. (2005). Energy use in New Zealand Households: Report on year 9 of the Household Energy End-use Project (HEEP)- June 2005, BRANZ Study Report 141. Wellington, New Zealand: BRANZ Ltd. Study Report 141, Judgeford, Porirua.

Kotnik, J. (2008). Container Architecture: This Book Contains 6441 Containers. Barcelona: Links International.

Mithraratne, N., \& Vale, B. (2003). Life cycle analysis model for New Zealand houses. Auckland, New Zealand: School of Architecture, The University of Auckland. 
www.demographia.com. (n.d.). www.demographia.com. Retrieved January 29, 2010, from http://www.demographia.com/db-intlhouse.htm

www.tefma.com. (n.d.). www.tefma.com. Retrieved January 29, 2010, from http://www.tefma.com/infoservices/benchmarking/areas/index.jsp

\section{Conclusions}

Adalberth, K. (1996). Energy use during the life cycle of single-unit dwellings: Examples. Lund, Sweden: Department of Buildings Physics, Lund University.

Buchanan, A. H., \& Levine, B. S. (1999). Wood-based building materials and atmospheric carbon emissions . Elsevier Ltd. , 427-437.

Mithraratne, N., Vale, B. V., \& Vale, R. (2007). Sustainable Living: the Role of Whole Life Costs and Values. London: Elsevier Limited.

Suzuki, M., Oka, T., \& Okada, K. (1994). The estimation of energy consumption and CO2 emission due to housing construction in Japan. Elsevier Ltd. , 165-169.

Yohanis, Y. G., \& Norton, B. (2002). Life-cycle operational and embodied energy for a generic single-storey office building in the UK. Elsevier Ltd. , 77-92.

www.zen.co.uk. (n.d.). Retrieved April 09, 2010, from http://www.zen17279.zen.co.uk/images/CCFREQUENTLY\%20ASKED\%20QUESTIONS.pdf 